\title{
Ischemia tolerance of the hypertrophied rat heart
}

Citation for published version (APA):

Snoeckx, L. H. E. H. (1987). Ischemia tolerance of the hypertrophied rat heart. [Doctoral Thesis, Maastricht University]. Rijksuniversiteit Limburg. https://doi.org/10.26481/dis.19871218ls

Document status and date:

Published: 01/01/1987

DOI:

10.26481/dis.19871218ls

Document Version:

Publisher's PDF, also known as Version of record

\section{Please check the document version of this publication:}

- A submitted manuscript is the version of the article upon submission and before peer-review. There can be important differences between the submitted version and the official published version of record.

People interested in the research are advised to contact the author for the final version of the publication, or visit the DOI to the publisher's website.

- The final author version and the galley proof are versions of the publication after peer review.

- The final published version features the final layout of the paper including the volume, issue and page numbers.

Link to publication

\footnotetext{
General rights rights.

- You may freely distribute the URL identifying the publication in the public portal. please follow below link for the End User Agreement:

www.umlib.nl/taverne-license

Take down policy

If you believe that this document breaches copyright please contact us at:

repository@maastrichtuniversity.nl

providing details and we will investigate your claim.
}

Copyright and moral rights for the publications made accessible in the public portal are retained by the authors and/or other copyright owners and it is a condition of accessing publications that users recognise and abide by the legal requirements associated with these

- Users may download and print one copy of any publication from the public portal for the purpose of private study or research.

- You may not further distribute the material or use it for any profit-making activity or commercial gain

If the publication is distributed under the terms of Article $25 \mathrm{fa}$ of the Dutch Copyright Act, indicated by the "Taverne" license above, 
ISCHEMIA TOLERANCE OF THE HYPERTROPHIED RAT HEART 



\title{
ISCHEMIA TOLERANCE OF THE
}

\section{HYPERTROPHIED RAT HEART}

\author{
PROEFSCHRIFT
}

ter verkrijging van de graad van doctor in de geneeskunde

aan de Rijksuniversiteit Limburg te Maastricht,

op gezag van de Rector Magnificus, Prof. Dr. F.I.M. Bonke, volgens het besluit van het College van Dekanen,

in het openbaar te verdedigen

op vrijdag, 18 december 1987, om 16.00 uur.

door

Luc Henricus Elisabeth Hyacinthus Snoeckx

geboren te Turnhout in 1947 
Promotor Prof. Dr. R.S. Reneman, Rijksuniversiteit Limburg

Co-promotor Dr. G.J. van der Vusse, Rijksuniversiteit Limburg

\section{Referenten}

Prof. Dr. H.A.J. Struyker-Boudier, Rijksuniversiteit Limburg Prof. Dr. W.A. Schaper, Max-Planck-Institut, W.G. KerckhofInstitut, Bad Nauheim, West-Duitsland.

\section{CIP-GEGEVENS KONINKLIJKE BIBLIOTHEEK, DEN HAAG}

Snoeckx, Luc Henricus Elisabeth Hyacinthus

Ischemia tolerance of the hypertrophied heart /

Luc Henricus Elisabeth Hyacinthus Snoeckx. -

[S.I.:s.n.]-I11

Proefschrift Maastricht - Met lit. opg.

ISBN 90-9001909-X

SISO 605.12 UDC $616.12(043.3)$

Trefw.: harthypertrofie.

Financial support by the Netherlands Heart Foundation for the publication of this thesis is gratefully aknowledged.

This investigation was supported by the Foundation of Medical Research MEDIGON (Grant 900516091).

Druk: Krips Repro, Meppel. Ontwerp omslag: Bert Daniëls, Oud-Heverlee. 
Voor Agnes, Andres en Jo 

Al onze wetenschap - die van het verleden, van het heden en van de toekomst - is niets vergeleken bij hetgeen we nooit zullen weten. Dat is niet erg. Dat is schitterend. Wanneer het onbereikbare oneindig is, dan heeft wetenschap zelf ook hoop op oneindigheid.

\section{Konstantin Tsiolkofski (1857-1935)}

Kennis op zichzelf kan ook harteloos zijn. Er is iets wat hoger is dan de oneindighied van de kennis, dat is de oneindigheid van het hart.

\section{Jevgeni Jevtoesjenko}





\section{CONTENTS}

1.1 Introduction

I.2 Possible factors involved in the diminished

I.3 Considerations regarding the present thesis

\section{CHAPTER II MATERIALS AND METHODS}

II.1 Description of the perfusion apparatus

II.2 Characteristics of the aortic outflow tract in the perfusion apparatus

$\begin{array}{ll}\text { II.3 Biochemical analysis } & 20\end{array}$

II.4 A special problem: enzyme stability in artificial 24 perfusion solutions

CHAPTER III A MICROCOMPUTER SYSTEM FOR HEMODYNAMIC MEASUREMENTS IN ISOLATED, EJECTING HEARTS

$\begin{array}{lll}\text { III.1 Introduction } & 29\end{array}$

$\begin{array}{lll}\text { III.2 Methods } & 30\end{array}$

III.2.1 Animal experiments 30

III.2.2 Computer program 31

$\begin{array}{lll}\text { III.3 Results } & 35\end{array}$

$\begin{array}{lll}\text { III.4 Discussion } & 38\end{array}$

CHAPTER IV HEMODYNAMIC, BIOCHEMICAL AND MORPHOLOGICAL CHARACTERIZATION OF THE ISOLATED, EJECTING RAT HEART PREPARATION

IV.1 Stability of the isolated, ejecting heart preparation 41

IV.1.1 Introduction 41

IV.1.2 Methods 41

IV.1.3 Results 43

IV.1.4 Discussion 51

IV.2 Myocardial enzyme activity at different ages $\quad 52$

IV.2.1 Introduction 52

IV.2.2 Methods 53

IV.2.3 Results 54

IV.2.3.1 Myocardial enzyme activity 54 in SHR and WKY hearts

IV.2.3.2 Measurements in Lewis rat hearts 55

$\begin{array}{lll}\text { IV.3 Morphology } & 58\end{array}$ 
CHAPTER $V$ RECOVERY OF HYPERTROPHIED HEARTS OF 16 MONTHS OLD SPONTANEOUSLY HYPERTENSIVE RATS DURING REPERFUSION AFTER A PERIOD OF GLOBAL ISCHEMLA

\begin{tabular}{|c|c|c|c|}
\hline V.1 & Introduction & & 63 \\
\hline V.2 & Methods & & 64 \\
\hline V.3 & Statistics & & 66 \\
\hline V.4 & Results & & 67 \\
\hline & $\mathrm{V} .4 .1$ & Hemodynamic variables & 67 \\
\hline & $V .4 .2$ & Biochemical data & 71 \\
\hline V.S & Discussion & & \\
\hline
\end{tabular}

CHAPTER VI RECOVERY OF HYPERTROPHIED HEARTS OF AORTABANDED RATS DURING REPERFUSION AFTER A PERIOD OF GLOBAL ISCHEMIA

$\begin{array}{lll}\text { VI.1 Introduction } & 79\end{array}$

$\begin{array}{lll}\text { VI.2 Methods } & 80\end{array}$

$\begin{array}{lll}\text { VI.3 Statistics } & 83\end{array}$

$\begin{array}{lll}\text { VI.4 Results } & 83\end{array}$

VI.4.1 Hemodynamics 86

VI.4.2 Biochemical data 89

$\begin{array}{lll}\text { VI.5 Discussion } & 96\end{array}$

CHAPTER VII RECOVERY OF HYPERTROPHIED HEARTS OF 18 MONTHS OLD SPONTANEOUSLY HYPERTENSIVE RATS DURING REPERFUSION AT DIFFERENT PERFUSION PRESSURES AFTER A PERIOD OF GLOBAL ISCHEMIA

$\begin{array}{lll}\text { VII.1 Introduction } & 103\end{array}$

$\begin{array}{lll}\text { VII.2 Methods } & 104\end{array}$

VII.2.1 Experimental set-up 104

VII.2.2 Regional myocardial perfusion 106

$\begin{array}{lll}\text { VII.3 Statistics } & 108\end{array}$

$\begin{array}{lll}\text { VII.4 Results } & 108\end{array}$

VII.4.1 Hemodynamics 109

VII.4.2 Regional myocardial flow 113

$\begin{array}{lll}\text { VII.4.3 Biochemical data } & 117\end{array}$

$\begin{array}{lll}\text { VII.5 Discussion } & 124\end{array}$ 
CHAPTER VII RECOVERY OF HYPERTROPHIED HEARTS OF 8 MONTHS OLD SPONTANEOUSLY HYPERTENSIVE RATS DURING REPERFUSION AT DIFFERENT PERFUSION PRESSURES AFTER A PERIOD OF GLOBAL ISCHEMIA

VIII.1 Introduction

VIII.2 Methods

VIII.2.1 Experimental set-up

VIII.3 Statistics

VIII.4

Results

VIII.4.1 Hemodynamics

138

VIII.4.2 Regional myocardial flow

VIII.4.3 Biochemical data

VIII.5

Discussion

CHAPTER IX GENERAL DISCUSSION

REFERENCES

SUMMARY

SAMENVATTING

CURRICULUM VITAE - BIBLIOGRAPHY - DANKWOORD 



\section{GENERAL INTRODUCTION}

\section{1. INTRODUCTION}

Protection of the hypertrophied human heart during cardiac surgery is a continuing problem for cardiac surgeons. Indeed, the pathologically hypertrophied heart shows a decreased tolerance to global ischemia, as induced during open heart surgery. This phenomenon was initially reported by Cooley and co-workers (1972). These investigators described patients with severe left ventricular hypertrophy in whom ischemic contracture of the ventricle ('stone heart') developed during the surgical procedure. Histological investigation of myocardial biopsies, taken from patients who developed the "stone heart' syndrome, revealed severe glycogen depletion, mitochondrial membrane damage, distension of the T-tubular system and sarcoplasmic reticulum, and a wide-spread degeneration of myofibrillar material (Lie and Sun, 1976). In the following years, it was recognized that the frequency of ischemic contracture and subendocardial necrosis during and after cardiac surgery was higher in hypertrophied than in non-hypertrophied bearts (Buckberg et al., 1977). In hearts of patients, undergoing cardiac valve replacement during 45 minutes of cardiac arrest without developing the "stone heart' syndrome, a more pronounced structural ischemic damage was documented when severe ventricular hypertrophy was present as compared with patients with only moderate hypertrophy (Schaper et al., 1978). Also in severely hypertrophied hearts Beyersdorf and co-workers (1980) found a close relation between degenerative signs as observed in myocardial tissue biopsies and poor post-operative recovery.

Therefore, in the last decade special attention has been paid to the protection of the hypertrophied myocardium at risk during cardiac surgery. 
Initially, experimental attempts were made in hypertrophied canine hearts to improve protection by topical cooling of the myocardium $\left(17^{\circ} \mathrm{C}\right)$ during the period of ischemia (Shida and Kobayashi, 1980). The functional recovery after ischemia, however, remained lower in the hypertrophied than in the non-hypertrophied control hearts. Earlier Ellis and co-workers (1977) reported that hypothermia combined with high potassium cardioplegia resulted in protection of the hypertrophied myocardium against the decrease in energy-rich phosphates induced by ischemia, and loss of intracellular enzymes during reperfusion following 60 minutes global ischemia. Unfortunately, this kind of protection did not prevent all forms of ischemic injury, as indicated by changes in nuclear chromatin, formation of intracellular edema, and pronounced decrease of $\mathrm{pH}$ as compared to patients without left ventricular hypertrophy (Warner et al., 1987). Restoration of post-ischemic myocardial function was also hampered, as indicated by the significant decrease of adenosine triphosphate (ATP) during the first 30 minutes of reperfusion (Coughlin et al., 1979). Nevertheless, protection with hypothermic cardioplegia resulted in a better post-ischemic functional recovery than with hypothermia alone (Menasche et al., 1985). Recently, intracoronary administration of perfluorocarbon emulsion was found to be superior over high potassium cristalloid or blood cardioplegia in protecting the hypertrophied myocardium during 3 hours of hypothermic arrest followed by one hour of normothermic reperfusion (Novick et al., 1985).

The underlying mechanisms responsible for the reduced tolerance to ischemia of the hypertrophied heart are incompletely understood. The factors possibly involved will be discussed in the following sections.

\section{2. POSSIBLE FACTORS INVOLVED IN THE DIMINISHED TOLERAN- CE TO ISCHEMIA OF HYPERTROPHIED HEARTS}

\section{2.1. Circulatory factor}

\section{Impaired coronary vasodilatatory reserve}

Circulatory factors can play an important role in the decreased tolerance to global ischemia of the hypertrophied heart. For instance, it bas been suggested that in the hypertrophying heart the growth of the vascular bed, if any, insufficiently matches the increase in muscle mass (Holtz et al., 1977; Henquell et al., 1977; Rakusan et al., 1984). To keep up with the metabolic demands of the myocardial tissue, the coronary vascular bed in the hypertrophied heart is relatively dilated, reducing the total coronary dilatatory reserve (Murray and Vatner, 1981), especially in the endocardial layers of the left ventricular wall (Hoffman et al., 1985; Breisch et al., 1986). Under resting conditions, controversial results are found concerning the flow distribution in the coronary system of the hypertrophied myocar- 
dium. In the rat heart, myocardial flow was found to be normally distribu ted (Tomanek et al., 1980). However, under the same conditions, a relative underperfusion of the endocardium as compared to the epicardium was found to be present in aorta-banded puppies (Einzig et al., 1981). A more pronounced underperfusion of the deep ventricular layers was observed during diastolic hypotension or increased metabolic demands during tachycardia (Borkon et al., 1982). Therefore, a mismatch in the ratio of the oxygen supply to demand, especially in the endocardial layers of the myocardium, could provoke a decrease in the content of energy-rich phosphates in the hypertrophied myocardial tissue, and concomitantly increased vulnerability of the myocardial tissue for ischemic damage (Breisch et al., 1986). Interestingly, variations in the degree of capillarization of the hypertrophied myocardium seem to occur depending on the stage of development of ventricular hypertrophy. In spontaneously hypertensive rats, it was found that coronary vasodilator reserve, tested by reactive hyperemia response, was decreased in the 7 months old rat as compared to the age-matched rat of the Wistar-Kyoto strain. However, the response in both groups was completely identical at the age of 12 months (Peters et al., 1984, Tomanek et al., 1982). These results suggest a decrement of coronary vasodilator reserve during actively development of left ventricular hypertrophy, as occurring in the spontaneously hypertensive rat during the $7^{\text {th }}$ month of life. In contrast, normalization seems to occur during the stabilized phase of hypertrophy (at 12 months of age). It is not known, however, to which extent the vasodilator reserve is affected in the very aged animal with left ventricular hypertrophy. Neither it is known how long periods of ischemia affect this vasodilator reserve capacity.

It is unknown to which extent the reduced post-ischemic recovery of the hypertrophied heart could be improved by increasing the perfusion pressure, applied to the coronary arteries. However, too high a coronary perfusion pressure during the initial reperfusion period may be deleterious for the functional recovery of the heart, since high perfusion pressures might result in intracellular edema. To circumvent this unwanted situation, in humans a low coronary perfusion pressure $(6.5 \mathrm{kPa})$ during the initial reperfusion phase following unclamping of the aorta has been recommended during open-heart surgery (Buckberg, 1977).

\section{2.2. Cellular factors}

\section{Reduced contents of energy-rich phosphates}

Beside differences in circulatory properties, cellular factors can play a role in the decrease of the ischemia tolerance of the hypertrophied heart. Katz and Tada (1972) were the first to relate the 'stone heart' phenomenon to the decrease in intracellular high-energy phosphate levels. The intracellular availability of these substances is essential for the maintenance of proper cell function. Decreased high-energy phosphate levels were found 
in the severely hypertrophied heart of man, especially in the endocardiall layers (Peyton et al., 1982a), and of the rat (Sink et al., 1981). Reduced levels of creatine phosphate, ATP and adenosine diphosphate (ADP) were not only found in the severely hypertrophied heart but also in the earlier, stable stage of development of hypertrophy, induced by swimming exercise or thyroxine treatment (Degenring et al., 1975) or banding of the aorta (Meerson, 1962; Reilly and Cooksey, 1979). ATP levels were found to be also reduced in the hypertrophied heart of relatively young (6 months of age) spontaneously hypertensive rats (Shimamoto et al., 1982). These observations indicate that reduced ATP levels are a general phenomenon in the various forms of cardiac hypertrophy (St Cyr et al., 1985).

Degenring and co-workers (1975) have shown that the lower ATP levels at the end of a period of global ischemia in the hypertrophied myocardium, as compared to the non-hypertrophied control hearts, are not only a consequence of a lower ATP content prior to ischemia, but also of an increased degradation of energy-rich phosphates during ischemia. This could be demonstrated by the more pronounced increase of the tissue contents of degradation products of adenine nucleotides, such as adenosine, inosine and hypoxanthine, in hypertrophied rat hearts and loss of these substances in the surrounding bathing fluid during the period of ischemia.

In line with these findings was the observation that the tolerance to global ischemia could be improved by pre-ischemic preservation of the tissue content of ATP induced by a 15 minutes arrested perfusion of the myocardium prior to ischemia (Peyton et al., 1982b). Therefore, the improved function of the hypertrophied heart after a period of global ischemia, when the myocardium was protected with hypothermic cardioplegia, has been ascribed to the higher levels of ATP in these hearts at the end of the ischemic period (Coughlin et al., 1979). However, the relationship between lower tissue ATP levels and increased susceptibility to ischemic insult is not unambiguous, because non-hypertrophied hearts could recover at relatively low ATP tissue contents following a period of ischemia (Rosenkranz et al., 1986). In addition, Neely and Grotyohann (1984) were not able to find any correlation between the extent of functional recovery and the post-ischemic tissue content of ATP in non-hypertrophied rat hearts.

\section{Increased susceptibility to electrical conduction disturbances}

The poor post-ischemic recovery of the hypertrophied heart has also been associated with a higher incidence of conduction disturbances as ventricular fibrillation (Hottenrott et al., 1973). This phenomenon can be caused by inhomogeneous reperfusion of the ventricular wall or by intrinsic changes in the hypertrophied myocardium, or both. For instance, it has been described that the pronounced occurrence of connective tissue in the aged human myocardium provokes nonuniform conduction of depolarization waves (Spach and Dolber, 1986). Since increased contents of connective tissue are also found in the hypertrophied myocardium (Thiedemann et al", 
1983), this type of heart is likely to be vulnerable to the described conduction disturbances. Another phenomenon which could be involved is the increase in total mass of the hypertrophied heart (Rensma, 1986). For instance, in human atria with increased size, the incidence of atrial fibrillation is enhanced as compared to the normal atrium (Henry et al., 1983).

\section{Stage of development of ventricular hypertrophy}

Another factor, that has to be considered to explain the decreased tolerance to ischemia of the hypertrophied myocardium, is the stage of development of hypertrophy. Comparison of the hypertrophy stages in humans and animals is difficult, since the speed at which the process of hypertrophy is progressing is most likely different. There is increasing evidence for a normal or even increased myocardial pump function of the pressure overloaded left ventricle during the phase of stable hypertrophy, referred to as the compensatory hyperfunction stage (Meerson, 1969). This has been established in left ventricles of relatively young spontaneously hypertensive rats (Hallbäck, 1975; Noresson et al., 1979; Lundin et al., 1982; Pfeffer and Pfeffer, 1983; Mirsky et al., 1983; Pfeffer and Pfeffer, 1985; Friberg and Nordborg, 1986) and in man, suffering from borderline and/or moderate primary hypertension (Hartford et al., 1985). In part, the increased myocardial performance can be explained by an enhanced (ortho)sympathetic drive to the heart (Pfeffer et al., 1974). Contraction duration of the myocardium, hypertrophied as a consequence of pressure overload, was found to be prolonged due to an increase in the time-to-peak tension, prolonged relaxation or both (Alpert et al., 1974; Jouannot and Hatt, 1975; Bing et al., 1978). The compensatory phase is also characterized by prominent biochemical alterations, which play an essential role in the effectuation of the mechanical adaptations to pressure overload. For instance, in hypertrophied hearts of spontaneously hypertensive rats, the DNA content was found to be normal during the onset of hypertension (van der Laarse et al., 1987), but significantly reduced, as compared to normotensive controls, when the hypertension was established (Sen et al, 1974). In aorta-banded rat hearts, the content of DNA was found to be decreased (Meerson, 1962), while the activity of the DNA-dependent RNA-polymerase and the total RNA activity was increased (Nair et al., 1968, Koide and Rabinowitz, 1969). Incorporation of labeled amino acids increased after constriction of the aorta or in rats with thyroxine-induced left ventricular hypertrophy (Meerson, 1962; Parmacek et al, 1986). Despite an enhanced rate of protein degradation during the initial phase of hypertrophy development, net accumulation of protein occurred, due to a substantial higher rate of protein synthesis. Faster rates of peptide chain initiation and elongation at the ribosomal site were documented in isolated rat hearts, hypertrophied as a consequence of aorta-banding or thyroxicosis (Morgan et al., 1985). The increased protein synthesis in the hypertrophying heart is mainly due to a higher content of ribosomes, rather than a more efficient initiation and/or elongation of peptide chains, as indicated by a $25 \%$ increa- 
se of ribosomal RNA within 4 days of thyroxine treatment (Siehl et al., 1985). However, the onset of net protein synthesis is a rather fast process, since it could be observed in isolated hearts within 60 minutes after switching the perfusion pressure (afterload) from 8.0 to $15 \mathrm{kPa}$ (Kira et al., 1984; Morgan et all, 1986). The importance of increased protein synthesis during the onset of myocardial hypertrophy is stressed by the observation made by Meerson (1969) that $80 \%$ of the rats, in which aorta-banding was performed, died within a few days after operation when protein synthesis was blocked by administration of actinomycin. One of the most striking findings in hypertrophied hearts of the spontaneously hypertensive rat and rat hearts, hypertrophied as a consequence of swimming exercise or thyroxine treatment, was the shift in isoenzymes of heavy chain myosin from the fast $V_{1}$ to the slow $V_{3}$ form, provoking a slower rate of contraction of the contractile apparatus (Holubarsch et al., 1985; Ringsgwandl et al., 1986; Pauletto et al., 1986), an improved economy of force generation, as indicated by a decreased heat production during contraction (Alpert and Mulieri, 1981; Alpert and Mulieri, 1982), and decreased oxygen consumption (Kissling et al. ,1982). A comparable phenomenon was observed in overloaded human atrial tissue (Buttrick et al., 1986). The slower rate of contraction is associated with an increased slow inward current of calcium. In the aged myocardium, calcium sequestration into the sarcoplasmic reticulum (SR) is depressed (Froeblich et al., 1978). This results in less calcium accumulation into the $S R$ and a greater loss of calcium via sarcolemmal exchange. Such a phenomenon requires a more effective calcium trigger to generate a comparable release of calcium from the SR and force development. Although the latter phenomenon has been described in the senescent non-hypertrophied rat heart (Lakatta and Yin, 1982; Capasso et al., 1983; Wei et al., 1984), the events occurring in the hypertrophied heart are comparable, but far more pronounced.

A sustained abnormally high hemodynamic load is followed by a permanent adaptation of the left ventricle and will finally result in the development of congestive heart failure. This process is characterized by a decrease in net nucleic acid and protein synthesis, fall in activity of cytosolic and mitochondrial enzymes, and degradation of muscle fibers. In the spontaneously hypertensive rat, Mirsky and co-workers (1983) have shown that the left ventricular contractile function, as assessed from the ejection fraction index-afterload relation, is already declining at the age of 18 months, while Pfeffer and Pfeffer (1983) found that the cardiac index in these rats was significantly lower at the age of 24 months, as compared with agematched, non-hypertrophied, control hearts. The latter phenomenon was associated with a significant increase in stiffness of the left ventricular wall and dilatation of the left ventricular chamber (Mirsky et al., 1983).

These observations could imply that the age of the spontaneously hypertensive rat determines the pump performance of the myocardium under aerobic circumstances. Even more important, the rat age may also affect the myocardial pump performance during recovery of the hypertrophied myo- 
cardium after structural damage, as induced, for instance, by global ischemia followed by reperfusion.

Altered properties of the sarcalemma

Recently, attention has been drawn to the effects of free oxygen radicals as mediators of reperfusion injury (van der Vusse and Reneman, 1985; Menasche et al., 1986). Degradation products of adenine nucleotides like hypoxanthine and xanthine accumulate in the ischemic myocardium. Readmission of oxygen during the initial reperfusion phase can induce production of oxygen free radicals by the conversion of hypoxanthine/xanthine in uric acid by xanthine oxydase (Schoutsen et $\mathrm{al}_{\text {., }}$ 1983), with concomitant formation of superoxide and hydroxyl radicals. Both radicals have detrimental effects on the sarcolemma and intracelfular membrane structures by peroxidation of polyunsaturated fatty acids, abundantly present in phospholipids. Under normal conditions the formation of superoxide radicals is controlled by the scavenger enzyme superoxide dismutase while hydroxyl radicals are neutralized by glutathione peroxidase and catalase. However, during ischemia, the activity of these enzymes is decreased (Gutkin and Petrovich, 1982). Ischemic protection of the non-hypertrophied rat heart with a high potassium cardioplegic solution to which glutathione peroxidase or superoxide dismutase was added, resulted in a better post-ischemic contractile performance than with the cardioplegic solution alone (Menasche et al., 1986). Another potent scavenger of oxygen free radicals is $\alpha$-tocopherol (vitamin $E$ ), which is normally present in the sarcolemma. Recently, the content of this compound was found to be significantly reduced in the hypertrophied heart of young spontaneously hypertensive rats, as compared to age-matched Wistar-Kyoto rats, i.e. 1.9 vs $8.4 \mathrm{ng} / \mu \mathrm{g}$ phospholipid (Burghardt and Janero, 1987). The lower content of this vitamin in the hypertrophied heart could exaggerate the ischemic damage occurring during reperfusion, especially when the amount of degradation products of adenine nucleotides is high (Degenring et al., 1975).

The composition of cellular membranes in the hypertrophied heart is altered as compared to the membranes in the non-hypertrophied heart. Significant changes in phospholipid content and composition were found in aorta smooth muscle cells (Nara et al., 1986), and in hearts of aortabanded rats (Reibel et al., 1986). In the latter, pronounced increases in the content of phosphatidylcholine (PC), sphyngomyelin and phosphatidylinositol (PI) were observed while linoleic acid was markedly reduced in PC, phosphatidylethanolamine, PI and cardiolipin. Since no decissive documentation on the effects of these changes on myocardial function is present, one can only speculate that the altered phospholipid composition is associated with the reduced tolerance to ischemia of the hypertrophied heart. 


\section{3. CONSIDERATIONS REGARDING THE PRESENT THESIS}

\section{3.1. Ain of the present thesis}

The aim of the present thesis is to clarify some aspects of the decreased tolerance to global ischemia of the hypertrophied heart. Since the preischemic myocardial adenine nucleotide content seems to play an important role in the extent of the post-ischemic functional recovery of the hypertrophied myocardium, special attention has been paid to the changes in tissue content of energy-rich phosphates prior to, during and after a period of global ischemia. These changes have been correlated with the loss of degradation products of adenine nucleotides, such as adenosine, inosine, hypoxanthine, xanthine and uric acid from the heart. Secondly, functional recovery has been studied using different perfusion pressures to investigate the effect of these interventions on coronary perfusion, the occurrence of tissue edema and loss of cellular membrane integrity resulting in the release of intracellular enzymes. Besides, variations in perfusion pressure have been used to study the pattern of wash-out of tissue metabolites, accumulated during the period of ischemia. In the third place, the effects of differences in age of the experimental animals on post-ischemic functional recovery have been evaluated. The tolerance to global ischemia was studied in the 8 months old and in the aged rat (16 and 18 months) with hereditary left ventricular hypertrophy, that is the spontaneously hypertensive rat. In addition the heart, hypertrophied as a consequence of aorta-banding, was studied.

\section{3.2. Choice of animal model and experimental setting}

\section{Animal model}

The spontaneously hypertensive rat was chosen because of the stable hypertension and the resemblance of the model with human essential hypertension (Okamoto, 1972; Frohlich et al., 1981). However, critics can be made on the use of the spontaneously hypertensive rat as a suitable model for human essential hypertension and cardiac hypertrophy.

Serious consideration has to be given to the fact that the development of cardiac hypertrophy in the spontaneously hypertensive rat is not only determined by the occurrence of increased systemic blood pressure, but also by genetic factors. It was shown that left ventricular hypertrophy can develop even without an increase in systemic blood pressure, which was prevented by the administration of nerve growth factor antiserum in weanling spontaneously hypertensive rats (Cutilletta et al., 1978), or by the administration of a combination of antihypertensive drugs during the development of hypertension (Tomanek et al., 1979; Jespersen et al., 1986). These findings could indicate that an intrinsic abnormality is present in the myocardium of the spontaneously hypertensive rat, enforcing the effects of increa- 
sed blood pressure on the development of cardiac hypertrophy. Therefore, the hypertrophied heart of the 5 months old aorta-banded rat was used for comparison with the 8 months old spontaneously hypertensive rat.

In humans, patients with essential hypertension have a higher body weight than non-hypertensive control subjects (Frohlich, 1986). In some spontaneously hypertensive rats, however, lower body weights are found than in normotensive controls. Until now, no definite explanation can be given for this discrepancy. Besides, it is unclear whether this phenomenon is generally present in the spontaneously hypertensive rat. It is not known to which extent this deviation could affect the development of cardiac hypertrophy. In all the spontaneously hypertensive rats investigated ventricular hypertrophy was prominent and heart weight was always at least $20 \%$ higher than in the control animals.

Another criticism concerns the stability of the increased levels of systemic blood pressure (Frohlich, 1986). Although we only measured blood pressure immediately before the experiments in the 16 months old rats, blood pressure was routinelly checked in the other spontaneously hypertensive rats during earlier life. Besides, in the spontaneously hypertensive rats blood pressure is routinely checked in large samples of the population breed in our laboratories. In the animals used in the present thesis, elevated blood pressure levels were always present.

Arterio-venous shunting has been described in subsets of spontaneously hypertensive rats as well as in Wistar-Kyoto rats (Sesoko et al., 1982). In such rats, myocardial hypertrophy can be present, but the underlying mechanisms leading to cardiac hypertrophy are different, since blood pressure is significantly lower in this type of model than in the model without shunting. Physiological shunting may be excluded by the precise determination of the heart weight and the heart weight to body weight ratio. In the spontaneously hypertensive rats used in the studies described in this thesis, we never found animals in which heart weight or the heart weight to body weight ratio was lower or equal to that found in the age-matched Wistar-Kyoto rat.

Other citicisms concern dissimilarities in the kidney autoregulatory system of humans and the spontaneously hypertensive rat (McGiff and Quilley, 1981). Although these factors can be of high importance in studying the role and function of the kidney in the development of hypertension, it is doubtful that they play a role in the development of cardiac hypertrophy.

\section{Experimental set-up}

Since cardiac function is affected by both neural and humoral factors the results of studies on the effects of ischemia and reperfusion in the intact animal may be difficult to interpret. Therefore, we have chosen the isolated, ejecting heart preparation to study the ischemia tolerance of the hypertrophied heart. Other factors favoring the use of isolated hearts are the precise control of coronary perfusion pressure, temperature, $\mathrm{pH}$ and composition of the perfusion fluid. 
The isolated heart preparation has provided new and better insights into the functional and biochemical mechanisms which determine myocardial performance (Neely and Morgan, 1974; Hallbäck et al., 1975; Behrsohn et al., 1977; Noresson et al., 1979; Taegtmeyer, 1980). Generally, the development of ejecting wertebrate and in particular mammalian isolated heart preparations has been ascribed to German investigators (Langendorff, 1895; Frank, 1895). However, it is commonly unknown that $H$. Newell Martin, American investigator and the first secretary of the American Physiological Society, was already working with the isolated heart preparation 15 years before Langendorff published his well-known manuscript (Martin, 1881). In his excellent review, Fye (1986) has highlighted the merits of H.N. Martin in the development of the isolated heart preparation as an indispensable link to the understanding of myocardial function.

Although the isolated heart preparation has been used since the end of the previous century, it was not until the last two decades that attempts were made to achieve stable and physiological performance of the isolated, ejecting heart of the rat (Neely et al., 1967; Behrsohn et al, 1977; Taegtmeyer, 1980). The introduction of artificial perfusion fluids, as the Krebs-Henseleit buffer, simplified the use of isolated organ perfusion systems (Krebs et al., 1931). However, because of the absence of proteins in these solutions, tissue edema remains a problem, which cannot always be solved by the addition of plasma substitutes, as serum albumin, dextran or sucrose. Another disadvantage of artificial perfusates is the absence of an oxygen-carrying capacity. Therefore, oxygen has to be transported in a dissolved form at as high as possible partial oxygen pressures (>80 kPa). Artificial oxygen carriers, like perfluorocarbons, have shown to be superior over the dissolved form in maintaining mechanical function at a normal level in ejecting rat bearts for relative long periods of time ( 6 hours; Segel and Rendig, 1982). Since major technical problems have to be solved to avoid unwanted foaming of perfusion fluids in which perfluorocarbons are present, glucose-containing cristalloid perfusion fluids are generally preferred over other blood substitutes.

Since only limited documentation exists on the behavior of the isolated, ejecting, hypertrophied rat heart in comparison to the non-hypertrophied heart, one of the first objectives of the present work was to achieve a stable, ejecting preparation of the hypertrophied rat heart, working at a left ventricular output, as close as possible to the output achieved under in-vivo circumstances. It has to be taken into account that, due to denervation during the isolation procedure, the (ortho)sympathetic drive of the heart decreases, inducing a considerable reduction in heart rate and contractility of the isolated heart. Besides, contractility is also hampered by the absence of circulating catecholamines in the artificial perfusion medium. 


\section{3.3. Outline of the thesis}

Chapter II will deal with an extensive description of the perfusion setup and the considerations given to the characteristics of the artificial aortic outflow tract. In this chapter methods, used for biochemical determinations in the various studies, are described as well.

Since manual aquisition of hemodynamic variables is time-consuming, an automated system for data aquisition in the isolated, ejecting heart preparation was developed (chapter III).

In chapter IV the hemodynamic and biochemical stability of the isolated heart preparation over a relative long period of time ( $>2$ hours) has been tested. The results of the biochemical determinations in native tissue of hypertrophied and non-hypertrophied hearts are also included in this chapter.

The tolerance to a short period of global ischemia (30 minutes) of relatively old (16 months) hypertrophied hearts of spontaneously hypertensive rats and non-hypertrophied hearts of age-matched Wistar-Kyoto rats is discussed in chapter $V$. Since we were basically interested in the functional and biochemical post-ischemic differences between hypertrophied and non-hypertrophied hearts and not in the eventual effects of cardioplegia and hypothermia, we have chosen to apply a normothermic period of ischemia without any attempt to protect the myocardium against ischemic damage. This chapter deals with the functional recovery during reperfusion following global ischemia as well as with the effects of global ischemia on the tissue contents of emergy-rich phosphates, glycogen, lactate and inorganic phosphate, and the loss of intracellular enzymes. Special attention has been paid to the contractile performance and ejection capacity of the hypertrophied hearts at different preloads and afterloads, as compared to non-bypertrophied control hearts.

Basically the same protocol has been used in a study on isolated, ejecting hearts of 5 months old abdominally aorta-banded and sham-operated rats, 10 weeks after surgery (chapter VI). The ischemic period was prolonged to 45 minutes. In this chapter, special attention has been paid to the loss of degration products of adenine nucleotides.

Chapter VII presents the results of 45 minutes global ischemia in aged (18 months) spontaneously hypertensive rat hearts and age-matched control hearts followed by reperfusion at different perfusion pressures. The functional performance of the left ventricle before ischemia and during the initial recovery phase after ischemia was related to the transmural distribution of coronary flow in the left ventricular wall. The experiments were performed on aged, 18 months old rats.

Similar experiments were performed on hearts of relatively young, 8 months old spontaneously hypertensive rats. The results are presented and discussed in chapter VIII.

Chapter IX contains the general discussion. 



\section{MATERIALS AND METHODS}

\section{1. DESCRIPTION OF THE PERFUSION SET-UP}

The perfusion system used is basically an extensive modification of the set-up for the isolated, ejecting rat heart, as originally described by Neely and co-workers (1967) and Taegtmeyer (1980). In Figure II. 1 the nonrecirculating perfusion apparatus, which was installed in a cage in which the environmental temperature could be held constant at $37^{\circ} \mathrm{C}$, is described. From a reservoir the oxygenated perfusate was pumped with a roller pump (Watson-Marlow) via silicone tubing into the system at a rate of 400 $\mathrm{ml} \cdot \mathrm{min}^{-1}$ through a filter (Millipore, $1.2 \mu \mathrm{m}$ pore size). After passage through a bottle, inserted for bubble trapping and reduction of peristaltic pressure pulses of the driving pump, the perfusate entered a tube, leading to an oxygenator, as originally described by Hems and co-workers (1966) and modified by Taegtmeyer (1980). Otherwise, the perfusate was directed immediately to the aortic cannula. The partition of the perfusate over the two lines was determined by the resistance $R_{1}$. Via the oxygenator, the perfusate entered the left atrial cannula or returned to the reservoir via an overflow in the oxygenator. The heart was allowed to eject by opening the resistor $R_{2}$ in the left atrial line. A compression chamber provided adequate compliance for the aortic cannula (see section II. 2). The left atrial fillling pressure could be changed by varying the height of the oxygenator. The high recirculating volume of perfusate and the constant cage temperature of $37^{\circ} \mathrm{C}$ provided a stable perfusate temperature; variations in temperature were found to be less than $0.2^{\circ} \mathrm{C}$.

Essentially different from the set-up, as described by Neely and coworkers (1967) and Taegtmeyer (1980), was the way in which aortic pressure was applied to the aortic valve. In their perfusion apparatus, the aortic 


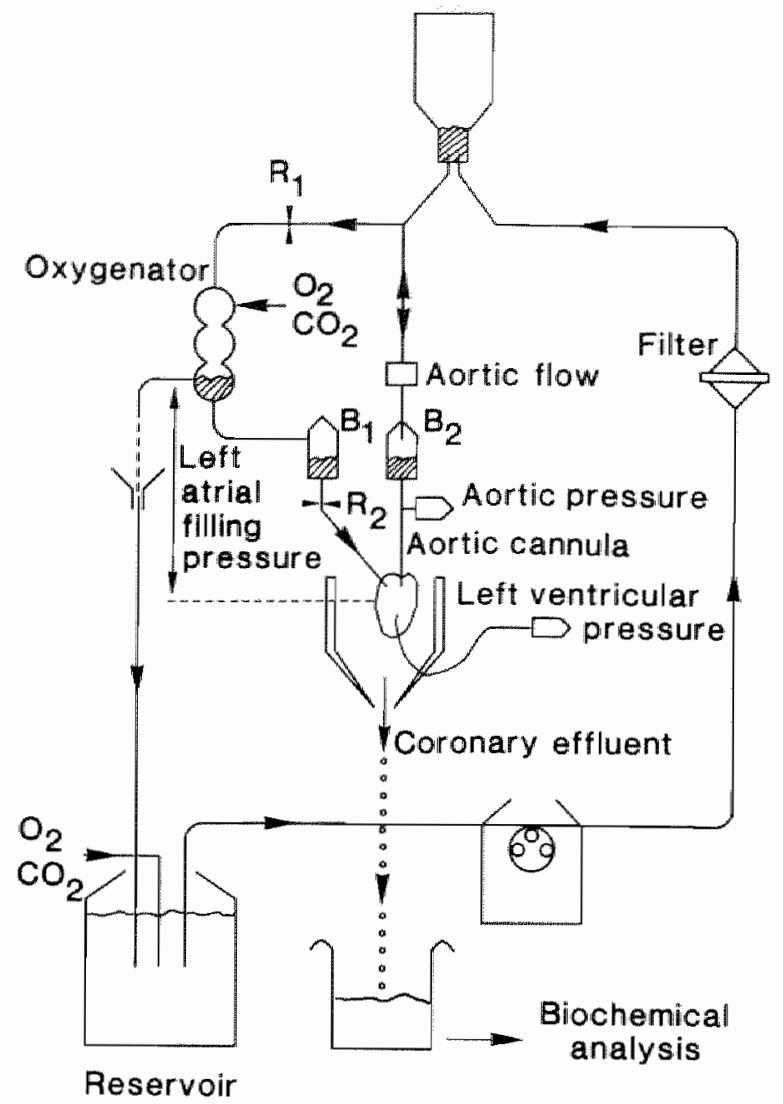

Figure 1. I Schematic representation of the perfusion apparatus. For detailed explanation see text. The heart is shown with the posterior wall in front. $R_{1}$ and $R_{2}=$ resistors; $B_{2}=$ bubble trap; $B_{2}=$ bubble trap and compression chamber.

pressure level required was reached by an hydrostatic water collumn, placed on the aorta. In the system, as used in the present study the aortic outflow tract was not in connection with open air, but coupled in series to the pump system in the apparatus. In this way the driving force for the aortic pressure during both retrograde and antegrade perfusion was induced by the roller pump. This set-up simplified the apparatus in two ways. Firstly, the aortic pressure level could be varied over a wide range by simply varying resistance $R_{x}$. Secondly, diastolic aortic pressure could be held constant during both retrograde and antegrade perfusion. In this way a stable coronary perfusion was provided, even when the ejection function was absent, as in hearts which did not adequately eject during reperfusion 
after a period of global ischemia. Therefore, the presented model can be described as an assisted heart model.

All experiments started with an initial retrograde perfusion period. Immediately after attachment of the heart at the aortic canmula, the perfusate entered the heart at a pressure determined by the volume displacement by the pump and the resistor $R_{x}$. This pressure was measured through a pressure transducer in the aortic cannula (CTC; see section II.2). A second cannula was connected to the left atrium for filling of the left atrium and left ventricle. The filling pressure was controlled by manual variation of the height of the oxygenator. Leakage from the left atrium, if any, was established visually. Left ventricular pressure was measured via a catheter inserted into the left ventricle via the apex of the heart and connected to a CTC pressure transducer. This catheter was very flexible and thin to avoid negative effects on the contraction pattern of the left ventricle. Besides, it was kept as short as possible in order to preserve high frequency information (up to $100 \mathrm{~Hz}$ ) of the pressure signal. The maximal positive first

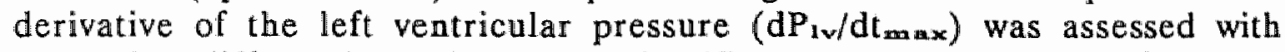
an analog differentiator (Janssen Scientific Instruments). Aortic flow was measured with an extracorporeal electromagnetic flow probe (Skalar, $3 \mathrm{~mm}$ ID) mounted in the aortic cannula and connected to a sine-wave electromagnetic flowmeter (Skalar, Transflow 601). The hemodynamic variables were recorded continuously on a four channel recorder (Hewlett Packard 7404). Coronary flow was measured by collecting the total amount of coronary effluent during a period of 1 minute. Cardiac output was calculated by adding the coronary and aortic flow values.

II 2.

PHYSICAL CHARACTERISTICS OF THE AORTIC OUTFLOW TRACT IN THE PERFUSION APPARATUS

The load imposed on the left ventricle of the heart is determined by the height of the left atrial pressure (preload) and the aortic pressure (afterload). In the isolated, ejecting heart, a third important factor has to be considered, i.e. the impedance of the aortic outflow tract. During the ejecting period the left ventricle of the isolated hearts is forced to eject perfusion fluid through an artificial, rigid, stainless steel outflow tract. Such a canmula is generally characterized by low compliance and relatively high inertia and resistance, especially when the cannula is long and narrow. The disadvantageous properties of such a cannula, however, can be minimized by a proper design. Figure II. 2 shows the design of the cannula in use in our laboratory. To reduce inertia and resistance to pulsatile flow, the length of the proximal part of the cannula is kept as short as possible, i.e. $7 \mathrm{~mm}$ and 
the internal diameter as wide as possible, i.e. $2.2 \mathrm{~mm}$. Immediately above the proximal part of the cannula the internal diameter is gradually enlarged to diminish turbulence.

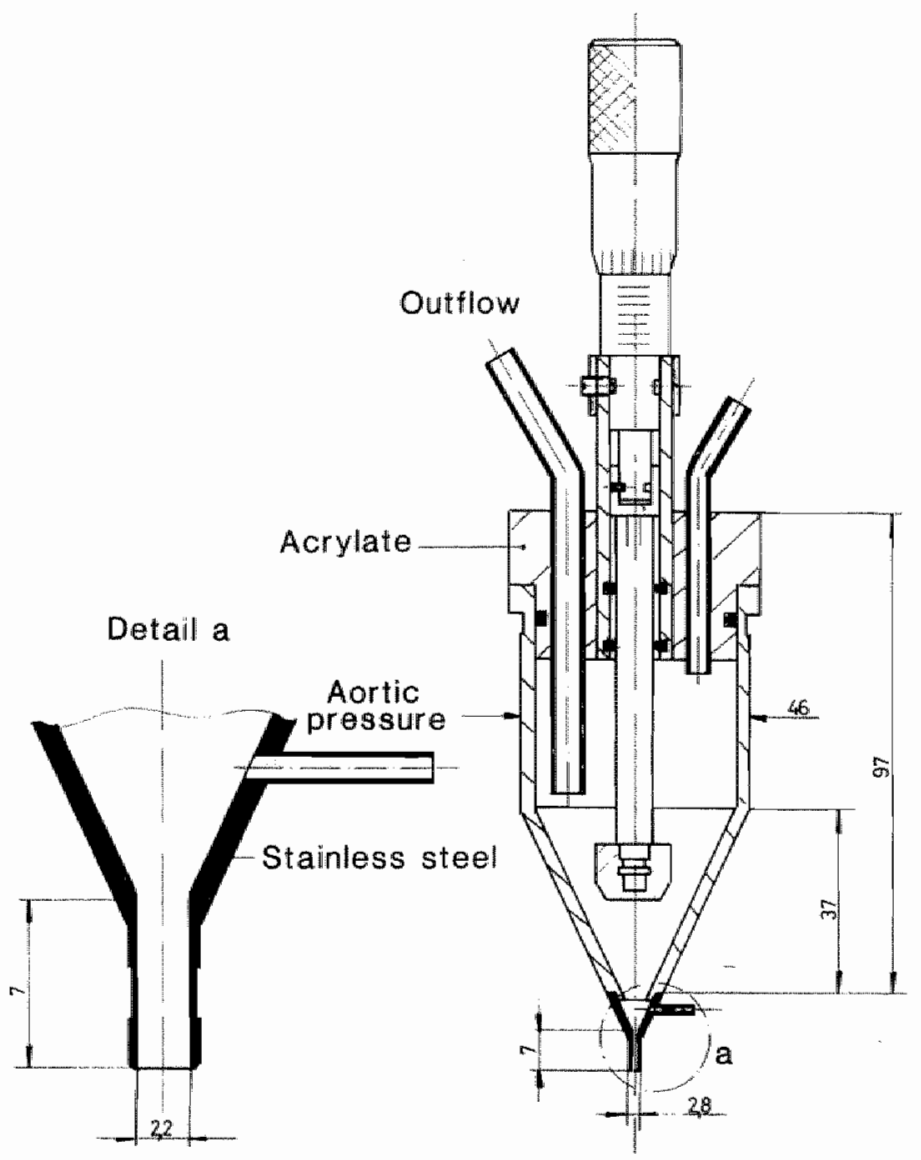

Figure II. 2 Defails of the aortic cannula (left) and compression chamber (right) used in the present studies. The compression chamber is constructed in acrylate at the base of which a stainless steel conus is mounted. A leflon plunger can be screwed in the conus during the periods of ischemia.

On the basis of these dimensions, one could theoretically calculate the height of the pressure pulse ( $\mathrm{dP}_{\text {tot }}$ ) generated in the aortic cannula $\mathrm{du}$ ring the ejection phase of the cardiac cycle (Figure II. 3 ). 


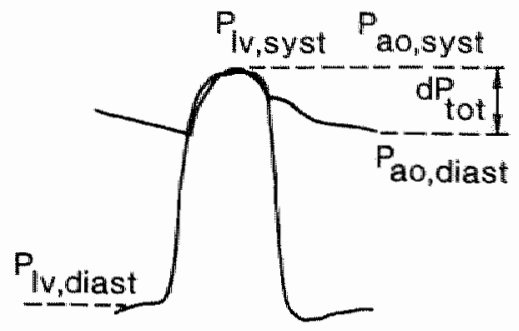

Figure $I_{3} 3$ The aortic pressure pulse dPsor generated by the ejecting force of the left ventricular chamber. The height of the pressure pulse is determined by the impedance of the aonic outfow tract.

According to the general, but difficult to solve equation of NavierStokes (Dinnar, 1981), the pressure variation ( $\mathrm{dP}_{\text {rot }}$ ) along a cylindrical tube depends on the velocity as well as on the acceleration of fluid within the tube. In a simpler approach, the pressure pulse ( $\mathrm{dP}_{\text {tor }}$ ) along a cylindrical tube can be approximated by the sum of three terms, i.e. the inertance term ( $\left(\mathrm{P}_{\text {iners }}\right)$, Bernouilli's turbulence term ( $\left.\mathrm{dP}_{\mathrm{borm}}\right)$ and the Poiseuille resistance term ( $d P_{\text {pois }}$ ) (van Bilsen et al., 1987). These terms can be expressed as follows:

$$
\begin{aligned}
& d P_{\text {inert }}=(\delta \cdot 1 \cdot d q / d t) / \pi \cdot r^{2} \\
& d P_{\text {born }}=1 \cdot \delta \cdot q^{2} / 2 \cdot \pi^{2} \cdot r^{4} \\
& d P_{\text {poit }}=8 \cdot \sigma \cdot 1 / \pi \cdot r^{4} \cdot q \\
& d P_{\text {cot }}=\Sigma\left(d P_{1 m a t}+d P_{\text {born }}+d P_{\text {po1 }}\right)
\end{aligned}
$$

in which

$$
\begin{array}{ll}
l & =\text { tube length }(7 \mathrm{~mm}) \\
r & =\text { tube radius }(1.1 \mathrm{~mm}) \\
q & =\text { peak volume flow }\left(\mathrm{ml}^{-1} \mathrm{~s}^{-1} \text {, see next paragraph }\right) \\
\delta & =\text { fluid density }\left(1050 \mathrm{~kg} \cdot \mathrm{m}^{-3}\right) \\
\sigma & =\text { fluid viscosity }\left(10^{-3} \mathrm{~Pa} . \mathrm{s}\right) \\
\mathrm{dq} / \mathrm{dt} & =\text { time derivative of peak volume flow. }
\end{array}
$$


In the various experiments described in chapters IV, V, VI and VIII maximal volume flows were reached during the recording of left ventricular function curves. The highest cardiac ouput value reached in the various experiments was about $100 \mathrm{ml} \cdot \mathrm{min}^{-1}$, corresponding with a peak volume flow of $10 \mathrm{ml} . \mathrm{s}^{-1}$. The time derivative of flow was calculated using an ejection time equal to $25 \%$ of the cardiac cycle. Heart rate was kept constant at a frequency of 300 cycles.min $^{-1}$ by bipolar stimulation with platinum electrodes, attached to the right atrial wall. Furthermore, the shape of the aortic flow profile was assumed to be parabolic.

The calculated $\mathrm{dP}_{\mathrm{tor}}$ should coincide with the aortic systolic to diastolic pressure drop, caused by ejecting hearts, loaded under various conditions. In Figure II. 4 experimentally obtained aortic pressure variations at various aortic flow values are presented. These pressure variations were recorded during the construction of pressure-volume curves in seven at random selected hearts, as discussed in chapter VI. In comparison, the theoretically calculated height of the aortic pressure pulse, as obtained at 4 assumed aortic flow values, is simultaneously presented.

Aortic pressure pulse $(\mathrm{kPa})$

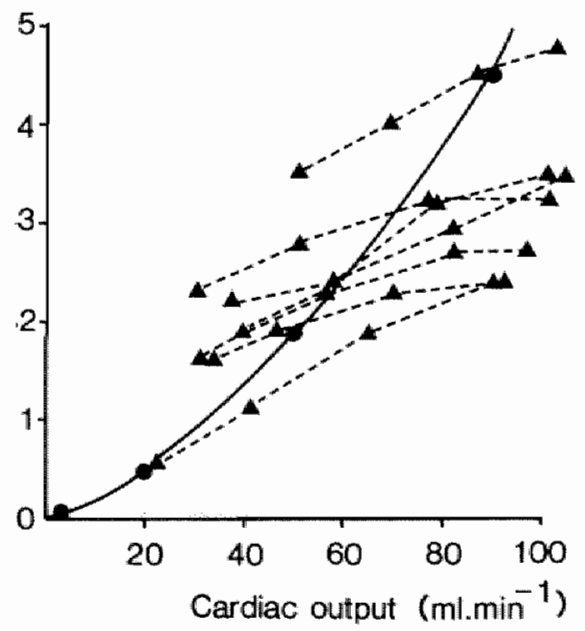

Figure 11.4 The relation between cardiac output and the height of the aartic pressure pulse ( $\left.d P_{\text {rod }}\right)$ above the aortic valve. The full line represents the theoretically calculated aortic pressure pulse height ( $d P_{x o x}$ ) at various cardiac output levels. The dotted lines show the relation between the height of the aortic pressure pulse (dPars) at various cardiac output levels, as obtained during the construction of left ventricular function curves in 7 randomly chosen isolated, ejecting rat hearts. 
In Table II. 1 the contribution of each of the terms, i.e. dPinarn, $d P_{b e r m}$, and $d P_{\text {pols }}$ to the height of $d P_{\text {ror }}$ is presented. The most important factor in the composition of $\mathrm{dP}_{\text {tor }}$ seems to be the Bernouilli term, especially when the flow is high.

Table II. I

Theoretically colculated effects of a rigid aortic cammula with a length of $7 \mathrm{~mm}$ and a radius of $1.1 \mathrm{~mm}$ on the aoric pressure pulse (Pos, kPa), created during the ejection of fluid volumes commonly encounte. red in the isolated, ejecting rat heart.

\begin{tabular}{|c|c|c|c|c|c|c|c|}
\hline $\begin{array}{c}\text { Assumed cardiac } \\
\text { output }\end{array}$ & $d P$ tot & $=$ & $d P_{\text {tinexter }}$ & + & $d P_{t a n}$ & + & $d P_{\text {pote }}$ \\
\hline $2 \mathrm{ml} \cdot \mathrm{min}^{-1}$ & 0.033 & & 0.029 & & 0.001 & & 0.003 \\
\hline $20 \mathrm{ml} \cdot \mathrm{min}^{-1}$ & 0.466 & & 0.290 & & 0.150 & & 0.026 \\
\hline $50 \mathrm{ml}^{-\mathrm{min}^{-1}}$ & 1.847 & & 0.800 & & 0.980 & & 0.067 \\
\hline $90 \mathrm{ml} \cdot \mathrm{min}^{-1}$ & 4.490 & & 1.450 & & 2.920 & & 0.120 \\
\hline
\end{tabular}

dPinare : inertance rerm; $d P_{b e r m}:$ Bernouilit's turbulence term; dPpots : Poisenille's resistance lerm.

The results show a reasonable coincidence of calculated and measured pressure pulse values. Under various loading conditions, the aortic pressure drop rarely exceeds $4 \mathrm{kPa}$, and thus resembles the in-vivo conditions in the aorta of the rat very well. At high aortic flow values, however, slightly lower pressure pulse values were measured than were calculated on the basis of the simplified Navier-Stokes equation. A possible explanation for this disagreement is the fact that the real $\mathrm{dP}_{\text {tor }}$ value is probably less than the sum of the values of the components, because the individual maxima do not coincide in time. Since Bernouilli's term, related to the pressure drop induced by turbulence, is the major term in the calculation of $\mathrm{dP}_{\mathrm{rot}}$, the cannula used behaves like a fluid resistance with little inertance. The beneficial effect of applying such a short cannula instead of a longer cannula has been shown by van Bilsen and co-workers (1987). 


\section{3.1 Determinations in coronary effluent}

During the various experiments described in the following chapters coronary effluent samples collected from the isolated hearts were immediately stored on ice. Bovine serum albumin was added, until a final concentration of $30 \mathrm{mg}$ per $\mathrm{ml}$ was reached, to samples in which enzyme activity had to be determined (see section II.4). After the experiments, samples were stored at $-80^{\circ} \mathrm{C}$ and assayed for enzyme activity later. The activities of the intracellular enzymes lactate dehydrogenase and aspartate aminotransferase were determined spectrophotometrically, using the techniques described by Bergmeyer and Bernt (1974a, 1974b).

The lactate concentration in the effluent was determined with a routine technique on a Technicon Autoanalyzer (van der Vusse et al, 1982).

Coronary effluent samples were also assayed for purine nucleosides and oxypurines such as adenosine, inosine, hypoxanthine, xanthine and uric acid (chapters VI, VII and VIII). The analysis was performed on a Varian 5500 high pressure liquid chromatograph, using the technique described by Harmsen and co-workers (1981). In short, $0.2 \mathrm{ml}$ samples of coronary effluent were eluted with $10 \mathrm{mmol}^{-1}\left(\mathrm{NH}_{4}\right) \mathrm{H}_{2} \mathrm{PO}_{4} / \mathrm{CH}_{3} \mathrm{OH}(10: 1, \mathrm{v} / \mathrm{v})$ on a chromatographic column at $60 \mathrm{ml} \cdot \mathrm{h}^{-1}(\mathrm{p}=8000 \mathrm{kPa})$. The column used was a $0.4 \mathrm{~cm}$ ID $\times 30 \mathrm{~cm}$ prepacked microBondapak/C18 column (Waters Association).

\section{3.2. Determinations in myocardial tissue}

The myocardial tissue contents of biochemical substances were determined in biopsies or in tissue, freeze-clamped as a whole, depending on the availability of the amount of ventricular tissue. In the experiments described in chapter VI, transmural biopsies of the left ventricular wall were taken with an electrically driven drillbore and immediately immersed into liquid nitrogen. The weight of the biopsies ranged between 20 and $25 \mathrm{mg}$ wet weight. In the other experiments, the ventricles were cut from the atria at the end of the pre-ischemic, ischemic or reperfusion periods and immediately freeze-clamped between pre-cooled Wollenberger clamps. The biopsy specimen and freeze-clamped ventricles were stored at $-80^{\circ} \mathrm{C}$ and analyzed for tissue contents of various biochemical substances later. All tissue samples were freeze-dried overnight at a temperature below $-30^{\circ} \mathrm{C}$. Then they were crushed with a glass rod in an extraction mixture, containing 3 mol. $\mathrm{I}^{-1}$ perchloric acid and $5 \mathrm{mmol} . \mathrm{I}^{-\mathrm{x}}$ dithiotreithol at a temperature of $-15^{\circ} \mathrm{C}$. Subsequently, the mixture was centrifuged at $1200 \mathrm{~g}$ and $4^{\circ} \mathrm{C}$ for 5 minutes. A known amount of the supernatant was removed and neutralized with $\mathrm{KH}_{2} \mathrm{CO}_{3}$, while the pellet was stored at $-80^{\circ} \mathrm{C}$ for determination of glycogen. The salt-precipitate of the neutralized extract was pelleted by centrifugation at $1200 \mathrm{~g}$ and $4{ }^{\circ} \mathrm{C}$ during 60 minutes. 
Tissue contents of adenosine triphosphate (ATP), adenosine diphosphate (ADP), adenosine monophosphate (AMP), guanosine triphosphate (GTP), guanosine diphosphate (GDP), guanosine monophosphate (GMP) plus uric acid (see below), inosine monophosphate (IMP), nicotinamide adenine dinu-

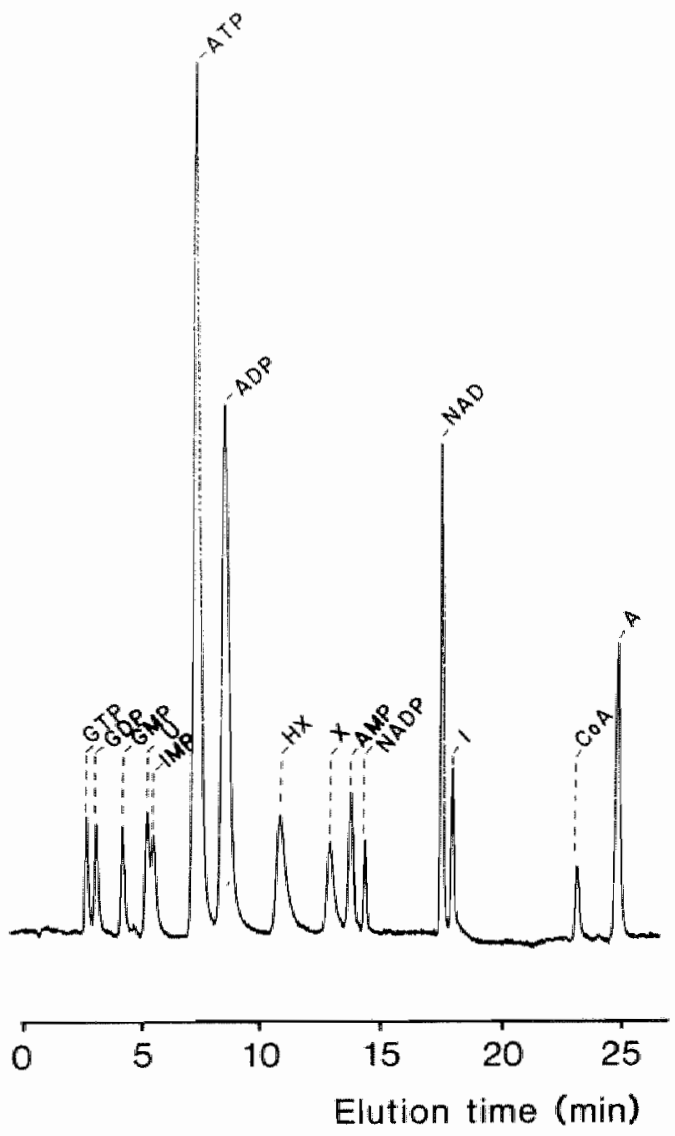

Figure II. 5 A 28 minutes elution of a standard mixture of substances, important for the myocardial energy metabolism. The amounts are given in pmot. GTP, GDP and GMP: guanosine triphosphate (83), guamosine diphosphate (77) and guanosine monophosphate (88), respectively; $U$ : uric acid (-); IMP, ATP, ADP and AMP: inosine monophosphate (109), adenosine triphosphate (862), adenosime diphosphate (609) and adenosine monophosphate (95), respectively; $H X$ and $X:$ hypoxanthine (289) and xanthine (183), respectively; NAD and NADP: nicotimamide adenine dinucleotide (173) and nicotinamide adenine dinucleotide phosphate (37), respectively; I: inosine (107); A: adenosine (215); COA: coenzyme A (72). 
cleotide (NAD), nicotinamide adenine dinucleotide phosphate (NADP), coenzyme A (CoA), and the degradation products adenosine, inosine, hypoxanthine and xanthine were determined in the supernatant by high pressure liquid chromatography on a VARIAN 5500, using the method described by Wijnants and van Belle (1985). In short, a sample $(10 \mu l)$ of the neutralized extract was injected on a reversed phase column (Lichrosorb RP-18, Merck) and eluted by gradient elution at a flow speed of $0.8 \mathrm{ml} \cdot \mathrm{min}^{-1}$. Solvent $A$ existed of an aqueous buffer of $\mathrm{NH}_{4}\left(\mathrm{H}_{2} \mathrm{PO}_{4}\right)(150 \mathrm{mM}, \mathrm{pH}=6.0)$, while solvent $B$ contained a $1: 1(\mathrm{v} / \mathrm{v})$ mixture of acetonitrile and methanol. Peaks were detected at $254 \mathrm{~nm}$, using an ultraviolet detector (Varian UV 200; flow cell $4.5 \mu \mathrm{l}$; path length $4 \mathrm{~mm}^{*}$ spectral band width $5 \mathrm{~nm}$ ). In Figure II. 5 the elution of a standard mixture of compounds, which can be found in myocardial tissue, over a period of 28 minutes is illustrated. The elution was started with $100 \%$ solvent A for a period of 6 minutes. From the $6^{\text {th }}$ to the $11^{\text {th }}$ minute solvent $A$ was reduced to $95 \%$. Concomitantly, solvent B increased to $5 \%$. Solvent A was further decreased to $85 \%$ from the $11^{\text {th }}$ to the $27^{\mathrm{th}}$ minute while solvent $B$ increased to $15 \%$. In Figure II. 6 four illustrative elutions of myocardial tissue extracts from hearts, freeze-clamped at different experimental moments are presented. The various peaks were indentified by comparing the retention times with the known standards or by co-elutions of known standard solutions. Unequivocal separation of the different products, present in the myocardium, was obtained, except for GMP and uric acid, which were incompletely separated in tissue extracts. Therefore, tissue contents of uric acid will not be shown.

Contents of creatine phosphate, inorganic phosphate $\left(\mathrm{P}_{\mathrm{i}}\right)$, lactate and glycogen in the myocardial tissue were determined according to van der Vusse and co-workers (1984). The tissue content of ATP of the hearts in the experiments described in chapter $\mathrm{V}$ was determined fluorimetrically (van der Vusse et al., 1984).

\section{3.3 Determinations in non-perfused native myocardial tissue}

The native myocardial contents of the metabolic products mentioned in the previous section were assessed in hearts freeze-clamped immediately after opening of the thorax, following the procedures described before.

With respect to the native activities of the enzymes lactate dehydrogenase (LDH) and aspartate aminotransferase (AST) the following procedure was followed. Hearts were excised immediately after opening of the thorax, weighed and washed in $100 \mathrm{ml}$ of an ice-chilled modified Tyrode's solution which contained (in mmol.1-1): $\mathrm{NaCl}(130.0), \mathrm{KCl}(5.6), \mathrm{CaCl}_{2}$ (2.2), $\mathrm{MgCl}_{2}$ (1.0), $\mathrm{NaH}_{2} \mathrm{PO}_{4}(1.2), \mathrm{NaHCO}_{3}(28.6)$ and $\mathrm{D}(+)$ glucose (11.1). Bovine serum albumin was added in a concentration of $30 \mathrm{mg} \cdot \mathrm{ml}^{-1}$ (see section II.4). The $\mathrm{pH}$ of this solution ranged from 7.35 to 7.45 . The atria and right ventricle were separated from the left ventricle. Then either of 2 procedures were 


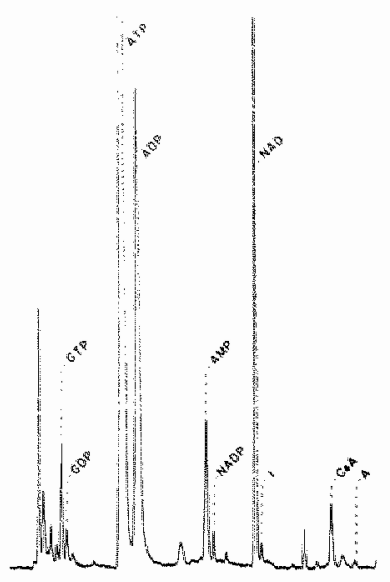

Native tissue

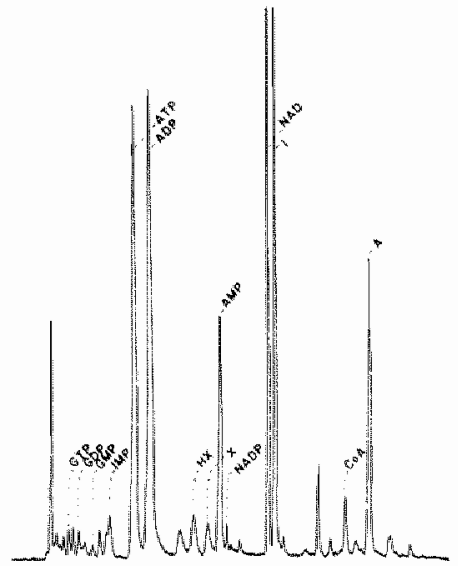

After $45 \mathrm{~min}$ global ischemia

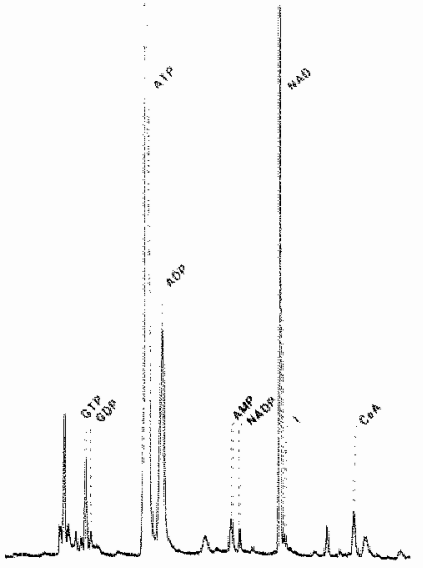

After $130 \mathrm{~min}$

aerobic perfusion

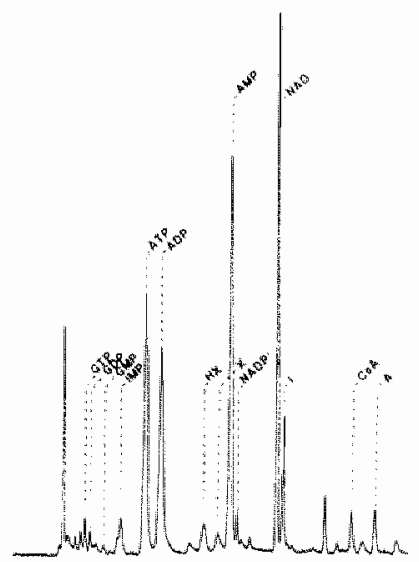

After 45 ischemia followed by $45 \mathrm{~min}$ reperfusion

Figure II.6 Elutions of 4 ventricular tissue extracts, obtained from hearts, freezeclamped immediately after opening of the thorax, after 130 minutes aerobic perfusion, at the end of 45 minutes global ischemia and after 45 minutes reperfusion following 45 minutes global ischemia in a non-recovering heart. For abbreviations see legend to Figure $I I$. 5. In native heart tissue, high levels of ATP and GTP are found in contrast with the walues after 45 minutes global ischemia and especially after 45 minutes of reperfusion in the non-recovering heart. Alternatively, levels of AMP and the degradation products adenasine, inosine, hypoxanthine and xanthine are increased in the ischemic and reperfused hearts. 
followed, depending on the availability of the amount of ventricular tissue. On many occasions it is advantageous to reduce the amount of tissue material for enzyme analysis so that other biochemical variables can be investigated in the remaining tissue material of the same heart. Therefore, in the first procedure a small piece of tissue (about $50 \mathrm{mg}$ wet weight) from the left ventricular wall was put in a tube, containing $3 \mathrm{ml}$ ice-cold Tyrode's solution, and homogenized immediately. In the second procedure, the total ventricle was freeze-clamped in pre-cooled Wollenberger clamps and stored at $-80^{\circ} \mathrm{C}$. In this situation analysis was started later on by thawing the complete ventricular tissue just prior to homogenization. The comparison of the results of both procedures will be discussed in chapter IV.

The tissue specimen were homogenized at $0^{\circ} \mathrm{C}$ by means of an UltraThurax (Janke \& Kunkel $A G$ ). Homogenization was performed during 5 minutes in 20 periods of 5 seconds each with intervals of 10 seconds between the periods. Then the homogenate was diluted with $47 \mathrm{ml}$ of the albumincontaining Tyrode's solution and sonicated for 5 minutes at $30 \mathrm{~W}$ in the tube, cooled in ice water. Afterwards the homogenate was diluted 26 times since the native enzyme activity in the tissue homogenate was too high. The homogenate was kept in ice and immediatelly analyzed for LDH and AST activities. The activities of both enzymes were determined spectrophotometrically, as described by Bergmeyer and Bernt (1974a; 1974b).

II 4.

A SPECIAL PROBLEM: CELLULAR ENZYME STABILITY IN ARTIFICIAL PERFUSION SOLUTIONS

\section{4.1 Introduction}

Release of intracellular enzymes from the heart is routinely used to quantitate the extent of damage inflicted upon the myocardial tissue. From preliminary studies we had the impression that the activity of intracellular enzymes was not stable when they were diluted in the artificial perfusion fluid commonly used (Tyrode's solution). Reduced enzyme activities in the coronary effluent will underestimate the extent of myocardial injury.

Therefore, we have investigated in more detail the activities of the enzymes lactate dehydrogenase and aspartate aminotransferase in a modified Tyrode's solution, which is in use in our laboratories to perfuse isolated rat hearts. To test the possible stabilizing effect of the presence of proteins in the perfusate (De Leiris et al., 1978), the enzyme activity was monitored when bovine serum albumin was added in a $30 \mathrm{mg} \cdot \mathrm{ml}^{-1}$ concentration, immediately after collection of the perfusate from the heart.

\section{4.2 Methods}

The experiments were performed in male Lewis rats $(n=3)$. The animals were anesthetized with ether. After thoracotomy the hearts were remo- 
ved from the body and immersed in ice-chilled Tyrode's solution. Remnant lung tissue and fat were removed. After weighing the hearts were attached to the perfusion apparatus, as described in section II.1. Retrograde perfusion was started at a pressure of $8.0 \mathrm{kPa}$ immediately after attachment of the heart to the aortic cannula, using a modified Tyrode's solution which contained (in mmol.1-1): $\mathrm{NaCl}(130.0), \mathrm{KCl}(5.6), \mathrm{CaCl}_{2}$ (2.2), $\mathrm{MgCl}_{2}$ (1.0), $\mathrm{NaH}_{2} \mathrm{PO}_{4}$ (1.2), $\mathrm{NaHCO}_{3}(28.6)$. $\mathrm{D}(+)$ glucose (11.1) was added as substrate. The $\mathrm{pH}$ of this solution ranged from 7.35 to 7.45 . A second cannula was connected to the left atrium; the filling pressure was set at $1.0 \mathrm{kPa}$. The hearts were allowed to eject by opening the left atrial inflow tract for a period of 30 minutes. At the end of the pre-ischemic period 30 minutes global, normothermic ischemia was induced by total cessation of flow to the heart. Thereafter the hearts were reperfused for 60 minutes. During the pre-ischemic and post-ischemic period the coronary effluent was collected for biochemical assay. Coronary effluent samples, taken at different time intervals during the experiments and collected at $0^{\circ} \mathrm{C}$ were divided as follows: a) samples without any additive; b) samples with the addition of bovine serum albumin to a final concentration of $30 \mathrm{mg} \cdot \mathrm{ml}^{-1}$; and c) samples diluted with Tyrode's solution to the same final volume as in samples described under b).

Samples with and without additives were assayed for enzyme activity within 2 hours after collection, and reassayed after storage at $-80^{\circ} \mathrm{C}$ or $20^{\circ} \mathrm{C}$ for 1,7 and 22 days. The activities of lactate dehydrogenase and aspartate aminotransferase present in the samples, were determined as described under II. 3.3 .

\section{4.3 Results}

As shown in Figure II. 7, the activity of lactate dehydrogenase was determined in 9 samples, taken from the coronary effluent of the 3 hearts and in which the original enzyme activity was higher than $10 \mathrm{U} . \mathrm{ll}^{-1}$. Lower activities were discarded to avoid errors induced by baseline interference. It is trivial that the inter-sample enzyme activity variation is prominent since the samples were taken at different time intervals during reperfusion. In all samples determined the addition of bovine serum albumin induced an increase of the enzyme activity (Table II. 2). The positive effect of albumin on the enzyme activity remained present up to 22 days after the storage of the samples at $-80^{\circ} \mathrm{C}$.

Blank samples of the Tyrode's solution to which bovine serum albumin was added in the same concentration as in the coronary effluent samples, showed no enzyme activity, proving that albumin had no effects on the analysis itself. Enzyme activity in the samples which were diluted with Tyrode's solution in the absence of albumin (C) was not significantly different from the corresponding non-diluted samples. Comparable results were obtained for the activity of aspartate aminotransferase (see Table IV, 2). 


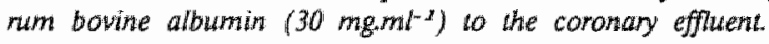

\begin{tabular}{ccccc}
\hline Assay at & $<2$ hours & 1 day & 7 days & 22 days \\
7 increase LDH & 44 & 73 & 51 & 43 \\
& $25-60$ & $52-107$ & $45-122$ & $31-84$ \\
Zincrease AST & 16 & 60 & 70 & 131 \\
\hline
\end{tabular}

Data are presensed as median values and $95 \%$ confidence limits. The enzyme activilies were assayed in coronary effluent samples $(n=9)$, collected during reperfusion after a 30 minutes period of global ischemia.

Storage of coronary effluent samples at $-20^{\circ} \mathrm{C}$ induced deleterious effects on the activity of both lactate dehydrogenase and aspartate aminotransferase. After 1 week of storage at $-20{ }^{\circ} \mathrm{C}$, a $30 \%$ reduction in lactate dehydrogenase activity was found in samples without any addition, while the activity in the samples to which albumin was added, was reduced to $14 \%$ of the initial activity. Comparable results were obtained for aspartate aminotransferase.

\section{4.4 Discussion}

The findings in the present study show that both lactate dehydrogenase and aspartate aminotransferase activities are negatively affected in artificial perfusion solutions devoid of blood constituents like albumin.

Secondly, it is shown that storage at $-80^{\circ} \mathrm{C}$ has no negative effects on the enzyme activity. In contrast, samples should not be stored at $-20^{\circ} \mathrm{C}$ in order to avoid loss of enzyme activity. The increased enzyme activity after addition of serum bovine albumin could be possibly explained by the observation that the protein structure becomes more rigid when proteins are allowed to bind to a complementary surface (Martinek et al., 1977a; Martinek et al., 1977b; Torchilin et al., 1978). This may favor the integrity of the active site of the enzyme molecule and inhibit the denaturation of the protein structure. We did not investigate the effects of any other protein-like 
blood constituent on the activity of the enzymes.

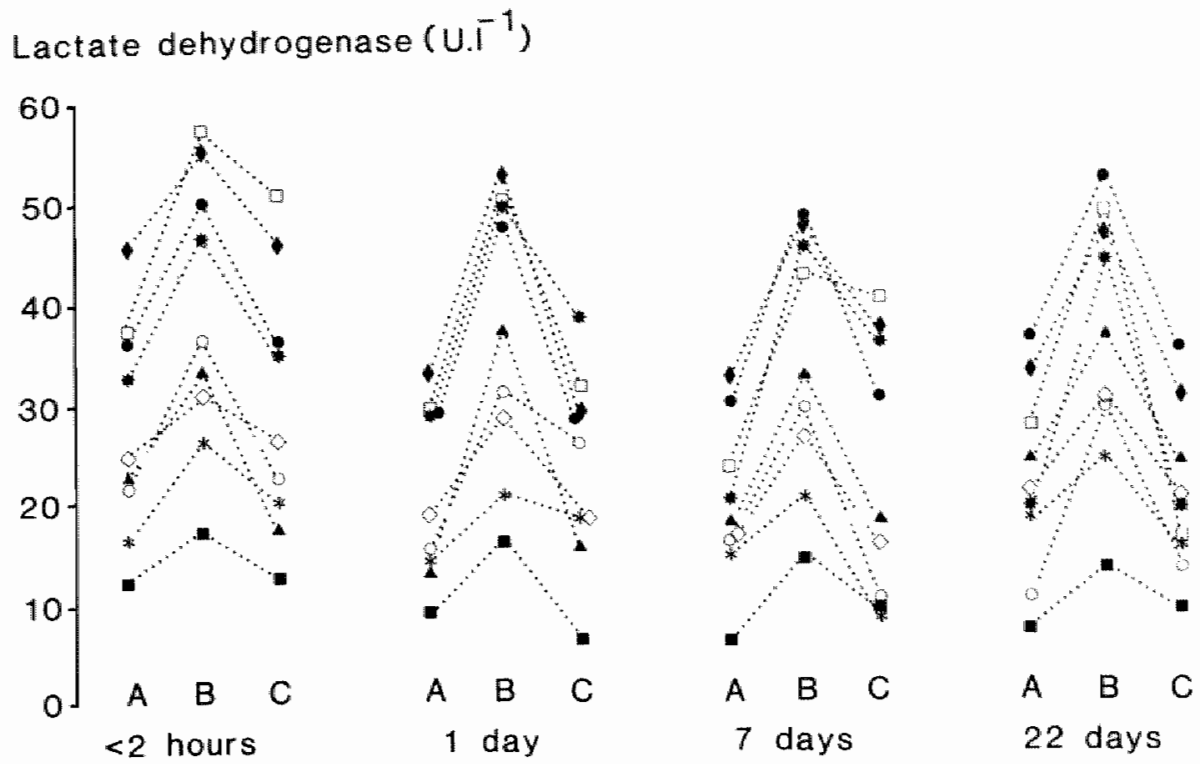

Figure II. 7 Effects of the addition of bovine serum albumin (30 $\mathrm{mg}$ per ml) on the activity of lactate dehydrogenase in coromary effluent samples, analyzed within 2 hours after collection and analyzed after various periods of storage at $-80^{\circ} \mathrm{C}$. A: samples without any additive; $B$ : samples to which albumin was added; $C$ : Samples diluted with Tyrode's solution.

The data presented demonstrate that the use of enzyme leakage from isolated hearts, perfused with artificial perfusates, as quantitative indicator of cellular membrane damage, is only allowed when adequate precautions are taken to prevent loss of enzyme activity, i.e. when serum bovine albu$\mathrm{min}$ is added immediately after collection of the coronary effluent. 

The use of microcomputers in collecting and processing experimental data has become widely accepted in the last decade. The enormous expansion of the capabilities of small computers also promotes their application in the on-line computation of cardiovascular variables. Beside the advantage of a more detailed insight into the experimental process, time-consuming activities, like data evaluation by hand, can be avoided.

A newly written computer program is described to study left ventricular function in isolated, ejecting rat hearts. Left ventricular function was investigated at different levels of left atrial filling pressure and diastolic aortic pressure levels. Important hemodynamic variablles like left ventricular systolic and diastolic pressure and its maximal positive and negative first derivative, aortic flow, and aortic pressure were continuously calculated and printed at minimal intervals of 6 seconds. The compuler program was run on an Apple IIe microcomputer in combination with a home-made pre-processor. The program for the preprocessor was written in 6809 assembly language, while the Apple Ile microcomputer was programmed in 6502 assembly language combined with Applesoft Basic. This automatization set-up has been used in the studies, described in chapters IV, VI, VII, and VII. 


\section{2.1. Animall experiments}

Male Lewis rats ( $\mathrm{n}=8$, age $=16$ weeks) were anesthetized with ether. The hearts were quickly removed from the thorax and immersed in ice-chilled Tyrode's solution. Remnant lung tissue and fat were removed. The hearts were weighed and attached to the perfusion apparatus, as described in chapter II. Left ventricular pressure was measured via a catheter inserted into the left ventricle through the apex of the heart. The first derivative of left ventricular pressure $\left(\mathrm{dP}_{1 \mathrm{v}} / \mathrm{dt}\right)$ was assessed with an analog differentiator (Janssen Scientific Instruments). Aortic pressure was measured in the aortic cannula. Both left ventricular and aortic pressure were measured with pressure transducers (CTC) with a frequency response of $100 \mathrm{~Hz}-3 \mathrm{~dB}$. The frequency response of the ana$\log$ differentiator was $100 \mathrm{~Hz}-3 \mathrm{~dB}$. Aortic flow was measured with an extracorporeal electromagnetic flow probe (Skalar, $3 \mathrm{~mm}$ ID) mounted into the aortic tract and connected to a sine wave electromagnetic flowmeter (Skalar, Transflow 601). An epicardial electrogram was recorded by connecting two small platinum hooks to the left ventricular wall. In the same way two electrodes were attached to the right atrium for bipolar stimulation. All hemodynamic variables were recorded continuously on an analog recorder (HP 7404) and calculated off-line for comparison with the values as assessed with the microcomputer. Coronary flow was measured by collecting the total amount of coronary effluent over periods of 1 minute. Cardiac output was calculated by adding the coronary and aortic flow values.

During an initial period of 10 minutes, all hearts were perfused retrogradely at a perfusion pressure of $8 \mathrm{kPa}$. Then, the left atrial cannula was opened and the hearts were allowed to eject during a period of 20 minutes. Left atrial pressure was set at $1.0 \mathrm{kPa}$, while diastolic aortic pressure was kept at $8.0 \mathrm{kPa}$. Under these circumstances mean systolic left ventricular pressure was $10.4 \mathrm{kPa}$, so that a mean coronary perfusion pressure of about $8.8 \mathrm{kPa}$ was reached. In the last 10 minutes of the period in which the hearts ejected, left ventricular function curves were constructed under steady state conditions. Cardiac output was measured at 4 different left atrial filling pressures, that is $0.66,1.32,1.98$ and $2.64 \mathrm{kPa}$. This procedure was repeated at 3 different end-diastolic aortic pressure levels, that is $8.0,13.3$ and $18.6 \mathrm{kPa}$. When all values reached steady state levels, the variables were recorded, and calculated by hand during at least 30 seconds. During these periods, coronary flow was measured, while the other variables were calculated by the microcomputer as described below. After construction of the left ventricular function curves, left atrial filling pressure and aortic pressure were reset to the control values. Heart rate was kept constant by stimulating the hearts at a frequency of 300 beats.min ${ }^{-1}$. 
The electrogram and the analog signals of left ventricular pressure and its first derivative, aortic pressure, and aortic flow were fed into an 8 bits pre-processor, which allowed sampling of the raw data (Figure III. 1). Simultaneously all data were stored on magnetic tape (Ampex PR 2200) for off-line analysis. The pre-processor was equipped with an 8 channel and 8 bits analog to digital convertor (ADC 0808 National), an 8 bits microprocessor (MC 6809 Motorola), a digital to analog convertor ( $4 \times \mathrm{AD} 7528$ Analog Devices) and a total memory of $14 \mathrm{~Kb}(7 \times 2 \mathrm{~Kb}$ TMM 2016 Toshiba). It also contained a serial (ACIA R 6551 Rockwell) and a parallel interface (VIA R 6522 Rockwell).
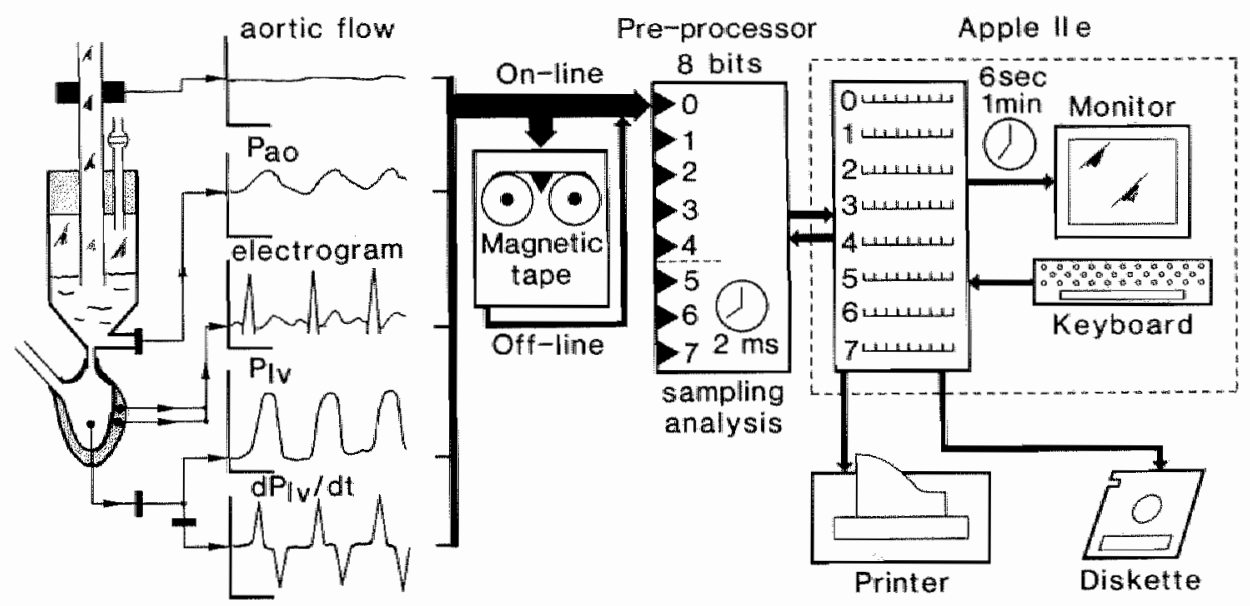

Figure III. I Schematic representation of the automated ser-up for the calculation of hemodynamic yariables in the isolated ejecting rat heart with the use of an Apple lle microcomputer in cambination with a pre-processor. Pan: aorsic pressure; $P_{L}$ : left ventricular pressure; $d P_{w} / d t:$ first derivative of left ventricular pressure.

In the pre-processor, all signals were continuously sampled and analyzed at a frequency of $500 \mathrm{~Hz}$. The analysis of the hemodynamic data is presented in Figure III. 2. The computation of each heart cycle was started at the top of the electrogram. The polarity of the electric pulses of the stimulator and the heart were set in opposite directions to avoid erroneous detection. The cycle time was measured as the time difference between the electrical depolarization maxima of two consecu- 


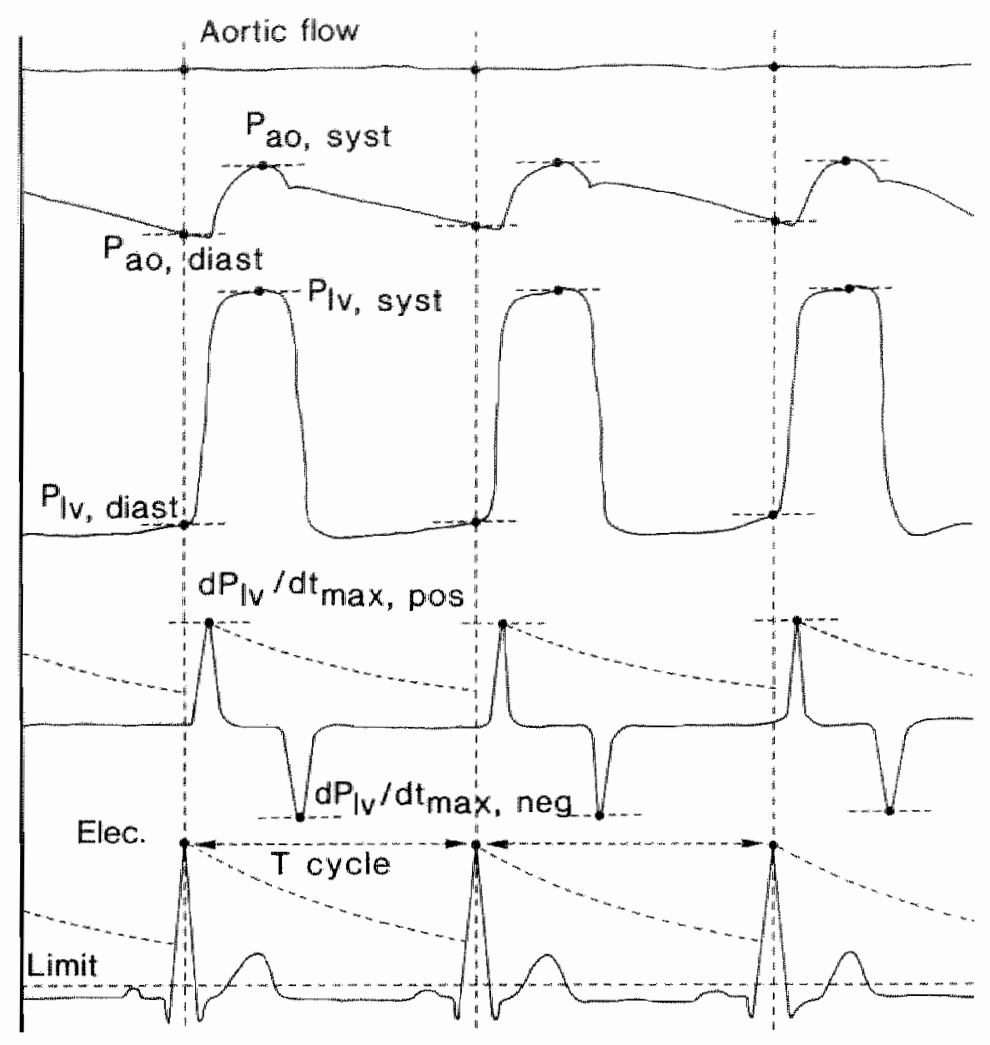

Figure M. 2 Analysis of the hemadynamic variables. The diastolic values of aortic and left ventricular pressure and the values of the mean aortic flow were desected at the maximal amplitude of ventricular depolarization. The systolic walues of the aortic and lefi ventricular pressure and maximal positive and negative values of the first derivative of the left ventricular pressure were identified as the maximal values of the respective variables. $P_{\text {aso }}:$ aortic pressure; $P_{1}$ : left ventricular pressure; $d P_{f w} / d t$ : first derivative of left ventricular pressure; Elec.: electrogram; $T_{c y}$ ats : duration of a cardiac cycle.

tive heart beats. To obtain adequate measurements for these time differences, two problems had to be solved. First, all significant spikes had to be identified as ventricular depolarizations, while insignificant changes in baseline level or small spikes should not be recognized. Second, temporary changes in amplitude of the electrogram, as may be induced by altered resistances or ischemia, had to be interpreted as true myocardial depolarizations. Therefore, the detected maximal value of the electrogram generated a threshold with the same amplitude as this maximal value. This threshold had an exponential decay, characterized by the following formula: 


$$
A_{t}=A_{\text {maxx }} \cdot e^{-\infty}
$$

in which

$$
\begin{aligned}
& \text { A }_{t}=\text { amplitude of the threshold } \\
& \text { Anm } x=\text { maximal amplitude of the electrogram } \\
& \alpha \quad=\text { value specifying the decay of the exponential } \\
& t \quad=\text { time for the decay steps (routinely set at } 80 \mathrm{~ms} \text { ). }
\end{aligned}
$$

A lower limit with a magnitude of $1 / 16^{\text {th }}$ of the maximal amplitude was built in to prevent the detection of very small spikes. Under these circumstances, all pulses with amplitude higher than the magnitude of the exponential at that moment could be detected. To test the reliability of this method, we investigated a standard period of 9 minutes, in which the shape of the electrogram (stimulated, non-stimulated, amplitude) was changed. This procedure was repeated with four different values for a. The number of depolarization complexes wrongly or not detected, were counted and compared with the total number of complexes.

The maximal amplitude of the electrogram was also used to identify the start of a new cardiac cycle. End-diastolic left ventricular pressure, diastolic aortic pressure and aortic flow were measured at the moment that this maximum was identified. Systolic left ventricular and systolic aortic pressure were identified as the maximal values reached in both signals during one heart beat. In the same way the maximal positive and negative values of the dPu/dt were found. If the electrogram could not be measured for any particular reason, computation of the hemodynamic variables of the following cardiac cycle could nevertheless be started. Therefore, a comparable routine as used for the detection of the electrogram, was applied at the first derivative of the left ventricular pressure signal. If a positive peak value of the first derivative was reached before a ventricular depolarization could be detected, a new cardiac cycle was started and all hemodynamic values were calculated as described, except for the left ventricular end-diastolic pressure, which was deleted in the subsequent data presentation, since values of this variable at the level of the positive $\mathrm{dP}_{\mathrm{u}} / \mathrm{dt}_{\max }$ were too high.

To control the quality of the detection algorithms a control routine was added to the pre-processor program. This routine enabled the experimentator to display the delayed analog signals (via the DA convertor) together with the control pulses representing the data points detected (by means of the VIA). The time offset of these pulses was identicall to that of the analog output signals. 
In this way eight data points were selected per cardiac cycle: the diastolic and systolic values of left ventricular and aortic pressure, the cycle time, the maximal positive and negative values of $d P_{1 v} / d t$ and aortic flow. The selected data points were stored in a buffer stack until an inquiry signal was transmitted from the Apple Ile computer (see Figure III. 1). Upon the inquiry signal, data-transmission was started from the pre-processor to the Apple processor (Rockwell 6502). Per heart beat, all selected walues were related to a set of data, yielding calibration factors for the different variables. These factors were introduced before the start of the experiment. Once multiplied with the respective factors, the walues were stored in eight buffer stacks with a standard length of nine values per stack. This length could be freely changed by the investigator. The first entered value on the stack was dropped when the maximal capacity of the stack was reached and a new value had to be stored.

A clock module started the reporting procedure of the system. At a standard interval of 1 minute, the median values of the currently ranked stack contents were determined and immediately transferred

\begin{tabular}{|c|c|c|c|c|c|}
\hline$I M E$ & $-1 R$ & 5 & ILVD & $\square P+$ & $d p-$ \\
\hline $9 \ldots$ & 312 & 9.3 & 1.3 & 1166 & 112 \\
\hline & 3 & 9.6 & 1.6 & & 123 \\
\hline & & & 1. & & 19 \\
\hline 0. & 3 & $\because$ & 1. & & \\
\hline & & & 1.1 & & \\
\hline & $0 \mathrm{~B}$ & 9. & 8 & 177 & 20 \\
\hline & $30 \%$ & 9. & & 188 & 12 \\
\hline & 312 & 9. & 1.1 & 177 & \\
\hline & 312 & ?. & 1.1 & $\| 77$ & \\
\hline & 30 & $\$$. & & 17 & $\infty$ \\
\hline 1 & 309 & 9 & 1. 4 & & \\
\hline & $36 \%$ & 9 & & & \\
\hline 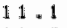 & $30 \%$ & 13. & 1.9 & 433 & 2 \\
\hline & $30 \%$ & 14. & 1.7 & 499 & \\
\hline & 309 & 13.6 & & 522 & \\
\hline$\infty$ & 312 & 13.6 & & 488 & \\
\hline .5 & 312 & 13. & $y, 7$ & 477 & \\
\hline 4 & $30 \%$ & 13. & & 477 & \\
\hline 1.7 & 303 & 13. & $1 * 7$ & 488 & 27 \\
\hline+9 & 390 & 13. & 1.7 & 477 & \\
\hline & 300 & 13.5 & & 477 & \\
\hline & 312 & 13,3 & $1+9$ & 477 & \\
\hline & $30 \%$ & & 1.7 & $48 \mathrm{~B}$ & \\
\hline & & & & $48 \mathrm{E}$ & \\
\hline & & & 1.7 & 499 & \\
\hline & & 7 & & $48 \mathrm{~B}$ & \\
\hline
\end{tabular}

\begin{tabular}{|c|c|c|}
\hline AOS & IAOD & AGF \\
\hline 8.8 & 8.4 & -11 \\
\hline 8 & 8,4 & -10 \\
\hline 8.8 & 8.4 & -10 \\
\hline 8.8 & 8.4 & -110 \\
\hline 8: . 8 & : 8.44 & -10 \\
\hline 8.8 & $8 \cdot 2$ & -11 \\
\hline 9.9 & 0,2 & -11 \\
\hline $3 . B$ & 8.4 & -11 \\
\hline घ. 8 & 8.4 & -11 \\
\hline 8.8 & $8 \cdot 4$ & -12 \\
\hline 0.8 & 8.2 & -13 \\
\hline 8.8 & $9 \cdot 4$ & -12 \\
\hline 9.6 & 9.0 & 49 \\
\hline 9.4 & $8 \cdot 6$ & 51 \\
\hline 9.0 & $e_{n} 4$ & 50 \\
\hline 9.0 & $8 \cdot 2$ & 50 \\
\hline$B .8$ & $B .0$ & 49 \\
\hline 8. 8 & $8 \cdot 2$ & 49 \\
\hline$\theta, 8$ & 8.0 & 50 \\
\hline 8.8 & $\theta, 0$ & 50 \\
\hline B. 6 & 0.0 & 50 \\
\hline 8.5 & $B .0$ & $\$ 0$ \\
\hline $8 \cdot 6$ & $B .0$ & 50 \\
\hline 8.4 & 8.0 & 51 \\
\hline 8.8 & $B .0$ & 51 \\
\hline 8.6 & 7 . & 51 \\
\hline
\end{tabular}

Figure III. 3 Typical sequence of an experiment. Note the changes in the variables al vime 11.1 , induced by opening the left atrial canmula, allowing the heart to eject. HR : heart rate in beats per min; LVS, LVD: systolic and diastolic left ventricular pressure in $k P a$, respectively; $d P+, d P$ : maximal positive and negative values of the first derivative of the left ventricular pressure in $\mathrm{KPa}_{\mathrm{s}} \mathrm{s}^{-1}$, respectively. AOS, AOD: systolic and diastolic aortic pressure in $k P a$, respectively; $A O F$ : aortic flow in mi. min.s. 
to the monitor screen and printer and simultaneously stored on diskette. The values were presented in arrays and were associated with the exact time as shown in Figure III. 3. The standard report interval of one minute could be freely changed by the investigator to 6 seconds. This procedure was followed during construction of the left ventricular function curves. As a consequence, the values were presented on screen and printer at 6 second intervals.

\section{3. RESULTS}

The results of the introduction of an exponential decay in the detection of the maximal amplitude of the electrogram are presented in Table III. 1. The total number of activations was counted over a total period of 9 minutes. During this period 2650 complexes were counted, corresponding to a heart rate of 294 beats. $\min ^{-1}$. The pre-processor detected 18 spikes wrong when an $\alpha$-value of 8.6 was used in the exponential formula. This represents $0.6 \%$ of the total number of depolarizations. With an $\alpha$-value of $17.3,0.22 \%$ of the beats were wrongly detected. The detection accuracy decreased when the $\alpha$-value was increased to 26 . In this case 40 beats were not or wrongly detected, representing $1.5 \%$ of the total number of beats. Finally, with an $\alpha$-value of $34.6,287$ beats were not detected. This represents $10.7 \%$ of the total number of heart beats. This means that the slope of the exponential has to be rather steep to detect all pulses.

Table HI. 1

The effects of different exponential decays on the number of wrongly or not detected depolarization waves during a total period of 9 minutes in which 2650 waves were counted.

$\begin{array}{lcc}\alpha-v a l u e & \begin{array}{c}\text { Number of beats } \\ \text { wrongly or not detected }\end{array} & \begin{array}{c}\text { Percentage } \\ 8.6\end{array} \\ 17.3 & 18 & .60 \\ 26.3 & 6 & .22 \\ 34.6 & 40 & 1.50 \\ & 287 & 10.70\end{array}$


Erratum: p. 36 Top line missing.

Read: The values of the variables as obtained with the method descri- 
bed for analyzing the hemodynamic data were found to be accurate. Figure III. 4 shows the correlations between the calculations made by hand on the analog recordings of the variables and the calculations made by computer. The data are presented for systolic aortic pressure and positive $d P_{i w} / d t_{m a x}$. In both cases correlation coefficients of 0.99 were found. A similar value was found for the other variables.
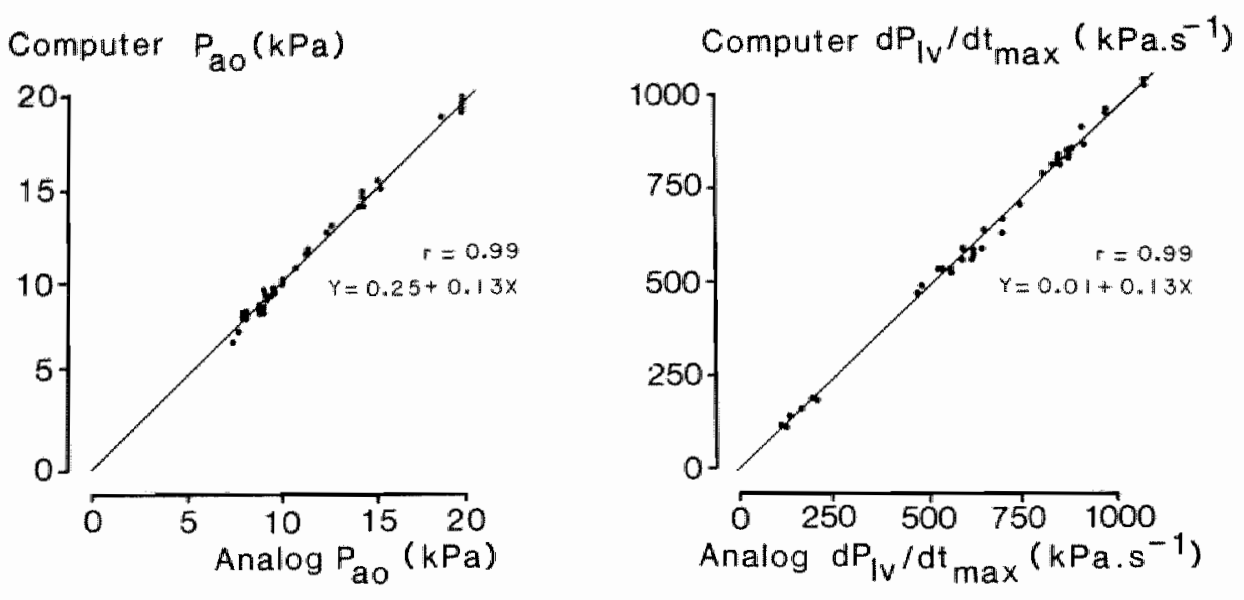

Figure 11.4

The relation between the values as calculated by computer (Computer) and by hand (Analog) for the systolic aortic pressure $(P$ ao $)$ and positive maximal first derivative of left ventricular pressure $\left(d P a / d t_{m a x}\right)$. The data refer to 39 pairs of walues. The linear regression lines and the correlation coefficients are shown.

The results of a representative left ventricular function curve are shown in Figure III. 5. The increase in left atrial filling pressure (preload) was followed by a fast increase in aortic flow, reaching a steady state again within 30 seconds. The changes in left ventricular pressure due to changes in preload however, were rather small. Only slight increments in the systolic pressure were observed at each preload increment. The increase in afterload from 8 to $13.3 \mathrm{kPa}$ resulted in a slight decrease in aortic flow at the 2 lowest preload levels, while at higher preloads no significant differences were observed. The increase in afterload resulted in a comparable increase in left ventricular systolic pressure. At the highest afterload level, i.e. $18.6 \mathrm{kPa}$, at each preload level aortic flow reached significantly lower values as compared to the corresponding values at lower afterload levels. Reversion of the sequences in the construction of function curves had no effect on the attained levels of cardiac output as compared to the showed sequence. 


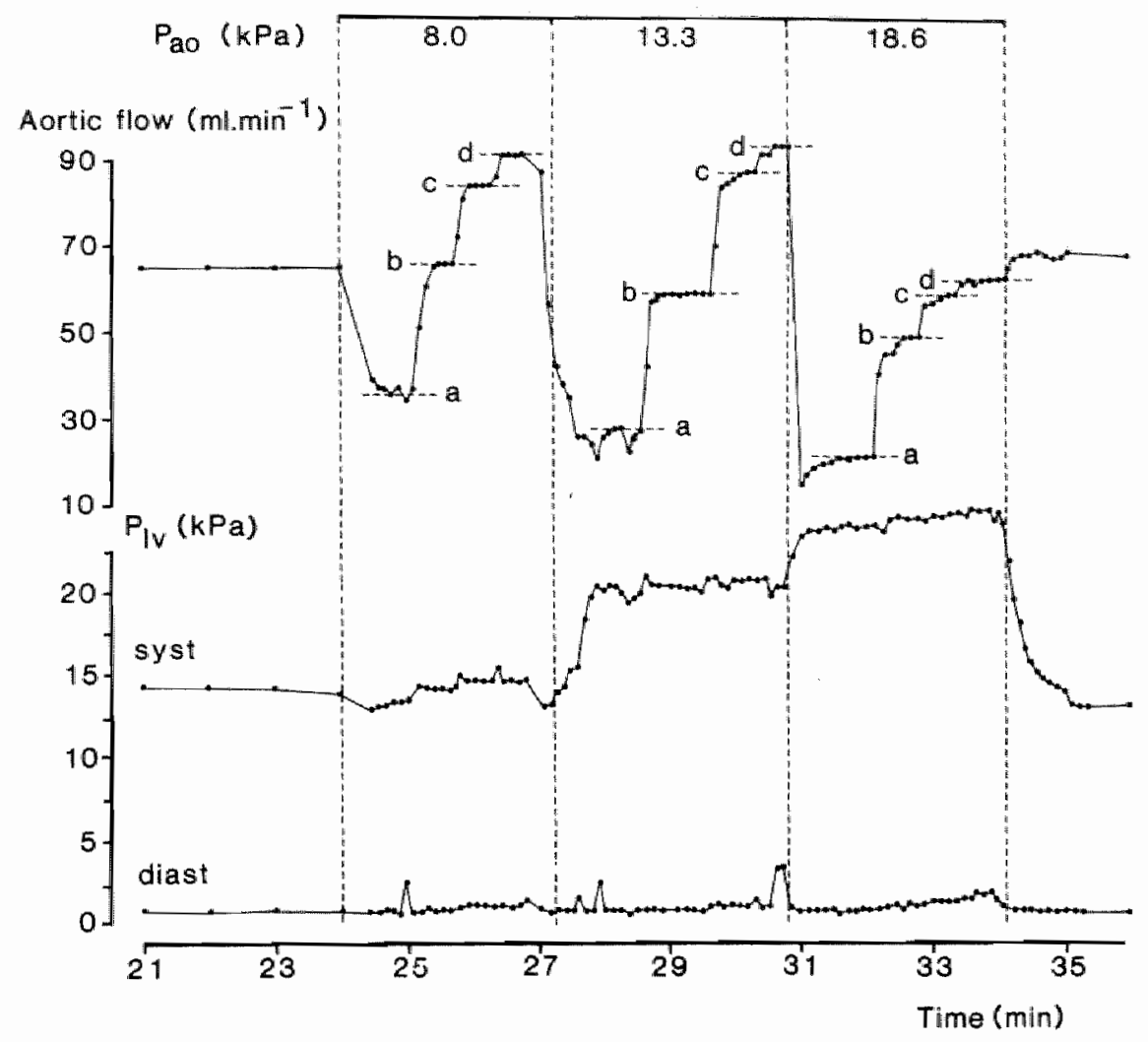

Figure IIL. 5 Plotted values of mean aortic flow and left ventricular systolic (Prw. syst) and end-diastalic (Pw,diass) pressure during the construction of a left ventricular function curve. The verical broken lines mark the 3 periods with different aortic pressure (Pao) balues (increase in afteriaad from 8 to $18.8 \mathrm{kPa}$ ). During these periods. the data are presented at o seconds intervals. The horizontal broken lines indicate the stabilized level of aortic flow at the 4 different left atrial pressure levels (preload), i.e. $0.66 \mathrm{kPa}$ (a), $1.32 \mathrm{kPa}$ (b), $1.98 \mathrm{kPa}$ (c), and $2.64 \mathrm{kPa}$ (d).

Figure III. 6 shows the results of the function curves obtained in the 8 isolated, ejecting hearts. Each increment in preload resulted in a pronounced increase of the cardiac output. The effects of an increased afterload on cardiac output are most outspoken at the highest afterload, that is $18.6 \mathrm{kPa}$. When all values were normalized for the values, attained at the highest preload during the lowest afterload, a cardiac output value of $70 \%$ was reached at the highest preload and afterload level. 


$\frac{P_{\mathrm{ao}}(\mathrm{kPa})}{8.0} \frac{13.3}{18.6}$

$P_{\text {ao }}(\mathrm{KPa})$

$8.0 \quad 13.3 \quad 18.6$

18.6

Cardiac output (mi min ${ }^{-1}$ )

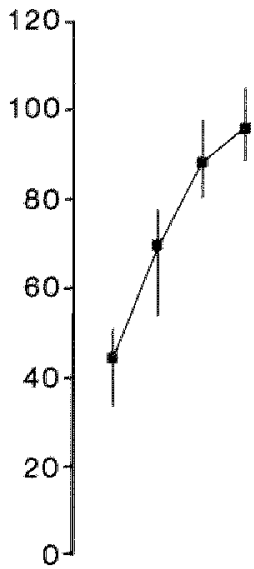

$\begin{array}{llllll}0.66 & 2.64 & 0.66 & 2.64 & 0.66 & 2.64\end{array}$ $P_{\text {la }}(\mathrm{KPa})$

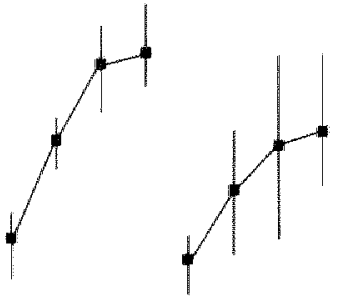

Variations in the cardiac output as induced by changes in afterload (aortic pressure, $\left.P_{a 0}\right)$ and preload (left atrial pressure, $P_{\text {sa }}$ ), as described in the text. Data are presented as median values and $95 \%$ confidence limits $(n=8)$.

\section{4. DISCUSSION}

The present data show that reliable results can be obtained by calculating hemodynamic variables with the use of two microprocessors. One microprocessor is especially designed for sampling and analysis of the raw data, while the second is used for sorting, presenting and storage of the selected data. Execution of all the routines described by a microprocessor as the Apple IIe is beyond the capabilities of this machine. The construction of a pre-processor not only simplifies the task of the main processor, but also creates space for the analysis of additional hemodynamic variables. Besides, this configuration allows on-line computation and presentation of the variables, which is preferred over off-line analysis. However, off-line analysis of the hemodynamic data remains possible with the present configuration.

As shown in Figure III. 5, rapid changes in hemodynamic variables as induced by changes in preload and/or afterload are adequately calculated and reproduced by the computer system. The accuracy of the assess- 
meat of the hemodynamic data depends in the first place on the time interval applied to the sampling procedure. Secondly, it also depends on the resolution of the pre-processor. Fourier analysis of the left ventricular pressure curve in dogs revealed no significant contribution to the pressure wave of frequencies above the 10th harmonic (Gersch et al., 1971). This means for the rat heart, with a heart rate of 300 beats. $\min ^{-1}$, that the frequency response has to be flat up to at least $50 \mathrm{~Hz}$. A sampling interval of $2 \mathrm{~ms}$, as applied in the described sampling routine, was found to be suitable for practical purposes, since a very high correlation was found between the values for $\mathrm{dP}_{1 \mathrm{v}} / \mathrm{dt}_{\max }$ as calculated by hand and by computer $(\mathrm{r}=0.99)$. Also at high $\mathrm{dP}_{1 v} / \mathrm{dt}_{\max }$ values no substantial deviations from the line of identity were observed (Figure III. 4).

The use of an 8 bits microprocessor implies that the resolution of the system is restricted to 256 points per full scale. Therefore, for each variable, accurate values can be calculated up to $0.4 \%$ of the full scale. It is believed that this resolution can be accepted for the calculation of the hemodynamic variables presented.

Calculation of the diastolic values of some of the hemodynamic variables at the moment of the depolarization wave of the electrogram could be a point of critique. Indeed, as a consequence of compliance of the aorta, in intact animals the end-diastolic aortic pressure is only reached just prior to the moment that the aortic valve opens. However, in the isolated heart, the compliance of the perfusion system is lower than that of the intact aorta (van Bilsen et al., 1984), despite the presence of a compression chamber in the aortic outflow tract. As a consequence, the aortic pressure at the end of the diastolic phase is determined by the pressure in the perfusion system and, therefore, completely flat, so that no errors are introduced by a slightly earlier detection of the pressure value.

The aortic flow value is also detected at the moment of the maximal electrogram value. Since the analog flow value was presented to the computer as mean flow, no flow differences are observed during one heart cycle. Therefore, the moment of detection is not critical. The pulsatile flow was not registrated, since the flow probe was located above the compression chamber instead of between the heart and the compression chamber. This compromise had to be made to improve the aortic outflow tract characteristics (see chapter II). 


\title{
HEMODYNAMIC, BIOCHEMICAL AND MORPHOLOGICAL
}

\author{
CHARACTERIZATTON OF THE ISOLATED,
} EIECTING RAT HEART PREPARATION

IV 1. HEMODYNAMIC AND BIOCHEMICAL STABILITY OF THE ISOLATED, EJECTING HEART PREPARATION

\section{1.1. Introduction}

Reliable interpretation of the effects of ischemia and reperfusion on the myocardial performance of isolated, ejecting rat hearts can only be obtained when myocardial function, as far as the cardiovascular and biochemical variables are concerned, is stable during aerobic perfusion over a longer period of time. Therefore, cardiac function was investigated in isolated, ejecting hypertrophied hearts of aorta-banded rats and non-hypertrophied hearts of sham-operated animals during 130 minutes of aerobic perfusion, and in hearts of 16 months old Wistar-Kyoto rats during 140 minutes aerobic perfusion.

To obtain information about the variations in the myocardial tissue content of biochemical substances, induced by such a period of isolated perfusion, the hearts of aorta-banded and sham-operated animals were freeze-clamped at the end of the perfusion period and analyzed chemically. For comparison, native myocardial tissue contents in non-perfused hearts were obtained from another group of aorta-banded and sham-operated animals.

\section{1.2. Methods}

Aorta-banded rats (Aobap; $n=6$ ) and sham-operated control rats $\left(\mathrm{Stap}_{\mathrm{ap}} \mathrm{n}=6\right)$ of 5 months of age were used for the experiments in which 
the isolated hearts were aerobically perfused during 130 minutes. Full description of the aorta-banding technique is giwen in chapter VI. The other experiments were performed on 16 months old Wistar-Kyoto rats, perfused during 140 minutes (WKY; $n=5$ ). Native tissue contents of biochemical substances were obtained in other groups of aorta-banded (Aobax; $\mathrm{n}=8$ ) and sham-operated animals ( $\mathrm{Sh}_{\mathrm{mat}} ; \mathrm{n}=6$ ), the hearts of which were freeze-clamped immediately after isolation from the thorax. Although the hearts of the WKY rats were not analyzed for tissue content of biochemical substances, the content of these structures was analyzed in native tissue of WKY rats $(n=4)$ and in hearts of age-matched spontaneously hypertensive rats (SHR; $n=6$ ).

The rats were anesthetized with ether. After thoracotomy, hearts which had to be perfused were removed from the thorax and immediately immersed in ice-chilled Tyrode's solution. Remnant lung tissue and fat were removed. The hearts were attached to the perfusion apparatus, described in chapter II, and perfused with Tyrode's solution, containing (in mmol.1-1): $\mathrm{NaCl}(130.0), \mathrm{KCl}(5.6), \mathrm{CaCl}_{2}$ (2.2), $\mathrm{MgCl}_{2}(1.0), \mathrm{NaH}_{2} \mathrm{PO}_{4}$ (1.2) and $\mathrm{NaHCO}_{3}$ (28.6). As substrates $\mathrm{D}(+)$ glucose (11.1) and pyruvate $(5.0)$ were added. The $\mathrm{pH}$ of this solution ranged between 7.35 and 7.45. Retrograde perfusion was immediately started at a perfusion pressure of $8.0 \mathrm{kPa}$. A second cannula was connected to the left atrium for filling of the left atrium and left ventricle; the filling pressure was set at $1.0 \mathrm{kPa}$. After 10 minutes of retrograde perfusion, the hearts were allowed to eject. Aortic pressure was measured $1 \mathrm{~cm}$ above the aortic valves in the aortic cannula. At antegrade perfusion the rat hearts developed left ventricular systolic pressures, reaching maximal values of $2.5 \mathrm{kPa}$ above the diastolic aortic pressure, which was kept at $8.0 \mathrm{kPa}$. This implies that mean coronary perfusion pressure was about $0.8 \mathrm{kPa}$ higher than diastolic aortic pressure. The hemodynamic variables and the electrogram were recorded and computed as described in chapter III.

In the group of WKY hearts, a slightly different Tyrode's solution was used. Pyruvate was omitted and sucrose (13.2 mM) was added. In these hearts, diastolic aortic pressure was kept at $10.7 \mathrm{kPa}$.

Retrograde perfusion was maintained during 10 minutes. Thereafter, the left atrial cannula was opened and antegrade perfusion was started for a period of 120 minutes. Heart rate was kept constant at 300 beats.min ${ }^{-1}$, using bipolar stimulation with small platinum electrodes attached to the right atrial wall. In the hearts of aorta-banded and shamoperated rats, left ventricular function curves were constructed at 3 different aortic and 4 different left atrial pressure loads at the beginning and at the end of the antegrade perfusion period. Left atrial pressure was increased in steps of $0.66 \mathrm{kPa}$ from 0.66 to $2.64 \mathrm{kPa}$ at a diastolic aortic pressure of $8.0 \mathrm{kPa}$. This procedure was repeated at aortic pressures of 13.3 and $18.6 \mathrm{kPa}$. At each step, hemodynamic variables were computed. Myocardial function had to be stabilized for at least one minute before the various variables were recorded. 
At the end of the perfusion period the hearts were disconnected from the perfusion apparatus and freeze-clamped as described earlier. The biochemical analysis of myocardial tissue and coronary effluent has been described in chapter II.

Differences between the values of the various hemodynamic and biochemical variables in the hearts of sham-operated and aorta-banded rats and between the biochemical variables before and at the end of 130 minutes aerobic perfusion were statistically evaluated using the Mann-Whitney U-test. The same test was used to evaluate the statistical significance of the differences in the biochemical variables obtained in native myocardial tissue of sham-operated and aorta-banded animals. Changes in the hemodynamic variables, occurring during 130 (aorta-banded and sham-operated) and 140 (WKY) minutes aerobic perfusion, were analyzed for statistical significance, using the Wilcoxon's matched-pairs signed-ranks test. P-values smaller than or equal to 0.05 were considered to be statistically significant.

\section{1.3. Results}

\section{Hemodynamics}

In awake, intact animals, the surgically induced narrowing of the abdominal aorta induced a systolic pressure gradient of at least $10 \mathrm{kPa}$ (see chapter VI). The hemodynamic variables in the isolated hearts of aorta-banded and sham-operated rats, aerobically perfused during 130 minutes are shown in Figure IV. 1. Non-hypertrophied hearts had a

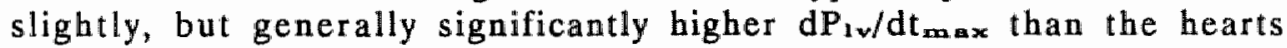
of aorta-banded animals during the ejecting period. Expressed per gram heart weight, generally significantly higher coronary flow values were found during the ejecting period in the control hearts than in the hypertrophied hearts. In both groups the highest cardiac performance was reached in the first hour of the ejecting period. The aortic flow tended to be higher during this period in the non-hypertrophied than in the hypertrophied hearts. The differences, however, did not reach the level of significance. Towards the end of the experiments, contractility ( $\mathrm{dP}_{\mathrm{iv}} / \mathrm{dt}_{\max }$ ) and aortic flow tended to decrease $(<10 \%$ as compared to the highest values reached) in both groups of hearts. However, the decrease was not statistically significant. Coronary flow remained stable in both groups throughout the experiments, reaching higher values in the sham-operated animals (Figure IV. 1).

Hypertrophy in the hearts of the aorta-banded rats was prominent. Although heart weight of the aorta-banded rats was only $10 \%$ higher than in the control hearts, the heart weight to body weight ratio was $25 \%$ higher in the aorta-banded rats (Table IV. 1 ).

During construction of left ventricular function curves, (Figure IV. 2), increasing left atrial pressure at a diastolic aortic pressure of 
8.0 $\mathrm{kPa}$ induced a consistent increase of the mean aortic flow, reaching maximal values of about $80 \mathrm{mlmin}^{-1}$. When cardiac output was calcu= lated by adding coronary flow to aortic flow, maximal fluid volumes of $100 \mathrm{ml} \cdot \mathrm{min}^{-1}$ were ejected in the control hearts. No significant differences were observed between both experimental groups at this aortic pressure level. At the next aortic pressure level $(13.3 \mathrm{kPa}$ ) the pressureflow curve was shifted downwards in the non-hypertrophied hearts, especially at the two highest left atrial pressure levels tested. This phenomenon was even more prominent at the highest diastolic aortic pressure, i.e. $18.6 \mathrm{kPa}$. The downward shift of the pressure-flow curve was
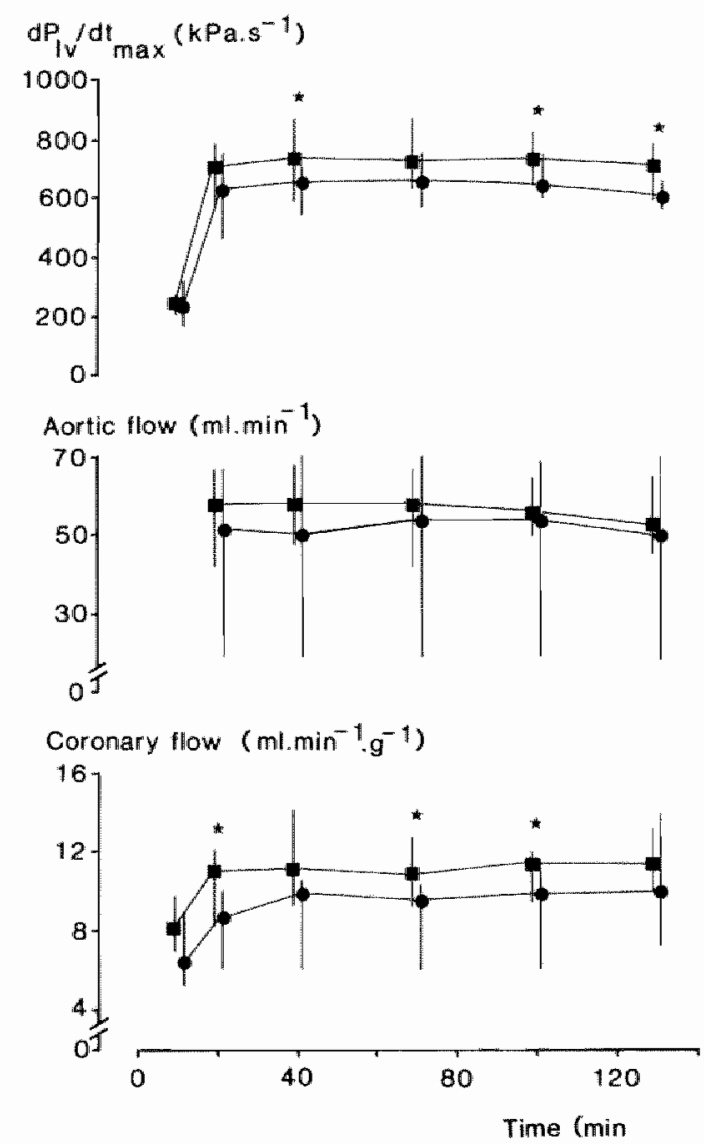

Figure $I V .1$ Hemodynamic data in isolated, ejecting hearts of sham-operated ( $\square$; $n=6)$ and aorta-banded $(0 ; n=6)$ animals during 130 minutes aerobic perfusion. Data are presented as median values and $95 \%$ confidence limits. $d P_{t w} / d t_{\max }$ : maximum first derivative of left ventricular pressure. $\star$ : significant difference between both groups $(p<0.05)$. 


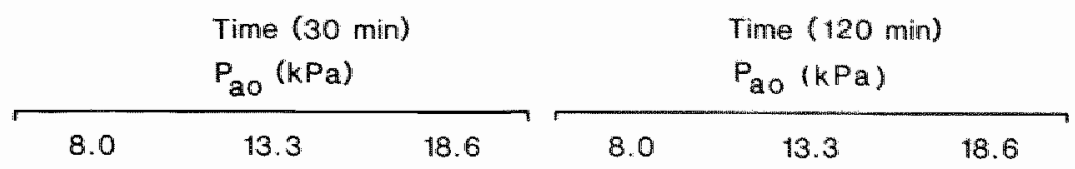

Aortic flow (ml. $\mathrm{min}^{-1}$ )

100
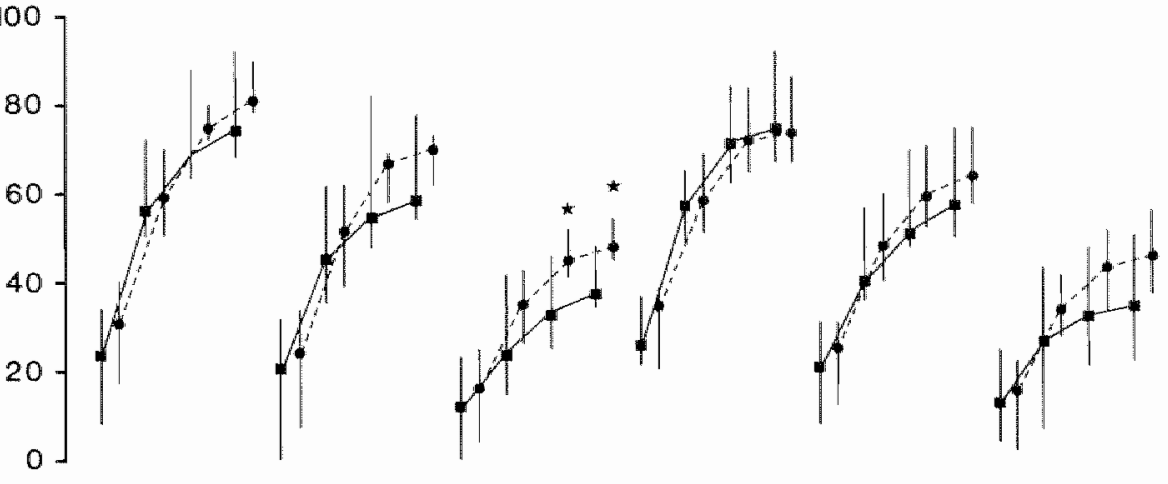

0.66

$2.640 .66 \quad 2.640 .66$

2.640 .66

2.640 .66

$$
\text { Pla (kPa) }
$$

Figure $N .2$ Left ventricular function curves in isolated, ejecting hearts of shamoperated $(\square ; n=6)$ and aorta-banded $(0 ; n=6)$ animais at the start (left panel, $t=20$ minutes) and the end (right panel, $t=110$ minutes) of 130 minutes aerobic perfusion. Data are presented as median values and $95 \%$ confidence limits. $P_{\text {ao }}$ " diastolic aortic pressure; $P_{l a}$ : left atrial pressure. $\star$ : sigmificant difference between both groups $\quad(p<0.05)$

less prominent in the group of hypertrophied hearts, especially at high preload levels. At the highest diastolic aortic pressure level significantIy higher aortic flows were observed in the hypertrophied hearts than in the control hearts at the two highest left atrial pressures. Table IV. 2 shows the percentage decrease in aortic flow, induced by increasing the diastolic aortic pressure. Since at the lowest aortic pressure level comparable flow values were attained in both groups, it was allowed to compare the percentage decreases in flow at higher aortic pressure levels relative to the values attained at this pressure level. In control hearts, at all 4 preload levels, an increase of aortic pressure from 8.0 to $13.3 \mathrm{kPa}$ induced a decrease in aortic flow of about $20 \%$. The same value was obtained in hypertrophied hearts at the lowest preload level. At higher preloads the decrease in aortic flow was about $15 \%$ smaller than in the control hearts, a non-significant difference. Increasing aortic pressure to $18.6 \mathrm{kPa}$ induced a much more pronounced decrea- 
se in aortic flow. In control bearts, depending on the left atrial filling pressure, this decrease ranged from 50 to $57 \%$. In hypertrophied hearts the decrease was significantly less, varying between 40 and $52 \%$, illustrating that the hypertrophied beart is less sensitive to changes in afterload than the non-hypertrophied control heart.

Table IV.I

Heart and body weight values 10 weeks after surgery in sham-operated and aorta-banded (Ao-band) rats. To calculate the ratio of heart weight and body weight $\left(H W / B W \cdot 10^{-2}\right)$ the heart weight at the beginning of the experiments was used.

\begin{tabular}{|c|c|c|c|c|}
\hline \multirow[t]{2}{*}{ Group } & \multicolumn{2}{|c|}{ Heart weight $(g)$} & \multirow[t]{2}{*}{ Body weight $(g)$} & \multirow[t]{2}{*}{$\mathrm{HW} / \mathrm{BW} \cdot 10^{-2}$} \\
\hline & pre & post & & \\
\hline $\begin{array}{l}\text { Sham } \\
(n=6)\end{array}$ & $\begin{array}{c}1.55^{\star} \\
1.33-1.70\end{array}$ & $\begin{array}{c}1.84^{\star} \\
1.70-1.97\end{array}$ & $\begin{array}{c}381^{\star} \\
342-394\end{array}$ & $\begin{array}{c}0.41^{\star} \\
0.36-0.46\end{array}$ \\
\hline $\begin{array}{l}\text { Ao-band } \\
(n=6)\end{array}$ & $\begin{array}{c}1.71 \\
1.59-2.35\end{array}$ & $\begin{array}{c}1.98 \\
1.72-2.25\end{array}$ & $\begin{array}{c}342 \\
316-360\end{array}$ & $\begin{array}{c}0.51 \\
0.47-0.68\end{array}$ \\
\hline
\end{tabular}

Data are presented as median values and $95 \%$ confidence limits. PreJpost : heart weight at the beginning and at the end of the perfusion experiments, respectively. $\star$ : significantly different from the corresponding values in the aorta-banded group $(p<0.05)$.

Reconstruction of the function curves at the end of the aerobic perfusion period showed almost identical results, as compared to the curves obtained early during the ejecting period, with one exception. The significant differences between hypertrophied and control hearts, as observed at the highest diastolic aortic pressure level at the beginning of the ejecting period, had disappeared.

The left ventricular performance of isolated hearts of WKY rats was also stable during a period of more than 2 hours perfusion (Figure IV. 3). No significant decreases in cardiac output or $\mathrm{dP}_{1 \mathrm{v}} / \mathrm{dt}_{\max }$ were noted. The left ventricular function curves in these hearts will be shown and discussed in chapter $V$. 


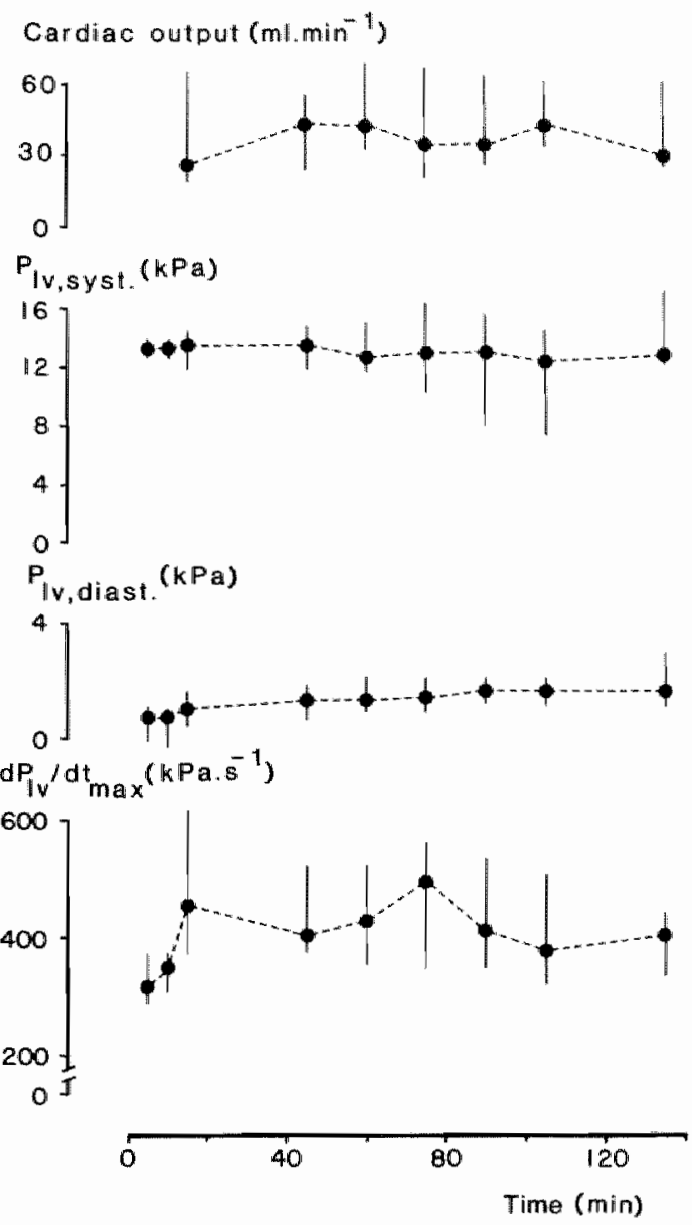

Figure $N .3$ Hemodynamic dota in isolated, ejecting hearts of Wistar-Kyoto $(n=5)$ rats during 140 minutes aerobic perfusion. Data are presented as median values and $95 \%$ confidence limits. Prwsys; Pavodiass: left ventricular systolic and end-diastalic pressure, respectively; $d P_{\text {swldt }}$ as : maximum first derivative of left ventricular pressure. 

sham-operated and aorta-banded rats, induced by the increase in diastolic aoricpressure $\left(P_{\text {ano }}\right)$ during the construction of pressure-wolume curves.

\begin{tabular}{|c|c|c|c|c|}
\hline & \multicolumn{2}{|c|}{ Sham $(n=6)$} & \multicolumn{2}{|c|}{ Aorta-banded $(n=6)$} \\
\hline $\begin{array}{l}\text { P.o increase } \\
P_{1 .} \text { (kPay }\end{array}$ & $8 \cdot 0->13.3$ & $8.0->18.6$ & $8.0->13.3$ & $8.0->18.6$ \\
\hline 0.66 & $\begin{array}{l}19 \\
0-100\end{array}$ & $\begin{array}{c}57 \\
32-100\end{array}$ & $\begin{array}{c}20 \\
15-59\end{array}$ & $\begin{array}{c}52 \\
37-76\end{array}$ \\
\hline 1.32 & $\begin{array}{c}19 \\
10-30\end{array}$ & $\begin{array}{c}56 \\
42-70\end{array}$ & $\begin{array}{c}14 \\
11-22\end{array}$ & $\begin{array}{c}41 \\
40-48\end{array}$ \\
\hline 1.98 & $\begin{array}{l}20 \\
7-29\end{array}$ & $\begin{array}{c}52^{\star} \\
49-71\end{array}$ & $\begin{array}{l}12 \\
10-21\end{array}$ & $\begin{array}{c}40 \\
32-44\end{array}$ \\
\hline 2,64 & $\begin{array}{c}19 \\
14-26\end{array}$ & $\begin{array}{c}50^{\star} \\
47-56\end{array}$ & $\begin{array}{c}16 \\
12-20\end{array}$ & $\begin{array}{c}41 \\
37-43\end{array}$ \\
\hline
\end{tabular}

Dala are presanted as median values and $95 \%$ confidence limits. $\star$ significanfly different from the corresponding values in the aora-banded group $(p<0.05)$.

\section{Biochemical data}

Adenine nucleotides, glycogen, lactate and inorganic phosphate in hearts of aorta-banded and sham-operated rats before and after 130 minutes aerobic perfission.

As shown in Table IV. 3, hearts of sham-operated and aorta-banded animals showed comparable native contents of adenine nucleotides. Energy charge values calculated were almost identical in both groups. The creatine phosphate content tended to be lower in the sham hearts, but the difference was nol significant. Higher hypoxanthine contents were found in the sham hearts. The level of the other biochemical variables were comparable in both groups. After 130 minutes aerobic perfusion, a slight but non-significant decrease in the total content of adenine nucleotides could be observed in both groups of hearts as compared to the contents in the native hearts. In contrast, the creatine phosphate levels were significantly increased in both groups of hearts. In the nonhypertrophied hearts, significantly higher energy charge values were 
Table $N .3$ Content of biochemical substances in heart tissue of sham-operated and aorta-banded rats, freeze-clamped immediately after isola-

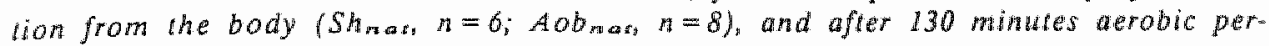
fusion (Shapo $n=6$; $A 0 b_{\text {apm }} n=6$ ).

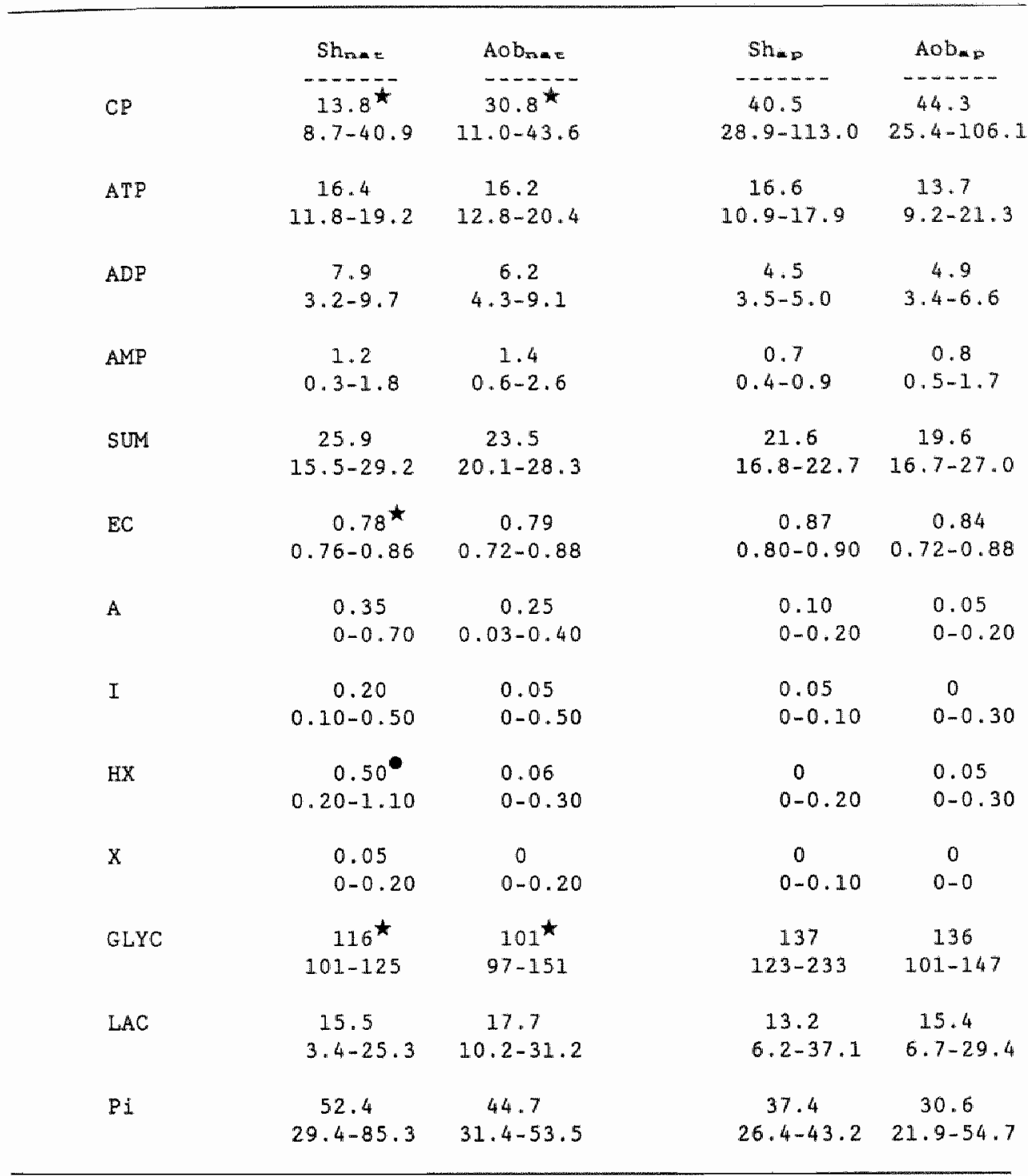

$C P$ : creatine phosphate; ATP, ADP and AMP: adenosine triphosphate, adenosine diphosphate, and adenosine monophosphate respectively; $S U M$ : sum of $A T P$, ADP and $A M P$; EC : energy charge ( $A T P+0.5 A D P) / S U M)$; $A$ : adenosine; " "inosine; HX : hypoxanthine; $X$ : xanthine; GLYC : glycogen; LAC : lactate; Pi : inarganic phosphate. All data are in $\mu$ mol.g $\mathrm{g}^{-x}$ dry weight. The data are presented as median walues and 95\% confidence limits. - significantly different from the values in the aorta-banded group $(p<0.05)$; : significantly different from the corresponding values in the aerobically perfused hearts $(p<0.05)$. 
found after 130 minutes aerobic perfusion as compared to the values in the native hearts. The same phenomenon was observed in bypertrophied hearts although the increase was not significant. Degradation products of adenine nucleotides were practically absent in the aerobically perfused myocardial tissue. Lactate and inorganic phosphate levels were low. As compared with the native hearts, the glycogen content was slightly increased.

Adenine nucleotides, glycogen, lactate and inorganic phosphate in hearts of 16 months old WKY and spontaneously hypertensive rats (SHR).

As shown in Table IV. 4, native hearts of SHR showed significantly lower concentrations of ATP than those of age-matched WKY rats. The values obtained in the native hearts of SHR were not different from the values obtained in native heart tissue of aorta-banded or shamoperated rats (Table IV. 3). It has to be mentioned, however, that the fluorimetrical determination of ATP contents in heart tissue resulted in slightly higher levels than when the determination of these substances was performed with HPLC. The latter method was used for the assessment of myocardial ATP levels in the hearts of aorta-banded and shamoperated rats. Although the creatine phosphate levels in WKY rat hearts

Table IV: 4

Tissue contents of energy-rich phosphates, glycogen and lactate in native heart tissue of 16 months old spontameously hypertensive rats $(n=6)$ and Wistar-Kyoto rats $(n=4)$.

\begin{tabular}{|c|c|c|c|c|}
\hline & & $\mathrm{SHR}$ & & WKY \\
\hline & $-\cdots$ & - - - - - - - & $\cdots \cdots$ & $-\ldots-\cdots--\infty$ \\
\hline $\mathrm{CP}$ & 13.5 & $(8-20)$ & 25.5 & $(11-39)$ \\
\hline ATP & 16.0 & $(12-20)$ & $24 \cdot 0^{\star}$ & $(15-32)$ \\
\hline GLYC & 142.0 & $(131-189)$ & $93.5^{\star}$ & $(90-138)$ \\
\hline LAAC & 15.0 & $(13-28)$ & $27.0^{\star}$ & $(25-31)$ \\
\hline
\end{tabular}

CP : creatine phosphate; ATP : adenosine triphosphate; GLYC: glycogen; LAC : lactate. All data are in $\mu$ mol.g-t dry weight. The valwes are presented as medians and $95 \%$ confidence limits. ATP was determined fluorimetrically (vas der Vusse et al., 1984). $\star$ : significantly different from the SHR group $(p<0.05)$. 
were almost twice as high as in the hypertrophied hearts of SHR, this difference did not reach the level of significance. Glycogen levels were significantly higher in the SHR hearts, while the lactate levels were significantly lower than in the hearts of WKY.

\section{1.4. Discussion}

It can be concluded that under the experimental circumstances the isolated, ejecting rat heart is a very stable and reliable preparation, on the condition that special care is taken on the oxygenation, thermostability, proper design of the aortic outflow tract and the inclusion of pyruvate into the perfusate (Snoeckx et al., 1986; van Bilsen et al., 1987). Under these conditions, the isolated, ejecting hypertrophied heart preparation is able to perform stable hemodynamic and biochemical work over longer periods of time i.e. more than 2 hours. These results do not differ from those, obtained in the isolated, ejecting, non-hypertrophied rat heart (Opie, 1984). Loss of myocardial function over a 130 minutes period of aerobic perfusion was limited to less than $10 \%$ when cardiac output, and less than $15 \%$ when the loss of energy-rich phosphates is considered. The latter value was calculated from the loss of degradation products of adenine nucleotides, which will be fully described in chapter VI. Calculations of the energy charge during and at the end of 2 hours of aerobic perfusion reveals an increased turnover of energy-rich phosphates and significantly increased creatine phosphate levels as compared to the values obtained in native tissue. These observations and others, like the low and stable release of lactate indicate that the oxygenation of the isolated hypertrophied heart model is at least sufficient as that of the non-hypertrophied control heart to obtain a stable hemodynamic and biochemical function. Finally, comparison of the loss of lactate dehydrogenase activity between control and hypertrophied hearts during 130 minutes aerobic perfusion reveals a comparable loss (see chapter VI), which can be regarded as negligible $(<2 \%$ of total tissue enzyme activity). Moreover, the released amounts of this enzyme are identical with those found in aerobically perfused, non-hypertrophied rat hearts (De Leiris and Opie, 1978). 


\section{2.1. Introduction}

The loss of high molecular weight substances, such as enzymes, from the intracellular space into the vascular compartment is considered to be a sensitive indicator of irreversible membrane injury associated with cell death. The quantitative measurement of enzyme activities in human serum have become a valuable tool in the study of myocardial diseases. The determination of intracellular enzyme activity in the coronary effluent of the isolated rat heart for the evaluation of myocardial damage was used already a decade ago (Waldenström et al., 1977). However, to determine quantitatively the extent of the myocardial damage, the total activity of intracellular enzymes in the myocardium has to be known (Willems, 1985).

Application of this method to the hypertrophied heart introduces special problems, since it is known that significant variations in geneexpression, underlying the different intracellular enzyme activities, can occur as a consequence of pressure overloading. Major transitions to enzyme isoforms, typical for the fetal and very young rat, occur in the mature rat as a consequence of persistent blood pressure increase. These transitions have been described among others for creatine kinase (Meerson and Javick, 1982; Younes et al., 1984), lactate dehydrogenase (Fox and Reed, 1969; Sobel et al., 1970) and myosin ATPase (Mercadier et al., 1981). However, in the myocardium of the spontaneously hypertensive rat, the described shift in myosin ATPase seems not to occur in the first year of life (Sharma et al., 1986). Alterations in activity of enzymes, involved in the synthesis of membrane phospholipds, have been suggested to be the basis of alterations in the 'de novo' synthesis of phospholipids in hearts, hypertrophied as a consequence of aorta-banding (Reibel et al, 1986). Secondly, considerable changes in the total enzyme activity can occur. In human hypertrophied hearts, analyzed postmortem, significantly reduced activities of lactate dehydrogenase were found (Stabilini et al., 1970). In addition, in SHR hearts, for instance, type I CAMP-dependent protein kinase was found to be reduced 3 -fold as compared to the levels in age-matched WKY rat hearts (Prashad, 1985).

In addition to possible differences introduced by changes in gene expression, we have also to consider difficulties in determining the right enzyme content of isolated rat hearts. As shown in chapter II, the activity of the intracellular enzymes lactate dehydrogenase and aspartate aminotransferase in the coronary effluent is positively affected by the presence of bovine albumin in the perfusate. This effect probably also plays a role in the determination of enzyme activities in tissue homogenates.

Therefore, considering the above mentioned problems, the present 
study was conducted to compare the activity of lactate dehydrogenase (LDH) and aspartate aminotransferase (AST) in hearts of 16 months old spontaneously hypertensive rats (SHR) and age-matched Wistar-Kyoto (WKY) rats. The enzyme activity was compared with that in younger animals, that is, rats of 8 months of age.

The effects of the addition of serum bovine albumin to tissue homogenates was investigated in hearts of relative young control rats, i.e. Lewis rats of 10 weeks of age.

On many occasions it is necessary to reduce the amount of tissue material for enzyme analysis so that other biochemical variables can be investigated in the remaining tissue material of the same heart. Although a uniform distribution of $\mathrm{LDH}$ across the left ventricular wall has been described (De Tata et al., 1986), it is not known whether comparable enzyme activities can be found at different sites of the left ventricular wall. Besides, the storage temperature of tissue specimen may affect the total enzyme activity. The activities of LDH and AST have been described to remain stable over longer periods of time, when dissolved in serum and stored at $-196^{\circ} \mathrm{C}$ (Jung et al., 1984). However, it is not known whether these enzymes a temperature of are also stable during storage at $-80^{\circ} \mathrm{C}$. Therefore, experiments were performed to compare the enzyme activity in myocardial tissue derived from different sites of the left ventricular wall, immediately, 24 hours and one week after isolation of the hearts from the body.

\section{2.2. Methods}

Experiments on hearts of SHR and WKY rats

The investigations were performed on isolated hearts of 8 months old male SHR $(n=8)$ and WKY $(n=6)$ rats and on hearts of 16 months old male SHR $(n=3)$ and WKY $(n=5)$ rats. The methods for isolation and homogenization of myocardial tissue is described in chapter II. Measurements were performed in triplo. It should be emphasized that the tissue enzyme activity was not affected by the presence of blood remnants in the coronary vessels (data not shown).

\section{Measurements in Lewis rat hearts}

Hearts $(n=6)$ were isolated from the body as described before. The left ventricle was separated from the atria and the right ventricle. Two pieces of myocardial tissue (about $50 \mathrm{mg}$ wet weight each) were isolated from the left ventricular wall. The pieces were transferred to $100 \mathrm{ml}$ Tyrode's solution with or without serum bovine albumin. Both pieces were homogenized as described in chapter II (section II 3.3). LDH and AST activities were determined immediately after the sonication procedu- 
re, and again two and four hours later. The reinvestigation of the tissue homogenates after two and four hours was performed to determine the flexibility of the procedure of analysis, since experimental circumstances do not always allow the immediate determination of the enzyme activity. Between the moment of homogenization and analysis of enzyme activities, the tissue homogenates were stored on ice.

In 3 other hearts, isolated from the body of 10 weeks old male Lewis rats, four pieces of the left ventricular wall were isolated from different regions (the septum, the anterior and posterior wall, and the apex). In each of these tissue pieces, enzyme activities were determined immediately after homogenization in the presence of bovine serum albumin. The rest of the left ventricle was freeze-clamped in liquid nitrogen and stored at $-80^{\circ} \mathrm{C}$. After 24 hours three tissue pieces were broken from the left ventricle, thawed in albumin-containing Tyrode's solution, and assayed for enzyme activity. The same procedure was repeated after one week in three other tissue pieces from the remaining left ventricle.

\section{2.3. Results}

\section{Myocardial enzyme activity in SHR and WKY rats}

The data obtained in the various groups of SHR and WKY rats are presented in Table IV. 5. Striking differences in both LDH and AST activities were present between the hearts of SHR and WKY at the age of 8 months. The hearts of SHR contained significantly less LDH and AST per gram heart weight than the hearts from the WKY rats. These differences, however, inverted at the age of 16 months. At that age, SHR hearts contained significantly more LDH than the hearts of the WKY rats. AST activity was also higher in the SHR than in the control hearts, but this difference did not reach the level of significance. As compared to the values in the older SHR groups, the LDH and AST activities of hearts of 8 months old SHR were significantly lower. In WKY rat hearts, however, the LDH activity was significantly higher at this age as compared with the values found in 16 months old rats. The AST activity was only slightly and not significantly higher in this group as compared to the older WKY group.

As compared to the values in the older SHR groups, the LDH and AST activities of hearts of 8 months old SHR were significantly lower. In WKY rat hearts, however, the LDH activity was significantly higher at this age as compared with the values found in 16 months old rats. The AST activity was only slightly and not significantly higher in this group as compared to the older WKY" group. 


\begin{tabular}{|c|c|c|c|c|}
\hline & \multicolumn{2}{|c|}{ SHR } & \multicolumn{2}{|c|}{ WKY } \\
\hline & $\begin{array}{l}8 \text { months } \\
(n=8)\end{array}$ & $\begin{array}{l}16 \text { months } \\
(n=3)\end{array}$ & $\begin{array}{l}8 \text { months } \\
(n=6)\end{array}$ & $\begin{array}{l}16 \text { months } \\
(\mathrm{n}=5)\end{array}$ \\
\hline $\mathbb{L D H}$ & $\begin{array}{r}286 * 0 \\
171-466\end{array}$ & $\begin{array}{c}424^{4} \\
409-458\end{array}$ & $\begin{array}{c}450 \\
366-466\end{array}$ & $\begin{array}{c}355 \\
320-388\end{array}$ \\
\hline $\mathrm{AST}$ & $\begin{array}{c}98^{\star \bullet} \\
84-111\end{array}$ & $\begin{array}{c}133 \\
118-166\end{array}$ & $\begin{array}{c}143 \\
113-165\end{array}$ & $\begin{array}{c}122 \\
107-156\end{array}$ \\
\hline
\end{tabular}

Enzyme activities were determined within 30 minutes after isolation of the heart from the body. Homagenization was performed in complete ventrictes in Tyrode's solution containing $30 \mathrm{mg} . \mathrm{ml}^{-1}$ bovine serum albumin as described in section II 3.3. Data are presented as median values and $95 \%$ confidence himits. $\star$ significantly dif. ferent from the values in the corresponding WKY group $(p<0.05)$; - significantly different from the values in the corresponding older group of the same rat sirain $(p<0.05)$.

Measurements in Lewis rat hearts

The effects of serum bovine albumin inclusion in the homogenate fluid of myocardial tissue of 10 weeks old Lewis rats is presented in Figure IV. 4. As in the coronary effluent, the addition of serum bovine albumin induced a pronounced and significant increase in the activity of the enzyme LDH in the myocardial tissue up to $37 \%$, as determined in the samples analyzed within 30 minutes after isolation. During the 4 hours that the homogenates were stored upon ice, there was no decline in enzyme activity.

In contrast to the effects in coronary effluent, a reversed effect on AST activity was observed in myocardial tissue homogenates, when bovine serum albumin was present. In all tissue samples homogenized in albumin-containing Tyrode's solution, a lower enzyme activity was found than in albumin-free homogenates, varying between 20 and $25 \%$. Tissue samples without albumin showed a slight increase of enzyme activity $(16 \%)$ after 4 hours of isolation from the body.

In Figure IV. 5 the data are presented as obtained in the hearts of 10 weeks old Lewis rats, in which enzyme activities were determined at different sites of the left ventricular wall homogenized and assayed imme- 
diately after isolation of the hearts from the body. There were no systematic differences in enzyme activities at the four different sites of the lefit ventricular wall. In all three hearts, the differences between the enzyme activities of LDH and AST in the individual pieces were extremely small. The largest variation in enzyme activity found in one heart was 9\%. All the individual LDH activities were localized within the $95 \%$ confidence limits of the enzyme activities found in the experiments in which the effect of serum bovine albumin was investigated (see Figure IV. 4). In the case of AST, in one heart 3 out of the 4 tissue pieces showed enzyme activities below the lowest limit of the AST activities found in the serum bovine albumin group. However, the deviation was extremely small.

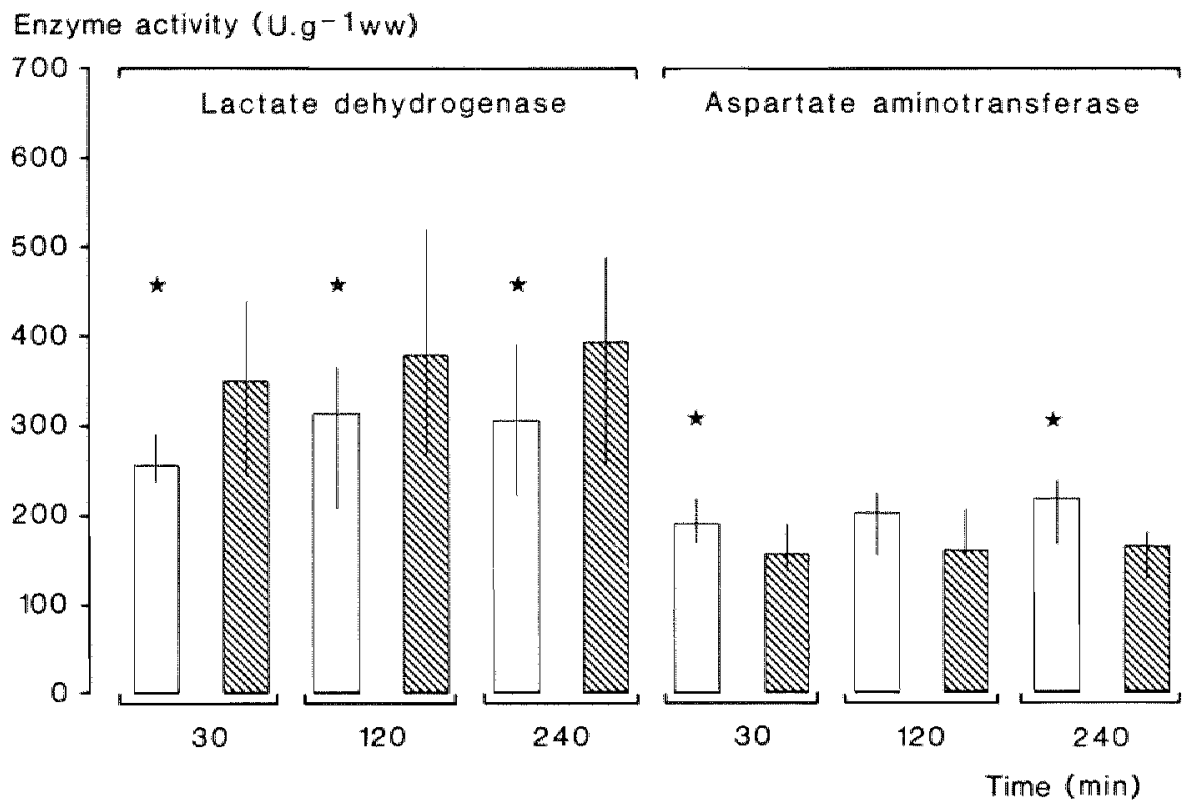

Figure $W .4$ The effects of the addition of $30 \mathrm{g.t}$ serum bovine albumin on the enzymatic activity of lactate dehydrogenase and aspartate aminotransferase in left ventricular tissue homogenates of 10 weeks old Lewis rats $(n=6)$. Enzyme acrivity was determined in rissue pieces without albumin (open bars) and with albumin (hatched bars) within 30 minules after the isolation of the hearts from the animal, and again 120 and 240 minutes after homogenization. In between, the homogenate was kept on ice. The values are presented as medians and $95 \%$ confidence limits. *: significantly different from the enzyme activity determined in the presence of albumin $(p<0.05)$.

Storage of the myocardial tissue at $-80^{\circ} \mathrm{C}$ revealed slightly, but not significantly decreased LDH activities after 24 hours and 1 week of storage. The activities of AST were not changed. 
In conclusion, bovine serum albumin has a positive effect on the activity of lactate dehydrogenase in myocardial tissue homogenates, as on the enzyme activity in the coronary effluent. In contrast, aspartate aminotransferase activity in myocardial tissue homogenates is partially inhibited by the presence of bovine serum albumin. This effect was not observed in coronary effluent samples. An explanation for this phenomenon is not at hand. For instance, it is not known whether aspartate aminotransferase can be activated by other intracellular substances and whether serum albumin can inhibit these activators. If this is the case, relating the loss of aspartate aminotransferase to the intracellular activity of the enzyme is rather complicated, since the enzyme is stabilized by bovine serum albumin in coronary effluent and inhibited in the myocardial tissue. Nevertheless, percentage loss of enzyme activity, as presented in the following studies, will always be related to the tissue enzyme activity determined in the presence of serum bovine albu$\min _{x}$ as is the case for the loss of activity of lactate dehydrogenase.

Enzyme activity $\left(U \cdot g^{-1} w w\right)$

Lactate dehydrogenase
Aspartate aminotransferase

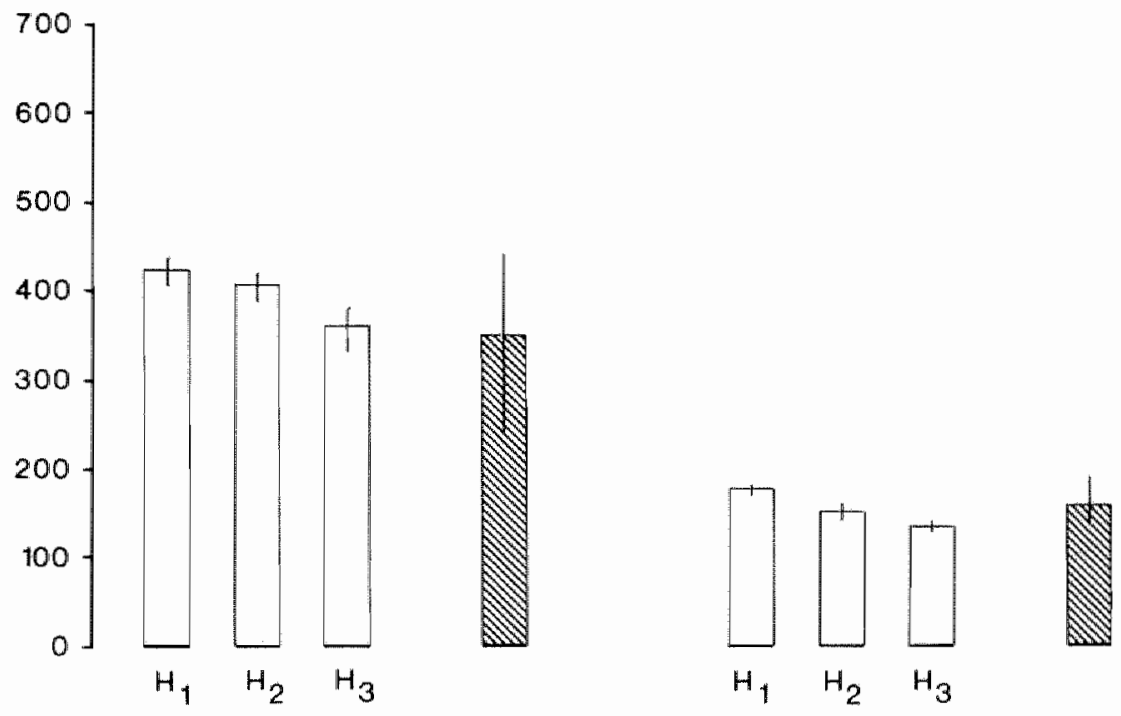

Figure $N .5$ Enzymatic activity of lactate dehydrogenase and aspartate aminorransferase in four different tissue pieces of 3 hearts $\left(H_{2}, H_{2}\right.$ and $\left.H_{3}\right)$. The harched bars are the values found in the 6 tissue pieces shown in Figure IV. 4 which were determined within 30 minutes after isolation. Data are presented as median values and $95 \%$ confidence limits. 
The present findings also indicate that the enzyme activity of both enzymes investigated is homogenously distributed over the left ventricular myocardium. Therefore, the use of enzyme activity determinations in small tissue biopsy samples of the left ventricular wall is permitted. The analysis of enzyme activity in tissue homogenates can be safely performed up to 4 hours after homogenization on the condition that the homogenates are stored in ice $\left(0^{\circ} \mathrm{C}\right)$. Besides, storage of the freezeclamped myocardial tissue at a temperature of $-80^{\circ} \mathrm{C}$ can be safely performed up to 1 week without significant loss of enzyme activity.

\section{4. MORPHOLOGY}

The occurrence of left ventricular hypertrophy in the mature rat, as in other mammals, is a physiological response to an abnormal hemodynamic function imposed by a sustained pressure overload. In the spontaneously hypertensive rat, hereditary factors have to be taken into account also (Cutilletta et al., 1978;, Tomanek et al., 1979). The increase in left ventricular mass is a consequence of bypertrophy of the striated muscle fibers (Anversa et al., 1971), in particular in the midwall layers of the left ventricle (Kuribayashi et al,, 1986). At the subcellular level stable, compensated hypertrophy is established by a significant increase of the relative volume of myofibrils (Tomanek et al. 1979). During the later, decompensated phase of ventricular hypertrophy the volume fraction of myofibrils is decreased (Schwarz et al., 1981). Furthermore, left ventricular enlargment may be associated with hyperplasia (abdominal aorta-banding) or hypertrophy and hyperploidy (spontaneously hypertensive rat) of vascular smooth muscle cells (Owens et al., 1985a; Owens, 1985b). Another phenomenon occurring during the development of left ventricular hypertrophy in the rat is the increase in connective lissue (Thiedemann et al., 1983). The increase in the amount of connective tissue keeps pace with the total increase in heart mass so that proportionaly the connective material remains unchanged (Moore et al, 1980; Turner et al, 1986). A comparable phenomenon is observed in the severely hypertrophied human heart (Schwarz et al., 1981). A greater and more variable intercapillary spacing has been established in the hypertrophied heart of the aged spontaneously hypertensive rat (Rakusan et al., 1984), and the unilateral nefrectomized rat (Henquell et al., 1977). A comparable phenomenon is observed in other mammals, like the pig (Breisch et al., 1986) and the dog (Tomanek et al., 1986).

The following pictures illustrate the morphological appearance of cardiac tissue of 16 months old spontaneously hypertensive rats and agematched Wistar-Kyoto rats, which were used for functional and biochemical investigations before and after global ischemia. After anesthesia of the animals, the hearts were removed from the thorax, immediately 
immersed in ice-chilled Tyrode's solution and prepared for aerobic perfusion, as described in chapter II (section II.1). After connection to the aortic cannula, retrograde perfusion was started with Tyrode's solution $\left(37^{\circ} \mathrm{C} ; \mathrm{PO}_{2}>80 \mathrm{kPa}\right)$ under a perfusion pressure of $10 \mathrm{kPa}$. After $10 \mathrm{minu}-$ tes perfusion was changed to a sodium phosphate buffer solution containing $2.5 \%$ glutaraldehyde and $4 \%$ sucrose for 5 minutes $\left(25^{\circ} \mathrm{C}\right)$. Afterwards the bearts were disconnected from the perfusion apparatus and post-fixated in glutaraldehyde containing solution during 2 hours. Small tissue samples taken from various sites of the left ventricular epicardium and endocardium, were fixated further in $1 \% \mathrm{OsO}_{4}$ solution during 1 hour. Debydration was performed in ethanol with increasing concentrations from 50 to $100 \% 24$ hours later. The dehydrated tissue specimen were embedded in blocks containing epon which was allowed to polymerize during 24 hours. Then the blocks were routinely cut for light and electron microscopy. Light microscopic specimen were contrasted with toluidine blue, while electron microscopic preparations were contrasted with uranylacetate and leadcitrate.

The photomicrographs IV.1-4 illustrate the light microscopic findings in the hypertrophied hearts of 16 months old spontaneously hypertensive rats. In epicardial as well as in endocardial tissue samples fibrosis is abundantly present in the interstitial and especially the perivascular space. The interstitial space is enlarged and degenerating myocytes are commonly seen. In cardiac tissue of the age-matched Wistar-Kyoto rat (illustrations IV.5 and IV.6), tissue appearance is normal. Strands of connective tissue are only occassionally present.

The electron microscopic illustration IV.7 presents a more detailed view of the hypertrophied cardiac tissue of the spontaneously hypertensive rat. Myofibrillar arrangement is chaotic, while connective tissue is abundantly present. Glycogen seems to be absent. However, when biochemically determined in whole tissue, glycogen levels are not lower in than in the control hearts (section IV.1.3.2). Different explanations for this discrepancy can be given. Firstly, sample bias can account for the observed differences. Secondly, it could be possible that in the hypertrophied heart glycogen is present in a more dispersed form, so that it cannot be visualized as clear as in the control heart.

The normal appearence of the cardiac tissue of the normotensive WKY rat is shown in the illustration IV.8. Note the abundant presence of glycogen and the normal arrangement of myofibrillar material. 

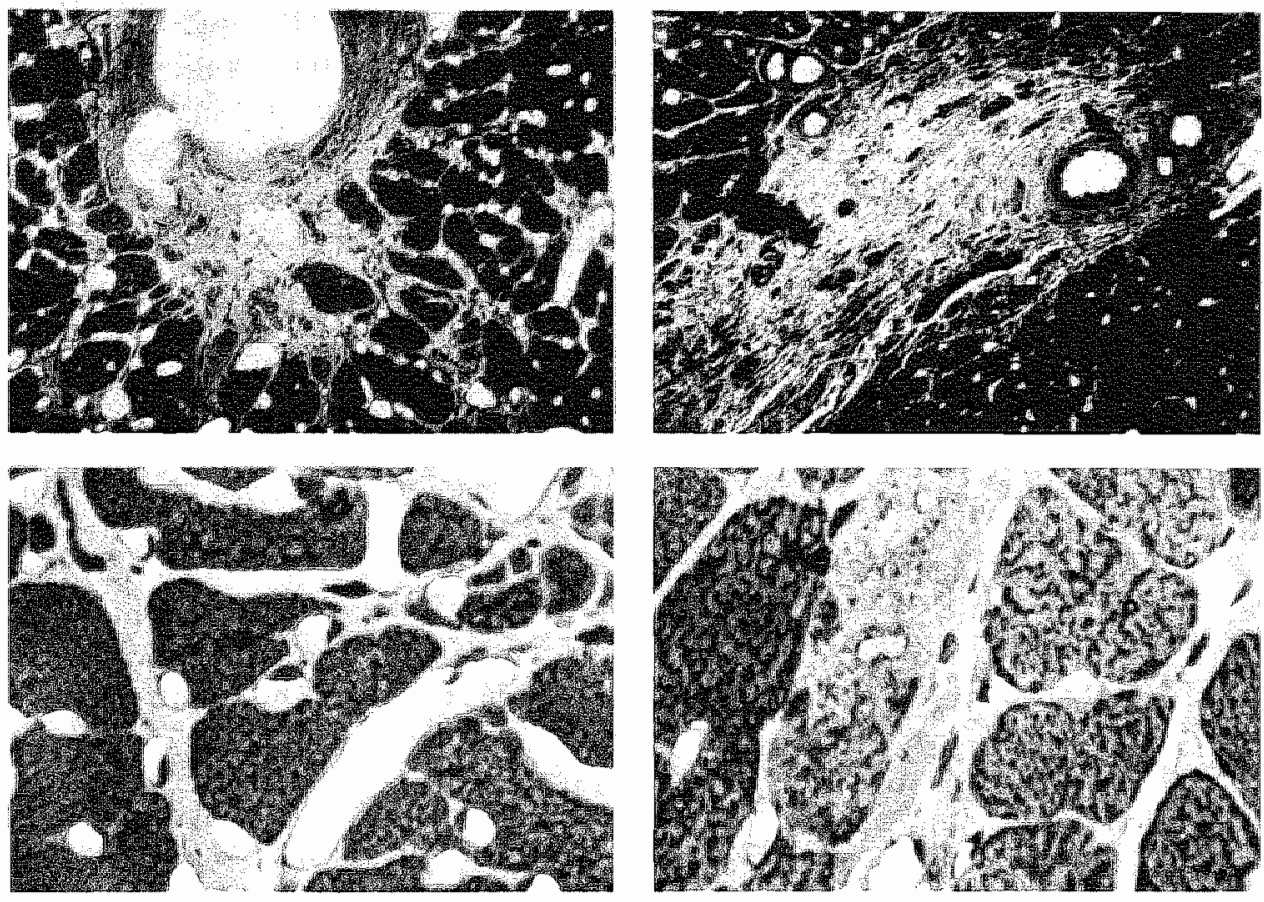

Illustrations IV. 1-4

Upper left and right: prominent fibrosis around coronary arteries in the epicardium and endocardium, respectively, of a 16 months old spontaneously hypertensive rat. Note the connective tissue between the myocytes (Magn. 10x). Lawer left and right: details of hypertrophied striated muscle cells in the epicardium and endocardium, respectively, of a 16 months old spon laneowsly hypertensive rat. A degenerating myocyle is present between normal cells. Magn. $100 x$
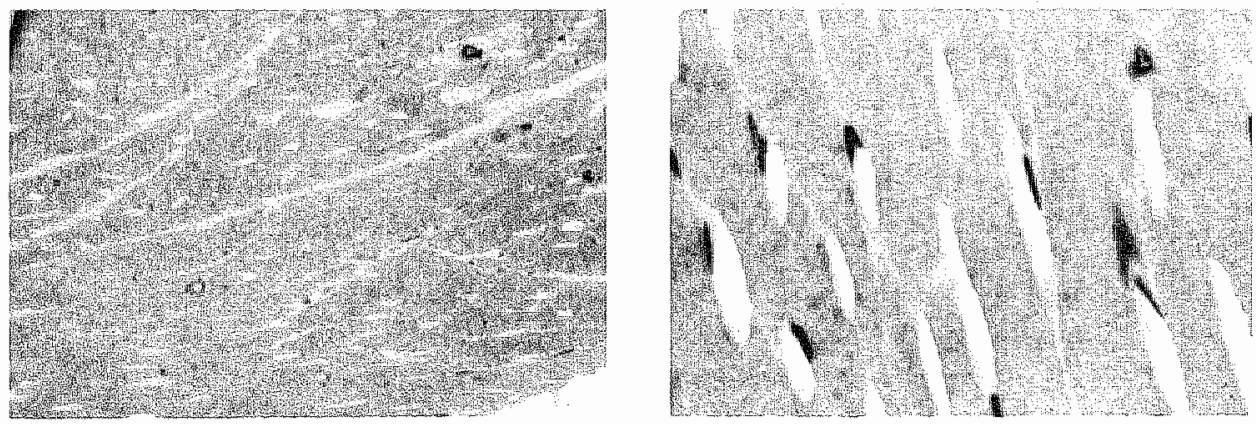

Illustrations $N, 5-6$

Non-hypertrophied myocardial tissue from the midwall zone of the left ventricle of a 16 months old Wistar-Kyolo rat. Connective tissue is almost absent. The cell appearance is nomal and the inter-cell distance is small as compared with hypertrophied myocardial tissue. Magn. left 10x; right $100 x$. 


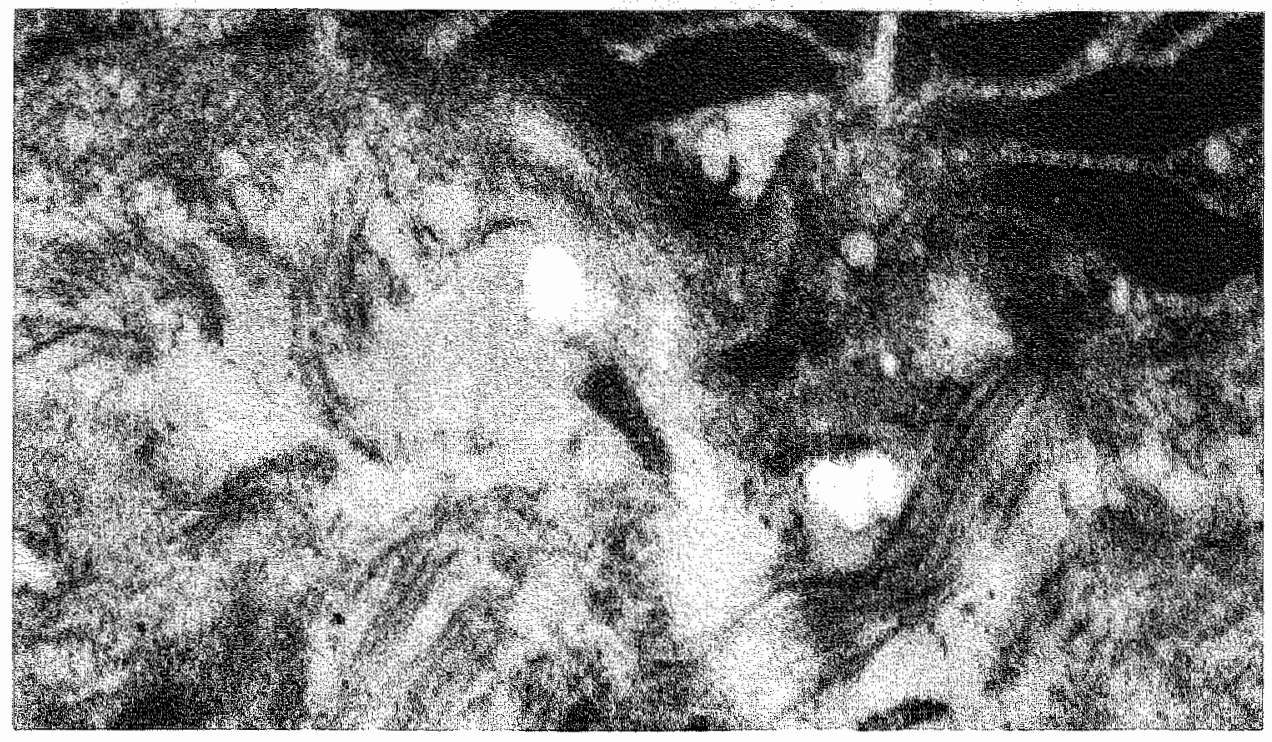

IMusination $I V .7$

Detall of the left ventricular epicardium of the heart of a spontaneously hypertensive rat ( 16 months of age). Structure of myofibrils and mitochondria is irregular. Interstitial fibrosis is commonly sen. Magn. $24090 x$

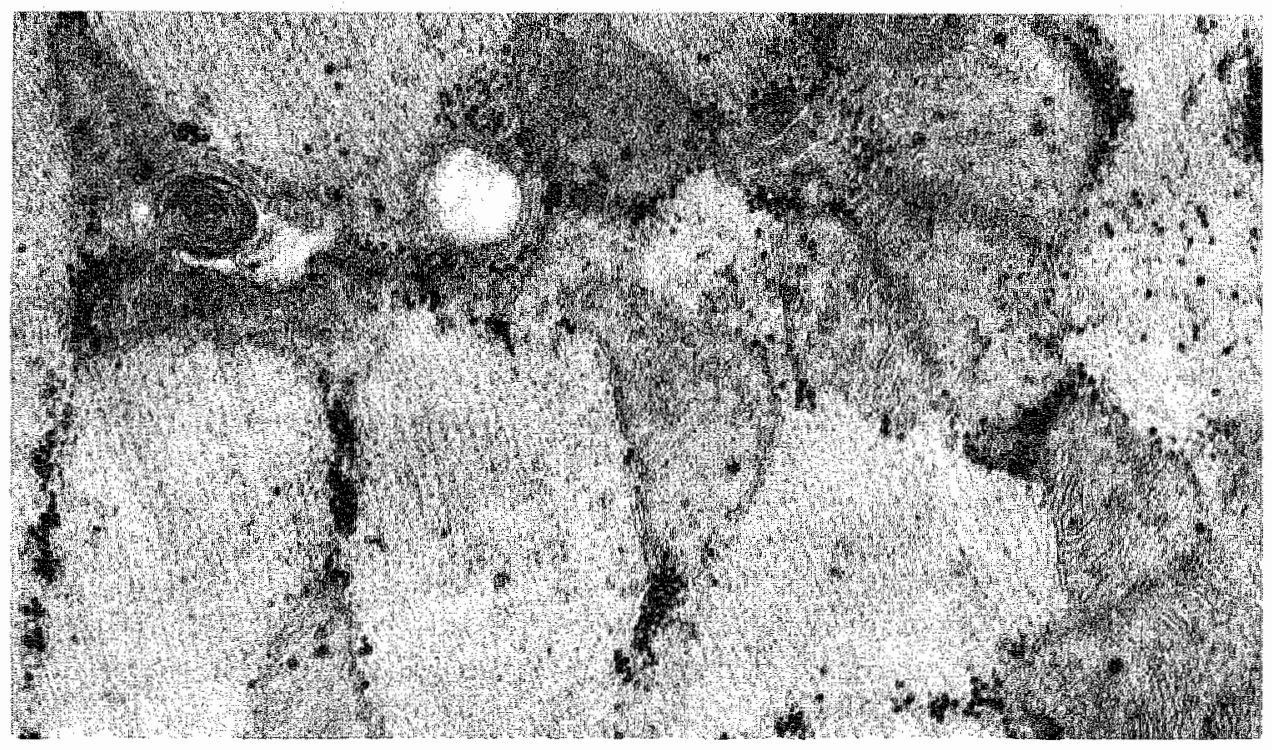

Ihustration N.8

Delail of the left ventricular epicardium of the heart of a WistarKyoto rat (16 months of age). Structure of myofibrils and mitochondria is nomal and regular. Note the presence of glycogen. Magn. $24090 x$. 



\title{
RECOVERY OF HYPERTROPHIED HEARTS OF 16 MONTHS OLD
}

\section{SPONTANEOUSLY HYPERTENSIVE RATS DURING REPERFUSION}

\author{
AFTER A PERIOD OF GLOBAL ISCHEMIA
}

\section{1. INTRODUCTION}

Protection of the hypertrophic heart during cardiac surgery is a continuing problem for cardiac surgeons, because these hearts are known to have a diminished tolerance to myocardial ischemia. In humans several investigators showed that there is a clear relation between the severity of heart disease pre-operatively and the tolerance to myocardial ischemia during cardiac surgery. Cooley and co-workers (1972) reported patients with severe left ventricular hypertrophy who developed ischemic contracture (stone heart) during the surgical procedure. In patients, undergoing valve replacement during 45 minutes of cardiac arrest, Schaper and co-workers (1978) observed a more pronounced structural ischemic damage in patients with severe ventricular hypertrophy than in patients with only moderate hypertrophy. In severe hypertrophied hearts, Beyersdorf and co-workers (1980) found a close relation between poor post-operative recovery and degenerative signs in myocardial biopsy specimen.

Many attempts have been made to mimic the situation of cardiac hypertrophy under experimental conditions (Degenring et al., 1975; Attarian et al., 1981; Sink et al., 1981; Peyton et al., 1982b). In these studies, hearts, hypertrophied by swimming exercise, thyroxine treatment or constriction of the ascending or abdominal aorta have been used. Studies on hearts, hypertrophied as a consequence of pathological disorders, however, are rarely available, despite the fact that in the spontaneously hypertensive rat (SHR) hypertension is associated with pronounced and reproducible left ventricular hypertrophy (Okamoto, 1972; Froh- 
lich et al., 1981). Besides, hearts of relatively old spontaneously hypertensive rats do have an impaired myocardial function (Pfeffer and Pfeffer, 1983; Mirsky et al., 1983), and therefore mimic the human situation.

In the present study we investigated the effect of 30 minutes of global, normothermic ischemia on myocardial function of isolated, ejecting, hypertrophied hearts from relatively old spontaneously hypertensive rats (SHR). The recovery of these hearts was compared with the recovery of isolated hearts of age-matched normotensive rats during reperfusion following the period of global ischemia. Myocardial function was evaluated by studying the pressure-flow relationship of the left ventricle before and after the period of ischemia. Recovery was further determined by assessing the loss of intracellular enzymes and by comparing the tissue contents of energy-rich phosphates at the end of the reperfusion period with those of non-perfused native hearts.

\section{2. METHODS}

\section{2.1. Experimental design}

The experiments were performed on isolated hearts obtained from 16 months old SHR and age-matched Wistar-Kyoto (WKY) rats. Group 1 consisted of eight SHR and eight WKY rats, the hearts of which were isolated and perfused. Group 2 consisted of six SHR and four WKY rats, which were used for the measurement of the native heart tissue contents of energy-rich phosphates, glycogen and lactate (see also chapter IV). The native heart tissue activities of the intracellular enzymes lactate dehydrogenase (LDH) and aspartate aminotransferase (AST) were measured in Group 3, consisting of three hearts of SHR and five hearts of WKY rats (see also chapter IV).

\section{Group 1}

The rats were weighed and trained for the measurement of tail systolic arterial blood pressure using an inflatable cuff combined with an audiotransducer. Table V. 1 gives the data on systolic arterial blood pressure, heart weight, body weight, and the ratio of heart weight and body weight in this group. All the variables were significantly higher in the SHR than in the WKY rats.

For the experiments the animals were anesthetized with ether. The hearts were removed from the body and immersed in ice-chilled Tyrode's solution. Remnant lung tissue and fat were removed. The hearts were weighed and attached to the perfusion apparatus, as described in chapter II. Retrograde perfusion was started at a pressure of $10.7 \mathrm{kPa}$ immediately after proper fixation of the aorta to the cannula using a well-oxygenated, modified Tyrodes solution $\left(\mathrm{PO}_{2}>80 \mathrm{kPa}\right)$. This solution contained (in mmol.1-1): $\mathrm{NaCl}(130), \mathrm{KCl}$ (5.6), $\mathrm{CaCl}_{2}$ (2.2), $\mathrm{MgCl}_{2}$ (0.56), 
$\mathrm{NaH}_{2} \mathrm{PO}_{4}$ (1.2), $\mathrm{NaHCO}_{3}(25), \mathrm{D}(+)$ glucose (11.1), and sucrose (13.2), The $\mathrm{pH}$ of this solution was maintained between 7.35 and 7.45 by adjusting the $\mathrm{NaHCO}_{3}$ concentration. A second cannula was connected to the left atrium for filling of the left atrium and left ventricle at any desired filling pressure. The hemodynamic variables were recorded continuously on a four channel recorder (HP 7404).

Table $V$ I

Systolic arterial blood pressure, heart weight, body weight, and the ratio of heart weight and body weight ( $H W / B W .10^{-2}$ ) in 16 months old SHR and WKY rats.

SHR

$(\mathrm{n}=8)$

WKX"

$(\mathrm{n}=8$ )

Systolic pressure ( $k P a)$

$$
\begin{aligned}
& 26.7^{\star}(25.8-27.9) \\
& 2.87^{\star}(2.57-3.37) \\
& 408^{\star}(366-433) \\
& 0.72^{\star}(0.59-0.85)
\end{aligned}
$$$$
15.9
$$$$
(14.6-17 \cdot 3)
$$

Heart weight (g)

$1.98(1.75-2.14)$

Body weight (g)

$360(350-368)$

$\mathrm{HW} / \mathrm{BW} \cdot 10^{-2}$

$0.56(0.49-0.60)$

Values are presented as medians and 95\% confidence limits * significanty different from the the WKY rats $(p<0.05)$.

The period of retrograde perfusion at a pressure of $10.7 \mathrm{kPa}$ was maintained for 10 minutes. Thereafter, the left atrial cannula was opened and the left ventricle was filled via the left atrium at a pressure of $1.0 \mathrm{kPa}$. Opening of the left atrial line resulted in the reversal of aortic flow, indicating that the heart was ejecting. The diastolic aortic pressure was kept at $10.7 \mathrm{kPa}$. The ejecting period was continued for 35 minutes. During this time interval the hemodynamic variables were recorded continuously. During the last 20 minutes of this ejecting period, pressure-flow curves were constructed under steady state conditions. Cardiac output was measured at four different left atrial filling pressures: $0.66,1.32,1.98$, and $2.64 \mathrm{kPa}$. This procedure was repeated at 3 different aortic pressures: $10.7,14.7$, and $18.6 \mathrm{kPa}$. At each step, a steady state myocardial function of at least 1 minute was required before the values of the various variables were recorded. The left atrial filling pressure and diastolic aortic pressure were then set at values similar to those before the pressure-flow curves were constructed. During the whole pre-ischemic period the coronary effluent was 
collected to measure release of lactate and intracellular enzymes such as LDH and AST.

After the control period, global ischemia was induced by total cessation of flow to the left atrium and coronary arteries for 30 minutes. Reperfusion was started by retrograde perfusion of the hearts for $10 \mathrm{mi}$ nutes under a pressure of $10.7 \mathrm{kPa}$. Thereafter, the left atrial cannula was reopened, allowing the hearts to eject. Reperfusion was continued for 50 minutes during which the coronary effluent was collected continuously to estimate the loss of activity of the intracellular enzymes and release of lactate. $\mathrm{LDH}$, AST and lactate were determined as described in chapter II. During the last 20 minutes of the reperfusion period, a second set of pressure-flow curves was constructed as during the preischemic period. At the end of the reperfusion period, the ventricles were separated from the atria and immediately freeze-clamped and stored for later analysis of the tissue content of ATP, creatine phosphate (CP), glycogen and lactate as described in chapter II.

\section{Group 2}

To assess the native heart tissue contents of ATP, CP, glycogen and lactate the rats of this group were anesthetized with ether. Subsequently, heparin was injected (1000 IU intravenously) and the thorax opened. Both ventricles were then separated from the atria and immediately freeze-clamped.

\section{Group 3}

To assess the native heart tissue activities of LDH and AST the same procedure was followed as in group 2, but after the thorax had been opened the complete hearts were excised and washed in ice-chilled Tyrode's solution, which contained bovine serum albumin in a concentration of $30 \mathrm{mg} \cdot \mathrm{ml}^{-1}$. The left ventricular tissue was homogenized and sonicated at $0^{\circ} \mathrm{C}$. Afterwards the homogenate was diluted 26 times so that enzyme activity was in a detectable range. The homogenate was kept on ice and immediately analyzed for LDH and AST activities. The activities of both enzymes were determined spectrophotometrically, using the earlier mentioned routine techniques as described by Bergmeyer and Bernt (1974a; 1974b; see also chapter II).

\section{3. STATISTICS}

Differences between the values of the various variables in the WKY and SHR bearts in groups 1,2 , and 3 and between these values in group 1 and in the groups 2 and 3 were evaluated for statistical significance using the Mann-Whitney U-test. In group 1 differences between the values of the variables in the pre-ischemic and post-ischemic pe- 
riods were evaluated for statistical significance by Wilcoxon's matchedpairs signed-ranks test. P-values smaller than or equal to 0.05 were considered to be statistically significant.

\section{4. RESULTS}

\section{4.1. Hemodynamic variables}

The hearts of both SHR and WKY rats in group 1 showed a comparable recovery in left ventricular pressure (Figure V. 1) during reperfusion after global, normothermic ischemia. Compared with pre-ischemic values, in both groups systolic pressure tended to decrease whereas diastolic pressure increased, especially during the initial 10 minutes of postischemic retrograde perfusion. In contrast, the recovery of $\mathrm{dP}_{\mathrm{lv}} / \mathrm{dt}_{\max }$ showed a pronounced discrepancy between both groups. During the period in which the hearts were allowed to eject, WKY rat hearts reached considerable higher values than the hearts of SHR. When the $d P_{1 v} / d t$ max values, as measured immediately before global ischemia, were taken as $100 \%$, a maximal post-ischemic recovery of $32 \%$ was reached in the SHR and of $91 \%$ in the WKY rat hearts. In the SHR group, 2 hearts completely failed to recover during the reperfusion period. In the WKY rats one heart showed a very poor mechanical recovery during the first 30 minutes of reperfusion but suddenly improved thereafter.

During pre-ischemic retrograde perfusion coronary flow in the hearts of SHR was $17 \mathrm{ml} . \mathrm{min}^{-1}$ and increased to $20 \mathrm{ml} \cdot \mathrm{min}^{-1}$ during the ejecting period. These values were consistently higher than those in the WKY rats, which ranged between $13 \mathrm{ml} . \mathrm{min}^{-1}$ (retrograde perfusion) and $16 \mathrm{ml} \cdot \mathrm{min}^{-1}$ (antegrade perfusion). Nevertheless, when coronary flow was corrected for heart weight almost identical values, i.e. $7.2 \mathrm{ml}$. $\min ^{-1} \cdot g^{-1}$, were obtained in both groups. (Figure V. 2: upper panel). During early reperfusion the WKY rat hearts showed prominent reactive hyperemia. Coronary flow returned to the pre-ischemic values within 10 minutes after perfusion had restarted. In contrast, this initial period of reactive hyperemia was absent in the SHR hearts. In these hearts coronary flow was very low at the start of reperfusion, and slowly increased to pre-ischemic values during the following 15 minutes. Coronary flow was maintained at that level thereafter.

During the pre-ischemic period cardiac output was similar in both groups (Figure V. 2: lower panel). Significantly higher values were noted in WKY hearts, however, when normalized for heart weight. These hearts ejected almost twice as much perfusate per gram heart weight as the SHR hearts. After the period of ischemia, a prominent recovery in cardiac output was seen in the WKY hearts. Compared with the values at the end of the pre-ischemic period, a maximum recovery of $66 \%$ was found. In contrast, cardiac output almost completely failed to recover in the SHR group. A maximum recovery of $13 \%$ (median value) was seen, 
which is significantly lower than that in the WKY hearts.

The pressure-flow curves before and after the period of global ischemia are shown in Figure V. 3. During the pre-ischemic period, at the lowest afterload $(10.7 \mathrm{kPa})$, thearts of WKY rats reached significantly higher cardiac output values than those of the SHR at all preload levels. At an afterload of $14.7 \mathrm{kPa}$, in the WKY rat hearts, the increases in cardiac output, as induced by increases in preload, were less pronounced than at the lowest afterload level. In contrast, in the SHR the

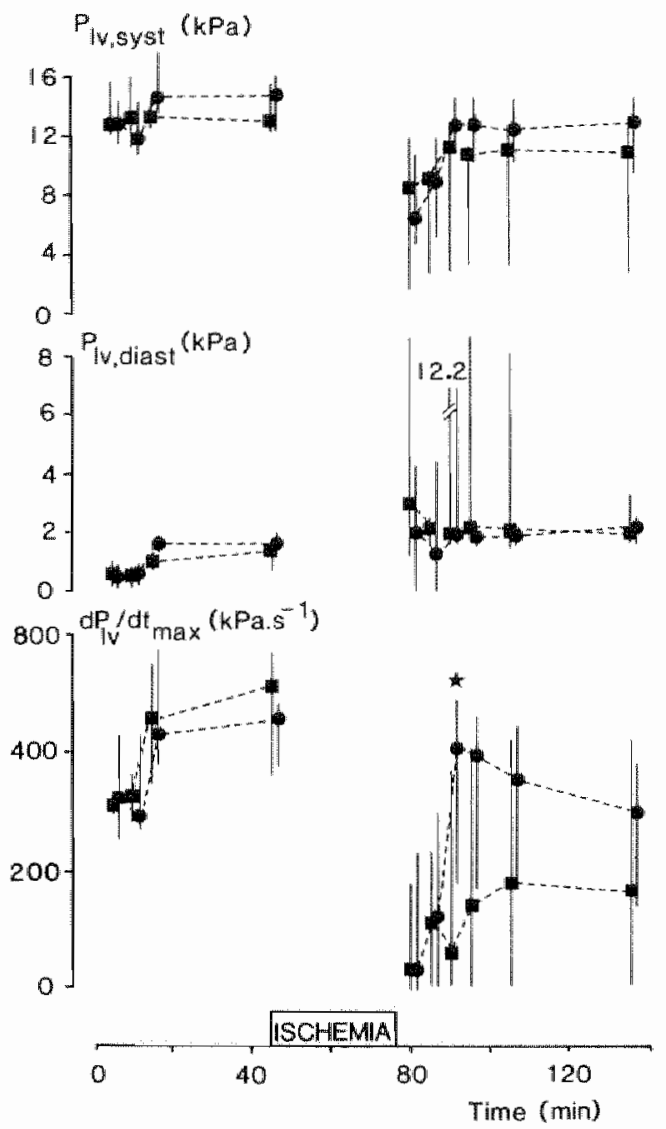

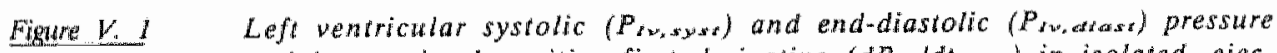
and is maximal positive first derivative (dPaldirax $)$ in isolated, ejecling hearts of 16 months old $\operatorname{SHR}\left(\mathbf{a}_{;} n=8\right)$ and WKY rats $(n=8)$ befare and after 30 minutes of global ischemia. Dara are presented as median values and $95 \%$ confidence limirs. The first two values during the pre-ischemic and reperfusion period were abtained during retrograde perfusion. significantly different from the SHR group $(p<0.05)$. 


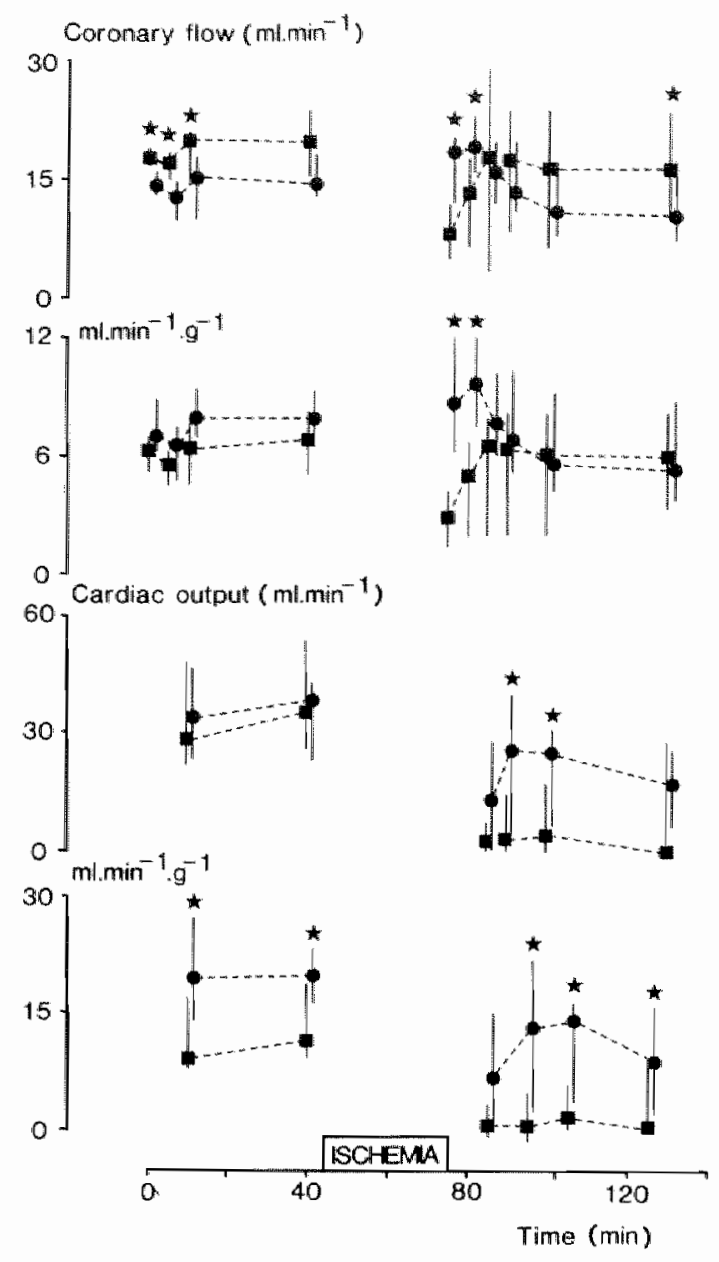

Figure V.2 Coronary flow and cardiac output in isolated, ejecting hearts of 10 months old SHR $\left(\mathbf{Q}_{;} n=8\right)$ and $W K Y$ rats $(\bullet ; n=8)$ before and after 30 minules of global ischemia. Data are presented as median values and $95 \%$ confidence limits. $\star$ : significantly different from the SHR group $(p<0.05)$.

increases in cardiac output as induced by increases in preload were similar at an afterload of 10.7 and of $14.7 \mathrm{kPa}$. At the highest afterload (18.6 kPa) cardiac output further decreased at all preload levels in the WKY rats and the pressure-flow curves became similar to the one in the SHR group.

During reperfusion after 30 minutes of global ischemia the myocardial function of SHR hearts was completely depressed at all afterload levels investigated. Recovery of cardiac output to some extent was 

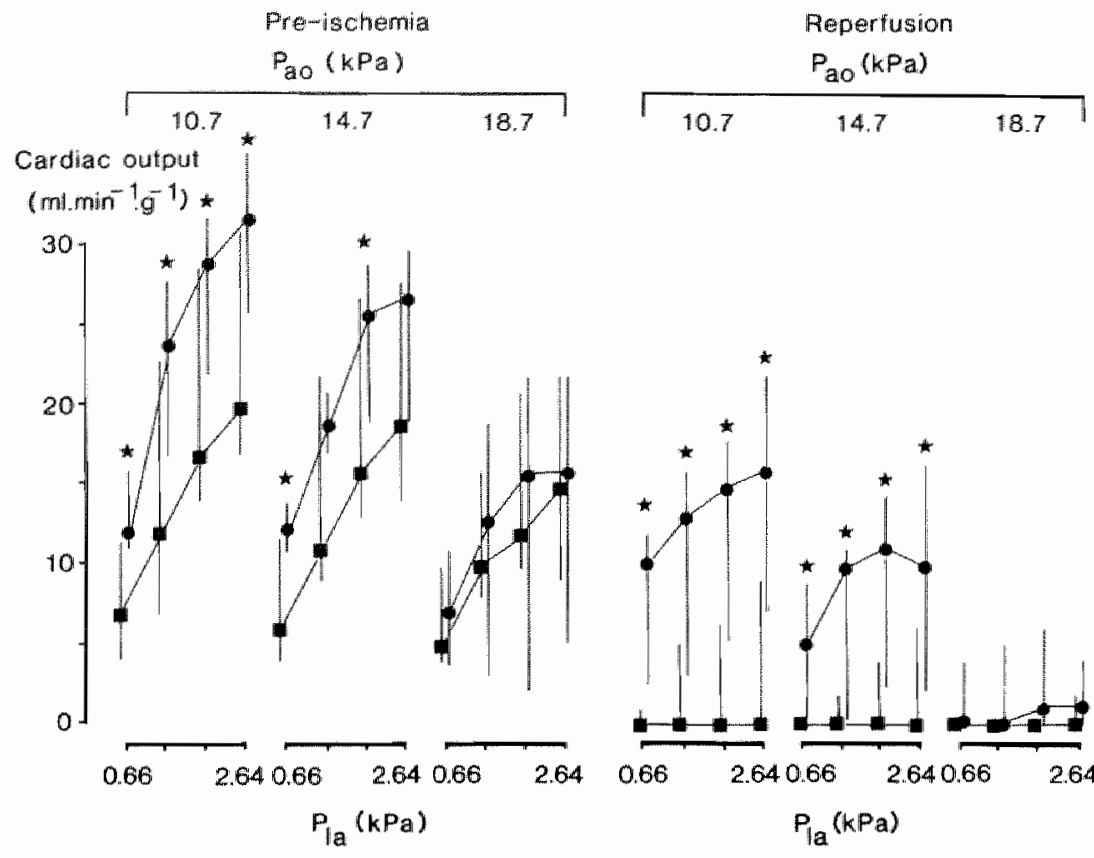

Figure V. 3 Effects of variations in afterload (diastolic aortic pressure, $P_{a 0}$ ) and preload (left atrial pressure, $P_{i a}$ ) on cardiac output in isolated, ejecling hearts of 16 months ald SHR $(0 ; n=8)$ and WKY rats $(0 ; n=8)$ before (pre-ischemia) and after (reperfusion) 30 minutes global ischemia. Data are presented as median walues and $05 \%$ confidence limits. : significantly different from the SHR group $(p<0.05)$.

noted in the reperfused WKY rat hearts. Pressure-flow relations showed a diminished capability of pump performance in response to increases in preload, especially at the two highest afterload levels tested. 
Findings in coronary effluent

The release of lactate during the pre-ischemic period was low in both groups (Figure V. 4). Immediately after reperfusion the quantities of released lactate increased to a similar extent in both groups. Normalization to pre-ischemic values occurred within 10 minutes of reperfusion.

The activities of intracellular enzymes released from the WKY rat and SHR hearts during the pre-ischemic period and after 30 minutes of global ischemia are shown in Figure V. 5. In the WKY rat hearts the release of $\mathrm{LDH}$ and AST was slightly increased, compared with the preischemic values, during the initial 15 minutes of reperfusion, but levelled off thereafter. In contrast, the SHR hearts showed a low release of enzymes during the first 15 minutes of reperfusion but a high release during the last 30 minutes of reperfusion; in the SHR the release was significantly higher than in the WKY rat hearts. The differences between both groups were even more pronounced when the basal mean enzyme loss was taken into account (broken lines in Figure V. 5). The total activity of enzymes lost in both groups throughout the reperfusion period is shown in Table V. 2. SHR hearts lost significantly higher LDH and AST activity than the WKY rat hearts. In relation to the total activities of enzymes present in these hearts, SHR lost $8.6 \%$ of their LDH and $3.9 \%$ of their AST activity, whereas WKY rat hearts lost only $2.5 \%$ of their LDH and $1.6 \%$ of their AST activity.

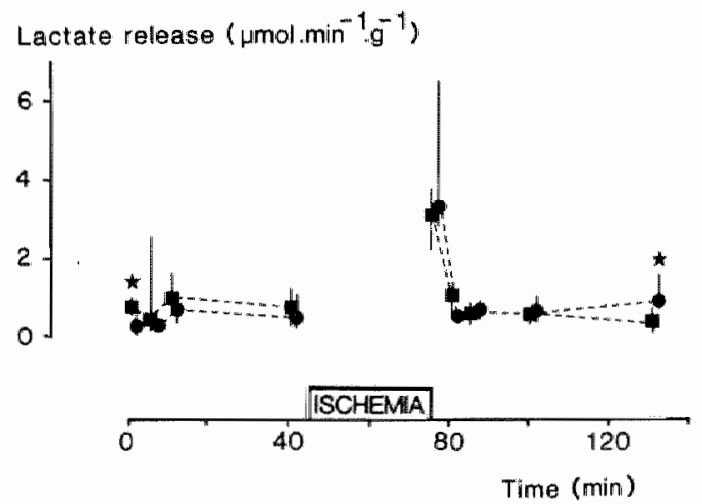

Figure V.4 Lactate release in isolated, ejecting hearts of 16 months old SHR (a: $n=8)$ and WKY rats $(0 ; n=8)$ before and after 30 minutes of global ischemia. Data are expressed as median values and $95 \%$ limits. $\star$ : significantly different from the SHR group $(p<0.05)$. 
Enzyme activity (Umin ${ }^{-1} g^{-1} \mathrm{ww}$ )

Lactate dehydrogenase
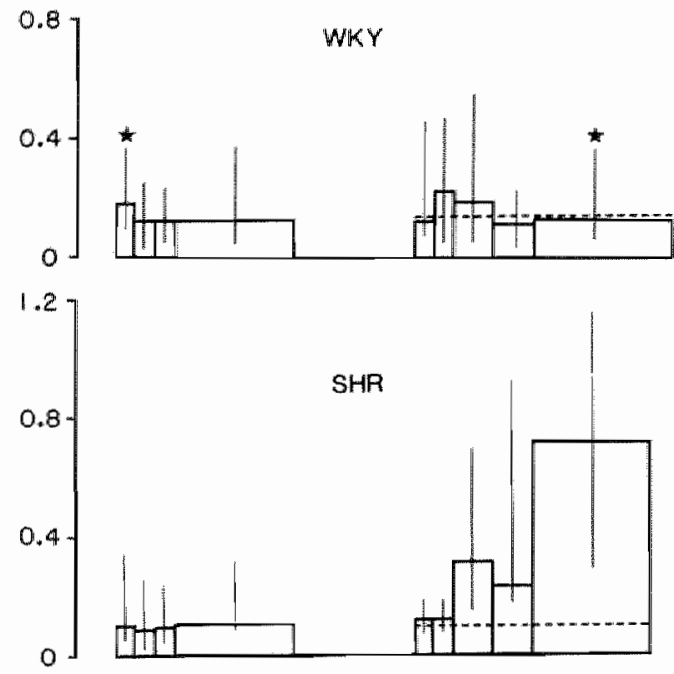

Aspartate aminotransferase
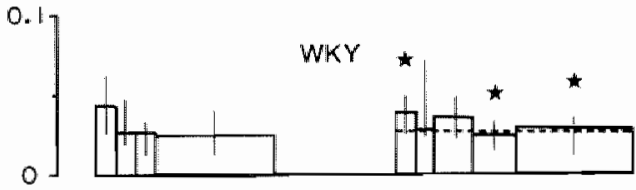

$\left.\begin{array}{l}0.2 \\ 0.1 \\ \\ 0\end{array}\right]$

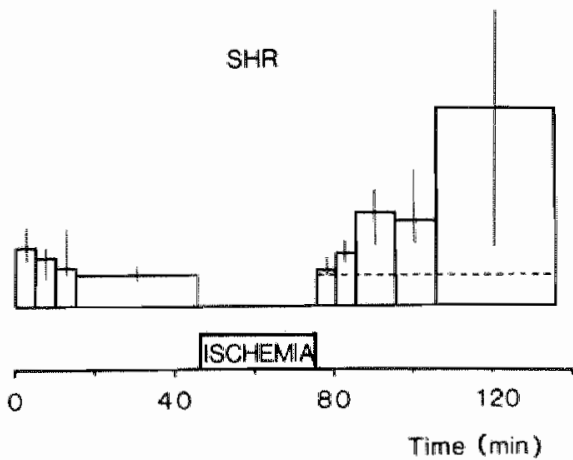

Figure V.5 Lass of lactate dehydrogenase and aspartate aminotransferase from isolased, ejecting hearts of 16 months old $S H R$ and $W K Y$ rats before and after 30 minutes of global ischemia. Data are presented as median values and 95\% confidence limits. Broken lines indicate the mean basal, pre-ischemic enzyme release. $\star$ : sigmificantly different from the SHR group $(p<0.05)$. 
Biochemical findings in myocardial tissue.

The tissue contents of energy-rich phosphates, glycogen, and lactate at the end of the experiments and the values obtained in native myocardial tissue are shown in Table V. 3. After one hour of reperfusion, the ATP concentrations were slightly lower in the SHR than in the WKY rat hearts. The native values, however, were significantly lower in the SHR than in the WKY rat hearts. The ATP content decreased to $47 \%$ of the native content in SHR hearts and to $42 \%$ of the native content in the WKY rat hearts. The myocardial glycogen contents at the end of the experiments were significantly decreased in both groups compared with the native values, which were significantly higher in the SHR hearts. The native lactate content was significantly higher in the WKY rat hearts than in the SHR hearts. In the SHR hearts the lactate content was significantly higher at the end of the experiments than in the native bearts. No significant changes in creatine phosphate content could be detected either between the experimental and native hearts or between the native hearts of the WKY rats and the SHR.

Table W. 2

Toral enzyme loss (U.g-t wet weight) during reperfusion of isolated hearts of 16 months old SHR $(n=8)$ and age-matched WKY rats $(n=8)$, specific activity of native hearts $(S H R, n=3 ; W K Y, n=5)$ and perceniage of enzyme activity lost.

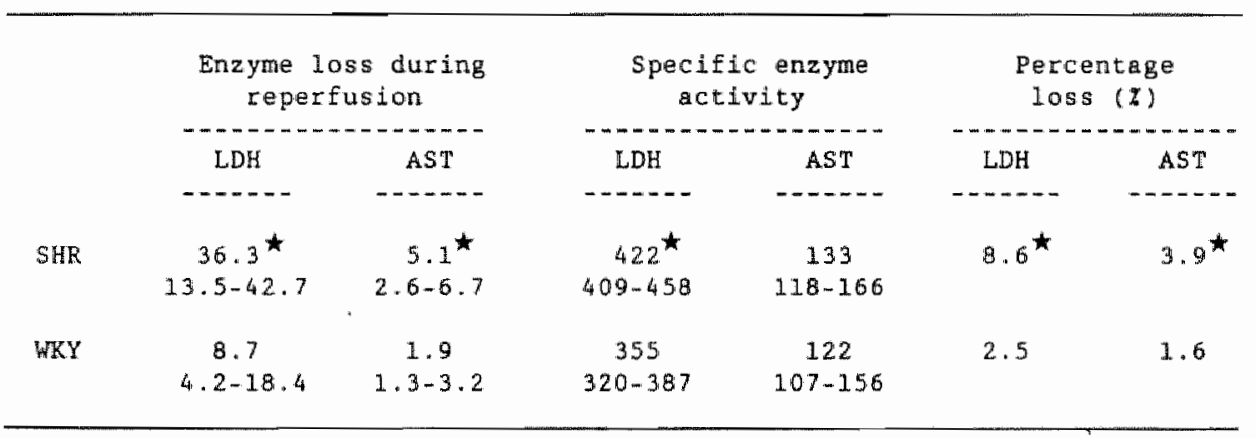

Data are expressed as median values and $95 \%$ confidence limils. $\star$ : significantly different from $W K Y$ rats $(p<0.05)$. 


\section{5. DISCUSSION}

The present study shows that significant hemodynamic and biochemical differences were found between hearts of relatively old spontaneously hypertensive rats and hearts of age-matched, non-hypertensive Wistar-Kyoto rats. These differences were seen in non-perfused native hearts, during pre-ischemic perfusion and during and after one hour of reperfusion following a period of 30 minutes global, normothermic ischemia.

In the perfusion conditions as applied in this study, the heart of the 16 months old spontaneously hypertensive rat had a lower cardiac output per gram heart weight than the Wistar-Kyoto rat heart of the same age despite a comparable coronary flow per gram heart weight. Also when perfusion pressure was altered, as during the recording of pressure-flow curves, the hypertrophied heart ejected less perfusate than the heart of the Wistar-Kyoto rat. The pressure-flow curves obtained during the pre-ischemic perfusion period show that the hypertrophied heart requires a higher left ventricular end-diastolic filling pressures than the control heart to eject comparable amounts of perfusate.

Table V. 3

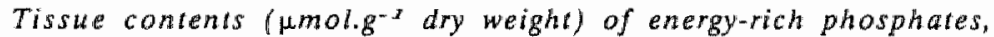
glycogen, and lactate in isolated hearts of 16 months old SHR and age-matched WKY rats, freeze-clamped immediately after isolation (Native) and at the end of 1 hour reperfusion following 30 minutes global ischemia (Reperfused).

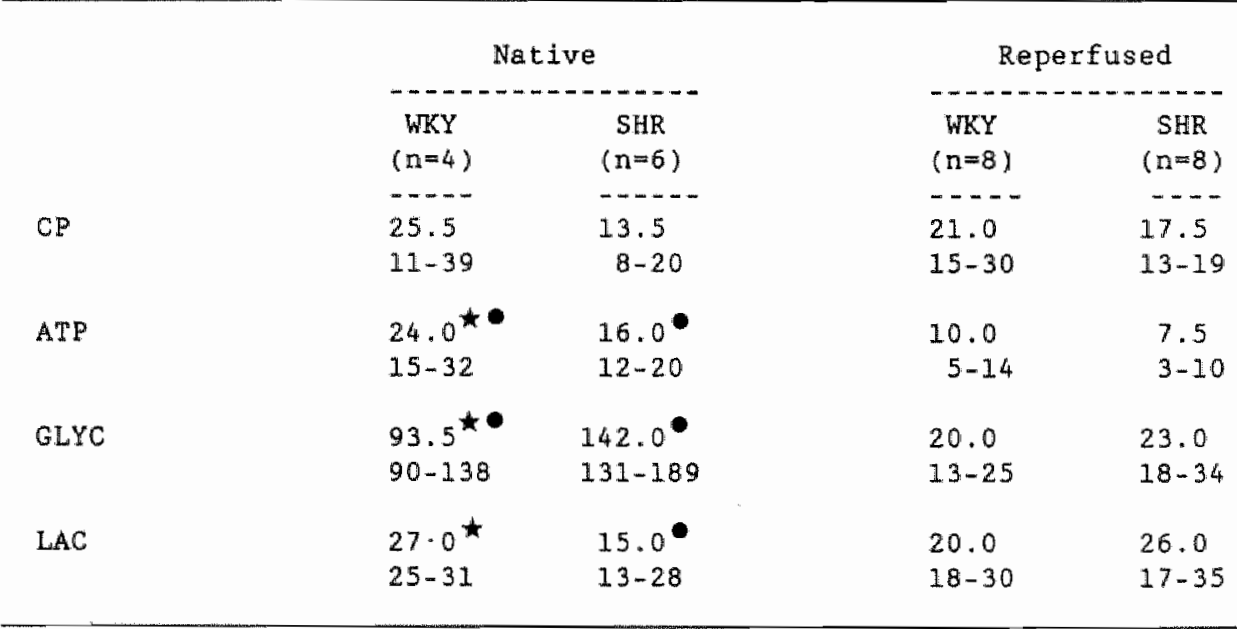

CP : crearine phosphate; ATP: adenosine triphosphate; GLYC : glycogen; LAC : laCfate. Data are presented as median values and $95 \%$ confidence limits. $\star$ : significantly different from the $S H R$ group $(p<0.05)$; : significantly different from the vahes in the corresponding reperfused hearts of the same strain $(p<0.05)$. 
This is especially obwious at lower afterload levels, that is, 10.7 and $14.7 \mathrm{kPa}$. Assuming the left ventricle to be a sphere, Hallbäck and coworkers (1975) calculated that the tangential tension per unit tissue mass of the left ventricle is lower in the spontaneously hypertensive rat than in the non-hypertensive rat. The reduced tangential wall tension most likely explains the reduced cardiac output response to an increase in end-diastolic filling pressure in the spontaneously hypertensive rat heart.

The present findings also show that in the spontaneously hypertensive rat left ventricular performance is independent of changes in afterload. At the three afterload levels tested, that is $10.7,14.7$ and 18.6

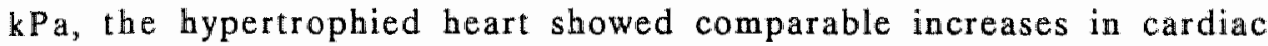
output in response to increase preloads. In the control heart, however, increasing the afterload resulted in lower cardiac output values at comparable preload levels. In contrast to the findings of Noresson and coworkers (1979), the pressure-flow curves in our study show that at high afterload levels the external work produced by hearts of spontaneously hypertensive rats is similar to that produced by hearts of control rats. In the study of Noresson and colleagues the heart of the spontaneously hypertensive rat reached higher levels of external work than the heart of the normotensive rat at high afterloads. This discrepancy can probably be explained by the differences in age of the hearts investigated. Noresson and colleagues used 5 months old rats, whereas we used rats of 16 months of age. Preliminary studies in our laboratory also show higher levels of external work at high afterload in the heart of younger spontaneously hypertensive rat than in the normotensive rat, i.e. at an age of 12 months.

The lower cardiac output found in the heart of the 16 months old spontaneously hypertensive rat compared with that of the normotensive rat could indicate that the spontaneously hypertensive rat heart has an impaired myocardial function. This idea is supported by the finding that from the total population of spontaneously bypertensive rats, from which our rats were obtained, almost $20 \%$ died during the two months preceding the experiments. Gross anatomical necropsy of these animals showed lung edema and massive enlargment of heart and liver. Besides, the significantly higher body weight in the spontaneously hypertensive rats suggest decongestion to be present in these animals.

However, the lower cardiac output in the spontaneously hypertensive rat heart during the pre-ischemic perfusion period could also be explained by a limited oxygen content of the perfusate so that the increased oxygen requirements of the hypertrophied heart could not be met. If so, maximal coronary vasodilation should be present in these hearts. Although maximal coronary vasodilator capacity has not been tested, indirect evidence can be provided that maximal vasodilation is not present in the hypertrophied hearts in the present study. During the recording of the pressure-flow curves, aortic flow as well as coronary flow increa- 
sed after increases in preload, indicating that the coronary vessels were not fully dilated. In addition, during the pre-ischemic period, the lacta te concentrations in the coronary effluent of the spontaneously hypertensive rat hearts were comparable with the values in the hearts of the Wistar-Kyoto rats, indicating that tissue anaerobiosis, if present, was not higher than in the control hearts.

The observations on cardiac output are not in agreement with the findings of Pfeffer and Pfeffer (1983). These investigators found that spontaneously hypertensive rats developed left ventricular dysfunction at the age of 24 months, as indicated by a significantly reduced mean arterial blood pressure, stroke volume, and cardiac index. These phenomena were not seen in their rat population at the age of 18 months. The reason for this discrepancy between their results and ours is unclear. It should be mentioned that the results of the cited investigators were obtained in intact, but anesthetized animals, while our results were obtained in isolated hearts. Besides, differences in breeding conditions between their and our laboratory have to be taken into account.

The heart of the relatively old spontaneously hypertensive rat shows a decreased tolerance to global, normothermic ischemia and reperfusion compared with the heart of the age-matched, non-hypertensive Wistar-Kyoto rat. In addition to the lack of hemodynamic recovery during reperfusion, as indicated by the low $\mathrm{dP}_{1 \mathrm{v}} / \mathrm{dtm}$ mx values and the almost complete absence of cardiac output, the hypertrophied heart lost considerable amounts of intracellular enzymes. The present study shows that during the first 10 minutes of reperfusion significantly lower coronary flow values were reached in the heart of the spontaneously hypertensive rat than in the control heart. This indicates that certain regions of the heart of the spontaneously hypertensive rat are not adequately reperfused so that the period of ischemia may be extended in these regions. This could also explain why smaller amounts of intracellular enzymes were released from the spontaneously hypertensive rat heart than from the control heart during the initial reperfusion phase. Van der Laarse and co-workers (1984), for instance, showed that at low coronary flow values the leakage of high molecular weight substances, such as the enzymes lactate dehydrogenase and aspartate aminotransferase, from the myocardium can be inhibited.

Diminished tolerance to global ischemia in the heart of the spontaneously hypertensive $\mathrm{rat}$ is also indicated by the increase in release of intracellular enzymes late during reperfusion, starting 15 minutes after restoration of flow. Alternatively, the increased release could be caused by delayed reperfusion of certain regions in the heart, in which tissue damage was extended by prolongation of the ischemia. Why the enzymes were released in increased amounts during this period can be explained by the increased afterload on these hearts during the performance of the function curves, resulting in an increased coronary perfusion pressure. This notion may imply that the recovery of the hypertrophied heart 
after a period of global ischemia could be dependent on the coronary perfusion pressure, under which these hearts are reperfused, especially during the initial reperfusion phase. The lack of complete tissue reperfusion in the heart of the spontaneously hypertensive rat is also supported by the finding that unlike the normotensive rat the tissue concentrations of lactate were higher at the end of the experiment as compared with the native values.

The enzyme aspartate aminotransferase is known to have two isoforms, typically occurring in the mitochondrion (mAST) and in the cytosol (cAST). The determination of both isoenzymes in the coronary effluent would shed more light on the specific damage of the mitochondrial and cell membrane (van der Laarse et al., 1981). However, due to the relative high dilution of the enzyme activity in the coronary effluent it was impossible to detect any enzyme activity after chromatographic separation of the enzyme present in the effluent samples. Therefore, the enzyme activity was determined as a whole. Nevertheless, as shown in Table V. 2, both control and hypertrophied hearts lost almost twice as much LDH as AST as related to the total tissue enzyme activity. This suggests that most probable only cytosolic AST was lost into the coronary effluent.

The ATP content was $33 \%(\mathrm{p}<0.05)$ and the creatine phosphate content $47 \%$ (NS) lower in the native hearts of spontaneously hypertensive rats than in the hearts of Wistar-Kyoto rats. These findings are in agreement with those of Peyton and co-workers (1982), who found significantly reduced contents of ATP and creatine phosphate in human hearts severely hypertrophied by pressure overload. Nevertheless, no significant differences in ATP and creatine phosphate contents could be found between the hearts of spontaneously hypertensive rats and non-hypertensive rats at the end of the experimental period. Of the eight hearts in the spontaneously bypertensive group, four showed very poor recovery in cardiac output during reperfusion. In all these hearts the ATP content was lower than or equal to $8 \mu \mathrm{mol} . \mathrm{g}^{-1}$ dry weight. Although the number of experimental animals is too small to investigate a possible relation belween the ATP concentrations at the end of the experiments and the hemodynamic recovery during the reperfusion period, the present data indicate that hearts with a low ATP content at the end of the reperfusion period fail to restore cardiac output. The importance of adequate ATP concentrations is also shown by the finding that ischemic contracture is delayed when left ventricular ATP contents are high (Hearse et al., 1977; Pfeffer and Pfeffer, 1983) or artificially kept at a higher level before the onset of ischemia (Peyton et al., 1982b).

In conclusion, discriminative variables, such as the contractile status of the heart, the cardiac output at various preload and afterload levels, and the loss of intracellular enzymes show substantial differences in the tolerance to ischemia between the heart of the spontaneously hypertensive rat and the non-hypertensive, age-matched control rat. 



\title{
RECOVERY OF HYPERTROPHIED HEARTS OF
}

\author{
AORTA-BANDED RATS DURING REPERFUSION
}

AFTER A PERIOD OF GLOBAL ISCHEMIA

\section{1. INTRODUCTION}

In humans left ventricular hypertrophy is associated with diminished tolerance of the heart to global ischemia and/or reperfusion, as induced during cardiac surgery (Cooley et al., 1972; Schaper et al., 1978; Buckberg, 1977; Beyersdorf et al., 1980). The stage of development of hypertrophy, as described in these cases, is often fairly advanced and deterioration of myocardial pump function may be encountered. In the previous chapter it was shown that in the old spontaneously hypertensive rat heart, which is considered to be representative of the situation in man (Mirsky et al., 1983; Pfeffer and Pfeffer, 1983), left ventricular pump function during reperfusion after a period of global ischemia was lower than in non-hypertrophied hearts of age-matched Wistar-Kyoto rats.

It is unknown, however, whether the decreased tolerance to ischemia and/or reperfusion is only found in the relatively old hypertrophied heart of the spontaneously hypertensive rat, or also in hearts in which hereditary hypertrophy is absent and left ventricular hypertrophy is present to a more modest degree. In such hearts left ventricular pump function is believed to be normal or enhanced (Noresson et al., 1979; Mirsky et all., 1983). This could be of special interest for the more or less physiologically hypertrophied heart, as in athletes involved in various kinds of sport activities (Snoeckx et al. 1982; Snoeckx et al, 1983), or in hereditary cardiomyopathies.

One of the possible explanations given for the diminished tolerance of the severely hypertrophied heart to global ischemia is the decreased myocardial tissue content of ATP (Sink et al., 1981; Peyton et al., 
1982a). Moreover, post-ischemic functional recovery seems to ameliorate by pre-ischemic conservation of ATP in the hypertrophied (Peyton et al., 1982b) as well as in the non-hypertrophied heart (Hearse et al., 1977). Reduced levels of creatine phosphate and ATP were also found in the hypertrophied heart during the stable, compensatory phase of myocardial hypertrophy (Reilly and Cooksey, 1979; Shimamoto et al., 1982). In this light, the present study was conducted to investigate the pre-ischemic and post-ischemic hemodynamic function and the associated biochemical events of isolated rat hearts in which the hypertrophy level had reached a stable, compensatory phase and in which left ventricular pump function was normal or even enhanced as compared to that in nonhypertrophied control hearts. The aorta-banded rat model, in which the descending aorta is partially constricted above the renal arteries for a period of 10 weeks, was used. It has been shown that in this type of model left ventricular hypertrophy is developed and stable between two weeks (Malik et al., 1976) and seven months (Meerson and Javick, 1982) after the surgical procedure.

Beside the functional recovery, post-ischemic cellular damage, if any, was evaluated by the loss of the intracellular enzyme lactate dehydrogenase. The biochemical status of the hypertrophied hearts at the beginning of the experiments, just before the period of global ischemia, at the end of the ischemic period and at the end of 45 minutes reperfusion following the period of global ischemia was compared with that of sham-operated animals by determining the tissue content of creatine phosphate, adenine nucleotides and their degradation products adenosine, inosine, hypoxanthine, and xanthine. The content of glycogen, lactate and inorganic phosphate was determined as well. The decrease of tissue contents of adenine nucleotides was related to the loss of degradation products of adenine nucleotides into the coronary effluent.

\section{2. METHODS}

Banding of the descending abdominal aorta was performed in male Lewis rats (age: 10 weeks), using the technique of Malik and co-workers (1976), resulting in stable left ventricular hypertrophy within 10 days after the surgical procedure. In short, rats were anesthetized with pentobarbital (100 mg/100 g body weight i.p.). Ampicilline (50 mg s.c.) was injected 30 minutes prior to surgery (van den Bogaard and Wiedema, 1985). Under sterile conditions the abdomen was opened on the left lateral side. The aorta was freed of connective tissue just above the renal arteries and constricted with a cotton thread. A needle (outer diameter $0.8 \mathrm{~mm}$ ) was included in the constriction and retracted afterwards. In sham-operated animals the aorta was only isolated. The abdomen was closed in layers and the animals were allowed to recover 
in individual cages. In total 66 rats were aorta-banded while 35 rats were sham-operated. All sham-operated animals recovered, while 21 aortabanded rats died within 3 days and 3 animals within 3 weeks after the surgical procedure. Thus, in total $42(63.6 \%)$ of the aorta-banded animals survived. At the moment of operation the animals were allotted at random to 5 groups (see below).

Two weeks after the abdominal operation, under light ether anesthesia catheters (polyethylene-10) were implanted in the femoral artery of ten, at random selected sham-operated animals and in the femoral and the brachial artery of ten also at random selected, aorta-banded animals, (Smits et al., 1982) to obtain information about the increase, if any, in systemic blood pressure. The catheters were guided subcutaneously to the neck of the animals where small incisions were made in the skin allowing exterioration of the catheters. After filling with heparinized saline ( $50 \mathrm{IU} \cdot \mathrm{m}]^{-1}$ ) the lumen of the catheters was closed with stainless steel plugs. After 2 days of recovery, in the awake animals blood pressure was measured with an external pressure transducer (CTC).

Table VI. 1 shows the allocation of the aorta-banded (Aob) and sham-operated $(\mathrm{Sh})$ animals to the various experimental groups. The $A o b_{n a x}$ and $S_{n a r}$ hearts were freeze-clamped immediately after removal from the body ten weeks after the abdominal operation. In these

Table V. 1

Allocation of the hearts of aorta-banded (Aob) and sham-operated (Sh) rats to the various experimental groups.

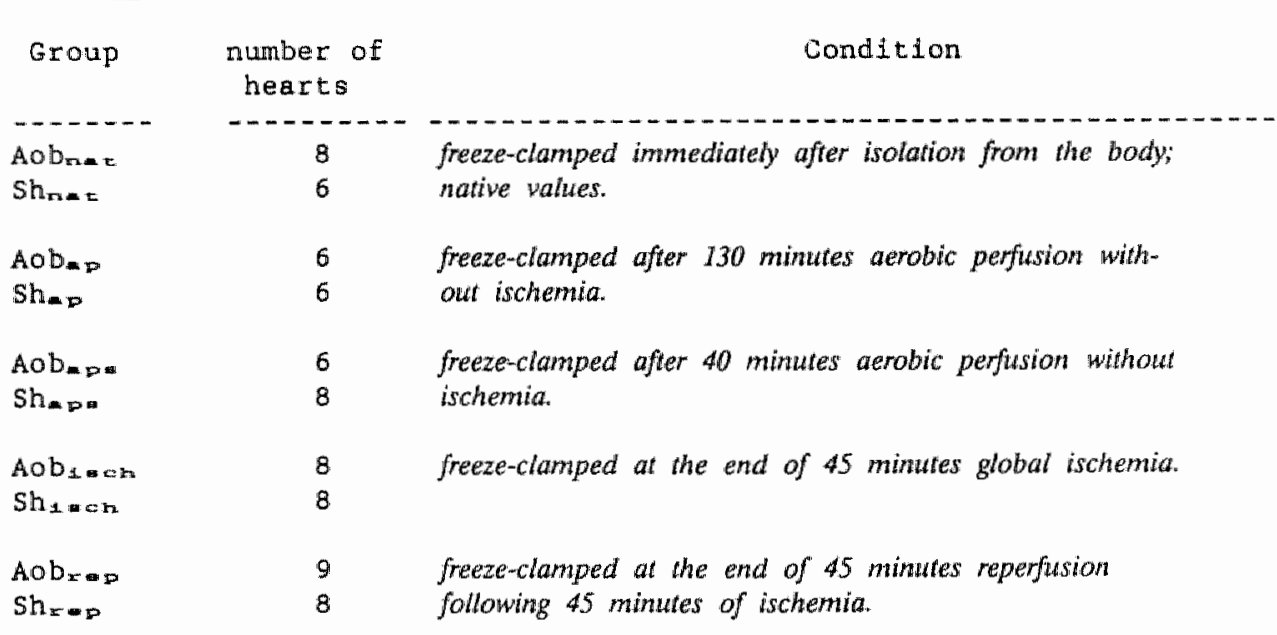


hearts native values of the tissue contents of adenine nucleotides and their degradation products, glycogen, lactate, and inorganic phosphate, were determined as described in chapter II. The results of these determinations were already shown and discussed in chapter IV. Aobap and $S h_{\text {p }}$ hearts were perfused during 130 minutes to obtain information about the hemodynamic and biochemical stability of the ejecting hearts under aerobic perfusion conditions. These results were also shown in chapter IV. Aobaps and $\mathrm{Sh}_{\mathrm{ap}}$ hearts were aerobically perfused during 40 minutes which corresponds with the length of the pre-ischemic period in other hearts. The hearts in the Aobisch. Shisch. Aobrep and $\mathrm{Sh}_{\mathrm{r}}$ groups were made ischemic during 45 minutes. The hearts in the Aobiach and $S h_{i a c k}$ groups were freeze-clamped at the end of the ischemic period while the hearts in the Aobrep and $\mathrm{Sh}_{\text {rop }}$ groups were freeze-clamped at the end of 45 minutes reperfusion following the period of global ischemia.

The animals were anesthetized with ether. After removal from the body the hearts were immediately immersed in ice-chilled Tyrode's solution. Remnant lung tissue and fat were removed. The hearts were weighed and attached to the perfusion apparatus described in chapter II. Retrograde perfusion was started at a pressure of $8.0 \mathrm{kPa}$ immediately after attachment of the heart to the aortic cannula. A second cannula was connected to the left atrium for filling of the left atrium and left ventricle. The filling pressure was set at $1.0 \mathrm{kPa}$. Aortic pressure was measured $1 \mathrm{~cm}$ above the aortic valves in the aortic cannula. Under the conditions described the rat hearts developed left ventricular systolic pressures, reaching maximal values of $2.5 \mathrm{kPa}$ above the diastolic aortic pressure, which was kept at $8.0 \mathrm{kPa}$. This implies that mean coronary perfusion pressure was about $0.8 \mathrm{kPa}$ higher than the diastolic aortic pressure mentioned. The hemodynamic variables and the ellectrogram, which was derived from two small platinum electrodes attached to the left ventricular wall, were fed into a home-made pre-processor connected to an Apple IIe microcomputer, allowing the on-line calculation of the hemodynamic variables, as described in chapter III.

Retrograde perfusion was maintained during 10 minutes. Thereafter, the left atrial cannula was opened and antegrade perfusion was started for a period of 30 minutes. Heart rate was kept constant at 300 beats. $\min ^{-1}$ through bipolar platinum stimulation electrodes attached to the right atrial wall. During this pre-ischemic period the hemodynamic variables were continuously computed. The coronary effluent was collected to measure the release of lactate, the degradation products of adenine nucleotides, such as adenosine, inosine, hypoxanthine, xanthine and uric acid, and the activity of lactate dehydrogenase (LDH).

Left ventricular function curves were constructed at 3 different aortic pressure loads and 4 different left atrial pressure loads, as described in detail in the previous chapter. Left atrial pressure was increased in steps of $0.66 \mathrm{kPa}$ from 0.66 to $2.64 \mathrm{kPa}$ at a diastolic aortic pressure 
of $8.0 \mathrm{kPa}$. This procedure was repeated at aortic pressures of 13.3 and $18.6 \mathrm{kPa}$. At each step, hemodynamic variables were computed. A steady state myocardial function of at least $\mathbb{1}$ minute had to be present before the walues of the various variables were recorded.

At the end of the pre-ischemic period, Aobaps and Shaps were disconnected from the perfusion apparatus, immediately freeze-clamped and immersed in liquid nitrogen. The tissue was stored at $-80^{\circ} \mathrm{C}$ for biochemical analysis as described in chapter II. The hearts of Aobison and Stisch were freeze-clamped at the end of the ischemic period while those of $A b_{\text {rop }}$ and $S h_{\text {rop }}$ were freeze clamped at the end of the reperfusion period. The reperfusion period started with an initial retrograde perfusion period of 15 minutes. Hearts were not paced in this period, but were paced at a rate of 300 beats. $\min ^{-1}$ thereafter. After the retrograde perfusion period hearts were allowed to eject under the same circumstances as during the pre-ischemic period. The coronary effluent was collected for biochemical assay, as during the pre-ischemic period. After 10 minutes of antegrade perfusion, left ventricular function curves were constructed as during the pre-ischemic period.

\section{3. STATISTICS}

Differences between the values of the various hemodynamic and biochemical variables in the sham and aorta-banded hearts in the various groups were evaluated for statistical significance using the Mann-Whitney U-test. Differences between the values of the variables in the preischemic and post-ischemic period were evaluated for statistical significance by Wilcoxon's matched-pairs signed-ranks test. P-values smaller than or equal to 0.05 were considered to be statistically significant.

\section{4. RESULTS}

The blood pressure values, as obtained in the selected aorta-banded and sham-operated groups of rats two weeks after abdominal operation are presented in Table VI. 2. In 2 aorta-banded rats, it was technically not possible to measure the pressure in the brachial or in the femoral artery. A systolic pressure gradient of at least $10.5 \mathrm{kPa}$ and a diastolic gradient of at least $7.2 \mathrm{kPa}$ over the abdominal constriction were found. The femoral artery blood pressure values were not significantly different in both groups.

The heart weight values, obtained before the start of the experiments, were about $20 \%$ higher in the aorta-banded than in the sham-operated animals ( $p<0.05$; Table VI. 3 ). The histogram of all heart weights in the various groups is shown in Figure VI. 1. Five hearts of aorta- 


\begin{tabular}{|c|c|c|c|c|}
\hline & Brachial & artery & Femara 1 & artery \\
\hline & $-\infty-\infty-\infty$ & $---\infty-\infty$ & $----m--$ & $----\infty$ \\
\hline & syet & diast & syst & diast \\
\hline & $-\infty$ & $\ldots-\cdots$ & $\cdots$ & 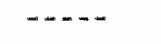 \\
\hline Sham $(n=10)$ & $\begin{array}{l}n \cdot d \\
n \cdot d\end{array}$ & $\begin{array}{l}n \cdot d . \\
n \cdot d .\end{array}$ & $\begin{array}{c}15.0 \\
13.3-17.0\end{array}$ & $\begin{array}{c}12 \cdot 1 \\
11.4-13.6\end{array}$ \\
\hline $\begin{array}{l}\text { Aorta-banded } \\
(n=8)\end{array}$ & $\begin{array}{c}24.5^{\star} \\
19.2-25.5\end{array}$ & $\begin{array}{c}18.6^{\star} \\
16.5-23.4\end{array}$ & $\begin{array}{c}14.4 \\
10.6-14.4\end{array}$ & $\begin{array}{l}11.4 \\
9.3-12.2\end{array}$ \\
\hline
\end{tabular}

Dasa are presented as median walues and $95 \%$ confidence limits and expressed in kPa. n.d. "not determined. : significantly different from the values in the femorat ariery $(p<0.05)$.

Number of hearts

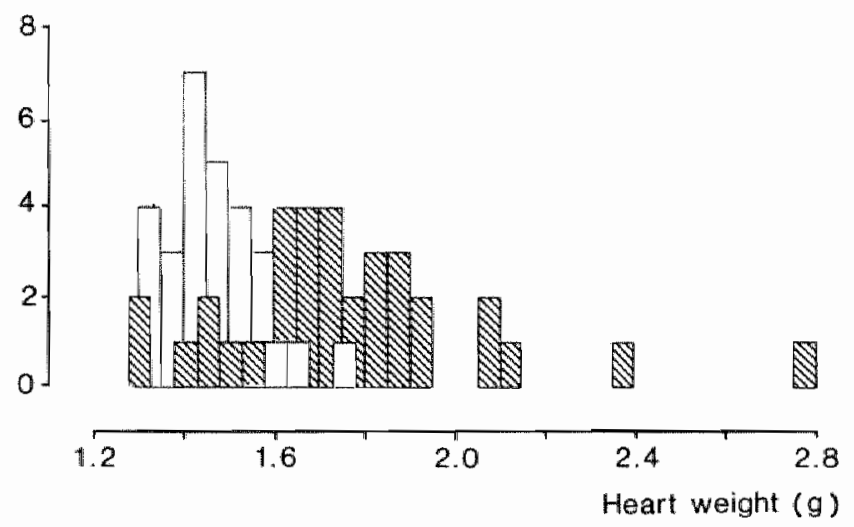

Figure L. I Histogram of the heart weight values obtained at the beginning of the experiments. Open bars represent the values in the sham groups $(n=29)$; hathed bars the waltes in the arta-banded groups $(n=29)$.

banded rats were excluded from the various groups since their weight was below the median heart weight value in the sham-operated group, and, therefore, regarded as non-hypertrophied. In two subgroups, i.e. $\mathrm{Sh}_{\mathrm{nat}}$ and $\mathrm{Sh}_{\mathrm{ap}}$, significantly different body weight values were found in the sham-operated and in the aorta-banded animals. However, when 
Heart and body weight values in the various groups of sham-operared (Sh) and aorta-banded (Aob) rats. The ratio of heart weight and body weight refers to the heart weight walues at the start of the in-vitro experimuents.

\begin{tabular}{|c|c|c|c|c|}
\hline \multirow[t]{2}{*}{ Group } & \multicolumn{2}{|c|}{ Hesrt weight (g) } & Body weight (g) & $\mathrm{HW} / \mathrm{BW} \cdot 10^{-2}$ \\
\hline & pre & post & & \\
\hline $\begin{array}{l}S h_{n}=t \\
(n=6)\end{array}$ & $\begin{array}{c}1.08 \\
0.87-1.14\end{array}$ & $\begin{array}{l}\text { n. } 8 \text {. } \\
\text { n.a. }\end{array}$ & $\begin{array}{c}336 \star \\
326-352\end{array}$ & $\begin{array}{l}\text { n.d. } \\
\text { n.d. }\end{array}$ \\
\hline $\begin{array}{l}S h=p \\
(n=7)\end{array}$ & $\begin{array}{c}1.52^{\star} \\
1.45-1.78\end{array}$ & $\begin{array}{l}\text { n.a. } \\
\text { n.a. }\end{array}$ & $\begin{array}{c}360 \\
326-386\end{array}$ & $\begin{array}{c}0.44^{\star} \\
0.41-0.46\end{array}$ \\
\hline $\begin{array}{l}S_{1}=\mathrm{cm} \\
(\pi=8)\end{array}$ & $\begin{array}{c}1.40^{\star} \\
1.34-1.42\end{array}$ & $\begin{array}{c}1.38^{\star} \\
1.30-1.43\end{array}$ & $\begin{array}{c}362 \\
353-3.70\end{array}$ & $\begin{array}{c}0.39^{\star} \\
0.36-0.46\end{array}$ \\
\hline $\begin{array}{l}S h_{x=p} \\
(n=8)\end{array}$ & $\begin{array}{c}1.48^{\star} \\
1.41-1.50\end{array}$ & $\begin{array}{c}2.01^{\star} \\
1.92-2.12\end{array}$ & $\begin{array}{c}368 \\
352-382\end{array}$ & $\begin{array}{c}0.40^{\star} \\
0.39-0.40\end{array}$ \\
\hline $\begin{array}{l}S h=p \\
(n=6)\end{array}$ & $\begin{array}{c}1.55^{\star} \\
1.33-1.70\end{array}$ & $\begin{array}{c}1.84^{\star} \\
1.70-1.97\end{array}$ & $\begin{array}{c}381^{\star} \\
342-394\end{array}$ & $\begin{array}{c}0.41^{\star} \\
0.36-0.46\end{array}$ \\
\hline$S h$ tor & $\begin{array}{c}1.48^{\star} \\
1.37-1.58\end{array}$ & $\begin{array}{c}1.82 \\
1.40-1.96\end{array}$ & $\begin{array}{c}360 \\
336-380\end{array}$ & $\begin{array}{c}0.40^{\star} \\
0.38-0.44\end{array}$ \\
\hline $\begin{array}{c}\mathrm{Aob}_{\mathrm{n} m} \mathrm{t}_{4} \\
(\mathrm{n}=8)\end{array}$ & $\begin{array}{c}1.48 \\
1.31-1.85\end{array}$ & $\begin{array}{l}\text { n.a. } \\
\text { n. } a .\end{array}$ & $\begin{array}{c}3.59 \\
340-400\end{array}$ & $\begin{array}{l}\text { n.d. } \\
\text { n.d. }\end{array}$ \\
\hline $\begin{aligned} & A O b=p=s \\
&(n=6)\end{aligned}$ & $\begin{array}{c}1.82 \\
1.55-2.77\end{array}$ & $\begin{array}{l}\text { n.a. } \\
\text { n.a. }\end{array}$ & $\begin{array}{c}356 \\
303-380\end{array}$ & $\begin{array}{c}0.49 \\
0.45-0.91\end{array}$ \\
\hline $\begin{array}{c}\text { AOb }_{1 \mathrm{a}}=\mathrm{n} \\
(\mathrm{n}=8)\end{array}$ & $\begin{array}{c}1.73 \\
1.65-1.90\end{array}$ & $\begin{array}{c}1.60 \\
1.49-1.92\end{array}$ & $\begin{array}{c}360 \\
320-386\end{array}$ & $\begin{array}{c}0.50 \\
0.45-0.59\end{array}$ \\
\hline $\begin{array}{c}A \circ b_{x}=p \\
(n=9)\end{array}$ & $\begin{array}{c}1.83 \\
1.72-2.10\end{array}$ & $\begin{array}{c}2.31 \\
2.27-2.43\end{array}$ & $\begin{array}{c}332 \\
326-370\end{array}$ & $\begin{array}{c}0.55 \\
0.48-0.57\end{array}$ \\
\hline $\begin{array}{l}A \circ B=D \\
(n=6)\end{array}$ & $\begin{array}{c}1.71 \\
1.59-2.35\end{array}$ & $\begin{array}{c}1.98 \\
1.72-2.25\end{array}$ & $\begin{array}{c}342 \\
316-360\end{array}$ & $\begin{array}{c}0.51 \\
0.47 \times 0.618\end{array}$ \\
\hline Aobtot & $\begin{array}{c}1.79 \\
1.65-2.09\end{array}$ & $\begin{array}{c}2.07 \\
1.57-2.32\end{array}$ & $\begin{array}{c}346 \\
330-376\end{array}$ & $\begin{array}{c}0.52 \\
0.45-0.57\end{array}$ \\
\hline
\end{tabular}

Pre and post: heart weight at the beginning and at the end of the experiments. Shror and Aobror: values in the total groups of sham-operated and aorta-banded animals, respectively. The ravio of heart weight to body weight is expressed as $H W / B W \cdot 10^{-2}$. Data are presented as median values and $95 \%$ confidence limits. M.d. : not devermined; na. : not applicable. - heart weight was only determimed in freezeclamped vemiricles, cut from the remaining heart tissue. $\star$ : significantly different from the corresponding values in the aorta-banded group $(p<0.05)$. 
the total group was regarded, no significant differences were present between the body weight values in both groups. In all aorta-banded groups significantly thigher heart weight to body weight ratio values were found than in the the sham-operated groups.

The ratio of the heart weight values at the end and those at the start of the experiments, was found to be increased in the hearts of the Aobap. Shap. Aobrop and $\mathrm{Sh}_{\text {rop. }}$. Besides, the increase in heart weight was more pronounced in reperfused than in aerobically perfused hearts. As compared to the values at the start of the experiments, the hearts aerobically perfused during 130 minutes showed an increase in weight of $19 \%$ (sham-operated) and $16 \%$ (aorta-banded), respectively. Sham bearts reperfused for 45 minutes following 45 minutes of global ischemia, showed an increase in weight of $36 \%$, while a $26 \%$ increase was observed in the aorta-banded, reperfused group.

\section{4.1. Hemodynamics}

During the pre-ischemic perfusion period, in all groups under investigation the hemodynamic variables reached comparable values as in the aerobically perfused hearts, described in chapter IV. Sham hearts showed slightly, but not significantly higher $\mathrm{dP}_{1 \mathrm{v}} / \mathrm{dt}_{\max }$ values than the aorta-banded hearts (see also Figure VI. 2).

During the first 15 minutes of reperfusion, heart rate gradually increased in the non-hypertrophied hearts (Figure VI. 2). Thereafter, stimulation was possible in all hearts of this group. The recovery in $\mathrm{dP}_{1 \mathrm{v}} / \mathrm{dt}$ $\max$ in these hearts amounted to $79 \%$ (median value) as compared to the pre-ischemic value. All hearts were capable to eject during the ejecting period. As compared to the pre-ischemic values, a maximal recovery in cardiac output of $71 \%$ was observed. As shown in chapter IV, cardiac output decreased about $7 \%$ during 130 minutes aerobic perfusion. Taking this decrease into account, the maximum post-ischemic recovery in cardiac output amounted to $77 \%$.

In 5 out of 9 hypertrophied hearts, normal electrical and mechanical recovery was absent during the reperfusion period. In these hearts absence of electrical activity was alternated by short periods of ventricular fibrillation or ventricular tachycardia. Consequently, it was not possible to stimulate these hearts, which did not eject any detectable amount of fluid. In the other 4 hearts mechanical and electrical recovery was present, so that they could be stimulated at a frequency of 300 beats. $\mathrm{min}^{-1}$. These hearts were analyzed as a separate subgroup, despite the fact that their number was rather small. In these hearts the recovery of $\mathrm{dP}_{\mathrm{Iv}} / \mathrm{dt}_{\max }$ was good towards the end of the reperfusion period. A value of $88 \%$ (median value) of the pre-ischemic value was reached, but the recovery of cardiac output was poor. Only $24 \%$ (median value) of the pre-ischemic value was reached (Figure VI. 2).

The coronary flow values per unit heart weight, as obtained in 
both groups of hearts, are shown in Figure VI. 3. In the pre-ischemic period during the ejecting phase, significantly lower flow values were obtained in the hypertrophied hearts. In the initial phase of the reperfusion period, reactive hyperemia was present in the control hearts. In the hypertrophied hearts, however, reactive hyperemia was completely absent and significantly lower coronary flow values, as compared to
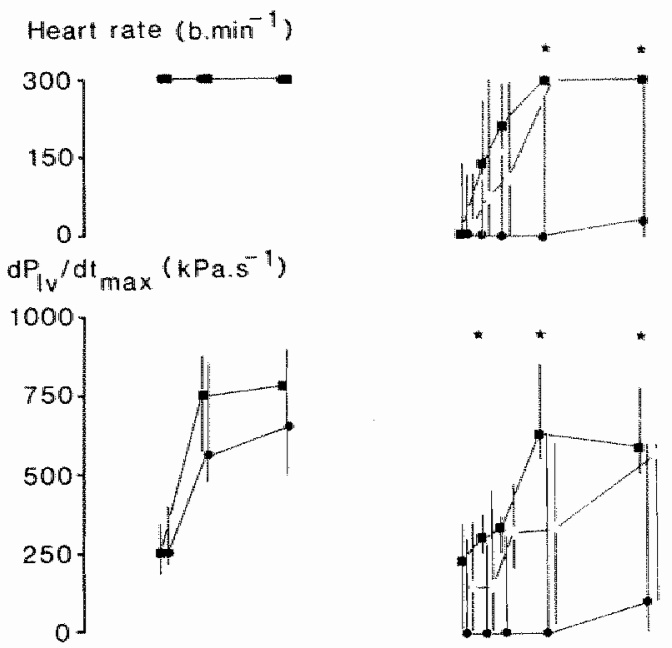

Cardiac output (ml.min $\left.{ }^{-1}\right)$

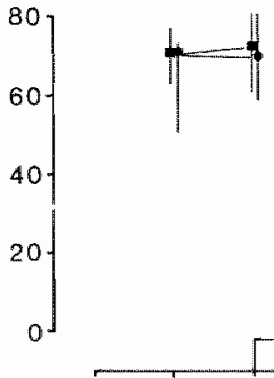

ISCHEMIA

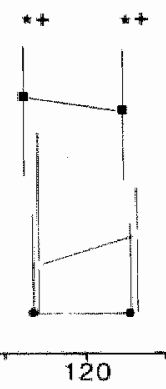

Time (min)

Figure VT. 2 Hemodynamic data in isolated, ejecting rat hearts of sham-operated (D; $m=8)$ and aorta-banded $(n ; n)$ animals before and after 45 minutes global ischemia. Recovering hypertrophied hearts are shown as a separate subgroup 10 ; $n=4$ ). The data are presented as median values and $95 \%$ confidence limits. dP fw/dinax: maximum first derivative of left ventricular pressure. *. significant differerce between sham and aorta-banded hearts; +: significant difference between sham and rocovering hypertrophied hearts $(p<0.05)$. 
the values in the control hearts, were observed throughout the reperfusion period. In the recovering hearts of this group, coronary flow values were higher, but still lower than those in the hearts of the shamoperated animals.

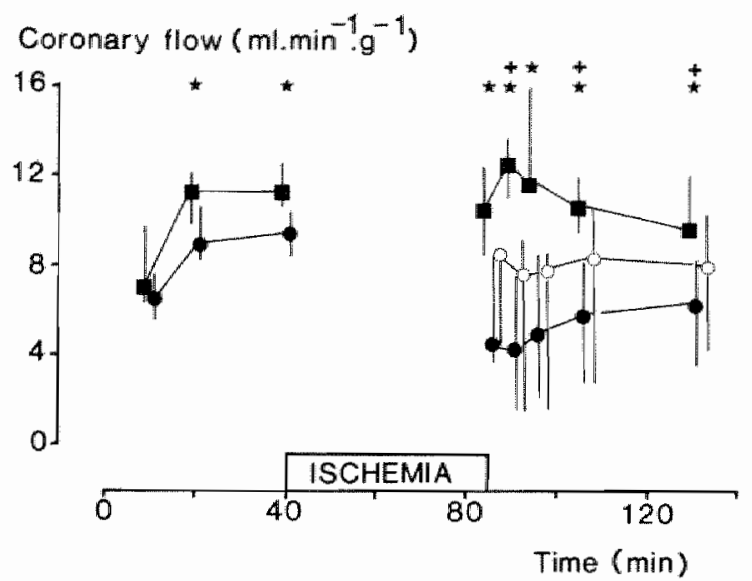

Figure V. 3 Coronary flow values in isolated, ejecting hearts of sham-operated ( $\mathbf{a}$; $n=8$ ) and aorta-banded ( $n=9$ ) rats before and after 45 mirutes giobal ischemia. Recoverimg hearts of aorta-banded rats are shown as a separate subgroup $(O ; n=4)$. Flows are normalized to the heart weight obtained at the start of the experiments. The data are presented as median values and $95 \%$ confidence limits. $\star$ : significant difference between sham and aorta-banded hearts; +: significant difference between sham and recovering hypertrophied hearts $(p<0.05)$.

The left ventricular function curves, obtained during the pre-ischemic period, were comparable to those obtained in the 130 minutes aerobic perfusion experiments, shown in chapter IV (Figure VI. 4). At the lowest afterload level, comparable amounts of perfusate were ejected by control and hypertrophied hearts. At high afterload and preload levels, cardiac output tended to be higher in the hypertrophied hearts, but these differences did not reach the level of significance. During reperfusion, sham hearts responded to the increase in preload at the two lowest afterload levels tested, but the increase in cardiac output was less than during the pre-ischemic period. At the highest afterload investigated, the hearts were almost incapable to eject fluid into the aorta, indicating a substantial loss of myocardial pump function. 


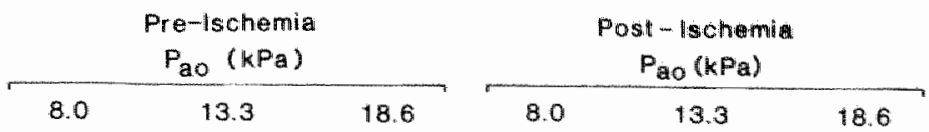

Cardiac output $\left(\mathrm{m} ! \mathrm{min}^{-1}\right)$

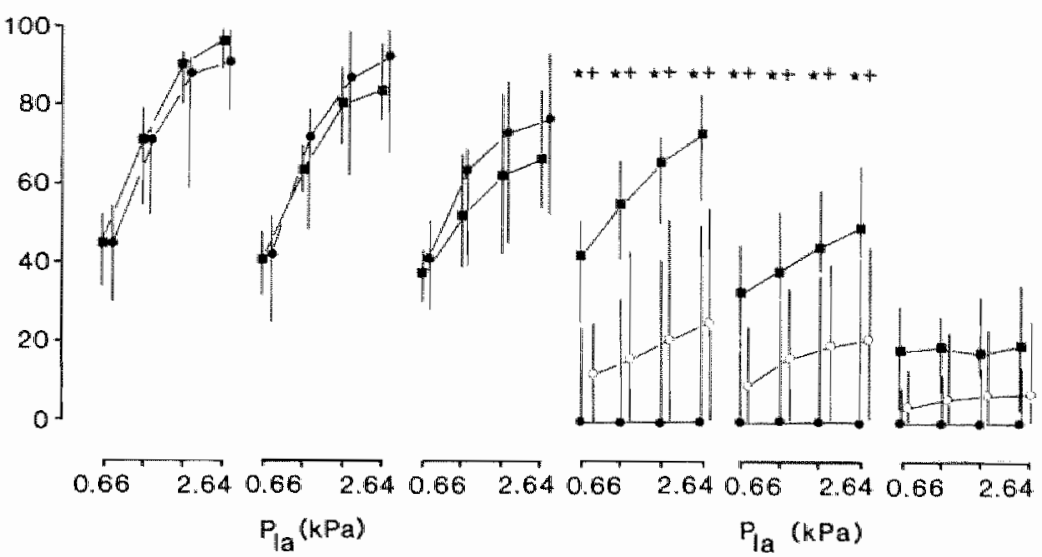

Figure VI. 4 Left ventricular function curves in isolated, ejecting hearts of shamoperated $\left(\mathbf{n}_{;} n=8\right)$ and aorfa-banded $(0 ; n=9)$ rats before and after 45 minutes global ischemia. Recovering hearts of aorta-banded rats are shown as a separale subgroup $(0 ; n=4)$. The data are presented as median values and $95 \%$ confidence limits. $P_{a O}$ : diastolic aortic pressure; $P_{t a}$ : left atrial pressure. : significant difference between sham and aorta-banded hearts;" +: significant difference between sham and recovering hypertrophied hearts $(p<0.05)$.

Since during reperfusion myocardial function was absent in 5 out of 9 hypertrophied bearts, the increase in preload and/or afterload could not provoke any response in these hearts. However, when the recovering hearts were taken as a separate group, a modest increase in cardiac oulput was observed by increasing the preload at the lowest afterload levels tested. This increase, however, was significantly less than in the sham hearts. At higher afterloads, almost no cardiac output could be recorded in these hearts (Figure VI. 4).

\section{4.2. Biochemical data}

Findings in coronary effluent

In the various groups during the pre-ischemic period, low and comparable amounts of lactate were released by the control and hypertrophied hearts varying between 2 and $2.5 \mu$ mol.min ${ }^{-1} \cdot \mathrm{g}^{-1}$ wet weight. In the control and hypertrophied hearts, reperfused after 45 minutes 
of global ischemia, significantly increased levels of lactate were found in the coronary effluent during the first 5 minutes of the reperfusion period, i.e. 7.8 and $6.8 \mu \mathrm{mol} \cdot \mathrm{min}^{-1} \cdot \mathrm{g}^{-1}$ wet weight, respectively. The difference between hypertrophied and control hearts was not significant. Thereafter, in both groups the amounts of lactate released were comparable to those found during the pre-ischemic period.

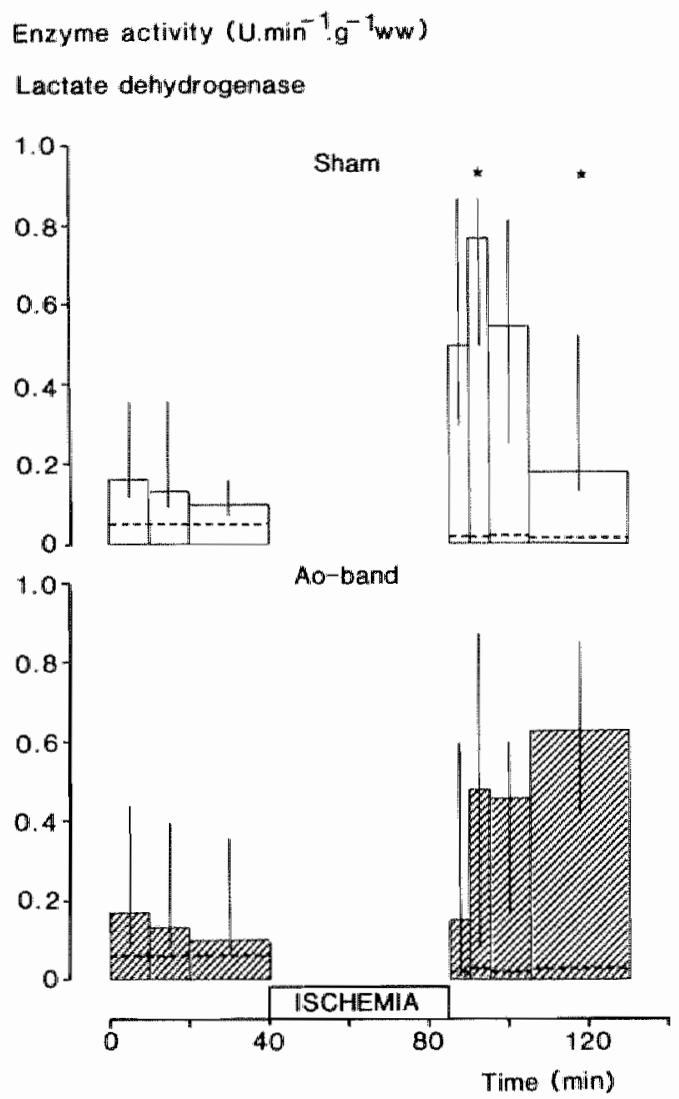

Finure VT. 5 Release of lacrate dehydrogenase from isolated, ejecting hearts of shamoperated (upper panel; $n=8$ ) and aortambanded (lower panel; $n=9$ ) rats before and after 45 minutes global ischemia. The activities of enzyme released by $S h_{\text {ap }}$ and Aobap hearts at comparable time intervals during 130 minutes aerobic perfusion are indicated by the broken limes within the bars. The data are presented as median values and $95 \%$ canfidence limits. $\star$ : significant difference between sham and aortabanded hearts $(p<0,05)$. 
During the 40 minutes of pre-ischemic perfusion, the hearts in the $\mathrm{Sh}_{\mathrm{r} \in \mathrm{p}}$ and $\mathrm{Aob}_{\mathrm{rep}}$ groups lost comparable amounts of $\mathrm{LDH}$, i.e. 4.7 and $4.6 \mathrm{U} \cdot \mathrm{g}^{-1}$ wet weight, respectively (Figure VI. 5). Almost identical amounts of enzyme were lost in the hearts of the other groups.

During reperfusion after global ischemia, hearts of sham-operated animals lost considerable amounts of LDH during the first 20 minutes of reperfusion. During the last 25 minutes of the reperfusion period the release rate of $\mathrm{LDH}$ was not significantly different from that during the pre-ischemic period. The pattern of enzyme release in the hypertrophied hearts was completely different from that in hearts of sham-operated animals. Very low amounts of enzyme were lost during the first 5 minutes of reperfusion, but at the end of the reperfusion period significantIy more enzyme was lost than in the sham hearts. In the recovering hearts of this group relatively high activities of $L D H$ were found in the coronary effluent collected during the first 10 minutes of the reperfusion period, a loss that remained high during the late reperfusion phase. Throughout the reperfusion period, sham hearts lost $18.6 \mathrm{U}^{-g^{-1}}$ wet weight, while hypertrophied hearts $(n=9)$ released $23.6 \mathrm{U} \cdot \mathrm{g}^{-x}$ wet weight. Subdividing the hypertrophied group into electrically recovering $(n=4)$ and non-recovering hearts $(n=5)$, revealed a loss of 28.6 U.g $^{-1}$ wet weight in the recovering hearts and $23.5 \mathrm{U.g}^{-1}$ wet weight in the nonrecovering hearts (a non-significant difference).

During the pre-ischemic period no significant differences were observed in the summated amounts of degradation products of adenine nucleotides, released by the control and hypertrophied hearts in the various groups (Figure VI. 6; Table VI. 4). During 40 minutes of preischemic, aerobic perfusion, hearts of the $S_{\text {rep }}$ and Aobrop groups lost 0.48 and $0.70 \mu \mathrm{mol} . \mathrm{g}^{-1}$ wet weight, respectively. In the other groups of hypertrophied and control hearts amounts varying between 0.38 and 0.64 $\mu \mathrm{mol} . \mathrm{g}^{-1}$ wet weight were lost (data not shown). Generally, in control as well as in hypertrophied hearts more than $50 \%$ of the degradation products was lost as uric acid. The remaining part was lost as inosine and sporadically hypoxanthine. No detectable concentrations of adenosine and xanthine could be found in the coronary effluent during the preischemic period.

During the first 5 minutes of the reperfusion period significantly more degradation products were released from the control than from the hypertrophied hearts. At this time inosine was the most prominent degradation substance found in the coronary effluent in both groups of hearts, while adenosine, hypoxanthine and xanthine were lost in almost comparable amounts (Figure VI. 6). During the late reperfusion period, a normalized release was observed in both groups. Recovering hypertrophied hearts released slightly higher amounts of degradation products during the first 5 minutes of the reperfusion period, as compared with the total group of hypertrophied hearts. Throughout the reperfusion period of 45 minutes, sham hearts lost $2.25 \mu \mathrm{mol}$ degradation products 


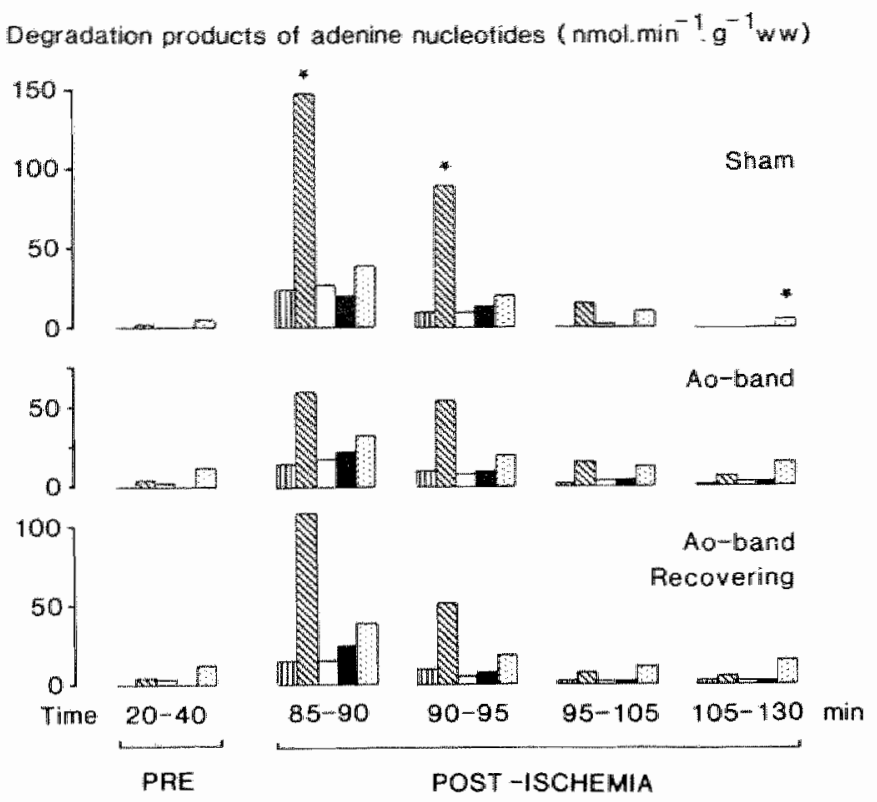

Figure VT. 6 Release of degradation products of adenine nucleotides from isolated, ejecting hearts of sham-operated (upper panel; $n=8$, and aorta-banded (middle panel; $n=9$ ) rals before and after 45 minules global ischemia. Results of functionally recovering hearts of aorta-banded rats are shown as a separate subgroup (bottom panel; $n=4)$. $\mathbf{0}$ : adenosine; : inosine; $\square$ : hypoxanthine; : xamihine; : uric acid. * : significant difference between sham and aorta-banded heants $(p<0.05)$.

per gram wet weight. The release from the hypertrophied hearts $(n=9)$ was found to be comparable, i.e. $2.20 \mu \mathrm{mol}_{\mathrm{g}}{ }^{-1}$ wet weight (Table VI. 4). The recovering hypertrophied hearts $(n=4)$ lost $2.19 \mu$ mol degradation products. $^{-1}$ wet weight. Throughout the reperfusion period, sham hearts lost relatively more inosine $(55 \%)$ than aorta-banded hearts $(42 \%)$, while the latter released significantly more uric acid (31\%) than the sham hearts $(20 \%)$.

Biochemical findings in myocardial tissue

As mentioned in chapter IV, comparable tissue contents of adenine nucleotides, energy charge, degradation products of adenine nucleotides, lactate and inorganic phosphate were found in hearts from $\mathrm{Sh}_{\mathrm{nax}}$ and Aobnax (see also Table VI. 5). The energy charge in both non-hypertrophied ( $S h_{\text {aps }}$ ) and hypertrophied (Aobaps) hearts was significantly higher than in the native hearts after a period of 40 minutes aerobic perfusion. This increase was significantly higher in the control than in the hypertrophied hearts. Glycogen levels were significantly lower in both non-hypertrophied and hypertrophied hearts after 40 minutes aerobic perfusion than in the corresponding native hearts. 
As already shown in chapter IV (Table IV. 3), prolongation of aerobic perfusion to 130 minutes induced a decrease of about $16 \%$ in the sum of ATP, ADP and AMP as compared to the amounts found in native myocardium.

In the hearts of Shisch and Aobisch, freeze-clamped at the end of the 45 minutes period of global ischemia, creatine phosphate, ATP and glycogen were very low. Increased amounts of degradation products of adenine nucleotides (especially inosine) as well as lactate and inorganic

Table M. 4

The cotal amounts of degradation products of adenine rucleotides (nmol.g.t wet weight) released before (PRE: 30 minules) and after 45 minules global ischemia (POST; 45 mimutes) and the post-ischemic percentage loss from hearts of stam-operated and aorta-banded (Alo-band) rats.

\begin{tabular}{ccccccc}
\hline & ADO & INO & HX & $X$ & TA & TOT \\
Sham $(\mathrm{n}=8)$ & & & & & & \\
PRE & 0 & 0 & 39 & 0 & 273 & 357 \\
& $0-0$ & $0-66$ & $0-150$ & $0-0$ & $225-303$ & $225-642$ \\
POST & 165 & 1256 & 202 & 208 & 447 & 2245 \\
& $107-183$ & $874-1629$ & $148-288$ & $82-226$ & $410-543$ & $2004-3116$ \\
Z LOSS & 7 & 56 & 9 & 9 & 20 & $100 z$
\end{tabular}

Ao-band ( $n=9$ )

$\begin{array}{ccccccc}\text { PRE } & 0 & 123 & 12 & 0 & 300 & 522 \\ & 0-0 & 0-177 & 0-102 & 0-0 & 241-567 & 318-807 \\ \text { POST } & 173 & 919 & 163 & 200 & 672^{\star} & 2203 \\ & 104-204 & 654-1151 & 113-302 & 170-340 & 575-729 & 1717-2612 \\ z \text { LOSS } & 8 & 42 & 7 & 9 & 31 & 100 z\end{array}$

Aa-band recovering $(n=4)$

\begin{tabular}{lcccccc} 
POST & 142 & 993 & 154 & 223 & 724 & 2190 \\
& $13-372$ & $449-1571$ & $65-301$ & $108-3.34$ & $453-888$ & $1329-3295$ \\
7 LOSS & 7 & 45 & 7 & 10 & 33 & 1007 \\
\hline
\end{tabular}

ADO: adenosine; INO: imosine; $H X$ : hypoxanthine; $X$ : xanthine; $U A$ : uric acid; TOT: sum of all products. Data are presented as median values and $95 \%$ confidence Vimits. $\star$ : significantly different from the sham group $(p<0.05)$. 
Tissue contens of adenine nucleotides, degradation products of adenine operated (Sh) and aona-banded (Aab) rats.

\begin{tabular}{|c|c|c|c|c|c|}
\hline & $\begin{array}{l}S h_{r m a} \\
(n=6)\end{array}$ & $\begin{array}{l}A O b_{n=1} \\
(n=8)\end{array}$ & $\begin{array}{l}S h=-\infty \\
(n=8)\end{array}$ & $\begin{array}{l}A O b_{-p} \\
(n=6)\end{array}$ & $\begin{array}{l}s h_{1-c h} \\
(n=8)\end{array}$ \\
\hline & $\cdots--\cdots$ & $-m----$ & $-\ldots-\ldots$ & $---m--n$ & $-\ldots+\cdots$ \\
\hline \multirow[t]{2}{*}{$C P$} & 13.8 & 30.8 & 36.6 & 22.7 & $4.7^{\circ}$ \\
\hline & $8.7-40.9$ & $11.0-43.6$ & $18.9-41.6$ & $15.2-8.3 .1$ & $2.4-8.0$ \\
\hline \multirow[t]{2}{*}{$\mathrm{ATP}$} & 16.4 & 15.2 & 18.4 & 16.3 & $7.2^{\circ}$ \\
\hline & $11.8-19.2$ & $12.8-20.4$ & $16.4-22.2$ & $13.5-22.1$ & $6.5-8.0$ \\
\hline \multirow[t]{2}{*}{$\mathrm{ADP}$} & 7.9 & 6.2 & $4 \ldots 6$ & 5.3 & $6.3^{\circ}$ \\
\hline & $3.2-9.7$ & $4 \cdot 3-9 \cdot 1$ & $3 \cdot 8-5 \cdot 3$ & $4.5-6.0$ & $5.9-6.7$ \\
\hline \multirow[t]{2}{*}{ AMP } & 1.2 & 1.4 & 0.5 & 1.0 & $2.5^{\circ}$ \\
\hline & $0.3-1.8$ & $0.6-2.6$ & $0.4-1.0$ & $0.5-1.5$ & $1.9-2.8$ \\
\hline \multirow[t]{2}{*}{ SUM } & 25.9 & 23.5 & 24.5 & 22.9 & $15.2^{\circ}$ \\
\hline & $15.5-29.2$ & $20.1-28.3$ & $20.7-26.5$ & $19.5-27.3$ & $14.4-17.0$ \\
\hline \multirow[t]{2}{*}{$\mathrm{EC}$} & $0.78^{\circ}$ & $0.79^{\bullet}$ & $0.88^{\star}$ & 0.83 & $0.66^{\circ}$ \\
\hline & $0.76-0.86$ & $0.72-0.88$ & $0.85-0.91$ & $0.81-0.90$ & $0.64-0.68$ \\
\hline \multirow[t]{2}{*}{ A } & 0.35 & 0.25 & 0.10 & 0.10 & $1.90^{\circ}$ \\
\hline & $0-0.70$ & $0.03-0.40$ & $0-0.30$ & $0-0.40$ & $1.80-2.40$ \\
\hline \multirow[t]{2}{*}{ I } & 0.20 & 0.05 & 0.20 & 0.20 & $5.40^{\circ}$ \\
\hline & $0.10-0.50$ & 0.0 .05 & $0-0.30$ & $0-0.40$ & $4.70-7.50$ \\
\hline \multirow[t]{2}{*}{$\mathrm{HX}$} & $0.50^{\star}$ & 0.06 & 0.70 & 0.55 & $3.00^{\circ}$ \\
\hline & $0.20-1.10$ & $0-0.30$ & $0.10-1.00$ & $0-1.20$ & $0.60-3.20$ \\
\hline \multirow[t]{2}{*}{$\mathrm{x}$} & 0.05 & 0 & 0 & 0 & $0.60^{\circ}$ \\
\hline & $0-0.20$ & $0=0.20$ & $0-0$ & $0-0.30$ & $0.40-0.80$ \\
\hline \multirow[t]{2}{*}{ GLYC } & $116^{\circ}$ & $101^{\bullet}$ & 93 & 87 & $38^{\circ}$ \\
\hline & $101-125$ & $97-151$ & $73-128$ & $67-158$ & $35-57$ \\
\hline \multirow[t]{2}{*}{ LAC } & 15.5 & 17.7 & 14.0 & 17.4 & $172.0^{\circ}$ \\
\hline & $3.4-25.3$ & $10.2-31.2$ & $9.6-17.9$ & $7.4-25.9$ & $154.7-186$ \\
\hline \multirow[t]{2}{*}{$P_{i}$} & 52.4 & 44.7 & 29.2 & 35.2 & $78.3^{\bullet}$ \\
\hline & $29.4-85.3$ & $31.4-53.5$ & $23.7-52.9$ & $27.4-50.8$ & $52.7-98.7$ \\
\hline
\end{tabular}

$C P$ : crealine phosphate $A T P, A D P$ and $A M P$ : adenosine triphosphate, adenosine $A M P_{;} E C$ : energy charge ((ATP $\left.\left.+0.5 A D P\right) / S U M\right) ; A:$ adenosine; $I$ : inosine; $H X$ : The right two columns show the data in functionally recovered $(n=5)$ and non-recodata are presented as median values and $95 \%$ confidence limits. $\star$ : significandly rent from the corresponding values in groups $S h_{\text {max }}$ and Aoblaps $(p<0.05)$. 
nucleotides, glycogen, lactate and inorganic phosphate in isolated hearts of sham-

\begin{tabular}{|c|c|c|c|c|}
\hline $\begin{array}{c}A o b_{1}=0 \mathrm{n} \\
(\mathrm{n}=8)\end{array}$ & $\begin{array}{l}S h_{x=p} \\
(n=8)\end{array}$ & $\begin{array}{c}\text { Aob }=D \\
(n=9)\end{array}$ & $\begin{array}{c}\text { Recovering } \\
\text { Aob }=p \\
(n=4)\end{array}$ & $\begin{array}{c}\text { Non-recovering } \\
\text { Aobrep } \\
(n=5)\end{array}$ \\
\hline 4.5 & 27.3 & 10.7 & 23.5 & 10.6 \\
\hline $2.1-7.6$ & $14.5-33.2$ & $5.0-31.4$ & $5.0-50.9$ & $2.1-20.1$ \\
\hline $5.9^{\circ}$ & $8.7^{\star \bullet}$ & $6.0^{\circ}$ & $7.3^{\circ}$ & $5.7^{\circ}$ \\
\hline $5.6-8.0$ & $8.1-9.7$ & $3.7-7.4$ & $5.0-9.7$ & $3.5-6.7$ \\
\hline $6.4^{\circ}$ & 3.9 & $3.4^{\circ}$ & $3.7^{\circ}$ & 3.1 \\
\hline $5.7-6.9$ & $3 \cdot 4-4 \cdot 4$ & $2.5-3.8$ & $2.5-3.8$ & $2.0-3.8$ \\
\hline $2.0^{\circ}$ & 1.1 & 1.2 & 0.9 & 1.6 \\
\hline $1.4-2.9$ & $0.6-1.2$ & $0.7-1.9$ & $0.6-1.2$ & $0.7-3.2$ \\
\hline $15.0^{\circ}$ & $14.0^{\star}$ & $10.6^{\circ}$ & $12.0^{\circ}$ & $10.3^{\bullet}$ \\
\hline $13.7-16.0$ & $12 \cdot 3-14.8$ & $8.7-12.1$ & $8.7-14.1$ & $6.4-12.1$ \\
\hline $0.64^{\circ}$ & $0.79^{\star 0}$ & $0.72^{\circ}$ & $0.77^{\star}$ & $0.71^{\circ}$ \\
\hline $0.60-0.72$ & $0.76-0.81$ & $0.69-0.78$ & $0.72-0.82$ & $0.52-0.73$ \\
\hline $2.40^{\circ}$ & 0.20 & 0.10 & 0 & 0.30 \\
\hline $1.50-3.20$ & $0-0.30$ & $0-0.50$ & $0-0.20$ & $0-0.60$ \\
\hline $4.70^{\circ}$ & 0.20 & 0.20 & 0 & 0.50 \\
\hline $4.10-6.20$ & $0-0.70$ & $0-0.90$ & $0-0.60$ & $0-2.40$ \\
\hline $1.50^{\circ}$ & 0.10 & 0.20 & 0.10 & 0.30 \\
\hline $0.50-3.00$ & $0-2.10$ & $0-1.20$ & $0-1.20$ & 0.1 .60 \\
\hline $0.50^{\circ}$ & 0 & 0 & 0 & 0 \\
\hline $0.30-0.60$ & $0-0$ & 0.0 .40 & $0-0.10$ & $0-0.60$ \\
\hline $53^{\circ}$ & 59 & $40^{\circ}$ & 66 & $33^{\circ}$ \\
\hline $30-65$ & $39-109$ & $29-81$ & $29-92$ & $24-50$ \\
\hline $171.7^{\circ}$ & $6.8^{\star \bullet}$ & 17.5 & 19.7 & 17.5 \\
\hline $151.1-214$ & $5.5-10.2$ & $12.7-48.9$ & $5.9-23.1$ & $12.7-99.4$ \\
\hline $82.3^{\bullet}$ & $57.7^{\bullet}$ & $62.6^{\circ}$ & 57.8 & 62.6 \\
\hline $66.5-106$ & $54 \cdot 3-63 \cdot 4$ & $52.5-82.4$ & $45.7-164.6$ & $52 \cdot 5-82 \cdot 4$ \\
\hline
\end{tabular}

diphosphate, adenosine manophosphate, respectively; SUM " the sum of ATP, ADP and hypoxanthine; $X$ : xanthine; GLYC ; glycogen; LAC : lactate; Pi: inorganic phoshafe; vered $(n=4)$ hearts of aorla-banded amimals. All data are in $\mu$ mol.g ${ }^{-1}$ dry weight. The different from the yalues in the aorta-banded group $(p<0.05)$; : significanily diffe- 
phosphate were found in both groups of hearts. Eventual differences between non-hypertrophied and hypertrophied hearts were not statistically significant.

During reperfusion after global, normothermic ischemia creatine phosphate levels increased in both groups of hearts. The levels tended to be higher in the sham hearts. However, when the recovering hypertrophied hearts were considered as a separate subgroup, almost identical values were found as in the control hearts. In the latter hearts, the ATP levels increased as compared to their end-ischemic content. In these hearts the increase was significantly higher than in the total group of hypertrophied hearts. Since energy charge was also enhanced. as compared to the end-ischemic values during reperfusion, regeneration of ATP from ADP and AMP had occurred in the control hearts. Regeneration of ATP in hypertrophied hearts was only present in the recovering hearts, as indicated by the significantly higher energy charge value than in the non-recovering hearts.

In Figure VI. 7 the evolution of the sum of the adenine nucleotides and their degradation products in both groups of hearts throughout the experiments are shown. In sham hearts during reperfusion, all degradation products, present in the myocardial tissue at the end of the ischemic period, were released into the coronary effluent.

At the end of the reperfusion period in non-hypertrophied and hypertrophied hearts the glycogen content remained at the levels found at the end of the ischemic period, while lactate and inorganic phosphate content returned to pre-ischemic levels. Significantly higher amounts of lactate were found in the reperfused hypertrophied hearts than in the reperfused non-hypertrophied hearts.

\section{5. DISCUSSION}

The results in the present study show that the hypertrophied heart of the aorta-banded rat has a decreased tolerance to global ischemia, as indicated by the significantly decreased pump performance during reperfusion following global ischemia. Although the results of the function curves during the pre-ischemic period indicate a better pump performance of the hypertrophied than the control heart, the former is unable to withstand high afterloads during the reperfusion period. The deterioration of the pump function is associated with significantly lower levels of energy-rich phosphates at the end of 45 minutes of reperfusion, as compared with the values found in the non-hypertrophied control hearts. However, the end-ischemic energy-rich phosphates levels are not significantly different, indicating that the differences between hypertrophied and non-hypertrophied hearts, observed at the end of reperfusion, are most likely caused by events occuring reperfusion period. 
Sum of adenine nucleotides and

degradation products $\left(\mu m o l g^{-1} \mathrm{dw}\right.$ )
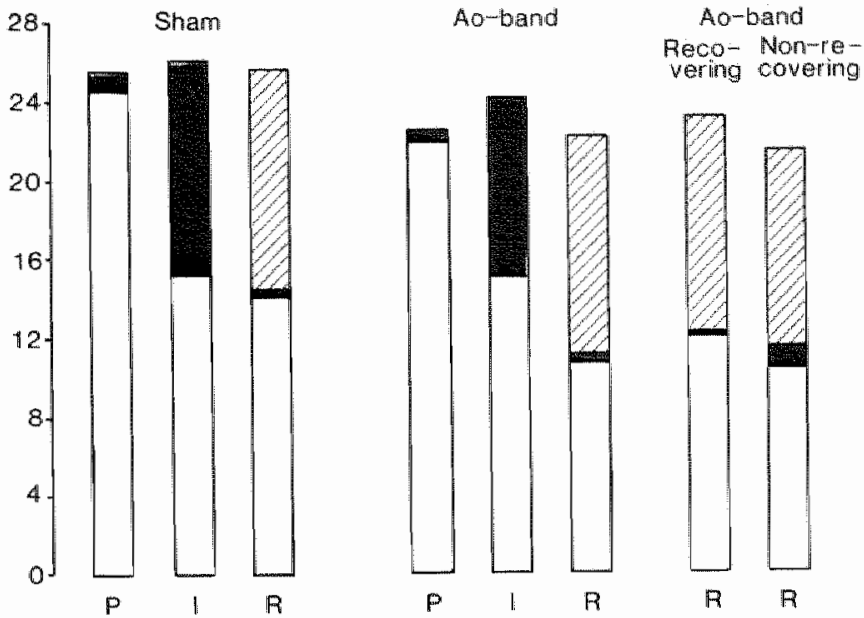

Figure V. 7 The sum of the tissue conterts of adenine nucleotides (ATP, ADP and $A M P ; \square$ ) and their degradation products (adenosime, inosine, hypoxanthine and xanthine; $\mathbf{0}$ ) and the degradation products recavered in the coronary effluent during the reperfusion period (adenosine, inosine, hypoxanthine, xanthine and uric acid; $\mathbb{Q})$ in hearts of sham-operated $(n=8)$ and aorta-banded $(n=9)$ animals. Results of recovering $(n=4)$ and non-recowering $(n=5)$ hypertrophied hearts are shown separately. Conversion from wet to dry weight of the degradation products in coronary effluent is oblained by multiplying the amounts released by a factor 5. $P$; preischemia $\quad(t=40$ minutes); $I$ : end-ischemia $(t=85$ minutes); $R$ : end reperfusion $(t=125$ minutes $)$.

In the hypertrophied hearts during the initial reperfusion phase coronary flow is significantly reduced and remains significantly lower as compared to the flow values in the control hearts. Associated with this phenomenon, loss of lactate dehydrogenase in the hypertrophied heart is significantly retarded during the initial phase of reperfusion, indicating a possible inadequacy of reperfusion of certain regions in the myocardial tissue. To a lesser extent, this phenomenon is also observed in the release of degradation products of adenine nucleotides but, interestingly, not in the release of lactate.

\section{5.1. Effects of aorta-banding in 10 weeks old rats}

Banding of the abdominal aorta induces a $30 \%$ increase of the ratio of heart weight and body weight. This result is comparable with the findings reported by Malik and co-workers (1976), who originally described this technique. Malik found a $26 \%$ increase in heart weight to 
body weight ratio within 6 days after surgery. The mortality rate, however, is higher in our study, i.e. $36 \%$ vs $21 \%$ in the report of Malik. There is no clear explanation for this difference, but a possible negative influence could be exerted by the anesthetics applied. We used pentobarbital in our animals, whereas Mallik and co-workers applied ether anesthesia. This assumption is supported by the observation that most of the non-surviving rats in our study died within 1 hour after the surgical procedure. Autopsy in these animals revealed absence of bleeding in the abdominal cavity.

The blood pressure rise induced by the banding of the aorta is at least as high as in the animals investigated by Malik and co-workers (10.5 vs $8.0 \mathrm{kPa}$ peak systolic pressure). This increase is present in all animals investigated $(n=8)$, suggesting an overall increase in heart weight in the aorta-banded animals. In contrast with a consistent increase in peak-systolic pressure in the selected animals, the increase in heart weight or in heart weight to body weight ratio is not uniform in the groups of aorta-banded animals. In fact, 5 out of 34 animals did not show ventricular hypertrophy since their heart weight remains below the median value of the heart weight in the sham-operated animals. When mortality rate and failure of hypertrophy development is taken into account, it can be concluded that in our study the banding technique of Malik and co-workers has an overall success rate of $56 \%$.

VI 5.2. Post-ischemic functional recovery and its relation to the heart weight to body weight ratio.

The present findings provide evidence that the lower tolerance to global ischemia of the hypertrophied heart also occurs in the myocardium of relatively young rats, in which hypertrophy is developed to a modest degree. It is believed that the stage of the hypertrophy in this type of animal is compensated and stable. This observation is based on the findings of Meerson and Javich (1982), who described stable, fully compensated bypertrophy to be present in this type of rat up to 7 months after the surgical procedure. Besides, the construction of left ventricular function curves during the pre-ischemic period in the present study reveals a normal pump function of the hypertrophied heart, even at low afterload levels. Besides, higher, although not significantly, cardiac output levels are reached in the hypertrophied than in the control hearts at the highest afterload level studied $(18.6 \mathrm{kPa})$. Therefore, it can be concluded that at this stage of hypertrophy, the heart of the aorta-banded rat is capable to a better pump performance than the nonhypertrophied hearts of the age-matched control rat, confirming observations of other investigators (Noresson et al., 1979; Mirsky et al., 1983). In Figure VI. 8 the relation between the post-ischemic recovery in cardiac output to the ratio of heart weight and body weight and to the heart weight in both groups of hearts is shown. Although the number 
of observations is rather small, the data indicate that there is an inverted relation between the extent of functional recovery and the degree of hypertrophy present in the myocardium of the aorta-banded animals.
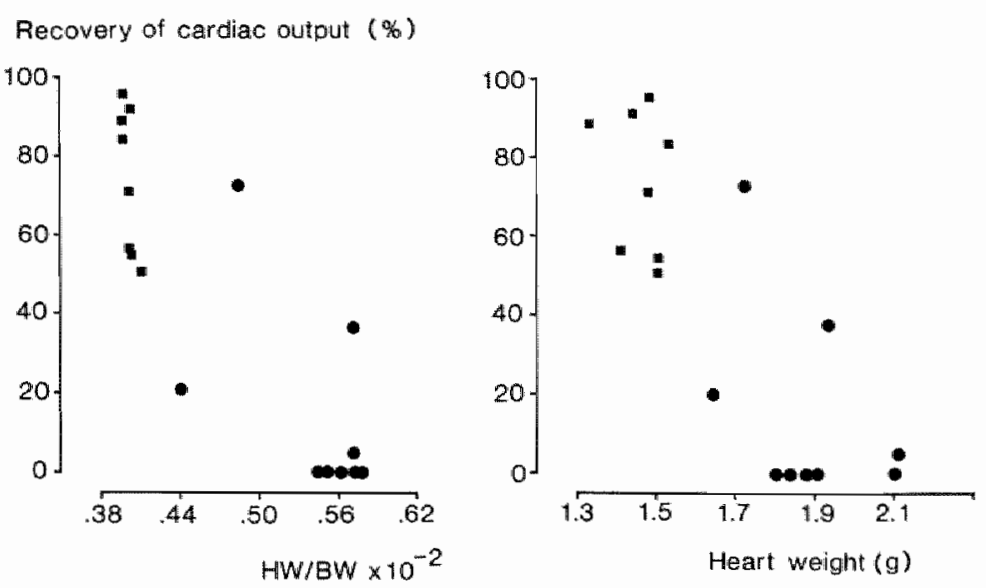

Figure $M .8$ Percentage recovery of cardiac output during reperfusion following 45 minutes global ischemia in isolated, ejecting hearts of sham-operated ( $\mathbf{D} ; n=8)$ and aorta-banded $(0 ; n=9$ ) rats, in relation to the ratio of body weight and heart weight ( $\mathrm{g} / \mathrm{g}$ left panel) and to the heart weight (g right panel).

VI 5.3. Biochemical findings in native, ischemic and reperfused myocardium

The biochemical findings in native tissue of the hypertrophied hearts, as observed in the present study, do not confirm earlier abservations (Reilly and Cooksey, 1979; Shimamoto et al., 1982). ATP, ADP and AMP, and creatine phosphate levels are identical in hypertrophied and non-hypertrophied hearts. Furthermore, comparable values of these substances are found at the end of the pre-ischemic and ischemic periods. These findings indicate that the differences found in the tissue at the end of the reperfusion period, have to be associated with events, only occurring during reperfusion. So, the poor functional recovery of the hypertrophied heart after a period of global ischemia, as described in this study, cannot be associated with a lower tissue content of energyrich phosphates before and/or at the end of the period of ischemia, as has been suggested by other investigators (Sink et al., 1981; Peyton et al., 1982a). A satisfactory explanation for the discrepancy between the earlier published findings and the present ones is not readily available. 
Although the biochemical variables studied in the present investigation did not reveal a significant biochemical difference between bypertrophied and non-bypertrophied hearts, a variety of other investigators have suggested that pronounced differences in myocardial fatty acid homeostasis exist between these two groups. These differences are exemplified, for instance, by reduced levels of carnitine, an essential cofactor in mitochondrial fatty acid consumption, in hearts of aorta-banded rats (Revis and Cameron, 1979, Reibel et al., 1987). This phenomenon was associated with a reduced activity of the plasmamembrane bound carrier protein for carnitine (Cantrell and Borum, 1982), and probably causes increased levels of lipid stores within the hypertrophied heart (Revis and Cameron, 1979). In contrast, increased levels of carnitine were found in the heart of the spontaneously hypertensive rat (Reibel et al., 1987). In cardiomyopathic hamsters it was recently shown that the artificial increase of intracellular carnitine by intraperitoneal pretreatment with L-carnitine during 6 weeks reduces the percentage area of necrosis, fibrosis and calcification (Yamashita et al., 1986). However, it is not known if the reduced levels of carnitine could play a role in the decreased tolerance to ischemia of the hypertrophied heart.

\section{5.4. Biochemical findings in coronary effluent of reperfused myo-} cardium

The comparable decrease of adenine nucleotides in hypertrophied and non-hypertrophied hearts during the period of ischemia is in line with the comparable, summated loss of degradation products of adenine nucleotides in both groups of hearts during the total reperfusion period, i.e. 2.20 and $2.24 \mu \mathrm{mol} . \mathrm{g}^{-1}$ wet weight, respectively. However, the pattern of release of the individual degradation products is different between both groups. The hypertrophied hearts release considerable higher amounts of uric acid than the non-hypertrophied hearts $(0.67$ and 0.45 $\mu \mathrm{mol} \cdot \mathrm{g}^{-1}$ wet weight, respectively), especially during the last 25 minutes of the reperfusion period. The non-hypertrophied hearts release more inosine ( 1.26 vs $0.92 \mu \mathrm{mol}^{-1}{ }^{-1}$ wet weight, respectively; NS). These observations suggest that the degradation towards uric acid is more pronounced in hypertrophied hearts. A definite explanation for this phenomenon is not at hand. A possible clue is given by the smaller release of degradation products from the hypertrophied hearts during the first 5 minutes of the reperfusion period. This retardation of wash-out may delay the passage of the initially formed degradation products from the intracellular into the vascular space. Since the enzymes nucleoside phosphorylase and xanthine oxydase are located at the endothelial site, an increased degradation of inosine into uric acid via hypoxanthine and xanthine can only be provoked when the passage is slow.

Otherwise, the more pronounced loss of uric acid from the hypertrophied hearts could also occur due to an increased enzyme activity of 
nucleoside phosphorylase in this type of beart, accelerating the turnover of inosine into hypoxanthine. To our knowlegde, differences in the activity of this enzyme has not been described. Moreover, at the end of the ischemic period, no significantly different amounts of degradation products are found in hypertrophied and control hearts. So, if this mechanism does play a role, enzyme activation must occur during the (initial) reperfusion period.

In both cases, however, the more pronounced degradation of inosine in the hypertrophied heart induces a temporarily higher flux through hypoxanthine and xanthine during the initial reperfusion period. Since under ischemic conditions xanthine dehydrogenase can be converted into xanthine oxydase (McCord and Roy, 1982), substantial amounts of superoxide and hydroxyl radicals can be produced during the (initial) reperfusion period. The excess formation of oxygen free radicals within the cardiac tissue is detrimental for the structure of the sarcolemma and other intracellular membrane structures (Rao et al., 1983). If this is the case, a more pronounced membrane damage might have occured in the hypertrophied hearts, presently studied.

\section{5.5. Effects of inadequate reperfusion}

Sarcolemma damage is leading to an increased loss of intracellular substances with high molecular weight, such as enzymes (Waldenström et al., 1977). In our experiments, lactate dehydrogenase is used as an indicator of membrane damage. Considerable higher enzyme activity is lost by the hypertrophied than by the control hearts throughout the 45 minutes period of reperfusion. This observation could support the above mentioned hypothesis of a more pronounced membrane damage in the hypertrophied hearts, for example, induced by oxygen free radicals. However, the interpretation of the enzyme activity loss is rather complicated. For instance, the slow release of enzyme activity during the initial reperfusion phase suggests a lack of adequate perfusion of some myocardial regions. If so, membrane damage could also be caused by a prolonged ischemia in certain regions of the heart, provoking an increased enzyme activity loss during the late reperfusion phase. Therefore, at this moment no decisive information can be given about the possible role of oxygen free radicals in the reperfused myocardium of the hypertrophied heart.

Increase in heart weight during the experiments is present in all groups of hearts, indicating edema formation to occur in both the hypertrophied and non-hypertrophied hearts. This edema formation is more pronounced in the reperfused than in the aerobically perfused hearts, suggesting that ischemia exaggerates the formation of tissue edema. Recently, the tissue water content in isolated rabbit hearts was found to increase by $20 \%$ during reperfusion after global ischemia, accompanied by an increase in coronary resistance of $26 \%$ as compared to the pre-ischemic 
values (Vogel et al., 1986). In our experiments on non-hypertrophied hearts, coronary resistance does not increase, as indicated by the comparable pre-ischemic and post-ischemic coronary flow values. In the hypertrophied heart, however, coronary resistance increases from 0.98 (preischemic; $t=45$ minutes) to $2.20 \mathrm{kPa}$.min.g.ml ${ }^{-1}$ (post-ischemic, $\mathrm{t}=90$ minutes), an increase of $124 \%$. These data could be explained by extensive edema formation in the hypertrophied heart. However, in reperfused hypertrophied as well as in control hearts an almost identical increase in heart weight is found. Besides, the water content of reperfused myocardial tissue of 7 hypertrophied and 3 control hearts, as determined by overnight drying, revealed almost identical values, i.e. 84.6 and $84.2 \%$, respectively. The tissue edema, occurring in the hypertrophied heart cannot be the sole explanation for the significantly increased coronary resistance. Other factors like the earlier mentioned lack of perfusion of some myocardial regions are likely to be involved.

\section{5.6. Effects of perfusion pressure}

It is not known to which extent the diminished tolerance of the hypertrophied heart to global ischemia can be associated with the relatively low perfusion pressure $(8.0 \mathrm{kPa})$ applied to the coronary arteries of these hearts during the initial reperfusion phase. Indeed, the data on coronary flow show that reperfusion of the tissue of the hypertrophied myocardium is hampered, which is confirmed by the slower release of lactate dehydrogenase and the significantly lower amounts of degradation products of adenine nucleotides lost during the first 5 minutes of the reperfusion period.

An eventual increase of the perfusion pressure will not only accelerate the readmission of oxygen to the ischemic tissue, but could also inhibit the retardation of the release of degradation products of adenine nucleotides, preventing the possible formation of excess oxygen free radicals. However, a too high perfusion pressure could also exaggerate the membrane damage by provoking excessive tissue edema. Therefore, the application of a higher coronary perfusion pressure is investigated in the study presented in chapter VII. 


\section{RECOVERY OF HYPERTROPHTED HEARTS OF 18 MONTHS OLD}

\section{SPONTANEOUSLY HYPERTENSIVE RATS DURING}

\section{REPERFUSION AT DIFFERENT PERFUSION PRESSURES AFTER}

\section{A PERIOD OF GLOBAL ISCHEMIA.}

\section{1. INTRODUCTION}

As described in chapter $V$, we investigated the effects of global normothermic ischemia on hypertrophied hearts of 16 months old spontaneously hypertensive rats (SHR). Based on results regarding hemodynamic variables, as cardiac output and the maximum positive first derivative of left ventricular pressure $\left(\mathrm{dP}_{\mathrm{w}} / \mathrm{dt}_{\mathrm{max}}\right)$, we concluded that hypertrophied hearts showed a diminished tolerance to ischemia as compared to non-hypertrophied control hearts. During the initial reperfusion phase coronary flow was found to be greatly depressed in the hypertrophied hearts. It is unknown whether this diminished reperfusion is associated with a reduced overall perfusion of the myocardium or with differences in perfusion between the various layers of the left ventricular wall. Besides, it is not known whether under these circumstances perfusion of the left ventricular wall of bypertrophied hearts is dependent on coronary perfusion pressure. The height of the coronary perfusion pressure during the initial reperfusion period could be of utmost importance, since high perfusion pressures could lead to intracellular edema (Vogel et al., 1986). Therefore, in humans undergoing open-heart surgery, a low coronary perfusion pressure (6.5 $\mathrm{kPa}$ ) has been advised during the initial reperfusion phase following aor ta-cross clamping (Buckberg, 1977).

The present study was conducted to investigate the effect of 45 minutes global, normothermic ischemia on the recovery of myocardial function of isolated hearts of 18 months old SHR's and age-matched, normotensive Wistar-Kyoto rats. The tolerance to ischemia was assessed 
by the restoration of hemodynamic function during reperfusion. To delineate the impairment of coronary perfusion in the post-ischemic hearts in more detail, transmural differences in flow were investigated with the use of radioactively labeled microspheres. Since underperfusion of the heart during reperfusion might exert detrimental effects on the metabolic state of the myocardium, the tissue content of creatine phosphate, adenine nucleotides like ATP, ADP and AMP and their degradation products adenosine, inosine, hypoxanthine and xanthine, was determined at the end of the reperfusion period. The tissue content of glycogen and lactate was also measured to obtain information about the effect on carbohydrate metabolism. Since Peyton and co-workers (1982) found that creatine phosphate and ATP levels were depressed in severely hypertrophied human hearts, and restoration of myocardial performance was related to the pre-ischemic ATP concentrations (Hearse et al., 1977; Peyton et al., 1982b), myocardial tissue content of creatine phosphate and adenine nucleotides was determined at the end of the pre-ischemic as well as at the end of the ischemic period. To quantify possible differences in the number of lethally damaged cells between hypertrophied and control hearts the release of lactate dehydrogenase was measured during reperfusion. To investigate the influence of perfusion pressure on myocardial flow and function under these circumstances, the hearts were perfused at two different diastolic aortic pressures, i.e. 8.0 and $13.3 \mathrm{kPa}$.

\section{2. METHODS}

\section{2.1. Experimental set-up}

The experiments were performed on isolated, ejecting hearts of 18 months old rats. The animals were randomly divided into 8 groups. Group WKYL $(n=7)$ and group WKYH $(n=6)$ consisted of hearts of control rats of the Wistar-Kyoto strain perfused at a diastolic aortic pressure of 8.0 and $13.3 \mathrm{kPa}$, respectively. Group SHRL $(\mathrm{n}=7)$ and group SHRH $(n=6)$ consisted of spontaneously hypertensive rat hearts, which were perfused at a similar low or high perfusion pressures as the corresponding WKY rat hearts. Additionally, groups of WKYL $(n=5)$, SHRL $(n=3)$, WKYH $(n=3)$ and SHRH $(n=4)$ consisted of hearts, the ventricles of which were partly freeze-clamped at the end of the pre-ischemic period and partly at the end of the ischemic period for biochemical determinations.

The rats were anesthetized with ether. After thoracotomy the hearts were removed from the body and immersed in ice-chilled Tyrode's solution. Remnant lung tissue and fat were removed. The hearts were weighed and attached to the perfusion apparatus as described in chapter II. Retrograde perfusion was started at a pressure of $8.0 \mathrm{kPa}$ im- 
mediately after attachment of the heart to the aortic cannula, using a well-oxygenated, modified Tyrode"s solution $\left(\mathrm{PO}_{2}>80 \mathrm{kPa}\right)$. The perfusion medium contained (in mmol.1-1): $\mathrm{NaCl}(130.0), \mathrm{KCl}(5.6), \mathrm{CaCl}_{2}$ (2.2), $\mathrm{MgCl}_{2}$ (1.0), $\mathrm{NaH}_{2} \mathrm{PO}_{4}$ (1.2) and $\mathrm{NaHCO}_{3}$ (28.6). As substrates, $\mathbb{D}(+)$ glucose (11.1) and pyruvate (5.0) were added. The $\mathrm{pH}$ of this solution ranged between 7.35 and 7.45. The electrogram, which was derived from two small electrodes attached to the left ventricular wall, and the hemodynamic variables were fed into a home-made pre-processor connected to an Apple Ile microcomputer, allowing the on-line calculation of heart rate, systolic and diastolic left ventricular and aortic pressures, the maximum positive $d P_{1 v} / d t_{m a x}$ and of aortic flow. This automation system has been described in detail in chapter III.

A second cannula was connected to the left atrium. The filling pressure was set at $1.0 \mathrm{kPa}$. Retrograde perfusion was maintained during 10 minutes. Then the left atrial cannula was opened and antegrade perfusion was started for a period of 30 minutes. Heart rate was kept constant at 300 beats.min ${ }^{-1}$, using bipolar stimulation via small platinum stimulation electrodes, attached to the right atrial wall. During this preischemic period, the hemodynamic variables were continuously computed. Depending on the protocol diastolic aortic pressure was kept at 8.0 or $13.3 \mathrm{kPa}$. Under the described conditions, the rat hearts developed left ventricular systolic pressures, reaching maximal values of $2.5 \mathrm{kPa}$ above the diastolic aortic pressure, implicating that mean coronary perfusion pressure was about $0.8 \mathrm{kPa}$ higher than the mentioned diastolic aortic pressure.

The coronary effluent was collected to measure the release of lactate, the breakdown products of adenine nucleotides, such as adenosine, inosine, hypoxanthine, xanthine and uric acid, and the activity of lactate dehydrogenase (LDH). At the end of the pre-ischemic period in hearts which had to reperfused after the period of global ischemia, radioactively labeled microspheres were injected to determine the coronary flow distribution in the left ventricular wall (see section VII 2.2). In these hearts, global, normothermic ischemia was induced by total cessation of flow to the heart for a period of 45 minutes. In the other hearts, at the end of the pre-ischemic period, the lower part of the left ventricle was cut from the heart and immediately freeze-clamped between pre-cooled Wollenberger clamps. In the remaining part of these hearts, global, normothermic ischemia was induced. At the end of the 45 minutes period of ischemia, the remaining ventricular tissue was separated from the atria and also freeze-clamped. In the intact hearts, the ischemic period was initially followed by a retrograde perfusion period of 15 minutes. The hearts were not stimulated during the period of ischemia and during the initial 10 minutes of the reperfusion phase. Stimulation was restarted at a rate of 300 beats.min ${ }^{-1}$ thereafter. Following the retrograde perfusion period, hearts were allowed to eject under the same circumstances as during the pre-ischemic period. The an- 
tegrade perfusion period lasted 30 minutes, so that the complete reperfusion time amounted 45 minutes. At the beginning and the end of the antegrade reperfusion phase, radioactive microspheres were injected (see section VII.2.2). The coronary effluent was collected for biochemical assay (see chapter II) as during the pre-ischemic period. At the end of the reperfusion phase, immediately after the injection of the microspheres, a transmural biopsy of the left ventricular wall was taken with an electrically driven drillbore and was immediately immersed in liquid nitrogen and stored within the drills at $-80^{\circ} \mathrm{C}$. The weight of the biopsies ranged between 20 and $25 \mathrm{mg}$ wet weight. Tissue contents of biochemical variables were determined as described in chapter II. At the end of the reperfusion period, the hearts were perfused with $2.5 \%$ glutaraldehyde during 5 minutes to facilitate the cutting procedure of the myocardial tissue for microsphere determination.

\section{2.2. Regional myocardial perfusion}

Radioactive microspheres (NEN, about $15 \mu \mathrm{m}$ in diameter) were used 10 measure the coronary flow distribution in the left ventricular wall. The microspheres were labeled with ${ }^{141} \mathrm{Ce},{ }^{103} \mathrm{Ru}$ or ${ }^{113} \mathrm{Sn}$, and suspended in $10 \%$ Dextran and $0.05 \%$ polysorbate 80 (Tween 80 , Sigma Chem). Before use the microsphere batches were routinely checked on purity, specific activity and integrity of the spheres, leakage of the nuclides from the spheres, and diameter distribution of the beads as described earlier (Reneman et al., 1975; Heyman et al., 1977).

The original suspension was diluted to a final concentration of $5.10^{4}$ microspheres.m l-1 $^{-1}$. This suspension was mixed by agitation and subsequently sonicated during 20 minutes before injection. Just prior to injection, the perfusion of the heart was turned on retrograde mode. Within the following minute the microspheres were injected, as a bolus, into the aortic cannula to be distributed in the coronary system. The total amount of microspheres injected was adjusted to each heart, so that an average concentration of 5000 microspheres per gram heart tissue was reached. Coronary effluent was sampled to measure loss of microspheres, if any, from the coronary system. At the end of the reperfusion phase, the hearts were weighed again and subsequently divided into 5 horizontal slices as shown in Figure VII. 1, i.e. the atria, 3 slices of both the left and right ventricles and the apex. The 3 ventricular slices were divided as follows: the right ventricular wall was separated from the left ventricle; thereafter the left ventricular slices were divided into 4 segments (anterior, lateral, posterior and septal), each of which was divided into an endocardial and an epicardial part. In this way, each of the 3 left ventricular slices was cut into 8 tissue samples, which were weighed and stored in a $2.5 \%$ glutaraldehyde fixation buffer. Since the apex sample was rather small, the whole slice was cut into an endocardial and an epicardial part in a circular way, which resulted in 2 tissue samples. In total 26 tissue samples were 


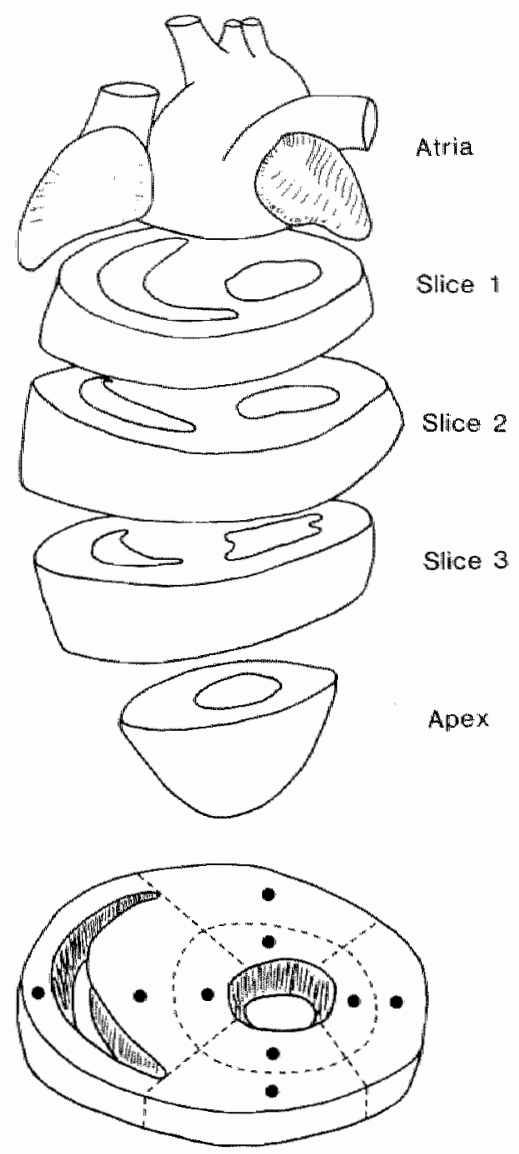

Figure VII. 1 Cutting procedure of the isolated rat heart at the end of the reperfusion period for counting of radioactive microsphere content. For more details see text.

counted from each left ventricle; the samples from the right ventricle were counted as a whole, as were the atria. The radioactivity levels of the different tissue samples were determined using a Packard MultiChannel Analyzer, as previously described in detail by Prinzen and coworkers (1981). Since no reference technique could be used, we were unable to calculate directly the absolute flow values from the radioactivity of each nuclide in the tissue samples. Therefore, the radioactivity of each nuclide in each tissue sample was related to the radioactivity of that nuclide in the total heart, including the right ventricle and the atria. By using the coronary flow values, as determined at the moment 
of injection of the specific microspheres, it was possible to calculate the flow in each tissue sample, applying the following formula:

$$
q_{1}=\frac{Q \cdot a_{1}}{W_{11} \cdot \Sigma_{1 a_{1}}^{n_{2}}}
$$

in which

$$
\begin{array}{ll}
q_{1} & =\text { flow in tissue sample } \mathrm{i}\left(\mathrm{mll} \cdot \mathrm{min}^{-1} \cdot \mathrm{g}^{-1}\right) \\
Q & =\text { coronary flow }\left(\mathrm{ml} \cdot \mathrm{min}^{-1}\right) \\
a_{1} & =\text { radioactivity in tissue sample } \mathrm{i}(\mathrm{cpm}) \\
\Sigma a_{1} & =\text { radioactivity in the total heart }(\mathrm{cpm}) \\
\mathrm{w}_{1} & =\text { weight of tissue sample } \mathrm{i}(\mathrm{gram}) \\
\mathrm{n} & =\text { number of pieces cut from one heart }
\end{array}
$$

\section{3. STATISTICS}

Differences between the values of the various variables in the WKY and SHR groups were evaluated for statistical significance using the Mann-Whitney U-test. Differences between the pre-ischemic and postischemic values within the groups were evaluated for statistical difference using Wilcoxon's matched-pairs signed-ranks test. P-values smaller than or equal to 0.05 were considered to be statistically significant.

\section{4. RESULTS}

The values of body and heart weights of all rats in the four groups are presented in Table VII. 1 . No significant differences were observed within each group between hearts, used for reperfusion experiments and hearts, freeze-clamped at the end of the pre-ischemic and ischemic period. Before the experiments the heart weight values were significantly higher in the SHR groups than in the corresponding WKY groups. Despite significantly higher body weight values in the WKY groups, the values for the ratio heart weight to body weight were significantly lower in the WKY groups as compared to the SHR groups.

At the end of the experiments, the heart weights in the WKY groups tended to increase, while those in the SHR groups tended to decrease, so that the initial significant differences between the control and hypertrophied heart weights disappeared. 
Table VI. 1 Heart weight values at the start and the end of the experiment, body weight and the ratio of heart weight at the start of the experiment and body weight (HW/BW.10-3) in WKY and $S H R$ rats.

\begin{tabular}{|c|c|c|c|c|}
\hline & \multicolumn{2}{|c|}{$\begin{array}{c}\text { Heart weight }(g) \\
\text { pre post }\end{array}$} & Body weight (g) & $\mathrm{HW} / \mathrm{BW} \cdot 10^{-2}$ \\
\hline WKYL & $\begin{array}{c}1.9 .5 \\
\text { 1. } 87-2.04 \\
(n=12)\end{array}$ & $\begin{array}{c}2.30 \\
2.03-2.41 \\
(n=7)\end{array}$ & $\begin{array}{c}504 \\
465-520\end{array}$ & $\begin{array}{c}0.40 \\
0.39-0.43\end{array}$ \\
\hline SHRL & $\begin{array}{c}2.55 \\
2.42-3.02 \\
(n=10)\end{array}$ & $\begin{array}{c}2.34 \\
2.30-3.16 \\
(n=7)\end{array}$ & $\begin{array}{c}442 \\
420-453\end{array}$ & $\begin{array}{c}0.57 \\
0.55=0.71\end{array}$ \\
\hline WKYH & $\begin{array}{l}1.93^{\star} \\
1.87-2.15 \\
(n=9)\end{array}$ & $\begin{array}{c}2.66 \\
2.27-3.13 \\
(n=6)\end{array}$ & $\begin{array}{c}507 \\
460-563\end{array}$ & $\begin{array}{c}0.40^{\star} \\
0.36-0.42\end{array}$ \\
\hline SHRH & $\begin{array}{c}2.78 \\
2.48-2.90 \\
(n=10)\end{array}$ & $\begin{array}{l}2.55 \\
2.29-4,3.3 \\
(n=6)\end{array}$ & $\begin{array}{c}44.1 \\
370-490\end{array}$ & $\begin{array}{c}0.64 \\
0.59-0.69\end{array}$ \\
\hline
\end{tabular}

Pre and post: heart weight at the beginning and the end of the perfusion experiments. WKYL and SHRL refer to hearts perfused at $8.0 \mathrm{kPa}$, WKYH and SHRH to hearts perfused at $13.3 \mathrm{kPa}$. Data are presented as median values and $95 \%$ confidence limits. $\star$ : significantly different from the the corresponding SHR group values; - : significantly different from the (post) walues in the hearts of rats of the same strain, perfused at $13.3 \mathrm{kPa}(\rho<0.05)$.

\section{4.1. Hemodynamics}

The hemodynamic data in the $8.0 \mathrm{kPa}$ groups are depicted in Figure VII. 2. Only the data for the reperfused groups are shown. During the pre-ischemic period, $\mathrm{dP}_{1 w} / \mathrm{dt}_{\mathrm{max}}$ and cardiac output reached significantly higher values in the WKYL group than in the SHRL group. Thus at the same heart rate, the hypertrophied hearts showed a lower myocardial pump function than the control hearts. In an absolute sense coronary flow (see Table VII. 2) was comparable in both groups reaching values between 20 and $22 \mathrm{ml} \cdot \mathrm{min}^{-1}$ during the ejecting phase. Expressed as flow per gram of heart weight, however, hypertrophied hearts had a significantly lower coronary flow than the control hearts.

During reperfusion, restoration of myocardial pump function was completely absent in the SHRL group. Except for one heart, there was 
no restoration of normal electrical and, consequently mechanical activity. In two hearts, short periods of normal sinus rhythm were interrupted by outbursts of ventricular fibrillation. In the 4 remaining hearts long

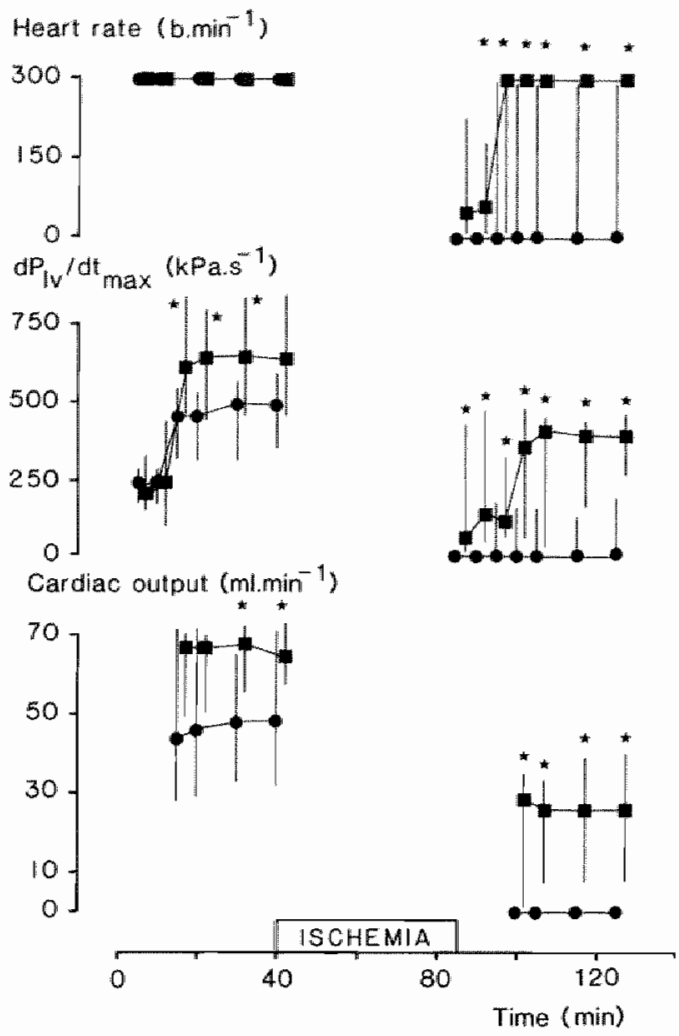

Figure VII. 2 Hemodynamic data in isolated, ejecting hearts of WKYL $(\mathbf{\square} ; n=7)$ and SHRL $(0 ; n=7)$, perfused at a diastolic aortic pressure of $8.0 \mathrm{KPa}$ before and after 45 minutes global ischemia. The data are presented as median values and

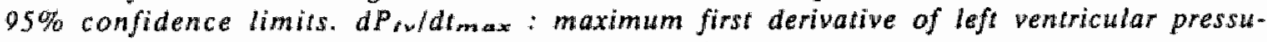
re. $\star$ : significantly higher in the WKYL group $(p<0.05)$.

periods of ventricular fibrillation were alternated with ventricular tachycardia. The coronary flow in all hearts of this group was severely depressed (Table VII. 2). In contrast, in the WKYL group myocardial function was partially restored in all hearts (Figure VII. 2). The hearts started to beat spontaneously within 5 minutes after restoration of flow. Cardiac stimulation was possible after 10 minutes of reperfusion and readmittance of preload resulted in restoration of cardiac output of $40 \%$ of the 
pre-ischemic value (median value). Coronary flow was restored to preischemic levels (Table VII. 2). In the initial reperfusion phase reactive hyperemia was absent, in both the WKYL and the SHRL hearts.

Table VIT. 2 Coronary flow in WKY and SHR hearts during the pre-ischemic and reperfusion periods, following 45 minutes of global ischemia.

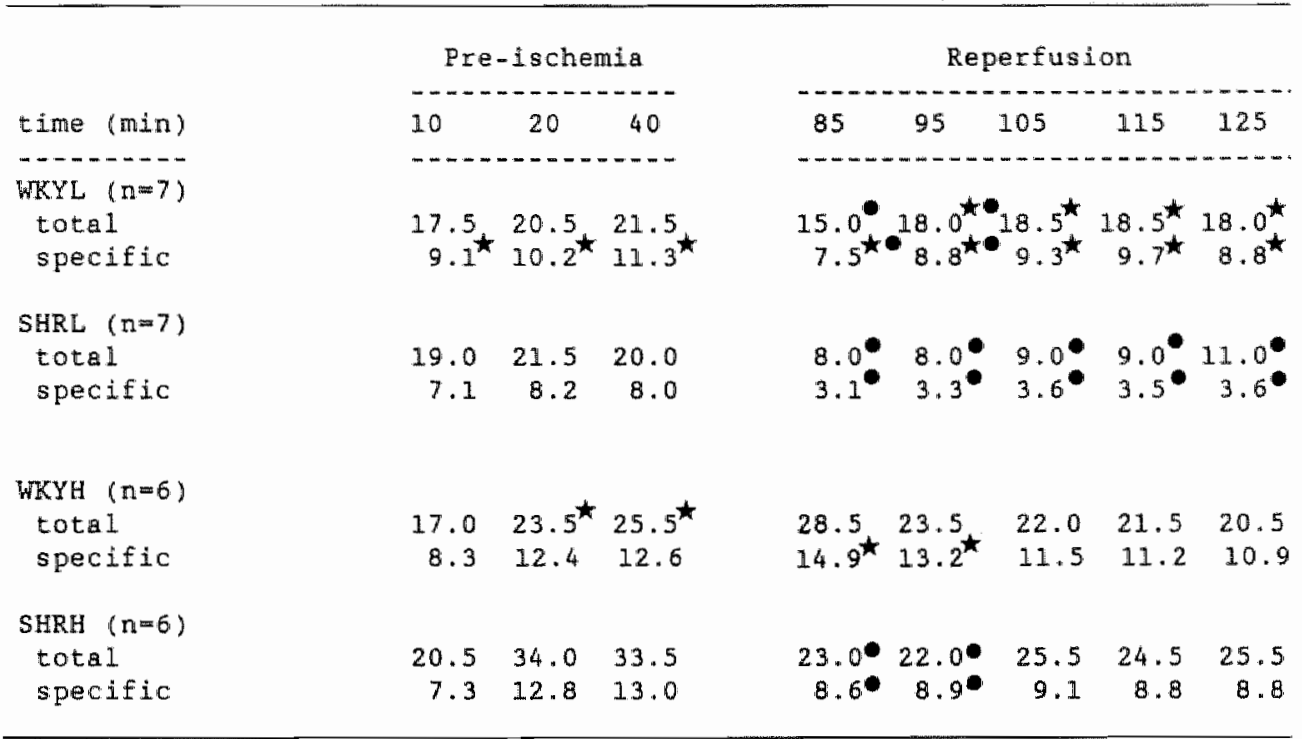

Total values are presented in ml.min'-; specific values are normalized on gram wet weight (ml.min- $\left.\mathrm{g}^{-2}\right)$. These walues are related to the heart weight values obtained at the beginning of the experiments. Data are presented as median values. $\star$ : significantly disferent from the walues in the corresponding SHR group; $\bullet$ significanly differen from the pre-ischemic waluse at $t=40$ minutes $(p<0.05)$.

The hemodynamic performance of hearts perfused at $13.3 \mathrm{kPa}$ is presented in Figure VII. 3 and Table VII. 2. During the pre-ischemic period, no significant differences were observed between the hemodynamic variables in the SHRH and WKYH groups, except for the coronary flow (Table VII. 2) which reached higher absolute values in the SHRH group than in the WKYH group. When normalized for heart weight, almost identical values were found in both groups. 


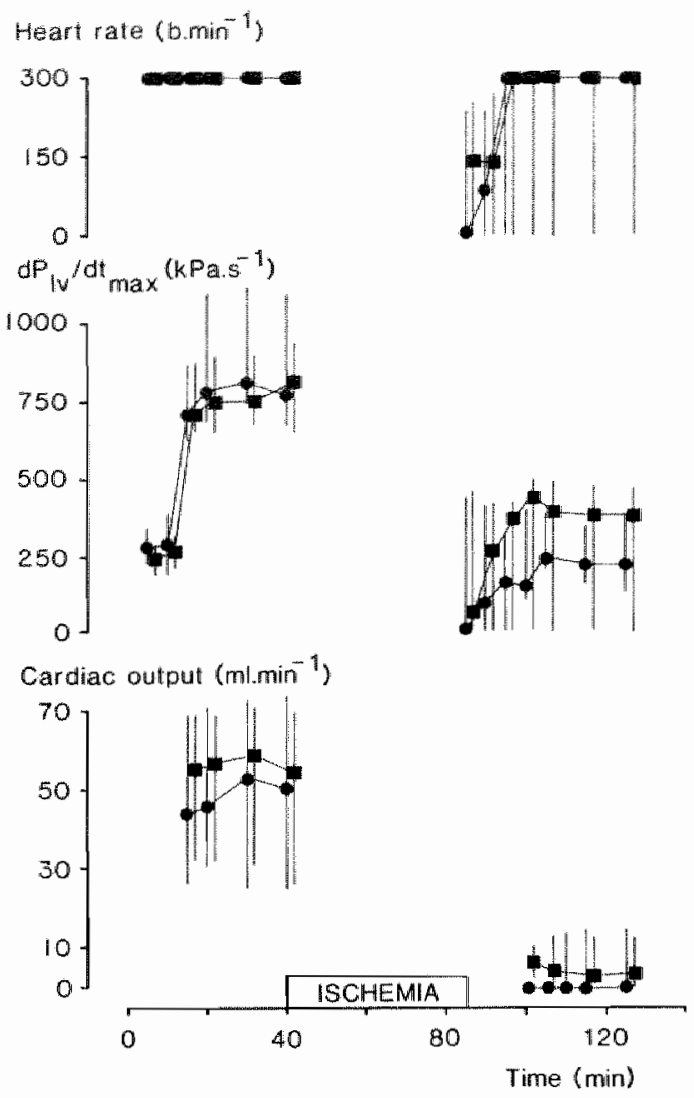

Figure VII. 3 Hemodynamic dola in isolated, ejecting hearts of WKYH $(\square ; n=6)$ and SHRH ( ; $n=6)$, perfused at a diastolic aortic pressure of $13.3 \mathrm{kPa}$, before and after 45 minutes global ischemia. The data are presented as median values and $95 \%$ confidence limils. dP.wldimax : maximum first derivative of left ventricular pressure.

During reperfusion, normal electrical activity was present in the hearts of both groups within the first 5 minutes, followed by a restoration of mechanical activity. Short periods of ventricular fibrillation were observed in only 2 hearts of the SHRH group. In both groups $\mathrm{dP}_{1 \mathrm{v}} / \mathrm{dt}_{\max }$ was restored, albeit to a limited extent. This restoration tended to be better in the WKYH hearts but did not result in cardiac output of any importance. Coronary flow was restored in the WKYH 
hearts to a comparable level as during the pre-ischemic period (Table VII. 2). Post-ischemic coronary flow was significantly better in the SHRH than in the SHRL hearts. Restoration of flow in the SHRH group was in the order of $70 \%$ as compared to their corresponding pre-ischemic walues.

\section{4.2. Regional myocardial flow}

The regional myocardial flow values in the WKY and SHR groups at a perfusion pressure of $8.0 \mathrm{kPa}$ are depicted in Figure VII. 4. Since in both groups no systematic differences were found between the endocardial flow values as well as the epicardial flow values in the 4 segments of each slice, the data in the endocardial and epicardial layers were pooled for each slice of the left ventricle. During the pre-ischemic period, in the WKYL hearts endocardial flow was slightly, but not significantly higher than the epicardial flow in 3 out of 4 slices of the left ventricular wall. In contrast, in the hypertrophied hearts significantly higher epicardial than endocardial values were found in 2 out of 4 slices. As a consequence the endocardial/epicardial flow rations were significantly higher in the WKYL hearts than in the SHRL hearts in 3 out of 4 slices (Table VII. 3). After 15 and 45 minutes of reperfusion of the control hearts, no significant differences were observed as compared with the pre-ischemic period, either in the epicardium or in the endocardium. In the SHRL hearts, myocardial flow was substantially diminished during reperfusion. The remaining coronary flow was almost completely redistributed towards the left ventricular epicardial layers. In the second and third slice endocardial flow was practically absent during the reperfusion period. In all 4 slices of the left ventricle the endocardial/epicardial flow ratio's were significantly higher in the control hearts than in the hypertrophied hearts during the reperfusion period (Table VII. 3).

The flow distributions in the groups perfused at $13.3 \mathrm{kPa}$ are presented in Figure VII. 5. Like in the $8.0 \mathrm{kPa}$ group, in the control WKYH hearts pre-ischemic flow tended to be higher in the endocardium than in the epicardium in 3 out of 4 slices. In contrast to the $8.0 \mathrm{kPa}$ group, in the $13.3 \mathrm{kPa}$ group of hypertrophied hearts higher endocardial than epicardial flow values were found in the pre-ischemic period in 3 out of 4 slices. Besides, the flow values were comparable with those in the WKYH hearts. No significant changes were noted in both ventricular layers of the WKYH hearts during the reperfusion phase as compared with the pre-ischemic values. In the SHRH epicardial flow during reperfusion was completely restored and reached pre-ischemic values. However, despite a pronounced improved endocardial flow, levels were still significantly lower than epicardial flows in all ventricular layers. At the end of the reperfusion phase, significantly lower endocardial flows were present in 3 out of 4 slices as compared to the end- 
reperfusion values in the control hearts.

This resulted in significantly lower endocardial/epicardial flow ratio's in 3 out of 4 slices in the SHRH hearts (Table VII. 3). Flow in the endocardial layers of the SHR hearts reperfused at $13.3 \mathrm{kPa}$ was found to be $43 \%$ (median value) of the pre-ischemic values.

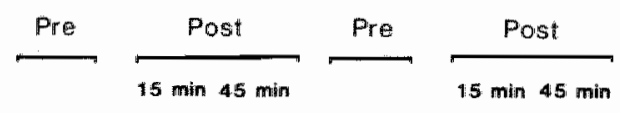

Flow (mi.min $\left.{ }^{-1} \cdot g^{-1} w w\right)$
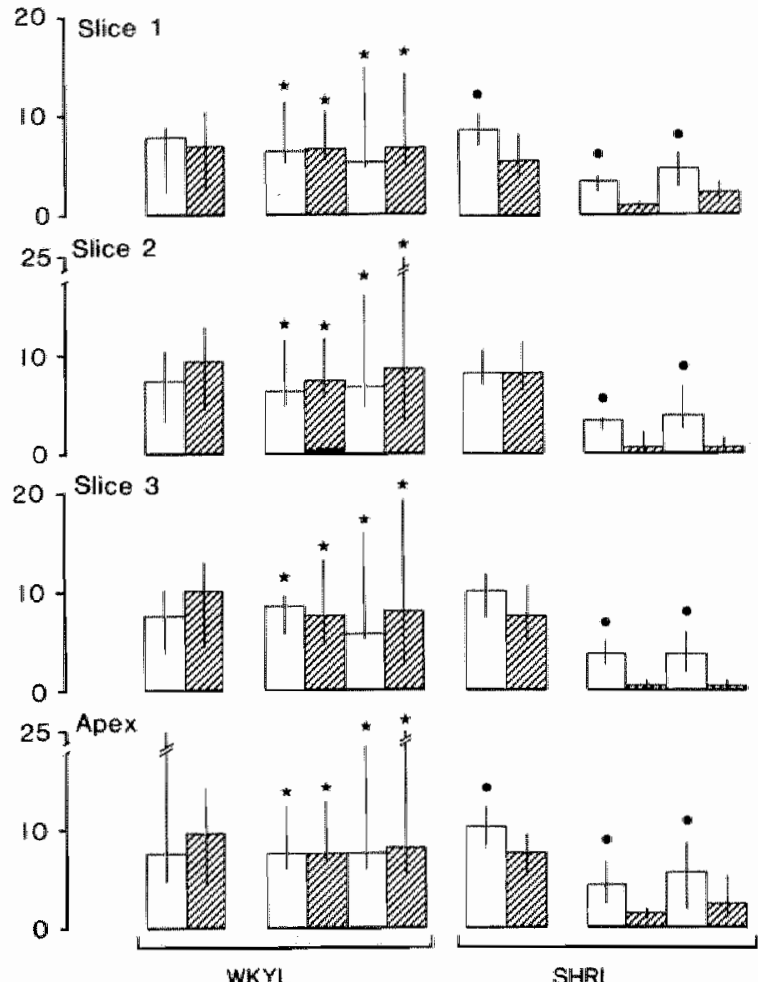

Figure VII. 4 Regional myocardial flow values in isolated, ejecting hearts of WKYL

(left panel, $n=7$ ) and SHRL (right panel, $n=7$ ), perfused at a diastolic aortic pressure of $8.0 \mathrm{kPa}$ before and after 45 minutes global ischemia. Slice 1 is close to the base of the heart. Data are presented as median values and $95 \%$ confidence limits. Open bars : epicardial flow; hatched bars : endocardial flow. $\star$ : significantly higher than the corresponding values in the SHR group; $\bullet$ : significant difference between epicardial and endocardial flow walues $(p<0.05)$. 


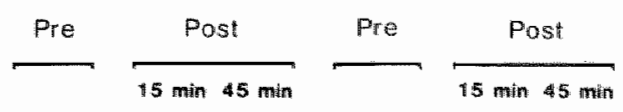

Flow (ml. $\left.\min ^{-1} \cdot g^{-1} w w\right)$
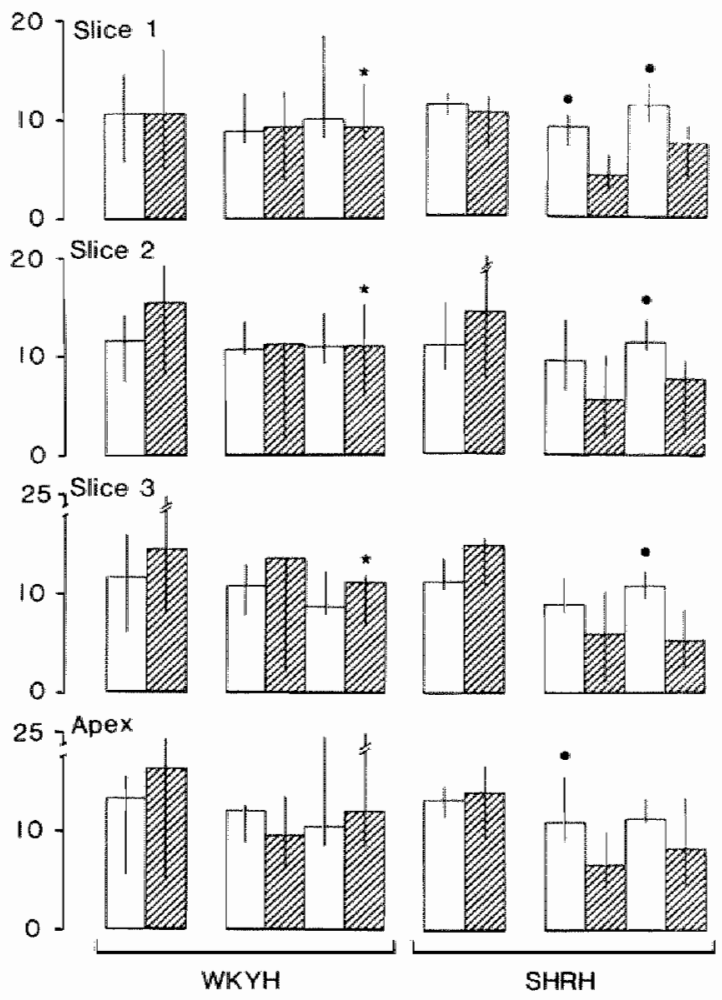

Figure VIS. S Regional myocardial flow values in isalated, ejecting hearts of WKYH (left panel, $n=6$ ) and SHRH (right panel, $n=6$ ), perfused at a diastolic aoric pressure of $13.3 \mathrm{kPa}$ before and after 45 minutes global ischemia. Slice $I$ is close to the base of the heart. Data are presented as median values and $95 \%$ confidence limirs. Open bars: epicardial flow; hatched bars : endocardial flow. $\$$ significantly higher than the corresponding values in the SHR group; : significant difference between epicardial and endocardial flow values $(p<0.05)$

No significant radioactivity was found in the coronary outflow during the first 5 minutes after the injection of the microspheres in all hearts. 
Table VII. 3 Endocardiallepicardial flow ratio's aluring the pre-ischemic period (Pre), affer 15 minutes (Rep 15) and 45 minutes reperfusion (Rep 45) following 45 minutes glabal ischemia in WKY and SHR hearts.

\begin{tabular}{|c|c|c|c|c|}
\hline & & Pre & Rep 15 & Rep 45 \\
\hline \multirow[t]{7}{*}{ WKYL $(n=7)$} & $\$ 1$ & $1.09^{\star}$ & $0.89^{\star}$ & $0.79 \star$ \\
\hline & $\mathrm{S2}$ & $\begin{array}{c}0.79-1.33 \\
1.37\end{array}$ & $\begin{array}{c}0.81-1.33 \\
1.07\end{array}$ & $\begin{array}{c}0.72-1.43 \\
1.31\end{array}$ \\
\hline & & $1.27-1.46$ & $0.66-1.61$ & $0.60-1.48$ \\
\hline & 53 & $1.25^{\star}$ & 1. $09 \star$ & $1.12^{\star}$ \\
\hline & & $1.02-1.40$ & $0.59-1.39$ & $0.41-1.39$ \\
\hline & 54 & 0.94 & $1.03^{\star}$ & $1.11 \star$ \\
\hline & & $0.40-1.95$ & $0.75-1.11$ & $0.56-1.24$ \\
\hline \multirow[t]{8}{*}{ SHRL $(n=7)$} & $\$ 1$ & 0.66 & 0.27 & 0.52 \\
\hline & & $0.54-1.00$ & $0.19-0.40$ & $0.26-0.68$ \\
\hline & $\$ 2$ & 1.11 & 0.11 & 0.09 \\
\hline & & $0.95-1.43$ & $0.02-0.70$ & $0.02-0.54$ \\
\hline & 53 & 0.77 & 0.07 & 0.09 \\
\hline & & $0.63-0.94$ & $0.01-0.31$ & $0.02-0.30$ \\
\hline & 54 & 0.76 & 0.39 & 0.36 \\
\hline & & $0.52-0.94$ & $0.31-0.82$ & $0.20-1.28$ \\
\hline \multirow[t]{8}{*}{ WKYH $(n=6)$} & 51 & 0.96 & 1,08 & 0.83 \\
\hline & & $0.76-1.30$ & $0.43-1.20$ & D. $57-1.16$ \\
\hline & \$2 & 1.44 & 0.85 & 0.88 \\
\hline & & $0.98-1.53$ & $0.16-1.18$ & $0.64-1.46$ \\
\hline & s3 & 1.23 & 0.90 & $1.08^{\star}$ \\
\hline & & $1.13-1.47$ & $0.19-2.03$ & $0.58-1.93$ \\
\hline & 54 & $1.22^{\star}$ & 1.10 & $1.01 \star$ \\
\hline & & $0.99-1.26$ & $0.51-1.13$ & $0.67-1.67$ \\
\hline \multirow[t]{8}{*}{ SHRH $(n=6)$} & S1 & 0.89 & 0.48 & 0.66 \\
\hline & & $0.62-1.10$ & $0.35-0.68$ & $0.40-0.81$ \\
\hline & s2 & 1.13 & 0.45 & 0.59 \\
\hline & & $0.92-1.53$ & $0.21-1.43$ & $0.17=0.84$ \\
\hline & S3 & 1.06 & 0.53 & 0.53 \\
\hline & & $1.02-1.37$ & $0.12-1.08$ & $0.52-0.78$ \\
\hline & 84 & 0.97 & 0.53 & 0.66 \\
\hline & & $0.84-1.18$ & $0.42-0.94$ & $0.40-1.23$ \\
\hline
\end{tabular}

WKYL and SHRL refer to hearts perfused at $8.0 \mathrm{kPa}, W K Y H$ and $S H R H$ to hearts perfused at $13.3 \mathrm{kPa}$. S1, S2, S3 and $S 4$ (apex) refer to the 4 slices of the left veniricle from the base to the apex. Data are presented as median values and $95 \%$ confidence limiss. $\star$ : significantly different from the walues in the corresponding SHR group $(p<0.05)$. 


\section{4.3. Biochemical data}

Findings in coronary effuent

Very low amounts of LDH were lost from the hearts in the various groups during the pre-ischemic period (Figure VII. 6). The highest value of $\mathrm{LDH}$ released during the whole pre-ischemic period was found in the WKYH group, i.e. 2.49 U.g. ${ }^{-1}$ wet weight.

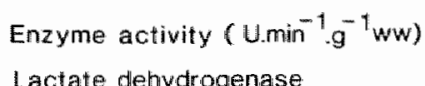

Lactate dehydrogenase

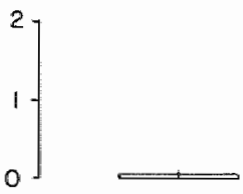

WKYL
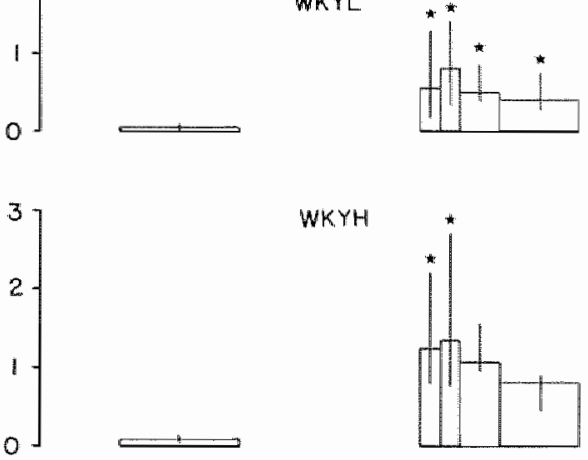

WKYH
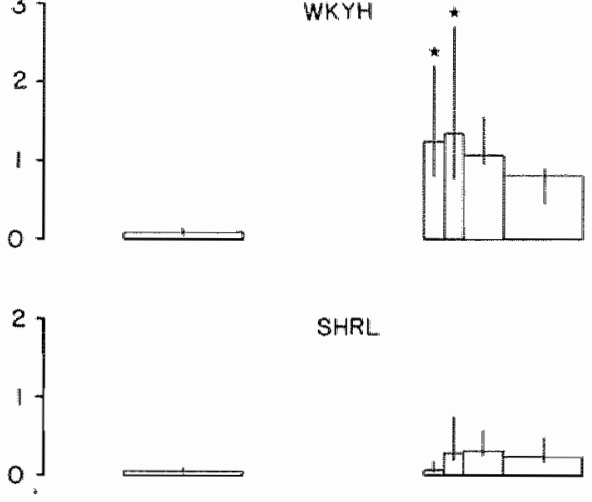

SHRL
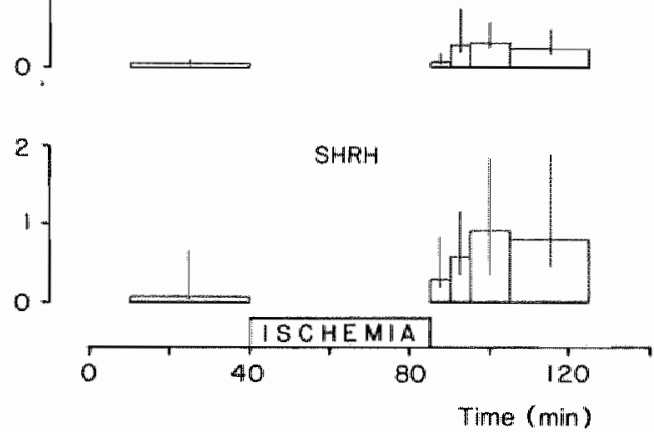

Figure VIJ. 6 The release of lactate dehydrogenase in isolated, ejecting hears of WKYL $(n=7), W K Y H(n=6)$, SHRL $(n=7)$ and SHRH $(n=6)$, before and after 45 minures global ischemia. Data are presented as median values and $95 \%$ confidence limits. : significantly higher than in the corresponding SHR group during the same time interval $(p<0,05)$. 
During the reperfusion phase, a marked difference in enzyme release was observed between control and hypertrophied groups, especially in the $8.0 \mathrm{kPa}$ groups. While in both WKY groups the enzyme release was maximal within 10 minutes of reperfusion, the maximal release in the SHR hearts was delayed and reached peak values after 15 minutes (Figure VII. 6). Throughout the 45 minutes reperfusion at $8.0 \mathrm{kPa}$, the WKYL hearts released 20.2 U LDH.g ${ }^{-1}$ wet weight, while the SHRL

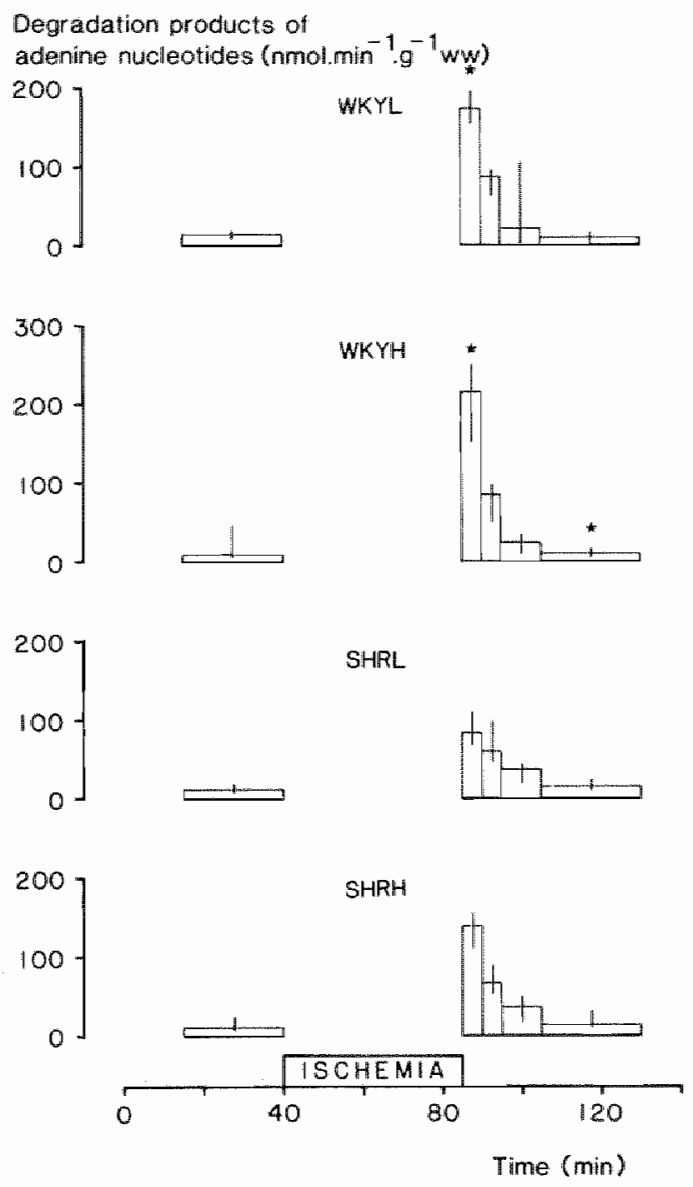

Figure $V I_{n} 7$ Release of degradation products of adenine nucleotides (sum of adenosine, inosine, hypoxanthine, xanthine and uric acid) in isolated, ejecting hearls of WKYL $(n=7)$, WKYH $(n=6)$, SHRL $(n=7)$ and SHRH $(n=6)$, before and after 45 minutes global ischemia. Values are presented as median values and $95 \%$ confidence limits. $\star$ : significantly different from the walues in the corresponding $S H R$ group during the same time interval $(p<0.05)$. 
hearts released only $9.0 \mathrm{U} \cdot \mathrm{g}^{-1}$ wet weight $(p<0.05)$. The hearts perfused at $13.3 \mathrm{kPa}$, released more enzyme than the hearts perfused at a lower pressure and the differences between WKY'S and SHR's disappeared; the WKYH released 29.9 U.g ${ }^{-1}$ wet weight, while the SHRH released 24.6 U. ${ }^{-1}$ wet weight throughout the reperfusion period (a non-significant difference).

During the 30 minutes pre-ischemic period, the SHRL hearts released almost twice as much lactate as the WKYL, i.e. 88.1 versus 52.4 $\mu$ mol.g ${ }^{-1}$ wet weight $(p<0.05)$. During this period, identical amounts were released by the WKYH and the SHRH hearts, i.e. $62.4 \mu \mathrm{mol} . \mathrm{g}^{-1}$ wet weight. An increased release of lactate was observed in all 4 groups during the first 10 minutes of reperfusion. During the 45 minutes of reperfusion, significantly more lactate was released by the WKYL hearts than by the SHRL hearts (in total 106.5 vs $83.1 \mu \mathrm{mol} . \mathrm{g}^{-1}$ wet weight; $\mathrm{p}<0.05$ ). In the $13.3 \mathrm{kPa}$ groups, however, the WKYH released less lactate than the SHRH hearts (in total 94.4 vs $110.4 \mu \mathrm{mol} . \mathrm{g}^{-1}$ wet weight; $\mathrm{p}<0.05$ ).

The total release of breakdown products of adenine nucleotides (the sum of adenosine, inosine, hypoxanthine, xanthine and uric acid), is shown in Figure VII. 7. During the first 5 minutes of the reperfusion phase significantly more degradation products were released from the WKY than from the SHR hearts at both perfusion pressures, tending to a more pronounced total release in the WKY hearts during the 45 minutes of reperfusion. These differences, however, did not reach the level of significance. In Table VII. 4 the detailed results of the different degradation products of adenine nucleotides are presented. The more pronounced release in the WKY than in the SHR groups can be largely explained by the increased amounts of inosine released in both WKY groups.

Biochemical findings in myocardial tissue

Hypertrophied hearts perfused at $8.0 \mathrm{kPa}$ showed significantly lower creatine phosphate, ATP and ADP levels at the end of the reperfusion period than the corresponding WKYL hearts, while the AMP levels were significantly higher in the hypertrophied SHRL hearts (Table VII. 5). The sum of ATP, ADP and AMP was also lower in the SHRL than in the WKYL hearts. Consequently, the energy charge was very low in the SHRL's, i.e. 0.49. The tissue levels of lactate and inorganic phosphate were high, while the glycogen levels were as low as 21.0 $\mu \mathrm{mol}^{-1}$ dry weight.

At the end of the reperfusion period, no significant differences were observed between the biochemical substances in the myocardial 
The tolal amounts of degradation products of adenine nucleotides (nmolg $\mathrm{g}^{-1}$ weight) released into the coronary effluent before (PRE; 30 minutes) and afrer (POST; 45 minutes) a period of 45 minutes global ischemia in WKY and SHR heants.

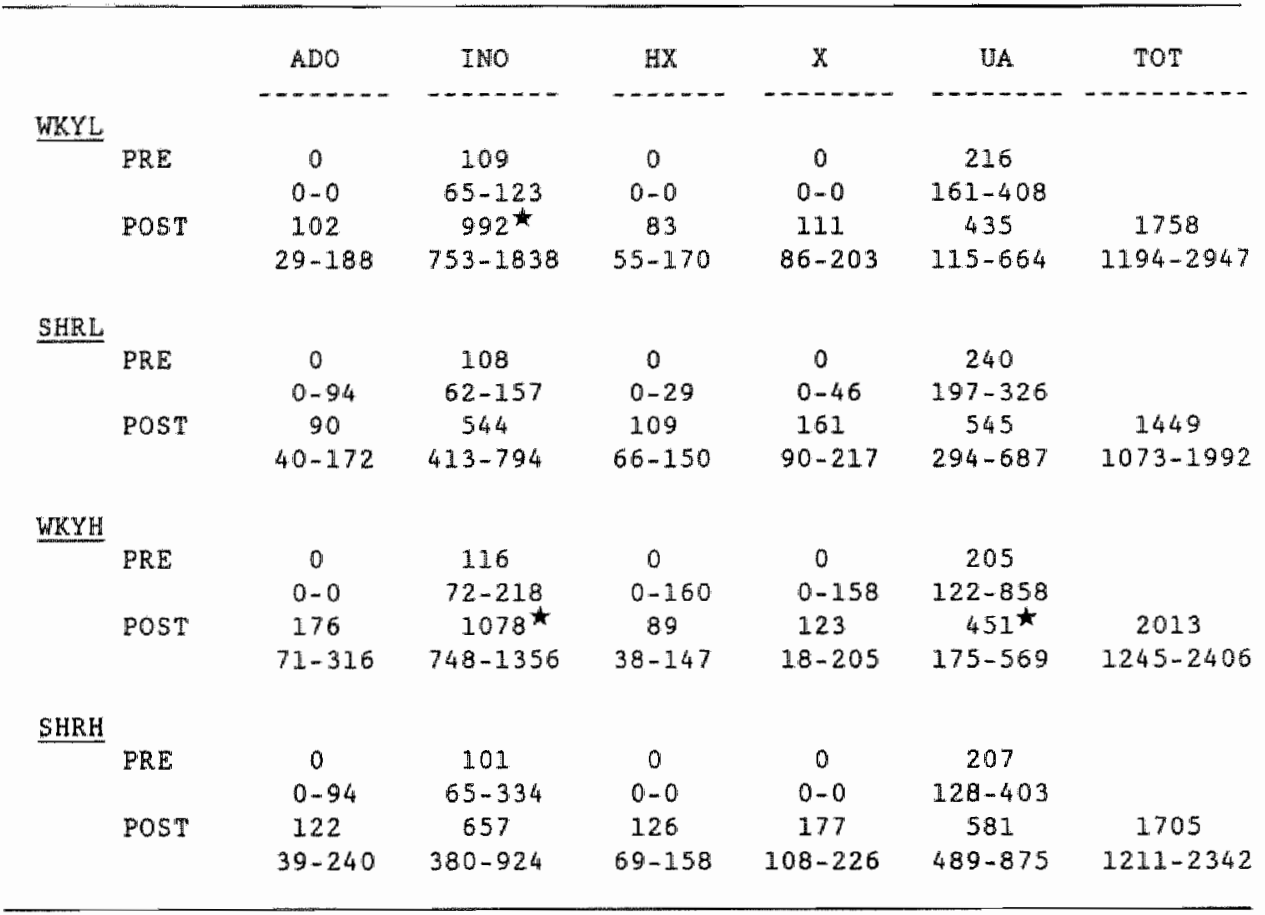

ADO : adenosine; INO : inosine; HX: hypoxanthine; $X$ : xanthine; $U A$ : uric acid: TOT : sum of all degradation producrs. Data are presented as median values and $95 \%$ confidence limits. $\star$ significantly different from the values in the corresponding SHR heants.

tissue of WKYH and SHRH perfused at $13.3 \mathrm{kPa}$ (Table VII. 5). In comparison to the WKYL hearts perfused at $8.0 \mathrm{kPa}$, the WKYH hearts contained significanuly smaller amounts of ATP, ADP and AMP, whereas the energy charge was almost identical. As compared to the values obtained in SHRL hearts, significantly higher amounts of creatine phosphate and ATP, and lower amounts of AMP were found in the SHRH, resulting in a significantly higher energy charge. The lactate and inorganic phosphate levels were significantly lower than in the SHRL while the glycogen levels were higher (Table VII. 5). 
Table VI. 5 Tissue values (umol.g dry weighl) of creatine phosphate, adenine nucleotides, glycogen, lactate and inorganic phosphote th WKY and SHR hearts at the end of the reperfusion phase following 15 minutes global ischemia.

\begin{tabular}{|c|c|c|c|c|}
\hline & $\begin{array}{l}\text { WKYL } \\
(n=7)\end{array}$ & $\begin{array}{l}\text { SHRL } \\
(n=7)\end{array}$ & $\begin{array}{l}\text { WRYH } \\
(n=6)\end{array}$ & $\begin{array}{l}\text { SHRH } \\
(n=6)\end{array}$ \\
\hline & $--1-n-1-n$ & $\ldots-\ldots$ & $-\ldots-n-\ldots$ & $\ldots-\cdots-n$ \\
\hline \multirow[t]{2}{*}{$\mathrm{CP}$} & $33.9^{\star}$ & 6.4 & 22.9 & $13.1^{\circ}$ \\
\hline & $26.4-40.1$ & $5.1-13.0$ & $12.2-26.9$ & $3.1-43.2$ \\
\hline \multirow[t]{2}{*}{ ATP } & $7.9^{\star}$ & 2.9 & 5.2 & $4.3 \circ$ \\
\hline & $4.1-9.0$ & $1.8-3.4$ & $2.9-5.4$ & $2.9-20.4$ \\
\hline \multirow[t]{2}{*}{$\mathrm{ADP}$} & $3.4^{\star}$ & 2.5 & 2.6 & 3.2 \\
\hline & $2.5-3.9$ & $2.0-3.1$ & $1.8-3.9$ & $2 \cdot 3-7 \cdot 3$ \\
\hline \multirow[t]{2}{*}{ AMP } & $1.1^{\star}$ & 3.7 & 0.7 & $0.8^{\circ}$ \\
\hline & $0.5-1.6$ & $1.9-5.0$ & $0.4-2.4$ & $0.2-3.5$ \\
\hline \multirow[t]{2}{*}{ SUM } & $12.7^{\star}$ & 8.7 & 8.7 & 10.0 \\
\hline & $8.4-14.6$ & $6.2-11.2$ & $5.4-11.6$ & $5.8-28.1$ \\
\hline \multirow[t]{2}{*}{$\mathrm{EC}$} & $0.78^{\star}$ & 0.49 & 0.75 & $0.71^{\circ}$ \\
\hline & $0.67-0.82$ & $0.37-0.60$ & $0.63-0.81$ & $0.51-0.86$ \\
\hline \multirow[t]{2}{*}{ GLYC } & $76.4^{\star}$ & 21.0 & 55.6 & $38.0^{\circ}$ \\
\hline & $49.7-88.2$ & $15.8-30.8$ & $31 \cdot 5-114 \cdot 0$ & $23.8-117.3$ \\
\hline \multirow[t]{2}{*}{ LAC } & $36.2 \star$ & 191.5 & 21.0 & $17.2^{\circ}$ \\
\hline & $22.4-39.0$ & $120.3-219.7$ & $8.3-72.8$ & $5.7-108.6$ \\
\hline \multirow[t]{2}{*}{$\mathbb{P i}_{i}$} & $53.6^{\star}$ & 74.1 & $64 \cdot 5$ & $56.0^{\circ}$ \\
\hline & $32.5-60.1$ & $67.6-101.9$ & $29.7-91.3$ & $37.6-58.8$ \\
\hline
\end{tabular}

$C P$ : creatine phosphate; $A T P, A D P$ and AMP: adenosine triphosphate, adenosine diphosphate and adenosine monophosphate, respectively: SUM: the sum of ATP, ADP and $A M P ; E C$ : energy charge ( (ATP+0.5ADP)/SUM); GLYC: glycogen; LAC : lactate; $P i$ : inorganic phosphate. The data are presented as median values and $95 \%$ confidence limits. $\star$ : significantly different from the data in the corresponding SHR group;

- significamtly different from the values in the corresponding hearts perfused at $8.0 \mathrm{kPa}(p<0.05)$.

The tissue content of the individual degradation products of adenine nucleotides, i.e. adenosine, inosine, hypoxanthine and xanthine at the end of the 45 minutes reperfusion period are presented in Figure VII. 8. Significantly more degradation products were found in the SHRL hearts than in the WKYL hearts. In the SHRL hearts $4.40 \mu \mathrm{mol}$ degrada- 
tion products.g $\mathrm{g}^{-1}$ dry weight were found as compared to $0.45 \mu \mathrm{mol} . \mathrm{g}^{-1}$ dry weight in the WKYL hearts $(p<0.05)$. At the higher perfusion pressure, no significant differences were observed between the two experimental groups. WKYH and SHRH hearts contained 0.45 and $0.65 \mu \mathrm{mol} . \mathrm{g}^{-1}$ dry weight, respectively.

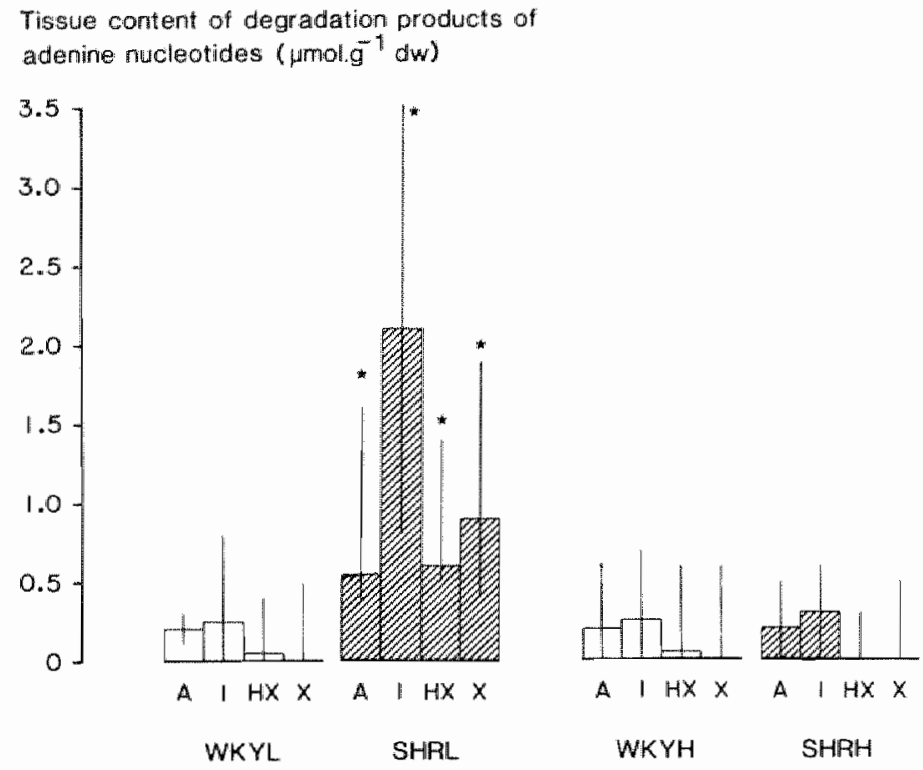

Figure VII. 8 Tissue contents of degradation products of adenine nucleotides at the end of the reperfusion phase after 45 minutes global ischemia in isolaled, ejecting hearts of WKYL (open bars) and SHRL (hatched bars; both groups : $n=7$; left panel), perfused at a diastolic aortic pressure of $8.0 \mathrm{kPa}$, and in hearts of WKYH (open bars) and SHRH (hatched bars; both groups : $n=6$; right panel), perfused at 13.3 APa. Data are presented as median values and $95 \%$ confidence limits. A : adenosine; $I$ : imosine; HX : hypoxanthine; $X$ : xanthine. $\star$ : significantly higher than in the corresponding WKY group $(p<0.05)$.

Table VII. 6 presents the tissue content of creatine phosphate, adenine nucleotides and their degradation products, glycogen, lactate and inorganic phosphate just prior to ischemia and at the end of the ischemic period in SHRL and WKYL rat hearts perfused at $8.0 \mathrm{kPa}$. No significant differences were observed between both groups at the end of the pre-ischemic period. At the end of the ischemic period, significantly lower levels of creatine phosphate and ATP were found in the tissue of both groups as compared to their respective pre-ischemic values, while the levels of the degradation products adenosine, inosine, 
Table WT. 6 Tissue cantent (mol.g-s dry weight) of biochemical substances at the end of the pre-ischemic period (PRE) and at the what of 45 minules global ischemia (ISCH).

\begin{tabular}{|c|c|c|c|c|}
\hline & \multicolumn{2}{|c|}{ WKYL $(n=5)$} & \multicolumn{2}{|c|}{ SHRL $(n=3)$} \\
\hline & DRE & ISCH & PRE & ISCH \\
\hline$C P$ & $25 \cdot 2^{\star}$ & $\begin{array}{c}4.1 \\
3.6-6.4\end{array}$ & $\begin{array}{c}22.5 \\
15.5-33.5\end{array}$ & $\begin{array}{c}4.4 \\
2.9-5.3\end{array}$ \\
\hline ATP & $\begin{array}{c}16.4^{\star} \\
10.9-19\end{array}$ & $\begin{array}{c}6.2 \\
3.9-8.0\end{array}$ & $\begin{array}{c}14.1^{\star} \\
13.2-17.2\end{array}$ & $\begin{array}{c}5.0 \\
3.3-6.1\end{array}$ \\
\hline$A D P$ & $\begin{array}{c}4.2 \\
4.1-5.9\end{array}$ & $\begin{array}{c}5.7 \\
4.2-5.8\end{array}$ & $\begin{array}{c}4.6 \\
3.1-4.8\end{array}$ & $\begin{array}{c}4.9 \\
4.1-5.2\end{array}$ \\
\hline AMP & $\begin{array}{c}0.6 \\
0.5-2.4\end{array}$ & $\begin{array}{c}1.2 \\
1.0-1.5\end{array}$ & $\begin{array}{c}0.5 \\
0.4-0.8\end{array}$ & $\begin{array}{c}1.5 \\
0.4-2.2\end{array}$ \\
\hline SUM & $\begin{array}{c}20.9^{\star} \\
19.2-24.2\end{array}$ & $\begin{array}{c}13.1 \\
9.9-14.8\end{array}$ & $\begin{array}{c}19.7^{\star} \\
16.7-22.3\end{array}$ & $\begin{array}{c}10.6 \\
10.4-11.7\end{array}$ \\
\hline $\mathrm{EC}$ & $\begin{array}{c}0.88^{\star} \\
0.72-0.88\end{array}$ & $\begin{array}{c}0.69 \\
0.62-0.73\end{array}$ & $\begin{array}{c}0.87^{\star} \\
0.84-0.89\end{array}$ & $\begin{array}{c}0.67 \\
0.55-0.69\end{array}$ \\
\hline A & $\begin{array}{c}0.22^{\star} \\
0.06-0.33\end{array}$ & $\begin{array}{c}1.57 \\
1.29-2.02\end{array}$ & $\begin{array}{l}0.06^{\star} \\
0.0 .20\end{array}$ & $\begin{array}{c}1.00 \\
0.37-1.83\end{array}$ \\
\hline I & $\begin{array}{c}0.21^{\star} \\
0.13-0.57\end{array}$ & $\begin{array}{c}4.65^{\circ} \\
3.81-5.85\end{array}$ & $\begin{array}{c}0.12^{\star} \\
0.09-0.72\end{array}$ & $\begin{array}{c}2.36 \\
1.49-3.50\end{array}$ \\
\hline $\mathbb{H X}$ & $\begin{array}{c}0 \star \\
0-0\end{array}$ & $\begin{array}{c}0.29 \\
0.21-0.51\end{array}$ & $\begin{array}{c}0^{\star} \\
0-0\end{array}$ & $\begin{array}{c}0.46 \\
0.42-0.55\end{array}$ \\
\hline $\mathrm{X}$ & $0_{0-0}^{\star}$ & $\begin{array}{c}0.42 \\
0.32-0.69\end{array}$ & $0^{+4}$ & $\begin{array}{c}0.50 \\
0.40-0.66\end{array}$ \\
\hline GLYC & $\begin{array}{l}108.7 \\
90.8-145.9\end{array}$ & $\begin{array}{c}75.1 \\
18.0-119.2\end{array}$ & $\begin{array}{c}136.9^{\star} \\
86.4-146.8\end{array}$ & $\begin{array}{c}39.1 \\
11.2-79.3\end{array}$ \\
\hline $\mathrm{LAC}$ & $\begin{array}{l}7.1^{\star} \\
5.3-11.8\end{array}$ & $\begin{array}{l}105.2 \\
79.6-129.3\end{array}$ & $\begin{array}{c}7.1^{\star} \\
7.1-30.6\end{array}$ & $\begin{array}{c}124.5 \\
104.4-135.7\end{array}$ \\
\hline$P 1$ & $\begin{array}{c}39.3^{\star} \\
29.6-62.0\end{array}$ & $\begin{array}{c}77.7^{\bullet} \\
70.5-87.2\end{array}$ & $\begin{array}{c}33.2^{\star} \\
23.3-45.1\end{array}$ & $\begin{array}{c}63.7 \\
63.5-68.9\end{array}$ \\
\hline
\end{tabular}

$C P$ : creatine phosphate; $A T P, A D P$ and $A M P$ : adenosine triphosphate diphosphate and monophosphate, respectively; $S U M: A T P+A D P+A M P ; E C$ : energy charge; ( $A T P+$ $0.5 A D P$ MSUM); $A$ : adenosine; $I$ : inosine, $H X$ : hypoxanthine; $X$ : xanthine; GLYC: glycogen; $L A C$ : lactate; $P i$ : inorganic phosphate. The data are presented as median values and $95 \%$ confidence limits. $\star$ : significantly different from the ischemic values in the hearts of the same strain; - siginificantly different from the corresponding values in the hypertophied hearts $(p<0.05)$. 
bypoxanthine and xanthine and of the content of lactate and inorganic phosphate were significantly increased. At the end of the ischemic period in the control hearts significantly higher amounts of inosine and inorganic phosphate were found than in the hypertrophied hearts. Comparing the end-ischemic values with the values at the end of the reperfusion period (Table VII. 5), energy charge levels were partly restored in the non-hypertrophied hearts, but were further decreased during reperfusion in the hypertrophied hearts. In these hearts, lactate levels remained high during reperfusion, while the glycogen content decreased further to very low levels.

At the end of the pre-ischemic period, in control hearts perfused at $13.3 \mathrm{kPa}$, significantly lower ADP and AMP levels were found than in the hypertrophied hearts at the same experimental moment, while the energy charge level was significantly higher (Table VII. 7). Both in SHR and WKY rat hearts, perfused at $13.3 \mathrm{kPa}$, global ischemia induced a significant decrease of creatine phosphate and ATP, while the levels of adenosine, inosine, hypoxanthine and xanthine and of lactate and inorganic phosphate were significantly increased. In control hearts, significantly increased ADP and AMP levels were detected at the end of the ischemic period, while the glycogen content was significantly decreased. In SHR, a comparable decrease in glycogen content was observed. However, due to the limited number of hearts, the difference did not reach the level of significance. At the end of the ischemic period, as in hearts perfused at $8.0 \mathrm{kPa}$, significantly higher inosine levels were detected in the control hearts as compared to the SHR hearts.

\section{5. DISCUSSION}

The findings in the present study show that, when perfused at a relatively low perfusion pressure i.e. $8.0 \mathrm{kPa}$, hypertrophied hearts have a decreased tolerance to ischemia as illustrated by the severely depressed myocardial function during reperfusion compared to non-hypertrophied control hearts. Under these circumstances restoration of myocardial flow in the hypertrophied hearts is severely impaired, especially in the endocardial layers. This underperfusion results in diminished release of lactate dehydrogenase, lactate and degradation products of adenine nucleotides, and the accumulation of these metabolites in the myocardial tissue.

When the hypertrophied hearts are reperfused at a relatively high perfusion pressure, i.e. $13.3 \mathrm{kPa}$, myocardial flow is enhanced in both layers, but the endocardial layer still remains underperfused as compared to the control hearts. In the hypertrophied hearts no accumulation of metabolites in the myocardium can be observed at the end of the reperfusion period, but the release of intracellular enzymes and degradation products of adenine nucleotides is significantly retarded 

minutes global ischemia (ISCH).

mucs global ischemia (ISCH).

\begin{tabular}{|c|c|c|c|c|}
\hline & WK & $n=3)$ & SHRF & $\begin{array}{l}=4) \\
------n-m\end{array}$ \\
\hline & PRE & ISCH & PRE & ISCH \\
\hline$C P$ & $\begin{array}{c}31.0 \star \\
27.4-45.5\end{array}$ & $\begin{array}{c}4.4 \\
2.3-5.1\end{array}$ & $24.1^{\star}$ & $\begin{array}{c}3.1 \\
2.3-5.1\end{array}$ \\
\hline ATP & $\begin{array}{c}17.7^{\star} \\
15.5-17.9\end{array}$ & $\begin{array}{c}5.7 \\
4.8-6.6\end{array}$ & $\begin{array}{c}14.3^{\star} \\
12.3-16.9\end{array}$ & $\begin{array}{c}6.5 \\
5.3-7.8\end{array}$ \\
\hline $\mathrm{ADP}$ & $\begin{array}{c}4.1^{\star 0} \\
3.8-4.6\end{array}$ & $\begin{array}{c}5.1 \\
5.0-5.7\end{array}$ & $\begin{array}{c}5.3 \\
4.6-6.2\end{array}$ & $\begin{array}{l}5.8 \\
5.5-6.1\end{array}$ \\
\hline AMP & $\begin{array}{l}0.6^{\star \bullet} \\
0.5-0.7\end{array}$ & $\begin{array}{c}1.1 \\
1.1-1.4\end{array}$ & $\begin{array}{c}1.4 \\
0.8-1.9\end{array}$ & $\begin{array}{c}1.4 \\
1.3-1.7\end{array}$ \\
\hline SUM & $\begin{array}{c}22.0^{\star} \\
20.3-23.1\end{array}$ & $\begin{array}{c}11.8 \\
11.3-13.4\end{array}$ & $\begin{array}{c}20.9^{\star} \\
20.4-22.3\end{array}$ & $\begin{array}{c}14.0 \\
12.3-14.7\end{array}$ \\
\hline EC & $\begin{array}{c}0.87^{*} \\
0.86-0.89\end{array}$ & $\begin{array}{c}0.70 \\
0.65-0.70\end{array}$ & $\begin{array}{c}0.81^{\star} \\
0.76-0.86\end{array}$ & $\begin{array}{c}0.68 \\
0.65-0.72\end{array}$ \\
\hline A & $\begin{array}{c}0 \star \\
0.0 .15\end{array}$ & $\begin{array}{c}1.62 \\
1.62-1.65\end{array}$ & $\begin{array}{l}0.46^{7} \\
0.0 .57\end{array}$ & $\begin{array}{c}1.47 \\
1.07-1.72\end{array}$ \\
\hline I & $\begin{array}{c}0.14^{\star} \\
0.06-0.20\end{array}$ & $\begin{array}{c}5.82 \\
5.63-6.50\end{array}$ & $\begin{array}{l}0.33^{\star} \\
0.0 .66\end{array}$ & $\begin{array}{c}3.12 \\
2.57-3.77\end{array}$ \\
\hline $\mathrm{HX}$ & $0_{0-0}^{\star}$ & $\begin{array}{c}0.36 \\
0.30-0.46\end{array}$ & $\begin{array}{c}0 \\
0-0\end{array}$ & $\begin{array}{c}0.36 \\
0.31-0.60\end{array}$ \\
\hline $\mathrm{X}$ & $0_{0-0}^{\star}$ & $\begin{array}{c}0.52 \\
0.51-0.58\end{array}$ & $\begin{array}{c}0 \star \\
0-0\end{array}$ & $\begin{array}{c}0.45 \\
0.36-0.78\end{array}$ \\
\hline GLYC & $\begin{array}{c}111.1^{\star} \\
100.0-111.4\end{array}$ & $\begin{array}{c}37.2 \\
29.7-79.2\end{array}$ & $\begin{array}{l}111.4 \\
65.0-137.6\end{array}$ & $\begin{array}{c}21.1 \\
19.7-67.9\end{array}$ \\
\hline LAC & $\begin{array}{c}11.1^{*} \\
9.0-12.1\end{array}$ & $\begin{array}{c}129.4 \\
101.2-137.2\end{array}$ & $\begin{array}{c}16.7^{k} \\
6.8-30.0\end{array}$ & $\begin{array}{c}107.8 \\
92.4-128.6\end{array}$ \\
\hline $\mathrm{Pi}$ & $\begin{array}{c}29.6^{\star} \\
29.2-41.4\end{array}$ & $\begin{array}{c}86.5 \\
82.5-88.9\end{array}$ & $\begin{array}{c}47.3^{\star} \\
25.2-48.7\end{array}$ & $\begin{array}{c}72.7 \\
65.4-78.8\end{array}$ \\
\hline
\end{tabular}

$C P$ : creatine phosphate; ATP, ADP and AMP : adenosine triphosphate, diphosphate and monophosphate, respectively; SUM : ATP +ADP+AMP; EC: energy charge; (GATP+ $0.5 A D P J / S U M) ; A$ : adenosine; $I$ : inosine, $H X$ : hypoxanthine; $X$ : xanthine; $G L Y C$; glycogen; LAC : lactate; $P_{i}$ : inorganic phosphate. The data ane presented as median values and $95 \%$ confidence limits. $\star$ : significantly different from the ischemic walues in the hearts of the same strain: $\bullet$ : significantly different from the corresponding walues in the hypertrophied hearts $(p<0.05)$. 
during the initial phase of the reperfusion period. Despite these improvements and the restoration of normal electrical and to some extent, mechanical activity, these hearts are not able to exert pump function of any importance. Also in the pre-ischemic period differences have to be appreciated between ejecting hypertrophied and control hearts, when perfused at a relative low perfusion pressure. In this situation the endocardium of the hypertrophied hearts is relatively underperfused, while myocardial function is depressed. The differences during the pre-ischemic period between hypertrophied and control hearts disappear when perfusion pressure is increased to $13.3 \mathrm{kPa}$.

\section{5.1. Function of the hearts in the pre-ischemic period}

In the pre-ischemic period myocardial function of the hypertrophied hearts perfused at $8.0 \mathrm{kPa}$ is depressed, as indicated by the significantly lower $\mathrm{dP}_{1 \mathrm{v}} / \mathrm{dt}_{\mathrm{xanx}}$ and cardiac output values as compared with the non-hypertrophied hearts. The lower contractile function of the hypertrophied hearts could be a consequence of too low a left atrial filling pressure (Hallbäck et al., 1975; Humphrey et al., 1984; Friberg et al., 1985; Snoeckx et al., 1986a). Indeed, the hypertrophied heart, especially that of the old spontaneously hypertensive rat, requires a relatively high end-diastolic pressure to compensate for the reduced tangential wall tension in these hearts (Hallbäck et al., 1975). However, it is uncertain whether in the present study the impaired left ventricular function of the hypertrophied heart is caused by the reduced wall tension alone. Reduced contractile function of the endocardium due to the underperfusion of this myocardial region may also play a role, especially since an increase in left atrial filling pressure at a relatively low diastolic aortic pressure does not improve left ventricular pump function to the same extent as in the non-hypertrophied heart (Alfaro et al., 1983; Snoeckx et al., 1986a). It is worthy to note that endocardial underperfusion was also found to be present in the empty beating, retrogradely perfused, hypertrophied dog heart at perfusion pressures of 4.0 and $8.0 \mathrm{kPa}$ (Kawachi et al., 1982).

Hypertrophied hearts perfused at $8.0 \mathrm{kPa}$ release increased amounts of lactate into the coronary effluent during the pre-ischemic period. Most probably, moderate tissue anaerobiosis might be the cause of the lactate release observed, since substantial underperfusion of the endocardial layers of the left ventricular wall occur during this period. This situation, however, does not lead to prominent tissue damage, since other indicators of myocardial anaerobiosis, like enhanced loss of lactate dehydrogenase and degradation products of adenine nucleotides do not occur during the same experimental phase. An increased release of lactate may also be caused by an increased $\mathrm{NADH} / \mathrm{NAD}+$ ratio in the hypertrophied heart, provoking the turnover of pyruvate to lactate (Kobayachi and Neely, 1982). The presence of relatively high concentra- 
tions of pyruvate, i.e. $5 \mathrm{mM}$, in the perfusate will create a favourable condition for increased lactate production when the intracellular NADH content is enhanced.

Increasing the afterload during the pre-ischemic period to 13.3 $\mathrm{kPa}$ results in normalization of myocardial flow and improvement of myocardial function in the hypertrophied heart, as illustrated by the normal coronary flow values per gram heart weight and the $45 \%$ higher $\mathrm{dP} \mathrm{iv} / \mathrm{dt}$ max values as compared with the hearts perfused at $8.0 \mathrm{kPa}$. Endocardial flow is normalized across the whole left ventricular wall and the amounts of lactate released are comparable with those released in the control hearts. These findings demonstrate that under aerobic conditions hypertrophied hearts require a higher afterload to maintain a hemodynamic and metabolic function comparable to that of the non-hypertrophied, control hearts.

In contrast, in the non-hypertrophied control hearts an increase in afterload from 8.0 to $13.3 \mathrm{kPa}$ results in a reduction of the performance, confirming previous observations (Snoeckx et al., 1986a). Invivo a diastolic aortic pressure of $13.3 \mathrm{kPa}$ cannot be considered as unphysiologically high. In the isolated perfused, ejecting rat heart, however, it is a relatively high pressure since colloid-osmotic forces, necessary for counterbalancing the hydrostatic forces exerted by the perfusion pressure, are absent in the artificial, crystalloid perfusate as used in this study. It is known that this imbalance provokes tissue edema, which in turn negatively affects myocardial pump function (Segel and Rendig, 1982). This idea is supported by the observation that during the experimental period the increase in weight of the non-hypertrophied hearts is more pronounced when perfusion pressure is high than when it is low ( 38 vs 10\%). This increase in heart weight during the experimental period is not seen in the hypertrophied hearts perfused at 13.3 $\mathrm{kPa}$, suggesting that in these hearts edema formation, if any, is limited. Why the bypertrophied hearts are more resistant to edema formation is incompletely understood.

\section{5.2. Function of the hearts during reperfusion after global ischemia}

From the myocardial flow distribution patterns, obtained during the initial reperfusion phase and at the end of reperfusion, it is obvious that major parts of the left ventricular wall of the hypertrophied hearts are not or inadequately perfused, when a perfusion pressure of $8.0 \mathrm{kPa}$ is applied. No-reflow was observed in large regions of the endocardium. In contrast to the non-hypertrophied heart, edema formation likely does not occur in the hypertrophied hearts (see above), suggesting that the no-reflow phenomenon is not caused by excessive swelling of the myocardial tissue. A possible explanation for the noreflow phenomenon is an altered reactivity of the coronary vessels of the hypertrophied heart. As shown by Folkow (1970) and by Hallbäck 
and co-workers (1979), the structural increase in arterial wall thickness in these rats is associated with an enhanced magnitude of vascular smooth muscle contraction. Secondly, in cultured aortic smooth muscle cells of hypertensive rats, it was found that the sodium-potassium pump is partially inhibited, inducing intracellular sodium excess, which in turn could enhance smooth muscle contraction (Yamori et all, 1982). Thirdly, it has been shown by Langer and co-workers (1981) that the sensitivity of alpha-adrenergic receptors in smooth muscle of spontaneously hypertensive rats is increased. If the latter mechanism plays a role, in the present study catecholamines have to be liberated from endogenous sites, since no circulating catecholamines were present in the perfusate. This mechanism could be important because the absence of perfusion prevents wash-out of substances like intercellular catecholamines, leaking from interstitial compartments (Abrahamsson et al., 1983; Carlsson et al., 1986; Dart et al., 1987), exacerbating the effects of $\alpha$-stimulation.

To our knowledge, radioactive labeled microspheres have never been used in the isolated rat heart for the measurement of regional myocardial flow. Handling of small tissue samples must be performed very carefully to avoid errors in weight measurements or in the precise partition of the tissue in endocardial and epicardial layers. Although the lowest weight of tissue pieces amounted to $20 \mathrm{mg}$, the radioactivity in this tissue yielded 6 times the background of the gammacounter. The considerable spread of radioactivity found in the various tissue samples does not directly implicate an increased measurement error, but may reflect flow heterogeneity in cardiac tissue (King et al., 1985; Bassingthwaighte et al., 1987).

The reduced leakage of lactate dehydrogenase and other intracellular substances from the hypertrophied hearts is most likely caused by the inadequate reperfusion of the myocardium, because enzyme release has shown to be diminished in rat hearts in which no-reflow occurs (Humphrey et al., 1984) or low flow (van der Laarse et al., 1984) is present. This idea is further supported by the present observation that low molecular weight metabolites, like lactate and degradation products of adenine nucleotides, accumulate in the myocardium, most probably in the endocardial layers. The lack of adequate reperfusion of the hypertrophied hearts also prolongs the ischemic period in the endocardial tissue and obviously inhibits the rephosphorylation of creatine and ADP. Hence, the energy charge is low in these hearts as compared to the recovering controls (Table VII. 5).

The diminished functional recovery of the non-hypertrophied hearts, perfused at $8.0 \mathrm{kPa}$, is probably a consequence of the global ischemia because under normoxic circumstances the isolated, ejecting rat heart has shown to be a hemodynamically and biochemically stable preparation for at least 2 hours (see chapter IV). In this respect the relatively bigh age of the rats, as used in this study, has to be conside- 
red because functional recovery following ischemia was found to decrease with age (Bove and Stammers, 1986). The fall in left ventricular function during the reperfusion phase, when increasing the perfusion pressure to $13.3 \mathrm{kPa}$, indicates that non-hypertrophied hearts are able to sustain load only to a limited extent following a substantial period of global ischemia.

In hypertrophied hearts, reperfused at a relatively high perfusion pressure, i.e. $13.3 \mathrm{kPa}$, some of the variables reflecting myocardial function have improved, as compared to the hypertrophied hearts perfused at a low perfusion pressure, i.e. $8.0 \mathrm{kPa}$. Myocardial flow is considerably, albeit not completely, restored, resulting in adequate wash-out of lactate and adenine nucleotide degradation products from the previously ischemic cells. As a consequence of increased supply of oxygen to the affected tissue, energy charge is significantly higher and creatine phosphate, ATP and glycogen levels are better preserved than in the hypertrophied hearts, perfused at $8.0 \mathrm{kPa}$. However, despite restoration of electrical and mechanical activity, pump function remains severely depressed. In this respect, we should keep in mind that increasing the afterload from 8.0 to $13.3 \mathrm{kPa}$, concomitantly enhances the workload of the heart. Obviously, the increased workload imposed counteracts the improved metabolic, electrical and contractile behaviour of the post-ischemic hypertrophied heart. It is questionable whether the relative underperfusion of the endocardium ( $43 \%$ of the pre-ischemic values) is the main cause of the absence of cardiac output in the spontaneously hypertensive rat hearts perfused at $13.3 \mathrm{kPa}$, since control hearts are also practically unable to eject against this aortic pressure despite complete restoration of myocardial flow. It is also doubtful that the lack of functional recovery is related to the relatively low ATP, ADP and AMP contents in these hearts, since it has been shown that hearts may functionally recover, even at very low (about $5 \mu$ mol.g ${ }^{-1}$ dry weight) adenine nucleotide levels (Rosenkranz et al., 1986).

Throughout the reperfusion period in both hypertrophied groups significantly lower amounts of inosine are released into the coronary effluent, as compared to the corresponding control hearts (Table VII. 4). This can likely be explained by a higher conversion rate of inosine rather than a diminished production of this substance in the ischemic hypertrophied heart. This is indicated by the higher amounts of hypoxanthine, xanthine and uric acid found in the coronary effluent of these hearts and also by the lower amount of inosine found in the tissue of hypertrophied hearts at the end of the ischemic period. The results shown in Figure VII. 9 suggest that the sum of the adenine nucleotides and their degradation products in myocardial tissue is substantially less in hypertrophied hearts made ischemic for 45 minutes (SHRL) than in the corresponding pre-ischemic hearts. Due to the limited number of hearts studied this difference did not reach the level of significance. Therefore, the physiological significance of this observation is uncertain. 


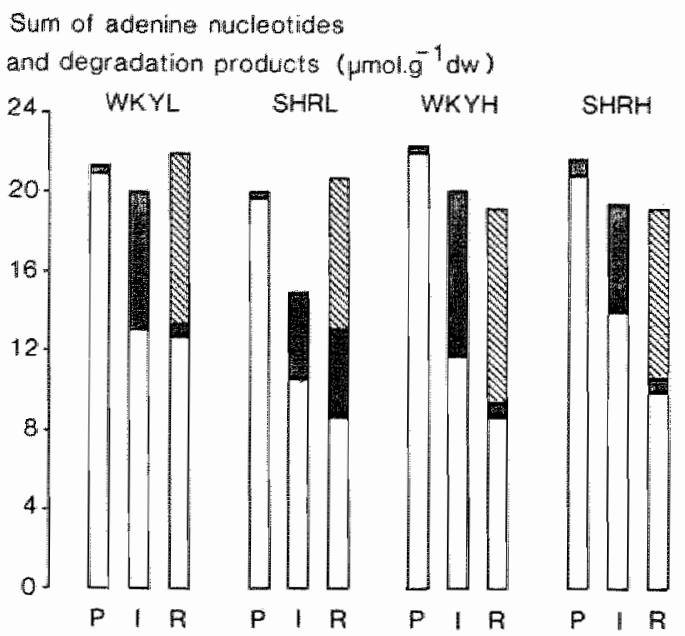

Figure VII. 9 The sum of the tissue contents of adenine nucleotides ( $\square$ ) and their degradation products ( $\mathbf{D})$, and the degration products released in the coronary effluent (W) during the reperfusion period in the 4 experimental groups. Conversion from wet to dry weight of the degradation products in coronary effluent is oblained by multiplying the amounts released by a factor 5. $P$ : pre-ischemia ( $t=40$ minutes); $I$ : end-ischemia $(t=85$ minutes $) ; R$ : end reperfusion $(t=125$ minutes $)$.

Despite an identical amount of degradation products released from WKY and SHR hearts of the $8.0 \mathrm{kPa}$ pressure groups during the 45 minutes reperfusion period, the relative composition of the products was significantly different between the two groups. Hypertrophied hearts released relatively more end-stage products such as xanthine and uric acid than the non-hypertrophied bearts did. The ratio xanthine plus uric acid to the sum of adenosine, inosine and hypoxanthine was found to 0.95 in the SHRL and 0.46 in the WKYL group $(p<0.05)$. A comparable phenomenon was found in the hearts perfused at $13.3 \mathrm{kPa}$. In WKYH a ratio of 0.41 was found, while in SHRH a value of 0.84 was calculated $(p<0.05)$. The pathophysiological consequence of this intriguing observation is incompletely understood. It is tempting to speculate that increased flux of inosine to uric acid may result in an enhanced production of oxygen free radicals by the (hypo)xanthine/xanthine oxydase system (van der Vusse and Reneman, 1985). If this is the case, in ischemic and reperfused hypertrophied hearts the involvement of injury, elicited by oxygen free radicals has to be considered as well. 
In conclusion, the findings in the present study show that hypertrophied hearts of relatively old spontaneously bypertensive rats bave a diminished tolerance to ischemia as compared to age-matched controll hearts, when perfused at a relatively low pressure. When following ischemia the hypertrophied hearts are reperfused at a relatively high pressure, these hearts remain unable to exert pump function of any importance despite the improvement of myocardial flow, the restoration of normal electrical and mechanical activity, and the absence of accumulation of metabolic degradation products. 


\section{AT DIFFERENT PERFUSION PRESSURES}

\section{AFTER A PERIOD OF GLOBAL ISCHEMIA}

\section{1. INTRODUCTION}

As shown in the chapters V and VII, the hypertrophied heart of the spontaneously hypertensive rat of 16 and 18 months old has a diminished tolerance to global ischemia as compared with the age-matched, non-hypertrophied heart, especially when perfused at a relatively low coronary perfusion pressure. When the perfusion pressure is elevated, so that the pre-ischemic regional myocardial perfusion pattern, and mechanical and biochemical function in the hypertrophied heart is normal and comparable with that of the non-hypertrophied control heart, the post-ischemic function of these hearts significantly improved but still not complete. Although mechanical function and normal electrical activity are present, these hearts are incapable to eject any fluid against the increased afterload.

In these studies, left ventricular pump function was described by the cardiac output and the positive maximal first derivative of the left ventricular pressure. Although these variables are generally used as effective indicators of myocardial mechanical function, they are probably not the most sensitive ones. Mirsky and co-workers (1983) showed that cardiac output is not lower in intact 18 months old spontaneously hypertensive rats, as compared to age-matched Wistar-Kyoto rats, but that the ratio of peak ejection fraction (described by the ratio of peak stroke volume to end-diastolic volume) and afterload was 
significantly lower in the 18 months old hypertrophied rats than in agematched, non-hypertrophied hearts and younger ( 8 and 12 months old) spontaneously hypertensive rat hearts. These findings could indicate that the hearts of the 16 and 18 month old spontaneously hypertensive rats are not working at the optimum of externally delivered work. In that case, the hypertrophied hearts shift more to the right on the curve, describing the relation between afterload and externally delivered work as compared to the heart of the non-hypertrophied control animals (Elzinga et al; 1980; Myhre et al., 1985).

In this light the diminished tolerance to ischemia of the hypertrophied heart of 16 and 18 months old spontaneously hypertensive rats (chapters V and VII), may be influenced by the relatively high age of the animals. Recently, Haneda and co-workers (1986) found a slightly better functional recovery in hearts of very young spontaneously hypertensive rats ( 3 months) during reperfusion, as compared to hearts of normotensive animals, after a short period of global ischemia. However, in hearts of relatively young aorta-banded rats ( 5 months of age; 10 weeks abdominal aorta-banding), we were unable to find a better functional and biochemical recovery than in hearts of age-matched, sham-operated animals (see chapter VI).

To obtain a better insight into the effect of age of the spontaneously hypertensive rat on the functional recovery after global ischemia, the present study was conducted to investigate the effects of 45 minutes global, normothermic ischemia and reperfusion on isolated, ejecting hearts of 8 months old spontaneously hypertensive rats and agematched, normotensive Wistar-Kyoto rats. As in the previous chapter, the hearts were perfused at two different diastolic aortic pressure levels, i.e. 8.0 and $13.3 \mathrm{kPa}$. The tolerance to ischemia was assessed by the restoration of hemodynamic function during reperfusion. Myocardial performance before and after global ischemia was assessed by monitoring left ventricular pressure-flow curves. To delineate a possible impairment of transmural coronary perfusion before and after global ischemia in the relatively young rat hearts in more detail, regional myocardial flow was obtained with radioactive microspheres.

To clarify the metabolic derangements in such young rat hearts, the tissue content of creatine phosphate, adenine nucleotides and their degradation products as well as of glycogen and lactate were determined in hearts, freeze-clamped at the beginning of the experiments, the end of the pre-ischemic period, the end of the ischemic period, and at the end of the reperfusion period. To quantify possible differences in the number of lethally damaged cells between hypertrophied and control hearts, the loss of lactate dehydrogenase into the coronary effluent was measured before and after ischemia. 


\section{2. METHODS}

\section{2.1. Experimental set-up}

The experiments were performed on isolated, ejecting hearts of 8 months old spontaneously hypertensive rats (SHR) and age-matched, Wistar-Kyoto (WKY) rats. The animals were randomly divided into 8 groups (Table VIII. 1). The groups $\operatorname{SHR}_{\max }(\mathbf{n}=3)$ and $W K_{\max }(n=3)$ consisted of hearts which were freeze-clamped after 10 minutes of retrograde perfusion and were used for native contents of biochemical substances.

Table VIII. 1 Allocation of the hearts of 8 months old spontaneously hypertensive rats ( $S H R$ ) and age-matched Wistar-Kyoto (WKY) rats to the various experimental groups.

\begin{tabular}{|c|c|c|}
\hline Group & $\begin{array}{c}\text { number of } \\
\text { hearts }\end{array}$ & Condition \\
\hline$---\infty-\infty$ & $--m-----n$ & 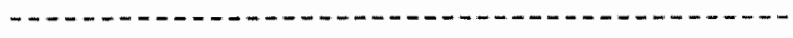 \\
\hline $\begin{array}{l}\mathrm{SHR}_{\mathrm{ma}}= \\
\text { WKY }\end{array}$ & $\begin{array}{l}3 \\
3\end{array}$ & $\begin{array}{l}\text { freeze-clamped after } 10 \text { minutes perfusion to remo- } \\
\text { ve blood; native walues. }\end{array}$ \\
\hline $\begin{array}{l}\text { SHRH } 1 \text { ach } \\
\text { WKY } Y_{\text {L }} \text { ach }\end{array}$ & 4 & $\begin{array}{l}\text { freeze-clamped in part at the end of the pre-ische- } \\
\text { mic period, and in part at the end of } 45 \text { minutes } \\
\text { global ischemia. }\end{array}$ \\
\hline $\begin{array}{l}\text { SHRL }=\propto p \\
\text { WKYL }=\infty\end{array}$ & $\begin{array}{l}4 \\
7\end{array}$ & $\begin{array}{l}\text { freeze-clamped at the end of } 45 \text { mimutes reperfusion } \\
\text { following } 45 \text { minutes of ischemia; hearts perfised at } \\
8.0 \mathrm{kPa} \text {. }\end{array}$ \\
\hline $\begin{array}{l}\mathrm{SHRH}_{x \rightarrow \infty} \\
\text { WKYH }_{x \rightarrow \infty}\end{array}$ & $\begin{array}{l}7 \\
4\end{array}$ & $\begin{array}{l}\text { freeze-clamped at the end of } 45 \text { minutes reperfusion } \\
\text { following } 45 \text { minutes of ischemia; hearts perfused at } \\
13.3 \mathrm{kPa} \text {. }\end{array}$ \\
\hline
\end{tabular}

The groups WKYLisch $(n=4)$ and SHRHinch $(n=4)$ consisted of bearts, which were perfused aerobically during 40 minutes, while the hearts were allowed to eject at a diastolic aortic perfusion pressure of 8.0 (WKYL $\mathrm{L}_{\mathrm{isch}}$ ) or $13.3 \mathrm{kPa}\left(\mathrm{SHRH}_{\mathrm{isch}}\right)$. At that moment a transmural left ventricular biopsy was taken to determine the the pre-ischemic myocardial content of biochemical products. The remaining of the tissue was subjected to 45 minutes global ischemia, and freeze-clamped thereafter for later biochemical analysis. The groups WKYL wp $(n=7)$ 
and $W_{K Y H}=p(n=4)$ consisted of control hearts perfused at a diastolic aortic pressure of 8.0 and $13.3 \mathrm{kPa}$, respectively. The group SHRLrep $(n=4)$ and group SHRH $(n=7)$ consisted of hypertrophied hearts, which were perfused at the same perfusion pressures as the corresponding WKYrop hearts. The hearts in these 4 groups were reperfused during 45 minutes after a 45 minutes period of global ischemia.

The rats were anesthetized with ether. After thoracotomy the bearts were removed from the body and immersed in ice-chilled Tyrode $e^{x}$ solution. Remnant lung tissue and fat were removed. The hearts were weighed and attached to the perfusion apparatus described in chapter II. Retrograde perfusion was started at a pressure of $8.0 \mathrm{kPa}$ immediately after attachment of the heart to the aortic cannula, using a well-oxygenated, modified Tyrode's solution $\left(\mathrm{PO}_{2}>80 \mathrm{kPa}\right)$, as described in the previous chapter. The electrogram, which was derived from two small platinum electrodes attached to the left ventricular wall, and the hemodynamic variables were fed into a home-made pre-processor connected to an Applelle microcomputer, allowing the on-line calculation of heart rate, systolic and diastolic left ventricular and aortic pressures, positive $\mathrm{dP}_{1} / \mathrm{dt}_{\max }$ and aortic flow. This automation system has been described in detail in chapter III. The heart rate was kept constant at 300 beats.min ${ }^{-1}$, using small platinum electrodes attached to the right atrial wall.

A second cannula was connected to the left atrium. The filling pressure was set at $1.0 \mathrm{kPa}$. After 10 minutes of retrograde perfusion the left atrial cannula was opened and antegrade perfusion was started for a period of 30 minutes. During this pre-ischemic period, the hemodynamic variables were continuously computed. Depending on the protocol diastolic aortic pressure was kept at 8.0 or $13.3 \mathrm{kPa}$. Under the experimental conditions, the rat hearts developed left ventricular systolic pressures, reaching maximal values of $2.5 \mathrm{kPa}$ above the diastolic aortic pressure. This implies that mean coronary perfusion pressure was about $0.8 \mathrm{kPa}$ higher than the diastolic aortic pressure, present in the perfusion system. The coronary effluent was collected to measure the release of lactate, the degradation products of adenine nucleotides, such as adenosine, inosine, hypoxanthine, xanthine and uric acid, and the activity of lactate dehydrogenase (LDH). The techniques are described in chapter II.

Left ventricular function curves were constructed at 2 different aortic pressure loads ( 8.0 and $13.3 \mathrm{kPa}$ ) and 3 different left atrial pressure loads. Left atrial pressure was increased in steps of $0.66 \mathrm{kPa}$ from 1.32 to $2.64 \mathrm{kPa}$ at the two diastolic aortic pressure levels. The hemodynamic variables were computed at each step. A steady state myocardial function of at least 1 minute had to be present before the values of the various variables were determined. 
At the end of the pre-ischemic period radioactively labeled microspheres were injected to assess the coronary flow distribution in the left ventricular wall. The full description of this technique is given in chapter VII. No radioactive microspheres were injected in the hearts of the groups WKY nar, WKYLisch, SHR nat and SHRHisch. Global, normothermic ischemia was induced by total cessation of flow to the heart. The ischemic period of 45 minutes was initially followed by a retrograde perfusion period of 15 minutes. The hearts were not stimulated during the period of ischemia and during the first 10 minutes of the reperfusion phase. Stimulation was restarted at a rate of 300 beats. $\min ^{-1}$ thereafter. Following the retrograde perfusion period the hearts were allowed to eject under the same external circumstances as during the pre-ischemic period. At the beginning and the end of the antegrade reperfusion phase, radioactive microspheres were injected. The coronary effluent was collected for biochemical assay, as during the pre-ischemic period. During the last 20 minutes of the ejection period pressureflow curves were constructed, as during the pre-ischemic period. At the end of the reperfusion phase, immediately after the injection of the microspheres, a transmural biopsy of the left ventricular wall was taken and stored within the drills at $-80^{\circ} \mathrm{C}$. All biopsy specimen were analyzed for the tissue contents of creatine phosphate, ATP, ADP, $A M P$, and their degradation products, and of glycogen, lactate and inorganic phosphate. The techniques used are described in chapter II. At the end of the reperfusion period, the hearts were perfused with $2.5 \%$ glutaraldehyde during 5 minutes to facilitate cutting of the myocardial tissue for microsphere determination.

At the end of the reperfusion phase, the hearts were weighed again and subsequently divided into 4 horizontal slices as described in the previous chapter. The radioactivity levels of the different tissue samples were determined using a Packard Multi-Channel Analyzer, as described in detail by Prinzen and co-workers (1981).

\section{3. STATISTICS}

Differences between the values of the various variables in the WKY and SHR groups were evaluated for statistical significance using the Mann-Whitney U-test. Differences between the pre-ischemic and postischemic values within the groups were evaluated for statistical difference by applying the Wilcoxon's matched-pairs signed-ranks test. P-values smaller than or equal to 0.05 were considered to be statistically significant. 
The heart and body weight values and heart to body weight ratio's in the SHR and WKY rats are presented in Table VIII. 2. SHR showed significantly higher values for heart weight and heart weight to body weight ratio than the WKY rats. The body weight walues of the two groups of rats were comparable.

Table VIIl. 2 Heart weight, body weight, and heart weight to body weight rario (HWIBW.10-2) in 8 months old WKY and SHR rats.

$\begin{array}{cccc} & & & \\ & \text { Heart weight }(\mathrm{g}) & \text { Body weight }(\mathrm{g}) & \mathrm{HW} / \mathrm{BW} .1 .0^{-2} \\ \mathrm{WKY}(\mathrm{n}=1 \mathrm{~B}) & 1.64 & 433 & 0.39 \\ & 1.51-1.79 & 398-450 & 0.37-0.40 \\ \text { SHR }(\mathrm{n}=18) & 2.06 & & 0.50 \\ & 2.00-2.13 & 403-420 & 0.49-0.51\end{array}$

Data are presented as median values and $95 \%$ confidence limits. * : significanily differen from the values in the SHR group $(p<0.05)$.

\section{4.1. Hemodynamics}

The hemodynamic data in the hearts perfused at $8.0 \mathrm{kPa}$ groups are depicted in Figure VIII. 1. At the end of the the pre-ischemic period significantly higher $d P_{u v} / d t_{\max }$ values were reached in the SHRL rop than in the corresponding non-hypertrophied group. Coronary flow per gram heart weight was significantly higher in the control than in the hypertrophied hearts throughout the pre-ischemic ejecting period.

During reperfusion restoration of electrical and mechanical function was present in both groups, except for one heart in the group of the hypertrophied thearts. All recovering hearts could be stimulated after 15 minutes reperfusion. In the group of hypertrophied hearts coronary flow per gram heart weight was lower than in the pre-ischemic period, especially within the first 10 minutes of reperfusion. In the nonhypertrophied hearts coronary flow per gram heart weight was completely restored to pre-ischemic levels. Reactive hyperemia was present in 


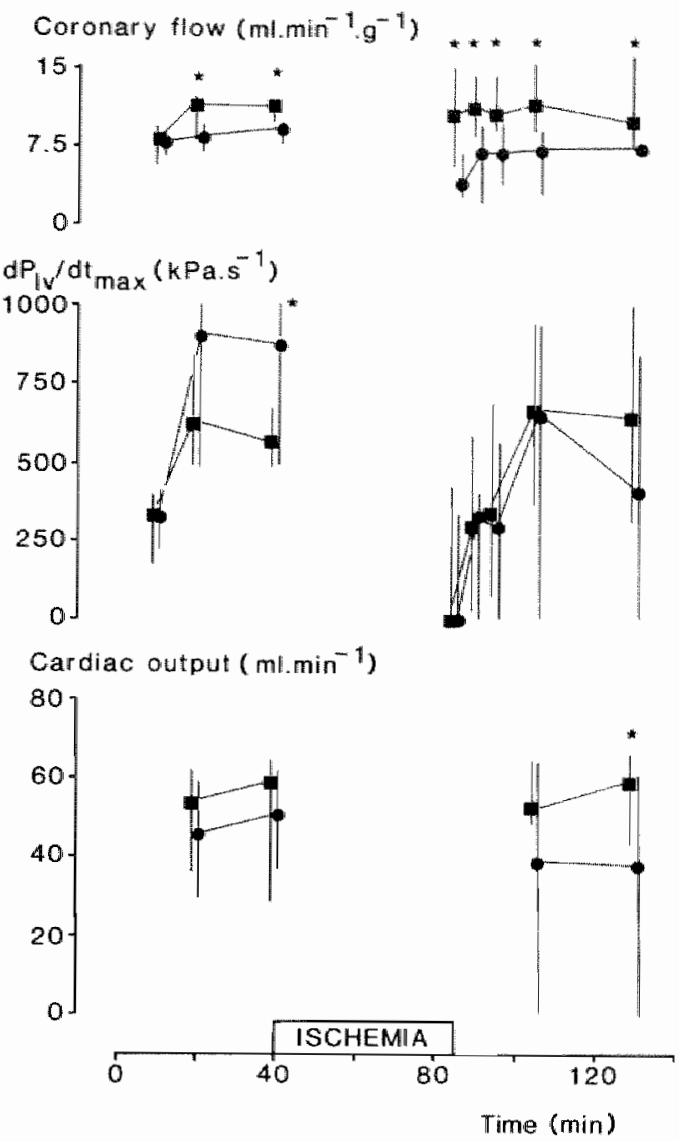

Figure WIII. 1

Hemodynamic dara in isolated, efecting hearts of 8 months old WKYL rep $(\mathbf{m} ; n=7)$ and $S H R L_{\text {rep }}(\bullet ; n=4)$, perfused at a diastoJic aortic pressure of $8.0 \mathrm{kPa}$, before and after 45 minutes giobal ischemia. The data are presented as median values and $95 \%$ confidence limits. $d P_{\text {d }}$ ditmax : maximum first derivative of left ventricular pressure. * significant difference between both groups $(p<0.05)$.

some non-hypertrophied hearts, but completely absent in the group of hypertrophied hearts. In the non-hypertrophied hearts left ventricular $\mathrm{dP} / \mathrm{dt}_{\mathrm{max}}$ and cardiac output were restored to pre-ischemic levels. In hypertrophied hearts, however, the restoration of contractile function and ejection was incomplete. The percentage recovery of cardiac output in these bearts amounted to $76 \%$ of the pre-ischemic value ( $t=40$ minutes). 
The hemodynamic performance of hearts perfused at $13.3 \mathrm{kPa}$ is presented in Figure VIII. 2. During the pre-ischemic period, no significant differences were observed between the hemodynamic variables in the SHRH rep and WKYH rep groups, except for a slightly, but significantly higher coronary flow per gram heart weight in the WKYHrop just prior to ischemia. During reperfusion coronary flow showed reactive hyperemia in control hearts, but not in hypertrophied hearts. In contrast to the hearts perfused at $8.0 \mathrm{kPa}$, coronary flow per gram heart

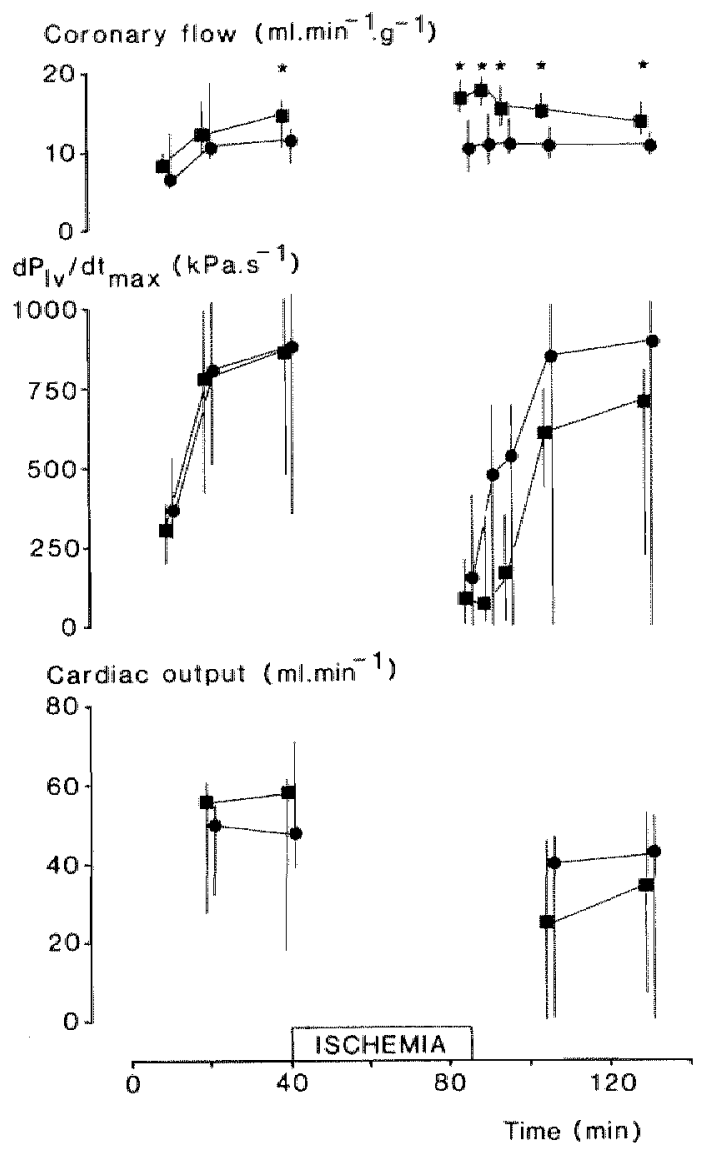

Figure VIII. 2

Hemodynamic data in isolated, ejecting hearts of 8 months old WKYH rap $(\mathbf{\square} ; n=4)$ and $S H R H_{\text {rap }}\left(\bullet_{i} n=7\right)$, perfused at a diastolic aortic pressure of $13.3 \mathrm{kPa}$, before and after 45 minutes global ischemia. The data are presented as median values and $95 \%$ confidence limits. $d P_{\mathrm{w}} / d t_{\max }$ : maximum first derivative of left ventricular pressure. : significant difference between both groups $(p<0.05)$. 
weight was not depressed in the latter hearts and reached values compat rable to those in the pre-ischemic period. The recovery of $\mathrm{dPav} / \mathrm{dtmax}$ and cardiac output in the hypertrophied hearts was almost complete. Cardiac output reached a median value equal to $90 \%$ of the pre-ischemic value. Otherwise, lower values were found in the control hearts. In these hearts, the recovery of $\mathrm{dP}_{\mathrm{lv}} / \mathrm{dt}_{\max }$ and cardiac output amounted to $82 \%$ and $59 \%$ (median values) of the pre-ischemic values, respectively. However, due to the limited number of hearts studied, the latter difference did not reach the level of significance.

At low perfusion pressure during reperfusion, reactive hyperemia was absent in hypertrophied as well as in non-hypertrophied hearts. In addition, in hypertrophied hearts coronary flow per gram heart lissue during reperfusion was lower than during the pre-ischemic period, especially in the initial reperfusion phase as compared to the pre-ischemic period. As shown in Table VIII. 3, coronary resistance was almost doubled in the hypertrophied hearts while it was not changed in the nonhypertrophied hearts.

Table WHI. 3 Coronary vascular resistance (CVR) in isolated, ejecting hearls of 8 months old SHR and WWK hearts at the end of the pre-ischemic period $(t=40$ minutes) and at the initial phase of the reperfusion period $(t=90$ minutes).

\begin{tabular}{|c|c|c|c|c|}
\hline & WKYL & SHRLix & WKYH & $\mathrm{SHRH}_{\mathrm{x}}$ \\
\hline CVR at $t=40 \mathrm{~min}$ & 0.83 & $0.94^{\star}$ & 1.14 & 1.20 \\
\hline CVR at $t=90 \mathrm{~min}$ & 0.81 & $1.90^{\circ}$ & 0.88 & 1.30 \\
\hline
\end{tabular}

Data are presented in kPa.min.g.ml-1; $\star$ : significantly different from the post-ischemic walues at $t=90$ minules $(p<0.05)$; : significantly different from the values in the WKYL mearts $(p<0.05)$

The results of the left ventricular function curves are presented in Figure VIII. 3. During the pre-ischemic period in the groups perfused at 8.0 and $13.3 \mathrm{kPa}$, the control hearts tended to eject more fluid than the hypertrophied hearts when aortic pressure and left atrial pressure were low. At the highest aortic pressure load of $13.3 \mathrm{kPa}$ hypertrophied hearts ejected amounts of fluid similar to those in the control hearts. 
During reperfusion at $8.0 \mathrm{kPa}$, the pump function in control hearts remained higher than in the hypertrophied hearts. When the hearts were reperfused at a high aortic pressure, however, hypertrophied hearts tended to reach higher output values than the control hearts when the hearts were perfused at high afterload in combination with a high preload.

WKYL and SHRL

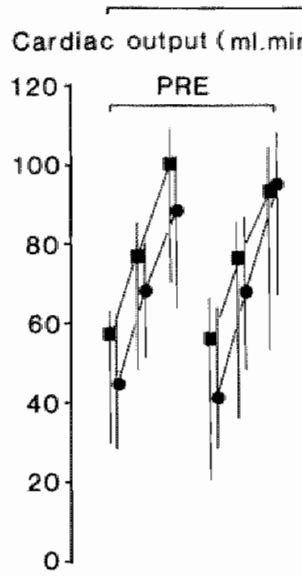

$P_{\mathrm{la}}(\mathrm{kPa})$

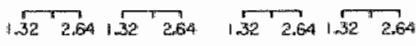

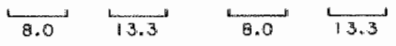

$$
\begin{aligned}
& \mathrm{P}_{\mathrm{ao}}(\mathrm{kPa})
\end{aligned}
$$

WKYH and SHRH

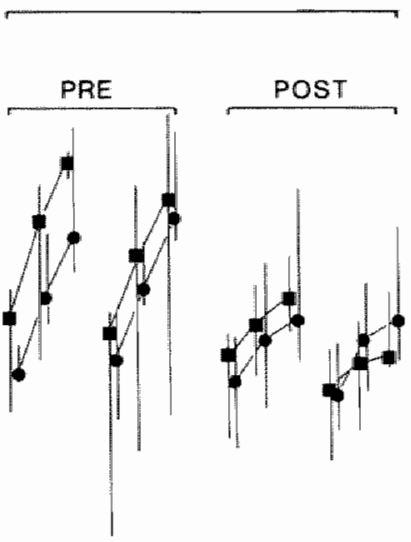

$$
\begin{aligned}
& P_{\text {la }}(\mathrm{kPa})
\end{aligned}
$$

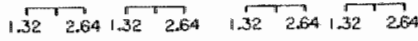

$$
\begin{aligned}
& \text { 8.0 } 13.3 \quad 13.3 \\
& P_{a 0}(k P a)
\end{aligned}
$$

\section{Figure VIII. 3}

Pressure-volume curves in isolated, ejecting hearts of 8 months old WKYL mop $(\mathbf{0} ; n=7)$ and SHRL rep $(n=4 ;$ left panel) and in hearts of 8 months old WKYH,op $(\mathbf{0} ; n=4)$ and $S H R H_{\text {rep }}(\bullet ; n=7 ;$ right panel) before (PRE) and after 45 minutes global ischenia (POST). Data are presented as median walues and $95 \%$ confidence limits. $P_{t a}$ : left atrial pressure (preload); $P_{a x}:$ diastolic aorvic pressure (afterload). $\star$ : significant difference between both groups $(p<0.05)$. 


\section{4.2. Regional myocardial flow}

The detailed flow distribution over the left ventricular wall in hearts perfused at $8.0 \mathrm{kPa}$ is presented in Figure VIII. 4. The pooled epicardial and endocardial flow values in these groups are presented
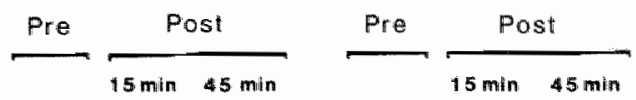

Flow $\left(\right.$ ml.min $\left.{ }^{-1} \cdot g^{-1}\right)$
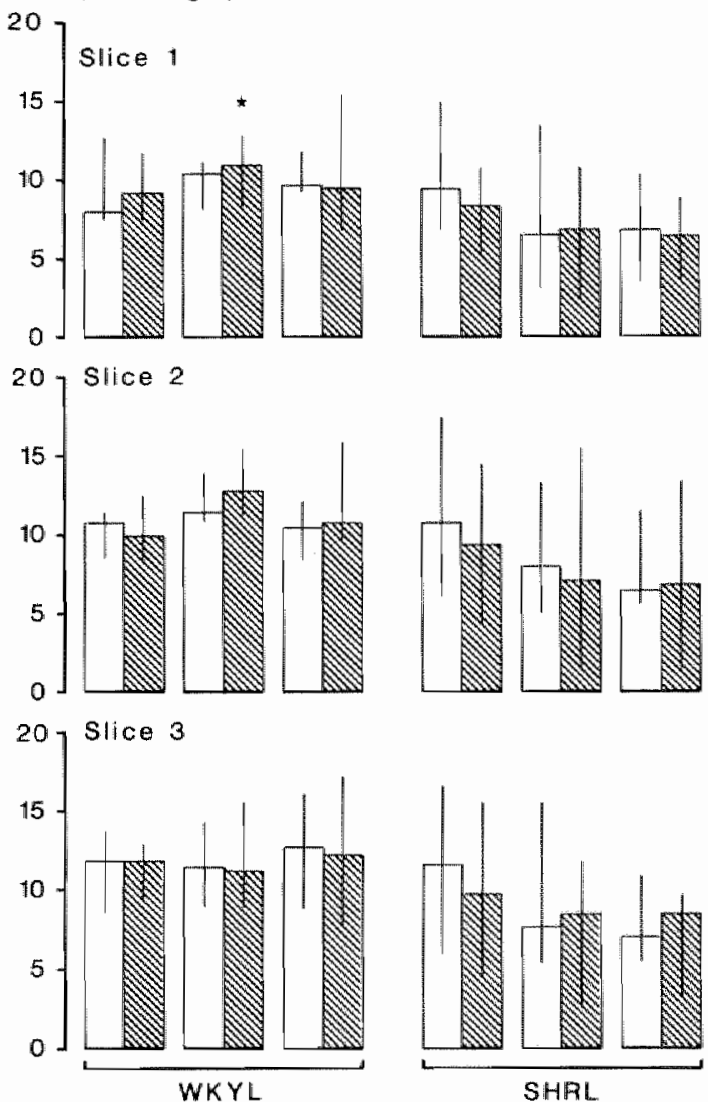

Figure VIII. 4

Regional myocardial flow values in isolated, ejecting hearts of 8 months old WKYL rep (left panel, $n=7$ ) and $S H R L_{\text {rap }}$ (right panel, $n=4$ ), perfused at a diastolic aortic pressure of $8.0 \mathrm{KPa}$ before and after $45 \mathrm{minu}$ tes global ischemia. Slice $I$ is close to the base of the heart. Data are presented as median values and $95 \%$ confidence limits. Open bars : epicardial flow; halched bars: endocardial flow. : significantly different from the corresponding values in the SHR group $(p<0.05)$. 
in Table VIII. 4. In WKYL $\mathrm{L}_{x=p}$ rat hearts, no significant differences were found between epicardial and endocardial flow throughout the experimental period. In hearts of $S H R L_{r o p}$ during the pre-ischemic period, the endocardial flow tended to be lower than epicardial flow, although the differences were not statistically significant. During the reperfusion period, in the SHRLrop hearts both epicardial and endocardial flow tended to be lower than the corresponding pre-ischemic values and the values in the non-hypertrophied hearts, especially during the initial phase of the reperfusion period. The overall endocardial flow in the hypertrophied hearts was significantly lower than in the non-hypertrophied hearts during this phase.

Table VIII. 4

The pooled eptcardial and endacardial flaw values (ml.min- $\mathrm{g}^{-1}$ wet weighl), determined before (Pre), 15 minutes after the start of reperfusion (Post 1) and at the end of the 45 minutes reperfusion period (Post 2) following 45 minutes global ischemia in the various experimental groups.

\begin{tabular}{|c|c|c|c|c|c|c|}
\hline & \multicolumn{2}{|c|}{ Pre } & \multicolumn{2}{|c|}{ Post 1} & \multicolumn{2}{|c|}{ Post 2} \\
\hline & $\mathbb{E p} 1$ & Endo & Ep1 & Endo & Epi & Endo \\
\hline $\begin{array}{l}\text { WKYLY }=P \\
(n=7)\end{array}$ & $\begin{array}{c}9.8 \\
8.6-12.7\end{array}$ & $\begin{array}{l}10.3 \\
7.1-12.6\end{array}$ & $\begin{array}{l}11.1 \\
7.9-14.6\end{array}$ & $\begin{array}{l}11.5^{\star} \\
8.2-16.4\end{array}$ & $\begin{array}{c}10.3 \\
4.8-14.7\end{array}$ & $\begin{array}{l}10.6 \\
4.7-17.8\end{array}$ \\
\hline $\begin{array}{l}S H R L_{x}=0 \\
(n=4)\end{array}$ & $\begin{array}{c}10.6 \\
6.3-16.4\end{array}$ & $\begin{array}{c}9.2 \\
4.7-13.6\end{array}$ & $\begin{array}{c}7.5 \\
4.4-14.1\end{array}$ & $\begin{array}{c}7.5 \\
2.0-12.6\end{array}$ & $\begin{array}{c}6.5 \\
4.9-11.0\end{array}$ & $\begin{array}{c}7.5 \\
2.5-13.0\end{array}$ \\
\hline $\begin{array}{l}W K Y H x=- \\
(n=4)\end{array}$ & $\begin{array}{c}11.5 \\
8.9-13.3\end{array}$ & $\begin{array}{c}11.9^{\star} \\
10.6-14.9\end{array}$ & $\begin{array}{c}14.6 \\
12.9-18.6\end{array}$ & $\begin{array}{c}15.8 \\
14.8-18 \cdot 3\end{array}$ & $\begin{array}{c}12.5 \\
8.8-16.7\end{array}$ & $\begin{array}{c}12.9 \\
11.1-15.0\end{array}$ \\
\hline $\begin{array}{l}\mathrm{SHRH}_{2}=0 \\
(n=7)\end{array}$ & $\begin{array}{c}9.5 \\
7.5-12.1\end{array}$ & $\begin{array}{c}7.0 \\
6.2-11.7\end{array}$ & $\begin{array}{c}12.3^{\circ} \\
10.8-17.1\end{array}$ & $\begin{array}{l}11.9 \\
6.1-18.3\end{array}$ & $\begin{array}{c}12.6 \\
6.1-16.2\end{array}$ & $\begin{array}{c}10.4 \\
9.2-14.5\end{array}$ \\
\hline
\end{tabular}

WKYLmep and SHRL rap refer to hearts perfused at $8.0 \mathrm{kPa}$; WKYHrop and SHRHrep to the hearts perfused a. $13.3 \mathrm{kPa}$. Data are presented as median values and $95 \%$ confidence limits. a : pre-ischemic and post-ischemic differences not stistically investigated $(n=4)$. $\star$ : significantly different from the values in the SHR hearts, perfused at the same perfusion pressure; : significanly different from the pre-ischemic values in the same hearts $(p<0.05)$.

In control hearts perfused at high diastolic aortic perfusion pressure $(13.3 \mathrm{kPa})$, a comparable transmural flow distribution pattern was found as in control hearts perfused at $8.0 \mathrm{kPa}$ (Figure VIII. 5). However, during reperfusion higher flows were observed at the start of the 
ejection period due to the reactive hyperemia. The endocardial flow tended to be higher than the epicardial flow throughout the reperfusion period, but this difference did not reach the level of significance. In hypertrophied hearts overall endocardial flow tended to be lower than epicardial flow during the pre-ischemic period. In contrast with the hearts perfused at $8.0 \mathrm{kPa}$, significantly higher epicardial flow values were found during the initial phase of reperfusion. As compared
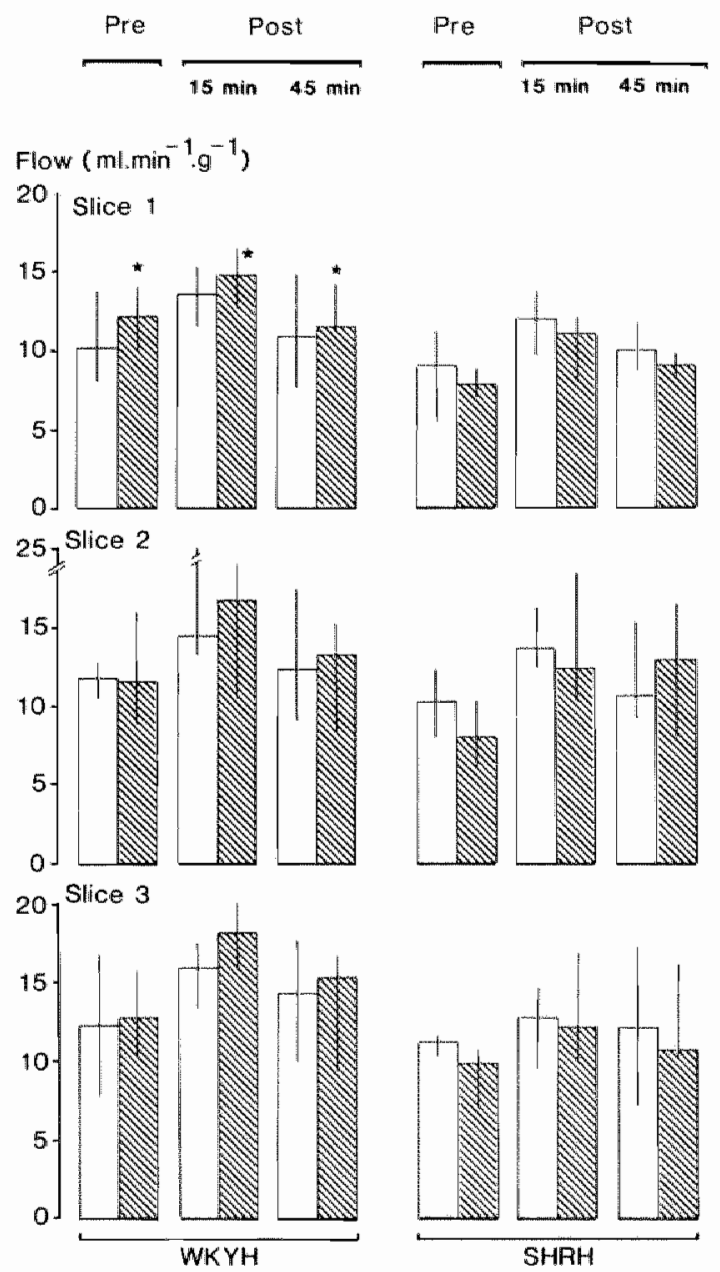

Figure MII. 5 Regional myocardial flow values in isolated, ejecting hearts of 8 months ald WKYH mop (left panel, $n=4$ ) and SHRH map (right panel, $n=7$ ), perfused at a diastalic aortic pressure of $13.3 \mathrm{kPa}$ before and after 45 minutes global ischemia. Slice 1 is close to the base of the heart. Data are prescnled as median values and $95 \%$ confidence limits. Open bars : epicardial flow; halched bars: endocardial flow. $\star$ : significanlly different from the corresponding values in the SHR soup $(p<0.05)$. 
to the values found in the control hearts, significantly lower endocardial flows were found in the endocardium of the slice, situated at the base of the heart (Figure VIII. 5). No significant differences were found between epicardial and endocardial flow during the reperfusion period.

\section{43. Biochemical data}

\section{Findings in coronary effluent}

Small amounts of LDH were released from the non-hypertrophied and bypertrophied hearts during the pre-ischemic period. During the reperfusion period in SHRL comparable pattern of enzyme loss was observed (Figure VIII. 6). All groups showed an increased enzyme release during the first 20 minutes of the reperfusion phase. At the end of the reperfusion period enzyme activity in the coronary effluent returned to the pre-ischemic values, especially when the perfusion pressure was low. Throughout the reperfusion period in non-hypertrophied hearts, enzyme release was more pronounced at high than at low perfusion pressure. Table VIII. 5 shows the total post-ischemic enzyme loss in the 4 reperfused groups. At low perfusion pressure hypertrophied hearts lost $16.3 \mathrm{U} \cdot \mathrm{g}^{-1}$ wet weight, corresponding to $7.8 \%$ of the total LDH activity of the hypertrophied heart of the 8 months old rat (see native values: chapter IV). The activity lost by the control hearts tended to be lower $\left(10.4 \mathrm{U} \cdot \mathrm{g}^{-1}\right.$ wet weight), corresponding with $2.8 \%$ of total myocardial $\mathrm{LDH}$ activity. However, the difference was not statistically significant. In contrast, during reperfusion, higher amounts of enzyme were released by the non-hypertrophied hearts than by the hypertrophied hearts when the perfusion pressure was high $(13.3 \mathrm{kPa})$. However, due to the differences in native enzyme content in the myocardial tissue of both groups, SHRH hearts lost slightly more enzyme than the non-hypertrophied WKYH rep. $_{\text {. }}$

Slightly higher amounts of lactate were released by the SHRL rep than by the WKYLrop hearts during the pre-ischemic period (Table VIII. 6). The pattern of lactate release was identical in all experimental groups (data not shown). During the first 5 minutes of reperfusion in the groups perfused at $8.0 \mathrm{kPa}$, WKYLrop and $S H R L_{\text {rop }}$ released comparable amounts of lactate, i.e. 6.6 vs $6.0 \mu \mathrm{mol} . \mathrm{min}^{-1} \cdot \mathrm{g}^{-1}$ wet weight, respectively. Also in WKYHrop and SHRH rop comparable lactate amounts were released, i.e. 6.8 and $7.7 \mu \mathrm{mol} . \mathrm{min}^{-1} \cdot \mathrm{g}^{-1}$ wet weight, respectively. In the later reperfusion phase, comparable values were found as during the pre-ischemic period. Throughout the reperfusion period, the overall release of lactate was comparable between the various groups. (Figure VIII. 5). 


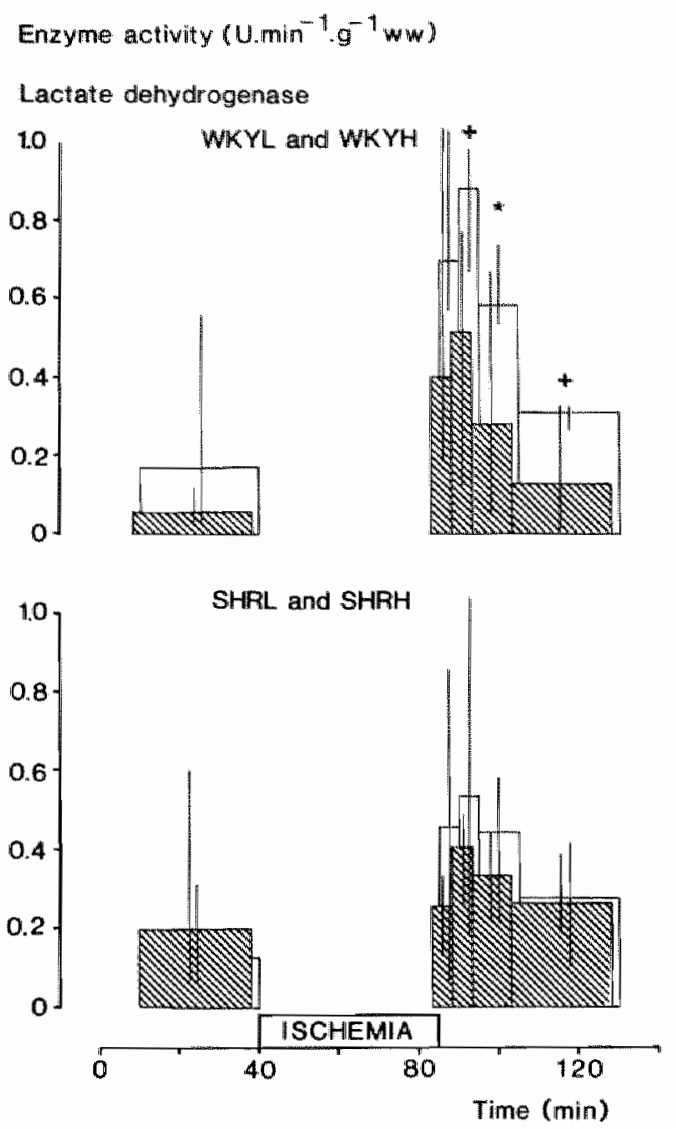

Figure VIII. 6 The release of laciate dehydrogenase in isolated, ejecting hearts of 8 months old WKYrop (upper panel) and SHR mo (lower panel) before and after 45 minutes global ischemia. Hafched bars: WKYL,m: $n=7_{i}$ SHRL rapi $n=4$. Open bars : WKYHrep : $n=4$; SHRH nop : $n=7$. Data are presented as median values and $95 \%$ confidence limits. " significantly different from the corresponding values in the SHR group; +: significantly different from the values in the corresponding groups, perfused at $8.0 \mathrm{kPa}(p<0.05)$.

The total release of the degradation products of adenine nucleotides, i.e. the sum of adenosine, inosine, hypoxanthine, xanthine and uric acid, is presented in Figure VIII. 7. During the first 5 minutes of the reperfusion phase significantly more degradation products were released from the WKY rep than from the SHR rop hearts at both high and low perfusion pressure. In the low perfusion pressure groups over the total reperfusion period $1.76 \mu \mathrm{mol} . \mathrm{g}^{-1}$ wet weight was lost from the control hearts, while SHR rop hearts lost $1.48 \mu \mathrm{mol}^{-1} \mathrm{~g}^{-1}$ wet weight. 
Activify of lactate dehydrogenase (U.g-x wet weight) released from isolated, ejecting hearts of 8 months old SHR and WKY rats before (Pre) and after (Post) 45 minutes global ischemia in relation to the total enzyme acivity, present in these hearts.

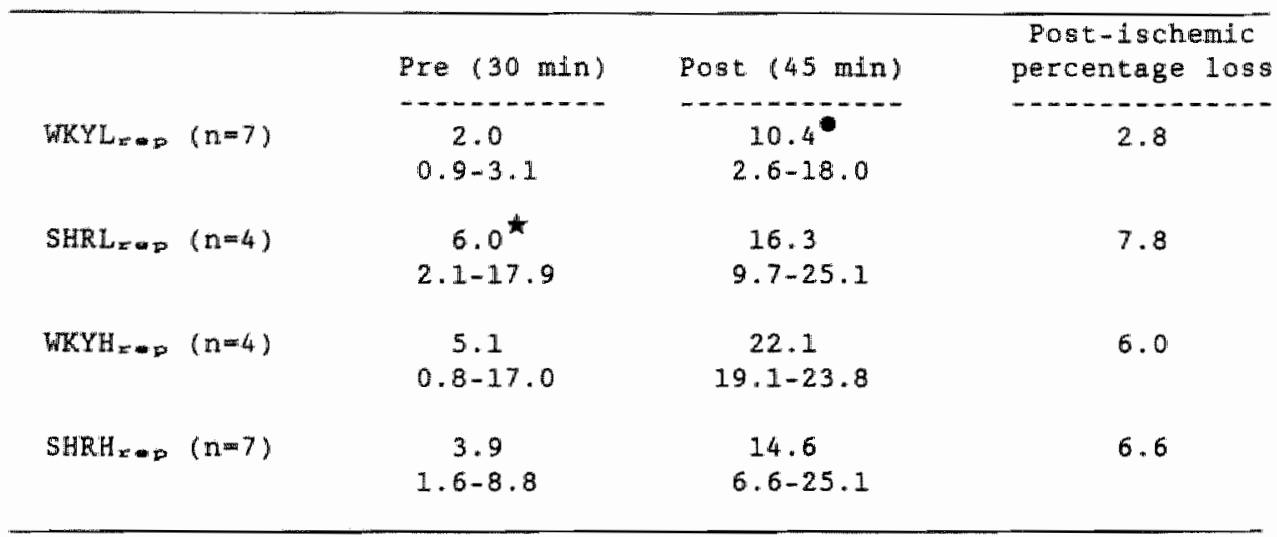

Percentage loss was calculated by relating the tolat post-ischemic enzyme loss lo the native tissue enzyme content, as presented in chapter IV. Data are presented as median values and $95 \%$ confidence limils. $\star$ : significantly different from corres. ponding walues in the WKY group; : significantly different from corresponding values in the $W K Y$ hearts, perfused at $13.3 \mathrm{kPa}(p<0.05)$.

Table VIH. 6 Loss of lactate ( $\mu$ mol.g wet weight) before (pre) and during 45 minutes reperfusion following 45 minules glabal ischemia (Post) from isolated hearts of 8 wonths old SHR and WKY rats.

\begin{tabular}{|c|c|c|c|c|}
\hline & $\begin{array}{c}\text { WKYLU } \\
(\mathrm{n}=7)\end{array}$ & $\begin{array}{l}\text { SHRL }=0 \\
(n=4)\end{array}$ & $\begin{array}{l}\text { WKYHrep } \\
(n=4)\end{array}$ & $\begin{array}{c}\text { SHRH } \\
(n-7)\end{array}$ \\
\hline & $\cdots+\cdots-n-$ & 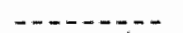 & 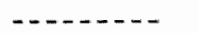 & $=---n-n$ \\
\hline Pre $(30 \mathrm{~min})$ & $\begin{array}{c}38.6 \\
26.1-47.9\end{array}$ & $\begin{array}{c}52.4^{\star} \\
45.9-63.2\end{array}$ & $\begin{array}{c}41.1 \\
31.5-45.3\end{array}$ & $\begin{array}{c}55.9 \\
38.1-62.2\end{array}$ \\
\hline Post $(45 \mathrm{~min})$ & $\begin{array}{c}88.9 \\
65.8-186.4\end{array}$ & $\begin{array}{l}106.8 \\
93.1-111.4\end{array}$ & $\begin{array}{c}96.3 \\
86.6-107.4\end{array}$ & $\begin{array}{c}105.0 \\
77.6-122.8\end{array}$ \\
\hline
\end{tabular}

Dala are presented as median values and $95 \%$ confidence limils. $\star$ : significamaly different from the values in the cortesponding WKY group $(p<0.05)$. 
Degradation products of adenine nucleotides (nmol.min ${ }^{-1} \cdot g^{-1}$ ww)

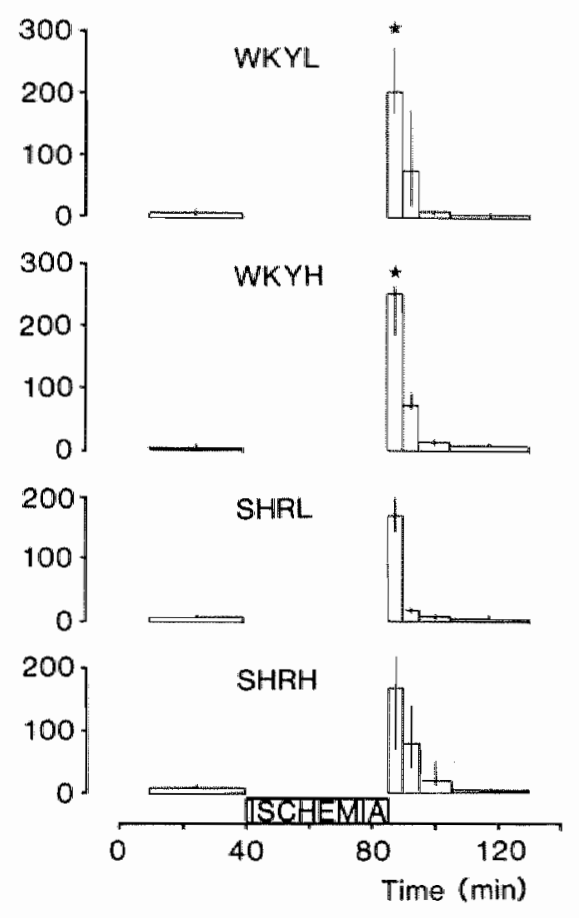

Figure VII. 7 Release of degradation products of adenine nucleotides (sum of adenosine, inosine, hypoxanthine, xanthine and uric acid) in isolated, ejecting hearts of 8 manths ald WKYL mep $(n=7)$, SHRL map $(n=4)$, WKYH mep $(n=4)$ and SHRH rep $(n=7)$ 'before and after 45 minutes global ischemia. Values are presented as median values and $95 \%$ confidence limits. : significantly higher than in the corresponding SHR group during the same time interval $(p<0.05)$.

This difference did not reach the level of significance. In the high perfusion pressure groups $1.93 \mu \mathrm{mol}^{-\mathrm{g}^{-1}}$ wet weight was lost by the control hearts as compared to $1.39 \mu \mathrm{mol} . \mathrm{g}^{-1}$ wet weight in the hypertrophied hearts. As in the groups perfused at $8.0 \mathrm{kPa}$, the higher, although non-significant, release in non-hypertrophied hearts was caused by a higher loss of inosine $(p<0.05)$. In these hearts, the release of uric acid tended to be higher (Table VIII. 7). 
Table WII. 7 The total amounts of degradation products of adenine nucleotides (nmol.g-l wel weight) lost from isolated hearts of 8 months old $S H R$ and WKY rats before (PRE; 30 minules) and after 45 minutes global ischemia (POST; 45 minutes), and the post-ischemic percentage loss.

\begin{tabular}{|c|c|c|c|c|c|c|}
\hline & ADO & INO & $H X$ & $\mathrm{x}$ & UA & TOT \\
\hline WKYYI $\quad(n=$ & $\cdots+\cdots$ & $-\cdots----$ & ----- & $-\cdots-\cdots$ & $--\cdots---$ & $-\cdots-\cdots$ \\
\hline \multirow{2}{*}{$\mathrm{PRE}$} & 0 & 0 & 0 & 0 & 236 & 246 \\
\hline & $0-0$ & $0-78$ & $0-0$ & $0-0$ & $165-406$ & $165-4.06$ \\
\hline \multirow[t]{2}{*}{ POST } & 151 & 866 & 90 & 107 & 501 & 1764 \\
\hline & $90-274$ & $429-1169$ & $50-206$ & $89-195$ & $353-726$ & $1156-2568$ \\
\hline * LOSS & 9 & 51 & 5 & 6 & 29 & $100 \%$ \\
\hline \multicolumn{7}{|c|}{ SHRL $=\infty \quad(n=4)$} \\
\hline \multirow{2}{*}{ PRE } & 0 & 18 & 0 & 0 & 243 & 303 \\
\hline & $0-0$ & $0-52$ & $0-0$ & $0-0$ & $232-277$ & $232-315$ \\
\hline \multirow[t]{2}{*}{ POST } & 124 & 615 & 107 & 128 & 469 & 1479 \\
\hline & $91-1146$ & $503-664$ & $100-135$ & $112-183$ & $443-624$ & $1249-1676$ \\
\hline 7 LOSS & 9 & 43 & 7 & 9 & 33 & 1002 \\
\hline \multicolumn{7}{|c|}{ WKYH $-\infty \quad(n=4)$} \\
\hline \multirow{2}{*}{ PRE } & 0 & 0 & 0 & 0 & 213 & 213 \\
\hline & $0-0$ & $0-0$ & $0-0$ & $0-0$ & $169-262$ & $169-262$ \\
\hline \multirow[t]{2}{*}{ POST } & 198 & $990^{\star}$ & 95 & 90 & 544 & 1930 \\
\hline & $120-293$ & $730-1006$ & $55-132$ & $76-136$ & $500-663$ & $1480-2182$ \\
\hline$\approx$ LOSS & 10 & 52 & 5 & 5 & 28 & $100 \%$ \\
\hline \multicolumn{7}{|c|}{$\underline{\mathrm{SHEH}} x-\infty(n=7)$} \\
\hline \multirow[t]{2}{*}{ PRE } & 0 & 0 & 0 & 0 & 222 & 222 \\
\hline & $0-9$ & $0-0$ & $0-0$ & $0-0$ & $175-293$ & $184-293$ \\
\hline \multirow[t]{2}{*}{ POST } & 124 & 550 & 79 & 106 & 469 & 1391 \\
\hline & $0-225$ & $417-971$ & $42-169$ & $53-198$ & $175-679$ & $890-1963$ \\
\hline z Loss & 10 & 39 & 6 & 8 & 37 & $100 \%$ \\
\hline
\end{tabular}

WKYL mep and SHRL,ep refer to hearts perfused at $8.0 \mathrm{kPa}$, WKYH rap and SHRH map to hearts perfused at $13.3 \mathrm{kPa}$. ADO : adenosine; INO : inasine; HX : hypoxanthine; $X$ : xanhine; UA : uric acid; TOT: sum of all degradation products. Data are presented as median values and $95 \%$ confidence limits. $\star$ : significantly different from the values in the corresponding $S H R$ hearts $(p<0.05)$. 
Significantly lower creatine phosphate and ATP contents were found in the native tissue of hypertrophied hearts, as compared to nonhypertrophied hearts (Table VIII. 8). ADP, AMP and inorganic phosphate contents were higher in the former hearts. Consequently, significantly lower energy charge levels were found in the hypertrophied than in the non-hypertrophied hearts. Interestingly, after 40 minutes of perfusion (see pre-ischemic values in Table VIII. 8), the significant differences in these variables between the two groups had disappeared. In the hypertrophied hearts creatine phosphate and ATP levels had increased, while the ADP and inorganic phosphate content had decreased. In the hypertrophied as well as the non-hypertrophied hearts the energy charge levels were higher, as compared to the values in the native tissue. At the end of the ischemic period in both groups the creatine phosphate and ATP contents were low and the ADP and AMP contents were high, resulting in a low energy charge, as compared to the pre-ischemic values. Lactate levels were high, while the glycogen contents were low in both groups, as compared to the pre-ischemic values. No significant differences were found between the sum of adenine nucleotides and the energy charge levels in control and hypertrophied hearts.

Hypertrophied hearts, reperfused during 45 minutes at $8.0 \mathrm{kPa}$ showed significantly lower ATP and glycogen contents than the corresponding WKY rop hearts (Table VIII. 9). As a consequence, energy charge was significantly higher in the control hearts. At high perfusion pressure (13.3 kPa), no significant differences were observed between the various variables in both groups.

At the end of 45 minutes reperfusion the tissue contents of the individual breakdown products of adenine nucleotides, as adenosine, inosine, hypoxanthine, and xanthine, were very low in the various groups (Table VIII. 9). The adenosine and inosine levels were lower than $0.5 \mu \mathrm{mol} . \mathrm{g}^{-1}$ dry weight. No hypoxanthine and xanthine could be detected. 


\begin{tabular}{|c|c|c|c|c|c|c|}
\hline & & $W K Y$ & & & SHR & \\
\hline & $\underset{(n=3)}{N a t}$ & $\begin{array}{l}\text { Pre } \\
(n=4)\end{array}$ & $\begin{array}{r}\mathbb{I} s \mathrm{ch} \\
(n=4)\end{array}$ & $\begin{array}{c}\text { Mat } \\
(n-3)\end{array}$ & $\begin{array}{c}\text { Pre }^{\mathrm{D}} \\
(\mathrm{n}=4)\end{array}$ & $\begin{array}{l}\text { Isch } \\
(n=4)\end{array}$ \\
\hline$C P$ & $\begin{array}{c}54.7 \\
35.2-59.4\end{array}$ & $\begin{array}{c}39.3 \\
37.2-59.2\end{array}$ & $\begin{array}{c}9.8 \\
9.2-10.5\end{array}$ & $\begin{array}{c}19.4 \\
16.1-22.7\end{array}$ & $\begin{array}{c}41.5 \\
40.1-43.0\end{array}$ & $\begin{array}{l}4.5 \\
2.0-4.9\end{array}$ \\
\hline ATP & $\begin{array}{c}21.8^{t h} \\
20.3-22.8\end{array}$ & $\begin{array}{c}19.9 \\
11.5-22.4\end{array}$ & $\begin{array}{c}6.9 \\
5.1-8.4\end{array}$ & $\begin{array}{c}16.6 \\
14.4-18.8\end{array}$ & $\begin{array}{c}19.1 \\
18.0-20.2\end{array}$ & $\begin{array}{c}6.2 \\
4.7-6.2\end{array}$ \\
\hline$A D P$ & $\begin{array}{c}4.4^{\star} \\
3.6-4.7\end{array}$ & $\begin{array}{c}3.8 \\
2.9-4.9\end{array}$ & $\begin{array}{c}6.5 \\
6.1-7.0\end{array}$ & $\begin{array}{c}6.1 \\
5.9-6.4\end{array}$ & $\begin{array}{c}4.2 \\
3.7-4.7\end{array}$ & $\begin{array}{c}7.0 \\
4.1-7.2\end{array}$ \\
\hline AMP & $\begin{array}{c}0.6^{\star} \\
0.5-0.6\end{array}$ & $\begin{array}{c}0.7 \\
0.6-1.1\end{array}$ & $\begin{array}{c}2.1 \\
1.7-2.2\end{array}$ & $\begin{array}{c}1.2 \\
1.2-1.2\end{array}$ & $\begin{array}{c}0.5 \\
0.4-0.7\end{array}$ & $\begin{array}{c}2.3 \\
1.1-2.5\end{array}$ \\
\hline SUM & $\begin{array}{c}26.0 \\
25.6-27.7\end{array}$ & $\begin{array}{c}24 \cdot 8 \\
15 \cdot 2-27.2\end{array}$ & $\begin{array}{c}15.2 \\
15.1-16.6\end{array}$ & $\begin{array}{c}23.9 \\
21.5-26.3\end{array}$ & $\begin{array}{c}23.9 \\
23.4-24.4\end{array}$ & $\begin{array}{c}15.7 \\
9.9-15.8\end{array}$ \\
\hline $\mathrm{EC}$ & $\begin{array}{c}0.90^{\star} \\
0.88-0.91\end{array}$ & $\begin{array}{c}0.89 \\
0.86-0.90\end{array}$ & $\begin{array}{c}0.66 \\
0.63-0.70\end{array}$ & $\begin{array}{c}0.82 \\
0.81-0.83\end{array}$ & $\begin{array}{c}0.89 \\
0.87-0.91\end{array}$ & $\begin{array}{c}0.63 \\
0.62-0.68\end{array}$ \\
\hline A & $\begin{array}{c}0 \\
0-0.4\end{array}$ & $\begin{array}{l}0.2 \\
0.0 .2\end{array}$ & $\begin{array}{c}2.3 \\
2.0-2.3\end{array}$ & $\begin{array}{c}0.1 \\
0.1-0.1\end{array}$ & $\begin{array}{l}0.1 \\
0.0 .2\end{array}$ & $\begin{array}{c}1.9 \\
0.8-2.7\end{array}$ \\
\hline$I$ & $\begin{array}{c}0.1 \\
0.1-0.1\end{array}$ & $\begin{array}{c}0.2 \\
0.1-0.6\end{array}$ & $\begin{array}{c}4.6 \\
4.5-6.0\end{array}$ & $\begin{array}{c}0 \\
0-0.2\end{array}$ & $\begin{array}{c}0.1 \\
0.1-0.1\end{array}$ & $\begin{array}{c}4.1 \\
2.2-6.0\end{array}$ \\
\hline $\mathrm{HX}$ & $\begin{array}{c}0 \\
0-0\end{array}$ & $\begin{array}{c}0 \\
0-0\end{array}$ & $\begin{array}{c}2.1^{\star} \\
1.9-2.3\end{array}$ & $\begin{array}{c}0 \\
0-0\end{array}$ & $\begin{array}{c}0 \\
0-0\end{array}$ & $\begin{array}{l}1.2 \\
0-1.7\end{array}$ \\
\hline$x$ & $\begin{array}{c}0 \\
0-0\end{array}$ & $\begin{array}{c}0 \\
0-0\end{array}$ & $\begin{array}{c}0.5 \\
0.5-0.6\end{array}$ & $\begin{array}{c}0 \\
0-0\end{array}$ & $\begin{array}{c}0 \\
0-0\end{array}$ & $\begin{array}{c}0.5 \\
0.4-0.7\end{array}$ \\
\hline GLY Y & $\begin{array}{c}72.5 \\
70.5-98.2\end{array}$ & $\begin{array}{c}85.3^{\star} \\
37.3-123.8\end{array}$ & $\begin{array}{c}63.7 \\
57.6-65.2\end{array}$ & $\begin{array}{c}59.9 \\
43.0-76.7\end{array}$ & $\begin{array}{c}13.7 .2 \\
123.3-151.1\end{array}$ & $\begin{array}{c}31.2 \\
14.4-82.0\end{array}$ \\
\hline LAC & $\begin{array}{c}6.7^{\star} \\
6.3-8.0\end{array}$ & $\begin{array}{l}10.7 \\
6.5-15.2\end{array}$ & $\begin{array}{c}125.3 \\
123.1-156.6\end{array}$ & $\begin{array}{c}11.1 \\
9.8-13.3\end{array}$ & $\begin{array}{c}10.7 \\
10.6-1.0 .8\end{array}$ & $\begin{array}{c}140.8 \\
95.4-182.4\end{array}$ \\
\hline PI & $\begin{array}{c}27.2^{\star} \\
21.0-36.1\end{array}$ & $\begin{array}{c}28.6 \\
27.5-36.5\end{array}$ & $\begin{array}{c}87.2 \\
80.5-98.9\end{array}$ & $\begin{array}{c}45.5 \\
43.7-47.2\end{array}$ & $\begin{array}{c}32.1 \\
24.2-40.1\end{array}$ & $\begin{array}{c}65.2 \\
48.6-104.4\end{array}$ \\
\hline
\end{tabular}

$C P$ : creatine phosphate; $A T P, A D P$ and $A M P$ : adenosine triphosphate, adenosine diphosphate and adenosine monophosphate respectively; $S U M: A T P+A D P+A M P ; E C$ : energy charge ((ATP+0.5ADP)/SUM); GLYC: glycogen; LAC : lactate; $P i$ : inorganic phosphate. $a$ : afterload $8.0 \mathrm{kPa} ; b$ : afterload $13.3 \mathrm{kPa}$. Dala are presented as median values and $95 \%$ confidence limits. *: significantly different from the data in the contesponding SHR group $(p<0.05)$. 
Table VII. 9 Tissue content ( $\mu$ mol.g-g dry weight) of biochemical substatices in isolated hearls of 8 months old SHR and WKY hearts at the end of the reperfusion period, following 45 minutes global ischemia.

\begin{tabular}{|c|c|c|c|c|}
\hline & $\begin{array}{c}W^{W Y L_{x}-p} \\
(n=7)\end{array}$ & $\begin{array}{c}\text { SURL } \\
(n=4)\end{array}$ & $\begin{array}{c}\text { WKYH } \\
(n=4)\end{array}$ & $\begin{array}{c}\text { SHRH } \\
(n=7)\end{array}$ \\
\hline & $-\cdots--n-\cdots$ & $-\ldots---n--$ & $-\ldots \ldots-\ldots$ & $-\ldots-\ldots-\ldots$ \\
\hline \multirow[t]{2}{*}{$\mathrm{CP}$} & 37.2 & 20.8 & 47.0 & 36.3 \\
\hline & $32.4-50.5$ & $6.5-38.7$ & $12.7-51.1$ & $14.7-48.6$ \\
\hline \multirow[t]{2}{*}{$A \mathbb{T P}$} & $10.8^{\star}$ & 7.1 & 9.7 & 9.8 \\
\hline & $9.7-12.9$ & $3.5-10.6$ & $9.4-11.6$ & $4.9-12.9$ \\
\hline \multirow[t]{2}{*}{$\mathrm{ADP}$} & 3.6 & 3.2 & 3.2 & 3.4 \\
\hline & $2.8-3.9$ & $2.9-9.4$ & $2.6-4.0$ & $3.3-3.6$ \\
\hline \multirow[t]{2}{*}{ AMP } & 0.7 & 0.8 & 0.5 & 0.6 \\
\hline & $0.5-0.8$ & $0.6-2.7$ & $0.4-0.6$ & $0.5-1.8$ \\
\hline \multirow[t]{2}{*}{ SUM } & 15.5 & 11.0 & 13.7 & 14.0 \\
\hline & $12.9-16.1$ & $9.1-20.6$ & $12.5-15.4$ & $10.0-16.8$ \\
\hline \multirow[t]{2}{*}{ EC } & $0.84^{\star}$ & 0.76 & 0.86 & 0.84 \\
\hline & $0.83-0.86$ & $0.55-0.81$ & $0.81-0.86$ & $0.66-0.87$ \\
\hline \multirow[t]{2}{*}{ A } & 0.2 & 0.2 & 0.1 & 0.1 \\
\hline & $0.2-0.3$ & $0.1-0.3$ & $0-0.2$ & $0-0.4$ \\
\hline \multirow[t]{2}{*}{$\mathbb{I}$} & 0.4 & 0.5 & 0.1 & 0.1 \\
\hline & $0-0.8$ & $0.1-1.5$ & $0-0.1$ & $0-1.1$ \\
\hline \multirow[t]{2}{*}{$\mathrm{HX}$} & 0 & 0 & 0 & 0 \\
\hline & $0-0$ & $0-0.7$ & $0-0$ & $0-0$ \\
\hline \multirow[t]{2}{*}{$\mathrm{x}$} & 0 & 0 & 0 & 0 \\
\hline & $0-0$ & $0-0.2$ & $0-0$ & 0.0 \\
\hline \multirow[t]{2}{*}{ GLYC } & $91.5^{\star}$ & 56.9 & 62.0 & 79.1 \\
\hline & $75.9-133.8$ & $26.3-87.7$ & $42 \cdot 2-96.1$ & $48.0-101.6$ \\
\hline \multirow[t]{2}{*}{ LAC } & 17.1 & 15.5 & 8.6 & 11.4 \\
\hline & $5.2-26.4$ & $12.3-38.7$ & $6.1-11.1$ & $10.2-23.9$ \\
\hline \multirow[t]{2}{*}{$P \dot{I}$} & 41.2 & 47.0 & 44.6 & 37.3 \\
\hline & $25.9-50.0$ & $33.5-57.1$ & $39.8-53.0$ & $33.2-62.1$ \\
\hline
\end{tabular}

CP: creatine phosphate; ATP, ADP and AMP: adenosine triphosphate, diphosphate, and morophosphate, respectively: SUM: ATP $+A D P+A M P ; E C:$ energy charge (CATP+ 0.5 ADPJ/SUM); GLYC : glycogen; LAC : lactale; $P_{t}$ : inorganic phosphate. Data are presented as median values and $95 \%$ confidence limits. * : significantly different from the data in the corresponding SHR group $(p<0,05)$. 
The findings in this study demonstrate that the functional and biochemical recovery in the hypertrophied heart of the 8 months old spontaneously hypertensive rat and the non-hypertrophied heart of the age-matched control rat after a period of global ischemia is dependent on the perfusion pressure applied to the coronary arteries. At a relatively low perfusion pressure $(8.0 \mathrm{kPa})$, recovery is almost complete in the non-hypertrophied heart. The hypertrophied heart recovers to a lesser extent. At a relatively high perfusion pressure (13.3 $\mathrm{kPa})$, recovery of the hypertrophied hearts tended to be better. At this afterload hypertrophied hearts are, for instance, more capable to withstand a high pressure load than the non-hypertrophied control hearts. At both aortic pressure levels, almost normal left ventricular flow distribution patterns are found in the control and hypertrophied hearts. In the hypertroptied hearts, only at the low perfusion pressure, a slight overall underperfusion of the left ventricular wall is observed during the initial reperfusion phase. Normal reflow in the hypertrophied heart is confirmed by the pattern of release of lactate dehydrogenase, which is comparable with that in the non-hypertrophied heart, and by the absence of sequestration of degradation products, such as lactate and purines, in the ventricular tissue. The tissue content of adenine nucleotides and glycogen and the level of the energy charge underline the better functional recovery of control hearts at the perfusion pressure. Interestingly, the better recovery of the hypertrophied heart at high perfusion pressure as compared to the low pressure group is also reflected by a slightly higher tissue content of adenine nucleotides, glycogen and energy charge.

In the 8 months old spontaneously hypertensive rat, the stage of hypertrophy can be regarded to be stable and compensated (Mirsky et al., 1983; Pfeffer and Pfeffer, 1985). This is confirmed by the results obtained in the left ventricular function curves. At high afterload (13.3 $\mathrm{kPa}$ ) comparable amounts of fluid are ejected by hypertrophied hearts and non-hypertrophied control hearts.

The calculation of the coronary vascular resistance in hearts perfused at $8.0 \mathrm{kPa}$, as shown in Table VIII. 3, reflects the increased reactivity of the coronary vascular bed of the hypertrophied heart of the spontaneouslly hypertensive rat (Folkow et al., 1970; Hallbäck et al., 1979; Langer et al., 1981; Yamori et al., 1982). In contrast to the experiments in the 16 and 18 months old rat hearts, however, the lower coronary flow is not solely confined to the endocardial layers, since flow was equally distributed over the endocardial and epicardial regions of the left ventricle. Reperfusion of the hypertrophied hearts at a higher perfusion pressure $(13.3 \mathrm{kPa})$ is not associated with a significant increase in resistance of the coronary vasculature (Table VIII. 3 ). However, significantly lower flows are found than in the non-hypertro- 
phied hearts, due to a prominent reactive hyperemia in the latter hearts and by significantly lower flow values in the endocardial layers of the hypertrophied hearts nearby the base of the heart.

Recently, in hearts of spontaneously hypertensive rats of slightly higher age (44 weeks) than the rats used in the present study, or in even younger animals (16 weeks), a lower functional recovery following a period of global ischemia was found than in age-matched controls (Mochizuki et al., 1986). It should be noted that the coronary perfusion pressure applied in the study of the cited investigators was equal to the low perfusion pressure used in our studies. In contrast, in 2 months old rats hearts, Haneda and co-workers (1986) found a slightly better functional recovery of the hypertrophied rat heart than in the nonhypertrophied heart at the same low perfusion pressure. However, the better functional recovery only occurred after a relative short period of ischemia (less than 10 minutes). After longer periods of ischemia functional recovery in the hypertrophied hearts was comparable or even worse than in the non-hypertrophied hearts. These results emphasize the importance of the height of the perfusion pressure, used to reperfuse the hypertrophied heart. In addition, the length of the ischemic period and the age of the animal should be considered as determining factors in the extent of the post-ischemic damage of the hypertrophied heart.

The better coronary perfusion of the hypertrophied heart of the relative young spontaneously hypertensive rat after a period of global ischemia, perfused at high perfusion pressure $(13.3 \mathrm{kPa})$, is also reflected by the comparable amount of activity of lactate dehydrogenase released by the hypertrophied and non-hypertrophied hearts. Indeed, both groups lost about $6 \%$ of the total activity of the enzyme present in the heart. Most important of all was the almost complete identical pattern of enzyme release, found in the four groups of reperfused hearts. Indeed, in all hearts, a maximal enzyme release occurred within 10 minutes of reperfusion, while almost normalized release values were found towards the end of the reperfusion period, indicating an homogeneous reperfusion of the left ventricular wall studied.

The same conclusion can be drawn from the results on the degradation products of adenine nucleotides, since a comparable pattern of release was found in all four groups of hearts. It should be noted that the hearts in the control groups lost significantly higher amounts of degradation products during the first 5 minutes of the reperfusion period, almost exclusively caused by a higher release of inosine. Interestingly, this enhanced release is not caused by a significantly enhanced tissue level of this substance or of adenosine at the end of the period of ischemia. Thus the higher release of inosine from the control hearts during the inital reperfusion phase seems to be a consequence of reperfusion alone. Recently, it was found that the activity of the enzyme 5'-nucleotidase is decreased in the hypertrophied pig heart (Panagia et al., 
1986). If so, the hydrolysis of $5^{*}$-AMP would be hampered, decreasing the formation of adenosine and other degradation products of adenine nucleotides. Besides, the tissue levels of AMP would be increased. However, we did not detect any difference in the amounts of adenosine produced between bypertrophied and control hearts, nor did we find enhanced AMP levels in the hypertrophied myocardium. Besides, it is not known to which extent the activity of $5^{\prime}$-nucleotidase can be affected by a period of ischemia, as applied in the present study. Further investigations on the precise content of AMP and adenosine in the myocardial tissue and loss of these substances in the coronary effluent during the immediate reperfusion phase are needed to answer this question.

Recently, in aorta-banded hearts, significant changes in phospholipid content and composition were found (Reibel et al., 1986). These changes could imply that cardiac membrane structure is altered in the pressure overloaded myocardium and that function could be affected by these changes, via the attenuation of membrane bound enzymes as $\mathrm{Na}+$ $\mathrm{K}^{+}$-ATPase, acetylcholinesterase, and 5'-nucleotidase. In pilot experiments, performed in a limited group of hearts of 8 months old spontaneously hypertensive rats, we were unable to detect significant changes in the composition and content of cardiac phospholipids.

Since vitamin $\mathrm{E}(\alpha$-tocopherol) is described to have potent antioxydant activity, a lower content of this compound in the heart of the spontaneously hypertensive rat as reported by Burghardt and Janero (1987), would exaggerate the ischemic damage occurring after the degradation of adenine nucleotides. Although the rats in which these changes were described, were even younger than our animals, we did not observe a decreased functional recovery in hypertrophied bearts of rats of 8 months of age as compared to their age-matched controls. So, if oxydative damage does play a role in the post-ischemic recovery in the rat of this age, it is probably only a modest one. 
The findings of the various studies, described in this thesis, provide evidence for a decreased tolerance to global ischemia of the aged (16 or 18 months) hypertrophied heart of the spontaneously hypertensive rat, as compared to the non-hypertrophied age-matched control heart. Increasing the perfusion pressure improves the post-ischemic recovery, but the myocardial pump function remains inadequate. In the hypertrophied heart of the younger spontaneously hypertensive rat ( 8 months), functional recovery following global ischemia is present provided that mean coronary perfusion pressure is high. When the perfusion pressure is low, functional recovery can be absent in young rats as shown in some hearts of 5 months old aorta-banded rats.

IX 1. THE FACTORS POSSIBLY PLAYING A ROLE IN THE DECREASED TOLERANCE OF THE HYPERTROPHIED RAT HEART TO GLOBAL ISCHEMLA

The findings in the various studies indicate that the decreased tolerance to ischemia and reperfusion of the hypertrophied heart is most likely related to more than one factor.

\section{1.1 The functional consequences of age}

In the hearts of the aged (16 and 18 months) spontaneously hypertensive rats investigated in the present thesis adequate functional and biochemical recovery after a period of global ischemia is never encountered. Even when pre-ischemic function (cardiac output, regional myocardial flow, lactate production) is normal and post-ischemic reperfusion conditions are optimal (accelerated wash-out of metabolites, 
rapid restoration of regular electrical activity), the hypertrophied hearts are incapable to eject fluid volumes of any importance. The effect of age on the functional and biochemical post-ischemic recovery is illustrated in Figures IX. 1 and IX. 2. In these figures the age of the animals, as studied in chapter VII and VIII, is related to the postischemic percentage recovery of cardiac output and to the energy charge at the end of the reperfusion period, respectively. In both control and hypertrophied hearts a more impaired functional recovery, associated with a lower energy charge, is found in the 18 than in the 8 months old animals.

An explanation for the lack of functional recovery in the aged hypertrophied heart could be found in the depressed pre-ischemic pump function of the left ventricle. Up to the age of 12 months in the spontaneously hypertensive rat a good correlation exists between the increase in heart weight and peak developed left ventricular pressure, attained at increased afterloads (Pfeffer and Pfeffer, 1985). Besides, up to this age an almost invariable ratio of heart weight and body weight is found in this animal. At more advanced age of the spontaneously hypertensive rat however, a further increase in heart weight occurs which is not met by an enhanced capacity of maximal pressure development. This deviation between the increase in mass and maximal functional capacity of the left ventricle is believed to represent an early marker for the transition of compensated hypertrophy to hypertrophy with left ventricular dysfunction (Mirsky et al., 1983). In the aged animals used in the present thesis, comparable phenomena are observed. During construction of function curves in the 16 months old spontaneously hypertensive rats (chapter V), it is shown that the pre-ischemic left ventricular pump function is depressed and that the ratio of heart weight to body weight is abnormally increased (about 30\%) as compared with the 8 months old animals. Therefore, it is believed that the left ventricular hypertrophy in the former animals is situated in the transition from the compensated to the non-compensated phase. If so, it is obvious that decompensation negatively affects the functional post-ischemic recovery of the hypertrophied heart of the spontaneously hypertensive rat.

IX 1.2 Altered coronary vascular reactivity and delayed post-ischemic wash-out of metabolites.

A second important phenomenon which plays a role in the impaired post-ischemic functional recovery of the hypertrophied heart of the spontaneously hypertensive and the aorta-banded rat is the lack of adequate reperfusion of the myocardial tissue, especially at low coronary perfusion pressures. This phenomenon is illustrated in Figure IX. 3 in which the maximal post-ischemic recovery of coronary flow per gram heart heart weight is related to the applied mean coronary perfusion pressure. In hypertrophied hearts of spontaneously hypertensive 
Cardiac output $(\$)$

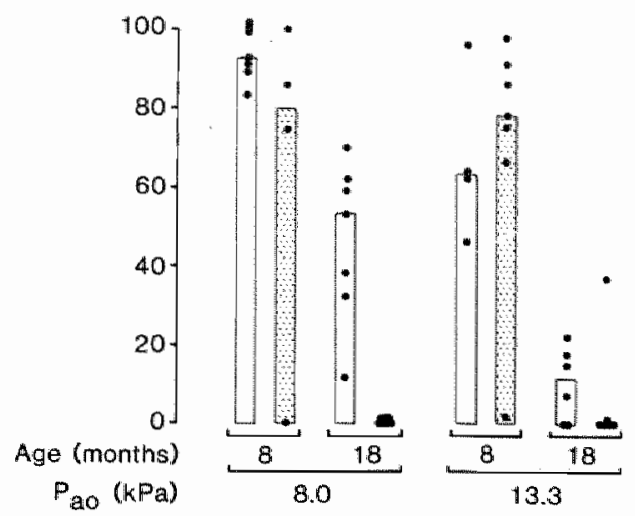

Figure $L X .1$ The maximal post-ischemic recovery of cardiac output in WKY (open bars) and $S H R$ (dorted bars) in relation to the age of the animals. All data are individually related to the pre-ischemic values. Nate that the 18 months old $S H R$ perfused at $13.3 \mathrm{kPa}$ were able, in contrast to the hearts perfused at $8.0 \mathrm{kPa}$. to develop left ventricular pressure, although cardiac output was absent. The height of the bars indicate the median value.

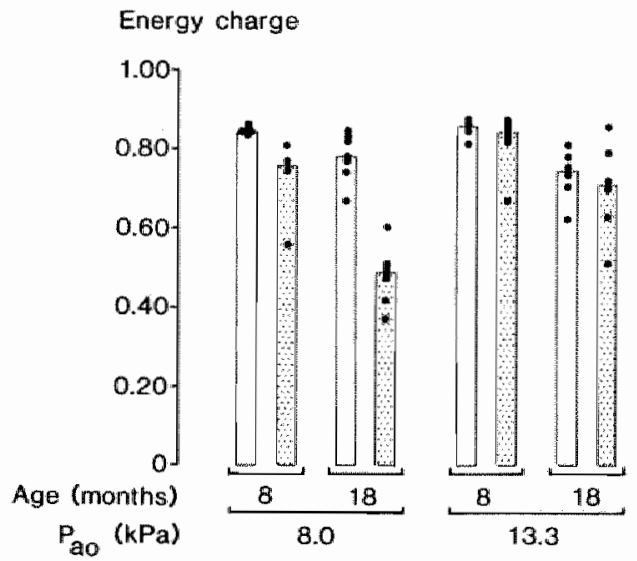

Figure $I X .2$ The recovery of energy charge at the end of the reperfustion period in $W K Y$ (open bars) and SHR (dotted bars) in relation to the age of the animals. The height of the bars indicate the median value. 
rats a low coronary perfusion pressure induces an impaired post-ischemic restoration of coronary flow. Comparable results are obtained in the hypertrophied heart of the aorta-banded rat. As already shown in Figure IX. 1, hypertrophied hearts, reperfused at low perfusion pressure show a less adequate functional recovery than hearts perfused at a high perfusion pressure. In the ald spontaneously hypertensive rat heart perfused at $8.0 \mathrm{kPa}$, the lower coronary flow is associated with a substantial subendocardial underperfusion (Figure IX. 4). Subendocardial underperfusion in the non-ischemic hypertrophied heart can occur when a relatively low perfusion pressure is applied and especially when the heart is fibrillating (Salerno et al., 1979; Bixler et al., 1979; Sink et al., 1983). However, the virtual lack of post-ischemic endocardial flow in the hypertrophied rat hearts used in the present thesis is likely not only caused by a low perfusion pressure and the fibrillating circumstances. It is known that the reactivity of the vascular smooth muscle cells in the spontaneously hypertensive rat is increased, especially in response to norepinephrine (Phelan and Simpson, 1986). Since ischemia induces an enhanced release of intracellular norepinephrine (Abrahamsson et al., 1983; Carisson et al., 1986), the allmost complete absence of endocardial flow in the coronary vessels in the endocardium of the hypertrophied hearts might be the effect of catecholamines released from endogenous sites during the ischemic insult. The altered postischemic reactivity of the vascular smooth muscle cell of the hypertrophied myocardium induces inhomogeneous reperfusion which provokes the higher incidence of ventricular fibrillation. As such, it negatively affects the post-ischemic functional recovery of the hypertrophied myocardium.

The lack of adequate reperfusion at low perfusion pressure of certain regions of the post-ischemic hypertrophied myocardium also delays the initial wash-out of intracellular enzymes and degradation products of adenine nucleotides. A delayed wash-out of metabolites can provoke the intramyocardial turnover of degradation products of adenine nucleotides into end-stage products as xanthine and uric acid. Higher concentrations of hypoxanthine and xanthine may stimulate the formation of oxygen free radicals provided that the enzyme xanthine oxydase is present. This in turn will negatively affect cellular membrane integrity by stimulating, for example, the degradation of phospholipids.

However, increasing the perfusion pressure during the initial phase of the reperfusion period enhances the load imposed on the left ventricular outflow tract. In young ( 8 months) spontaneously hypertensive rats, a high perlusion pressure can be preferred since the post-ischemic pump function is prominent and hardly impaired as compared to the preischemic function. The hearts of aged spontaneously hypertensive rats, however, are incapable to withstand such an increased load during reperfusion, as indicated by the absent cardiac output in 18 months old rats (chapter VII) and by the lack of left ventricular pump function at high 


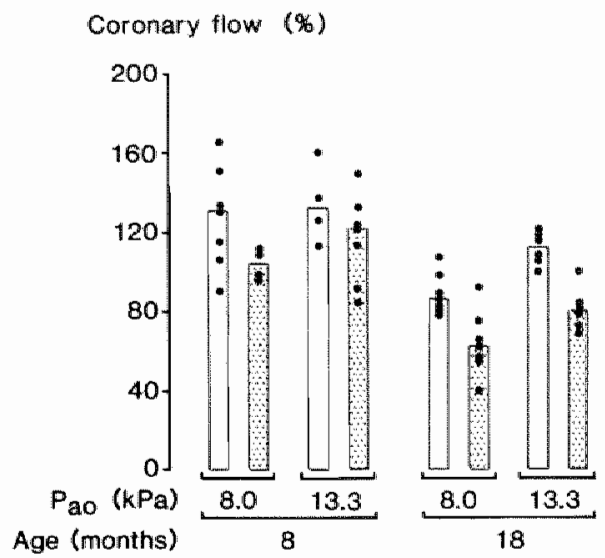

Figure $2 X .3$ The maximal post-ischemic recovery of coronary flow in WKY (open bars) and SHR (dotted bars) in relation to differences in diastolic coronary perfusion pressure. All data are individually related to the pre-ischemic values. The height of the bars indicate the median value.

Regional myocardial flow (\%)

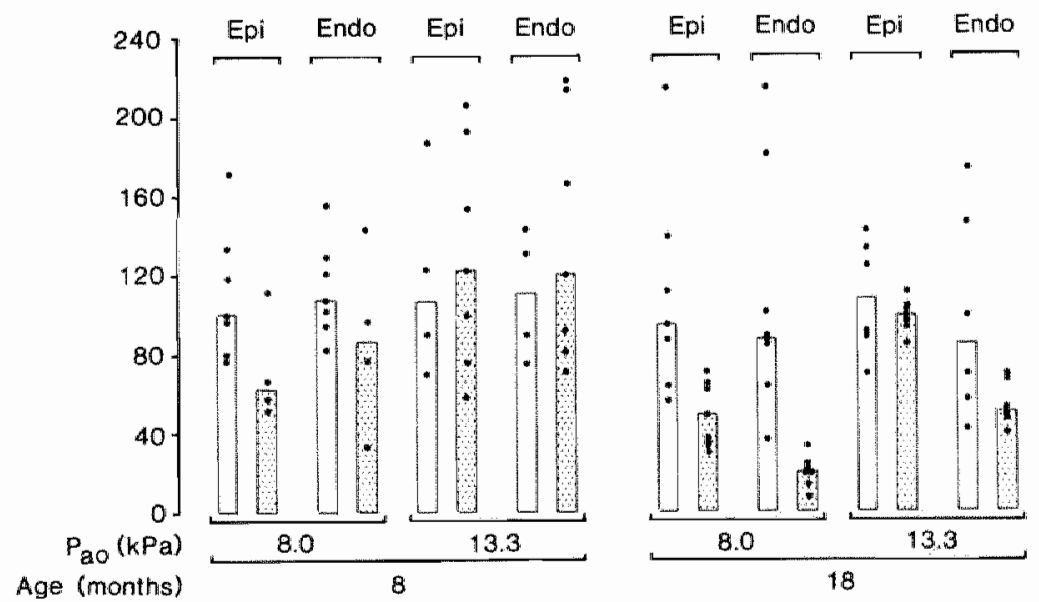

Figure $I X .4$ The recovery of epicardial and endacardial flow in WKY (open bars) and SHR (dotted bars) in relation to differences in diastolic coronary perfusion pressure. All data are individually related to the pre-ischemic values. The height of the bas indicate the median value. 
afterloads during the post-ischemic construction of function curves (chapter V). Mevertheless, in these hearts normal electrical activity is restored as is the capability to develop intraventricular pressure.

\section{2. FINAL CONCLUSIONS}

Applying a higher perfusion pressure during the initial phase of the reperfusion period seems to offer major advantages for the functional recovery of the hypertrophied heart.

Firstly, a high reperfusion pressure induces a faster and more homogeneous reperfusion of all ventricular layers. An increased coronary flow during the initial reperfusion phase improves the rate at which oxygen is supplied to the ischemic myocardial tissue, especially in the deeper ventricular layers. This is beneficial, especially since in the hypertrophied heart an increase in perfusion pressure during the reperfusion period does not induce formation of massive tissue edema. Besides, the findings in the present thesis suggest that edema formation plays a minor role, since the increase in heart weight in hypertrophied hearts reperfused at high perfusion pressure is always lower than in non-hypertrrophied control hearts, perfused at low perfusion pressure, and in which functional recovery is very prominent (chapters VII and VIII).

Secondly, a higher perfusion pressure and homogeneous tissue reperfusion is associated with a faster restoration of normal ellectrical activity. In none of the isolated hearts reperfused at a high perfusion pressure, ventricular fibrillation is observed.

Thirdly, at the end of 45 minutes of reperfusion at high perfusion pressure in hypertrophied hearts the ATP and creatine phosphate content is better conserved than in hypertrophied hearts, perfused at low perfusion pressure. This is probably due to a better phosphorylation of ADP and creatine in hearts perfused at a high perfusion pressure, since the energy charge is found to be higher than in hypertrophied hearts perfused at low perfusion pressure.

Finally, by increasing the perfusion pressure harmful metabolites are removed from the ischemic cardiac tissue at a higher rate, preventing possible cellular membrane damage. As mentioned earlier, increasing the perfusion pressure also enhances the load imposed on the aortic valve, and thus on the left ventricular outflow tract. The hypertrophied hearts of aged rats are incapable to eject against such a high load, although mechanical function and normal electrical activity are present. These results indicate that reperfusion of the severely hypertrophied heart after a period of global ischemia can be performed preferentially at a selective increased coronary perfusion pressure without enhancing the load on the left ventricle. Since harmful metabolites are washed out relatively quickly at increased perfusion pressures, it can be suggested that this situation has to be sustained only for a limited period of time. 
Abrahamsson, T., O. Almgren, and L. Carlsson. Ischemia induced noradrenaline release in the isolated rat heart: influence of perfusion substrate and duration of ischemia. J. Mol. Cell. Cardiol. 15: 821-830, 1983.

Alfaro, A., T. Schaible, A. Malhotra, T. Yipintsoi, and J. Scheuer. Impaired coronary flow and ventricular function in hearts of spontaneously hypertensive rats. Cardiovasc. Res. 17: 553-561, 1983.

Alpert, N.R., H.H. Gale, and N. Taylor. Mechanical and biochemical correlates of cardiac hypertrophy. Circ. Res. 34 \& 35. Suppl. II: 71-82, 1974.

Alpert, N.R., and L.A. Mulieri. Heat, mechanisms, and myosinATPase in normal and hypertrophied heart muscle. Fed. Proc. 41: 192-198, 1981.

Alpert, N.R., and L.A. Mulieri. Increased myothermal economy of isometric force generation in compensated cardiac hypertrophy induced by pulmonary artery constriction in the rabbit. Circ. Res. 50: 491-500, 1982.

Anversa, P., L. Vitalli-Mazza, O. Visioli, and G. Marchetti. Experimental cardiac hypertrophy: a quantitative ultrastructural study in the compensatory stage. J. Mol. Cell. Cardiol. 3: 213-227, 1971.

Attarian, D.E., R.N. Jones, W.D. Currie, R.C. Hill, J.D. Sink, C.O. Olsen, W.R. Chitwood, and R.S. Wechsler. Characteristics of chronic left ventricular hypertrophy induced by subcoronary valvular aortic stenosis. I. Myocardial blood flow and metabolism. J. Thorac. Cardiovasc. Surg. 81: 382388, 1981.

Attarian, D.E., R.N. Jones, W.D. Currie, R.C. Hill, J.D. Sink, C.O. Olsen, W.R. Chitwood, and R.S. Wechsler. Characteristics of chronic left ventricular hypertrophy induced by subcoronary valvular aortic stenosis. II. Response to ischemia. J. Thorac. Cardiovasc. Surg. 81: 389-395, 1981. 
Bassingthwaighte, J.B., M.A. Malone, T.C. Moffett, R.B. King, S.E. Little, J.M. Link, and K.A. Krohn. Validity of microsphere depositions for regional myocardial flows. Am. J. Physiol. 252: H184-H194, 1987.

Behrsohn, M.M., and J. Scheuer. Effects of physical training on end-diastolic volume and myocardial performance of isolated rat hearts. Circ. Res. 40: 510-516, 1977.

Bergmeyer, H.U. and E. Bernt. UV-assay for lactate dehydrogenase with pyruvate and NADH. In: Bergmeyer H.U, ed. Methods of enzymatic analysis. Verlag Chemie GmbH Weinheim: 2: 574-579, 1974.

Bergmeyer, H.U. and E. Bernt. UV-assay for aspartate aminotransferase. In: Bergmeyer H.U, ed. Methods of enzymatic analysis. Verlag Chemie GmbH Weinheim: 2: 727-733, 1974.

Beyersdorf, F., O. Elert, and P. Satter. Determination of maximal ischemic tolerance of the human heart by ultrastructural recording of preischemic degree of myocardial hypertrophy and degeneration. Ann. Thorac. Surg. 30: 356-363, 1980.

Bing, O.H.L., B.L. Fanburg, W.W. Brooks, and S. Matsushita. The effect of the lathyrogen $\beta$-amino proprionitrile (BAPN) on the mechanical properties of experimentally hypertrophied rat heart muscle. Circ. Res. 43: 632-637, 1978.

Bixler, T.J., P.G. Magee, J.T. Flaherty, T.J. Gardner, and V.L. Gott. Beneficial effect of pulsatile perfusion in the hypertrophied ventricle during ventricular fibrillation. Circulation 60 Suppl 1. I-142-I-146, 1979.

Borkon, A.M., M. Jones, J.H. Bell, and J.E. Pierce. Regional myocardial blood flow in left ventricular hypertrophy. J. Thorac. Cardiovasc. Surg. 84: 876-885, 1982.

Bove, E.L., and A.H. Stammers. Recovery of left ventricular function after hypothermic global ischemia. J. Thorac. Cardiovasc. Surg. 91: 115$122,1986$.

Breisch, E.A., F.C. White, L.E. Nimmo, and C.M. Bloor. Cardiac vasculature and flow during pressure-overload hypertrophy. Am. J. Physiol. 251: H1031-H1037, 1986.

Buckberg, G.D. Left ventricular subendocardial necrosis. Ann. Thorac. Surg. 24: 379-393, 1977.

Burghardt, B.M., and D.R. Janero. Low membrane vitamin E content in the spontaneously hypertensive rat heart enhances the susceptibity of cardiac phopholipids to oxydative damage. Fed. Proc. 46 (3): 410, 1987.

Buttrick, P.M., A. Malhotra, R. Brodman, L. McDermott, and L. Lam. Myosin isoenzyme distribution in overloaded human atrial tissue. Circulation 74: 477-483, 1986.

Cantrell, C.R., and P.R. Borum. Identification of a cardiac carnitine binding protein. J. Biol. Chem. 257: 10599-10604, 1982.

Capasso, J.M., A. Malhotra, R.M. Remily, J. Scheuer, and E.H. Sonnenblick. Effects of age on mechanical and electrical performance of rat myocardium. Am. J. Physiol. 245: H72-H81, 1983. 
Carlsson, L., T. Abrahamsson, and $\mathrm{O}$. Almgren. Release of noradrenaline in myocardial ischemia. Importance of local inactivation by meuronal and extraneuronal mechanisms. J. Cardiovasc. Pharmacol. 8: 545-553, 1986.

Cooley, D.A, G.J. Reul, and D.C. Wukash. Ischemic contracture of the heart: "stone heart". Am. J. Cardiol. 29: 575-577, 1972.

Coughlin, T.R., S. Levitsky, M. O'Donoghue, L. Williams, R.N. Wright, K. Roper, and $\mathrm{H}$. Feinberg. Evaluation of hypothermic cardioplegia in ventricular hypertrophy. Circulation 60 Suppl. 1: I-164-I-169, 1979.

Cutilletta, A.F., M. Benjamin, W.S. Culpepper, and S. Oparil. Myocardial hypertrophy and ventricular performance in the absence of hypertension in spontaneously hypertensive rats. J. Mol. Cell. Cardiol. 10: 689-703, 1978.

Dart, A.M., R.A. Riemersma, A. Schömig, and A. Ungar. Metabolic requirements for release of endogenous noradrenaline during myocardial ischemia and anoxia. Br. J. Pharmac. 90: 43-50, 1987.

Degenring, F.H., R. Rubio, and R.M. Berne. Adenine nucleotide metabolism during cardiac hypertrophy in rats. J. Mol. Cell. Cardiol. 7: 105113, 1975.

De Leiris, J., and L.H. Opie. Effect of substrates and of coronary artery ligation on mechanical performance and on release of lactate dehydrogenase and creatine phosphokinase in isolated working rat hearts. Cardiovasc. Res. 12: 585-596, 1978.

De Tata, V., V. Fierabracci, Z. Gori, and E. Bergamini. Transmural distribution of glucose metabolizing enzymes across the left and right ventricle heart walls in three different mammalian species. Comp. Biochem. Physiol. 84B: 549-553, 1986.

Dinnar, U. The Navier-Stokes equation. In: Cardiovascular 1luid dynamics. CRC Press, Florida pp. 87-88, 1981.

Dukes, I.D., and E.M. Vaughan Williams. Resistance to hypoxia-induced shortening of action potential duration of hypertrophied rabbit hearts. Cardiovasc. Res. 18; 597-603, 1984.

Ellis, R.J., W. Prior, and P.A. Ebert. Advantages of potassium cardioplegia and perfusion hypothermia in left ventricular hypertrophy. Ann. Thorac. Surg. 24: 299-306, 1977.

Elzinga, G., H. Piene, and J.P. DeJong. Left and right ventricular pump function and consequences of having two pumps in one heart. A study on the isolated cat heart. Circ. Res. 46: 564-574, 1980.

Einzig, S., J.L. Leonard, M.R. Tripp, R.V. Lucas, C.R. Swayze, and I.J. Fox. Changes in regional myocardial blood flow and variable development of hypertrophy after aortic banding in puppies. Cardiovasc. Res. 15: 711-723, 1981.

Folkow, B., M. Hallbäck, Y. Lundgren and L. Weiss. Background of increased flow resistance and vascular reactivity in spontaneously hypertensive rats. Acta Physiol. Scand. 80: 93-106, 1970. 
Fox, A.C., and G.E. Reed. Changes in lactate dehydrogenase composition of hearts with right ventricular hypertrophy. Am. J. Physiol. 216: 1026$1033,1969$.

Frank, O. Zur Dynamik des Herzmuskels. Zeitschr. Biol. 32:370-437, 1895. Froehlich, J.P., E.G. Lakatta, E. Beard, H.A. Spurgeon, M.L. Weisfeldt, and G. Gerstenblith. Studies of sarcoplasmic reticulum function and contraction duration in young, adult and aged myocardium. J. Mol. Cell. Cardiol. 10: 427-438, 1978.

Friberg, P., and C. Nordborg. Functional, morphological and metabolic characteristics of isolated hearts from normotensive and spontaneously hypertensive rats before, during and after renal hypertension. Acta Physiol. Scand. 126: 161-171, 1986.

Friberg, P., M. Nordlander, S. Lundin, and B. Folkow. Effects of ageing on cardiac performance and coronary flow in spontaneouslly hypertensive and normotensive rats. Acta Physiol. Scand. 125: 1-11, 1985.

Frohlich, E.D. Is the spontaneously hypertensive rat a model for human hypertension? J. Hypert. 4 (suppl. 3): S15-S19, 1986.

Frohlich, E.D., M.A. Pfeffer, and J.M. Pfeffer. Systemic hemodynamics and cardiac function in spontaneously hypertensive rats: similarities with essential hypertension. In: The heart in hypertension. Ed. B.E. Strauer. Springer Verlag, Berlin. pp 53-71, 1981.

Fye, W.B. H.N. Martin and the isolated heart preparation: the link between the frog and open heart surgery. Circulation 73: 857-864, 1986.

Gersch, B.J., C.E.W.Hahn, and C. Prys-Roberts. Physical criteria for measurement of left ventricular pressure and its first derivative. Cardiovasc. Res. 5: 32-40, 1971.

Hallbäck, M. Interaction between central neurogenic mechanisms and changes in cardiovascular design in primary hypertension. Experimental studies in spontaneously hypertensive rats. Acta Physiol. Scand. 424 Suppl.: 34-36, 1975.

Hallbäck, M., O. Isackson, and E. Noresson. Consequences of myocardial structural adaptations on left ventricular compliance and the Frank-Starling relationship in spontaneouly hypertensive rats. Acta Physiol. Scand. 94: 259-270, 1975.

Hallbäck-Nordlander, M., E. Noresson, and P. Thoren. Hemodynamic consequences of left ventricular hypertrophy in spontaneously hypertensive rats. Am. J. Cardiol. 44: 986-993, 1979.

Haneda, T., K. Ichihara, Y. Abiko, and S. Onodera. Functional and metabolic responses to ischemia in the perfused heart isolated from normotensive and spontaneously hypertensive rats. Jap. Circ. J. 50: 607-613, 1986.

Harmsen, E., J.W. de Jong, and P.W. Serruys. Hypoxanthine production by ischemic heart demonstrated by HPLC of blood purine nucleosides and oxypurines. Clin. Chim. Acta 115: 73-84, 1981.

Hartford, M., J.C.M. Wikstrand, I. Wallentin, S.M.G. Lungman, and G.L. Berglund. Left ventricular wall stress ans systolic function in untreated primary hypertension. Hypertension 7: 97-104, 1985. 
Hearse, D.J., P.B. Garlick, and S.M. Humphrey. Ischaemic contracture of the myocardium. Mechanisms of prevention. Am. J. Cardiol. 39: 986-993, 1977.

Hems, R., B.D. Ross, M.N. Berry, and H.A. Krebs. Gluconeogenesis in the perfused rat liver. Biochem. J. 101: 284-292, 1966.

Henquell, L., C.L. Odoroff, and C.R. Honig. Intercapillary distance and capillary reserve in hypertrophied rat hearts beating in situ. Circ. Res. 41: 400-408, 1977.

Henry, W.L., J. Morganroth, A.S. Pearlman, C.E. Clark, D.R. Reswood, S.B. Itscoitz, and S.E. Epstein. Relation between echocardiographic determined left atrial size and atrial fibrillation. Circulation 53: 273-279, 1976.

Heyman, M.A., B.D. Payne, J.I.E. Hoffman, and A.M. Rudolph. Blood flow measurements with radionuclide-labeled particles. Prog. Cardiovasc. Dis. 20: $55-79,1977$.

Hoffman, J.I.E., R.W. Bear, F.L. Hanley, L.M. Messina, and M. Grattan. Regulation of transmural myocardial blood flow. J. Biomech. Engin. 107: $29,1985$.

Holtz, J., W. von Restoroff, P. Bard, and E. Bassenge. Transmural distribution of myocardial blood flow and of coronary reserve in canine left ventricular hypertrophy. Bas. Res. Cardiol. 72: 286-292, 1976.

Holubarsch, Ch., R.P. Goulette, R.Z. Litten, B.J. Martin, L. A. Mulieri, and N.R. Alpert. The economy of isometric force development, myosin isoenzym pattern and myofibrillar ATPase activity in normal and hyperthyroid rat myocardium. Circ. Res. 56: 78-86, 1985.

Hottenrott, C.E., B. Towers, and H.R. Kurkji. The hazard of ventricular fibrillation in hypertrophied ventricles during cardiopulmonary bypass. J. Thorac. Cardiovasc. Surg. 66: 742, 1973.

Humphrey, S.M., R.W. Thomson, and J.B. Gavin. The influence of the noreflow phenomenon on reperfusion and reoxygenation damage and enzyme release from anoxic and ischaemic isolated rat hearts. J. Mol. Cell. Cardiol. 16: 915-930, 1984.

Jespersen, L.T., U. Baandrup, N.C.B. Nyborg, P. Jacobsen, J. Winther, E.O. Mikkelsen, M.J. Mulvaney, and O. Lederballe. Is intracellular calcium a trophic stimulus in spontaneously hypertensive rat cardiovascular muscle? J. of Hypertension 4 (suppl. 3): S141-S143, 1986.

Jouannot, P., and P.Y. Hatt. Rat myocardial mechanics during pressureinduced hypertrophy development and reversal. Am. J. Physiol. 229: 355$364,1975$.

Jung, K., K. Bader, and K.D. Grützmann. Long-term stability of enzymes in human serum stored in liquid nitrogen. Enzyme 31: 209-216; 1984.

Katz, A.M., and M. Tada. The "stone heart": a challenge to the biochemist. Am. J. Cardiol. 29: 578-580, 1972.

Kawachi, Y., R. Tominaga, M. Yoshitoshi, A. Sese, K. Tokunaga, and M. Nakamura. Influence of perfusion pressure on oxygen supply and demand in beating empty hypertrophied dog hearts. J. Surg. Res. 33: 103-111, 1982. 
King, R.B., and J.B. Bassinghtwaighte. Radioactivity. In: Data in Medicine. Eds. R.S.Reneman and J. Strackee. Martinus Nyhoff. The Hague, The Netherlands. pp. 79-113, 1976.

Kira, Y., P.J. Kochel, E.E. Gordon, and H.E. Morgan. Aortic perfusion pressure as a determinant of cardiac protein synthesis. Am. J. Physiol. 246: C247-C258, 1984 .

Kissling, G., H. Rupp, L. Malloy, and R. Jacob. Alterations in cardiac oxygen consumption under chronic pressure overload. Significance of isoenzyme pattern of myosin. Bas. Res. Cardiol. 77: 255-270, 1982.

Kobayashi, K., and J.R. Neely. Control of maximum rates of glycolysis in rat cardiac muscle. Circ. Res. 44: 166-175, 1979.

Koilde, T. and M. Rabinowitz. Biochemical correlates of cardiac hypertrophy. II. Increased rate of RNA synthesis in experimental cardiac hypertrophy in the rat. Circ. Res. 24: 9-18, 1969.

Krebs, H.A., and K. Henseleit. Untersuchungen uber die Harnstoffbildung im Tierkorper. Hoppe-Seyler's Zeitschrift fur Physiol. Chemie 210: 3366, 1932.

Kuribayashi, T., K. Furukawa, H. Katsume, H. Ijichi, and Y. Ibati. Regional differences of myocyte hypertrophy and three-dimensional deformation of the heart. Am. J. Physiol. 250: H378-H388, 1986.

Lakatta, E.G., and F.C.P. Yin. Myocardial aging: functional alterations and related cellular mechanisms. Am. J. Physiol. 242: H927-H941, 1982.

Langendorff, $O$. Untersuchungen am überlebenden Säugetierherzen. Pflügers Arch. 61: 291-332, 1895.

Langer, S.Z., N.B. Shepperson and R. Massingham. Preferential noradrenergic innervation of $\alpha$-adrenergic receptors in vascular smooth muscle. Hypertension, 3, Suppl.1: I-112-I-118, 1981.

Levitsky, S., and H. Feinberg. Biochemical changes in ischemia. Ann. Thorac. Surg. 20: 21, 1975.

Lie, J.T and S.C. Sun. Ultrastructure of ischemic contracture of the left ventricle: "stone heart". Mayo Clin. Proc. 51: 785-793, 1976.

Lundin, S., P. Friberg, and M. Hallbāck-Nordlander. Left ventricular hypertrophy improves cardiac performance in spontaneously hypertensive rats. Acta Physiol. Scand. 114: 321-328, 1982.

McCord, J.M., and R.S. Roy. The patophysiology of superoxide; roles of inflammation and ischemia. Can. J. Physiol. Pharmacol. 60: 1346-1352, 1982.

McGiff, J.C., and C.P. Quilley. The rat with spontaneous genetic hypertension is not a suitable model of human essential hypertension. Circ. Res. 48: 455-463, 1981.

Malik, A. J.M. Shapiro, J. Yanics, A. Rojales, and A.S. Geha. A simplified method for producing rapid ventricular hypertrophy in rats. Cardiovasc. Res. 8: 801-805, 1976.

Martin, H.N. On a method of isolating the mammalian heart. Johns. Hopkins University Circ. 10: 127, 1881. 
Martinek, K., A.M. Klibanov, V.S. Goldmacher, and I.V. Berezin. The prin ciples of enzyme stabilization. I. Increase in thermostability of enzymes covalently bound to a complementary surface of a polymer support in a multipoint fashion. Biochim. Biophys. Acta. 485: 1-12, 1977.

Martinek, K., A.M. Klibanov, V.S. Goldmacher, A.V. Tchernysheva, V.V. Mozhaev, I.V. Berezin, and B.O. Glotov. The principles of enzyme stabilization. II. Increase in the thermostability of enzymes as a result of multipoint noncovalent interaction with a polymeric support. Biochim. Biophys. Acta. 485: 13-28, 1977.

Meerson, F.Z. Compensatory hyperfunction of the heart and cardiac insufficiency. Circ. Res. 10: 250-258, 1962.

Meerson, F.Z. The myocardium in hypertension, hypertrophy and heart faillure. Circ. Res. 24: Suppl. 2: 1-8, 1969.

Meerson, F.Z., and M.P. Javich. Isoenzyme pattern and activity of myocardial creatine phosphokinase under heart adaptation to prolonged overload. Bas. Res. Cardiol. 77: 349-358, 1982.

Menasche, P., C. Grousset, C.S. Apstein, F. Marotte, C. Mouas, and A. Piwnica. Increased injury of hypertrophied myocardium with ischemic arrest: preservation with hypothermia and cardioplegia. Am. Heart J. 110: 1204-1209, 1985.

Menasche, P., C. Grousset, Y. Gaudell, and A. Piwnica. A comparative study of free radical scavengers in cardioplegic solutions. Improved protection with peroxydase. J. Thorac. Cardiovas. Surg. 92: 264-271, 1986.

Mercadier, J.J., A.M. Lompre, C. Wisnewsky, J.L. Samuel, J. Bercovici, B. Swynghedauw, and K. Schwartz. Myosin isoenzymic changes in several models of rat cardiac hypertrophy. Circ. Res. 49: 525-532, 1981.

Mirsky, I., J.M. Pfeffer, M.A. Pfeffer, and E. Braunwald. The contractile state as the major determinant in the evolution of left ventricular dysfunction in the spontaneously hypertensive rat. Circ. Res. 53: 767-778, 1983.

Mochizuki, S., M. Taniguchi, T. Kudo, H. Yabe, H. Maeno, K. Takahashi, and M. Nagano. Functional and metabolic properties in hearts from aged spontaneously hypertensive rats. Jap. Circ. J. 50: 1007-1014, 1986.

Moore, G.W., G.M. Hutchins, B.H. Bulkley, J.S. Tseng, and P. F. Ki. Constituents of the human ventricular myocardium: Connective tissue hyper plasia accompanying muscular hypertrophy. Am. Heart J. 100: 610-616, 1980.

Morgan, H.E., B.H.L. Chua, D. Siehl, Y. Kira, P.J. Kochel, and E.E. Gordon. Mechanical factors affecting protein turnover in isolated rat hearts. Fed. Proc. 45: 2563-2567, 1986.

Morgan, H.E., E.E. Gordon, Y. Kira, D.L. Siehl, P.A. Watson, and B.H.L. Chua. Biochemical correlates of myocardial hypertrophy. The Physiologist 28: 18-27, 1985 .

Murray, P.A., and S.F. Vatner. Reduction of maximal coronary vasodilator capacity in conscious dogs with severe right ventricular hypertrophy. Circ. Res. 43: 25-33, 1981. 
Myhre, E.S.P., and H. Piene. External work and arterial load in canine left ventricular ischaemic failure: evidence of ventricle-load mismatch. Clin. Physiol. 5: 189-200, 1985.

Nara, Y., T. Sato, S. Mochizuki, M. Mano, R. Horie, and Y. Yamori. Metabolic dysfunction in smooth muscle cells of SHR. J. of Hypert. 4: S105S107, 1986.

Nair, K.G., A.F. Cutilletta, R. Zak, T. Koide, and M.Rabinowitz. Biochemical correlates of cardiac hypertrophy. I. Experimental model; changes in heart weight, RNA content, and nuclear RNA polymerase activity.

Circ. Res. 23: 451-462, 1968.

Neely, J.R., H. Liebermeister, E.J. Battersby, and H.E. Morgan. Effect of pressure development on oxygen consumption by the isolated rat heart. Am. J. Physiol. 212: 804-814, 1967.

Neelly, J.R., and H.E. Morgan. Relationship between carbohydrate and lipid metabolism and the energy balance of heart muscle. Ann. Rev. Physiol. 36: 413-459, 1974.

Neely J.R., and L.W. Grotyohann. Role of glycolytic products in damage to ischemic myocardium. Dissociation between adenosine triphosphate levels and recovery of function of reperfused ischemic hearts. Circ. Res. 55: 816-824, 1984.

Noresson, E., S.E. Ricksten, M. Hallbäck-Nordlander, P. Thoren. Performance of the hypertrophied left ventricle in spontaneously hypertensive rat. Effect of changes in preload and afterload. Acta Physiol. Scand. 107: 1-8, 1979.

Novick, R.J., H.J. Stefaniszyn, R.P. Michel, F.D. Burdon, and T.A. Salerno.

Protection of the hypertrophied pig myocardium. A comparison of crystalloid, blood and Fluosol-DA cardioplegia during prolonged aortic clamping. J. Thorac. Cardiovasc. Surg. 89: 547-566, 1985.

Okamoto, K. Cardiac hypertrophy in SHR. In: Okamoto K., ed. Spontaneous hypertension. Its pathogenesis and complications. Tokyo: Igaku Shoin; Berlin; Heidelberg, New York: Springer Verlag. pp. 168-169, 1972.

Opie, L. Adequacy of oxygenation of isolated perfused rat heart. Bas. Res. Cardiol. 79: 300-306, 1984.

Owens, G.K. Differential effects of antihypertensive drug therapy on vascular smooth muscle cell hypertrophy, hyperploidy, and hyperplasia in the spontaneously hypertensive rat. Circ. Res. 56: 525-536, 1985.

Owens, G.K., and M.A. Reidy. Hyperplastic growth response of vascular smooth muscle cells following induction of acute hypertension in rats by aortic coarctation. Circ. Res. 57: 695-705, 1985.

Panagia, V., C.E. Heyliger, P.K. Singal, and N.S. Dhalla. Subcellular distribution of cardiac 5'-nucleotidase: Alteration of microsomal pool in hypertrophied pig heart. J. Mol. Cell. Cardiol. 18: 815-826, 1986.

Parmacek, M.S., N.M. Magid, M. Lesch, R.S. Decker, and A.M. Samarel. Cardiac protein synthesis and degradation during thyroxine-induced left ventricular hypertrophy. Am. J. Physiol. 251: C727-C736, 1986. 
Pauletto, P., G. Vescovo, G. Scannapieco, A. Angelini, A.C. Pessina, L. Dalla Libera, U. Carraro, and C. Dal Palu. Changes in rat ventricular isomyosins with regression of cardiac hypertrophy. Hypertension 8: 1143$1148,1986$.

Peters, K.G., R.D. Wangler, R.J. Tomanek, and M.L. Marcus. Effects of long-term cardiac hypertrophy on coronary vasodilator reserve in SHR rats. Am. J. Cardiol. 54: 1342-1348, 1984.

Peyton, R.B., R.N. Jones, D. Attarian, J.D. Sink, P. van Trigt, W.D. Currie, and A.S. Wechsler. Depressed high-energy phosphate content in hypertrophied ventricles of animal and man. The biological basis for increased sensitivity to ischemic injury. Ann. Surgery 196: 278-284, 1982.

Peyton, R.B., P. van Trigt, G.L. Pellom, R.N. Jones, J.D. Sink, and A.S. Wechsller. Improved tolerance to ischemia in hypertrophied myocardium by preischemic enhancement of adenosine triphosphate. J. Thorac. Cardiovasc. Surg. 84: 11- 15, 1982.

Pfeffer, M.A. and E.D. Frohlich. Hemodynamic and myocardial function in young and old normotensive and spontaneously hypertensive rats. Circ. Res. 32, 33. Suppl. 1: I-28-I-35, 1973.

Pfeffer, M.A., and J.M. Pfeffer. Blood pressure and left ventricular dysfunction in the spontaneously hypertensive rat. Fed. Proc. 42: 26982702, 1983.

Pfeffer, M.A., and J.M. Pfeffer. Left ventricular hypertrophy and pressure generating capacity in aging genetically hypertensive rats. J. Cardiovasc. Pharmacol. 7: S41-S45, 1985.

Phelan, E.L., and F.O. Simpson. Vascular reactivity in genetic models of hypertension. J. Hypertension 4. Suppl 3. S25-S27, 1986.

Prashad, N. Reduced levels of cardiac cAMP-dependent protein kinase in the spontaneously hypertensive rat. J. Biol. Chem. 260: 10125-10131, 1985.

Prinzen, F.W., G.J. van der Vusse, and R.S. Reneman. Blood flow distribution in the left ventricular free wall open-chest dogs. Bas. Res. Cardiol. 76: 431-437, 1981.

Rakusan, K., P.W. Hrdina, Z. Turek, E.G. Lakatta, H.A. Spurgeon, and G.D. Wolford. Cell size and capillary supply of the hypertensive rat heart: quantitative study. Bas. Res. Cardiol. 79: 389-395, 1984.

Rao, P.S., M.V. Cohen, and H.S. Mueller. Production of free radicals and lipid peroxides in early experimental myocardial ischemia. J. Mol. Cell. Cardiol. 15: 713-716, 1983.

Reibel, D.K, B. O'Rourke, and K.A. Foster. Mechanisms for altered carniline content in hypertrophied hearts. Am. J. Physiol. 252: H561-H565, 1987.

Reibel, D.K., B. O'Rourke, K.A. Foster, H. Hutchinson, C.E. Uboh, and R.L. Kent. Altered phospholipid metabolism in pressure-owerload hypertrophied hearts. Am. J. Physiol. 250: H1-H6, 1986.

Reilly, P.J. and J.D. Cooksey. Cardiac energy stores and creatine in experimental cardiac hypertrophy. Proc. Soc. Experim. Biol. Med. 161: 193$198,1979$. 
Reneman, R.S., A.H.M. Jagenau, W. van Gerven, J. Dony, and P. Beirnaert. The radioactive microsphere method for the assessment of regional myocardial blood flow after coronary artery occlusion. Inaccuracies due to variations in the diameter distribution of the spheres. Pflügers Arch. 353: $337-347,1975$.

Rensma, P.L. Atrial arrhythmias and measurement of the wavelength in a chronic dog model. PhD Thesis, Rijksuniversiteit Limburg, Maastricht, 1986.

Revis, N.W., and A.J.V. Cameron. Metabolism of lipids in experimental bypertrophic hearts of rabbits. Metabolism 28: 601-613, 1979.

Ringsgwandl, G., W. Motz, H. Meyrl, A. Schneider, K.Schwartz, and B.E. Strauer. Rapid transient analysis of myosin cross-bridge kinetics in hypertrophied hearts. Fed. Proc. 45: 2585-2590, 1986.

Rosenkranz, E.R., F. Okamoto, G.D. Buckberg, J. Vinten-Johansen, B.S. Allen, J. Leaf, H. Bugyri, H. Young, and R.J. Barnard. Studies of controlled reperfusion after ischemia. II. Biochemical studies: Failure of tissue adenosine triphosphate to predict recovery of contractile function after controlled reperfusion. J. Thorac. Cardiovasc. Surg. 92: 488-501, 1986.

Salerno, T.A., H.M. Shizgal, and A.R.C. Dobell. Pulsatile perfusion: its effects on blood flow distribution in hypertrophied hearts. Ann. Thorac. Surg. 27: 559-563, 1979.

Schaper, J., F. Schwartz, W. Flameng, and F. Hehrlein. Tolerance to ischemia of hypertrophied human hearts during valve replacement. Bas. Res. Cardiol. 73: 171-187, 1978.

Schoutsen B., J.W. de Jong, E. Harmsen, P.E. de Tombe, and P.W. Achterberg. Myocardial xanthine oxydase/dehydrogenase. Biochim. Biophys. Acta 762: 519-524, 1983.

Schwarz, F., J. Schaper, D. Kittstein, W. Flameng, P. Walter, and W. Schaper. Reduced volume fraction of myofibrils in myocardium of patients with decompensated pressure overload. Circulation 63: 1299-1304, 1981.

Segel, L. and S. Rendig. Isolated working rat heart perfusion with perfluorochemical emulsion Fluosol-43. Am. J. Physiol. 242: H485-H489, 1982.

Sen, S., R.C. Tarazi, P.A. Khairallah, and F.M. Bumpus. Cardiac hypertrophy in spontaneously hypertensive rats. Circ. Res. 34: 775-781, 1974.

Sesoko, S., B.L. Pegram, I. Kuwajima, and E.D. Frohlich. Hemodynamic studies in spontaneously hypertensive rats with congenital arteriovenous shunts. Am. J. Physiol. 242: H722-H725, 1982.

Sharma, R.V., J.P. McEldoon, and R.C. Bhalla. Age dependent changes in myosin ATPase activity in the myocardium of spontaneously hypertensive rats. Cardiovasc. Res. 20: 52-60, 1986.

Shida, H. and M. Kobayashi. Effect of hypothermia during ischemia on myacardial contractility in nonhypertrophied and hypertrophied ventricles. Jap. Circ. J. 44: 172-178, 1980. 
Shimamoto, N., N. Goto, M. Tanabe, T. Imamoto, S. Fujiwara, and M. Hirata. Myocardial energy metabolism in the hypertrophied hearts of spontaneously hypertensive rats. Bas. Res. Cardiol. 77: 359-371, 1982. Siehl, D., B.H.L. Chua, N. Lautensack-Belser, and H.E. Morgan. Faster protein and ribosome synthesis in thyroxine-induced hypertrophy of rat heart. Am. J. Physiol. 248: C309-C319, 1985.

Sink, J.D., R.C. Hill, D.E. Attarian, and A.S. Wechsler. Myocardial blood flow and oxygen consumption in the empty beating, fibrillating, and potassium-arrested hypertrophied canine heart. Ann. Thorac. Surg. 35: 372-379, 1983.

Sink, J.D., G.L. Pellom, W.D. Currie, R.C. Hill, C.O. Olsen, R.N. Jones, and R.S. Wechsler. Response of the hypertrophied myocardium to ischemia. Correlation with biochemical and physiological parameters. J. Thorac. Cardiovasc. Surg. 81: 865-872, 1981.

Smits, J.F.M., T.G. Coleman, T.L. Smith, C.M. Kasbergen, H. van Essen, and H.A.J. Struyker-Boudier. Antihypertensive effect of propranolol in conscious hypertensive rats: central hemodynamics, plasma volume, and renal function during $\beta$-blockade with propranolol. J. Cardiovasc. Pharmacol. 4: 903-914, 1982.

Snoeckx, L.H.E.H., J.J.W. Schrijen, M. van Bilsen, W.J.E.P. Lammers, T. van der Nagel, G.J. van der Vusse, and R.S. Reneman. A microcomputer system for haemodynamic measurements in isolated, working rat hearts. Comp. Biol. Med. 4: 301-309, 1986.

Snoeckx, L.H.E.H., G.J. van der Vusse, W.A. Coumans, P.H.M. Willemsen, T. van der Nagel, and R.S. Reneman. Myocardial function in normal and spontaneously hypertensive rats during reperfusion after a period of global ischaemia. Cardiovasc. Res. 20:67-75, 1986.

Snoeckx, L.H., Abeling H.F., Lambregts J.A., and Reneman R.S. Echocardiographic dimensions in athletes in relation to their training program. Med. \& Science in Sports \& Exercise 14: 428-434, 1982.

Snoeckx, L.H., Abeling H.F., Lambregts J.A., and Reneman R.S. Cardiac dimensions in athletes in relation to variations in their training program. Eur. J. Appl. Physiol. 52: 20-28, 1983.

Sobel, B.E., P.D. Henry, B.J. Erhlich, and C.L. Bloor. Altered myocardial lactic dehydrogenase isoenzymes in experimental cardiac hypertrophy. Lab. Invest. 22: 23-27, 1970.

Spach, M.S., and P.C. Dolber. Relating extracellular potentials and their derivatives to anisotropic propagation at microscopic level in human cardiac tissue. Circ. Res. 58: 356-371, 1986.

Stabilini, R., G. Fiorelli, F. Radice, M. Marinari, and A. Agostoni. Lactate dehydrogenase and aspartate aminotransferase isoenzymes in normal and hypertrophiec human heart. Cardiology 55: 28-33, 1970.

St. Cyr, J., R. Bianco, J. Foker, G. Noren, N. Staley, T. Chung Wang, and S. Einzig. Myocardial high-energy phosphate levels in cardiomyopathic turkeys. J. Surg. Res. 41: 256-259, 1986. 
Taegtmeyer, H. Metabolic activities of the isolated rat heart. PhD Thesis, University of Oxford, 1980.

Thiedemann, K-U., Ch. Holubarsch, I. Medugorac, and R. Jacob. Connective tissue content and myocardial stiffness in pressure overload hypertrophy. A combined study of morphologic, morphometric, biochemical, and mechanical parameters. Bas. Res. Cardiol. 78: 140-155, 1983.

Tomanek, R.J. The role of prevention or relief of pressure overload on the myocardial cell of the spontaneously hypertensive rat. A morphometric and stereological study. Lab. Invest. 40: 83-91, 1979.

Tomanek, R.J., J.L. Liesfeld, M.H. Laughlin, R.D. Wangler, and N.C. Wilson. The relative distribution of coronary blood flow in rats with moderate and marked left ventricular hypertrophy. Can. J. Physiol. Pharmacol. 58: $830-835,1980$.

Tomanek, R.J., P.J. Palmer, G.L. Peiffer, K.L. Schreiber, C. L. Eastham, and M.L. Marcus. Morphometry of canine coronary arteries, arterioles, and capillaries during hypertension and left ventricular hypertrophy. Circ. Res. 58: 38-46, 1986.

Tomanek, R.J., J.C. Searls, and P.A. Lachenbruch. Quantitative changes in the capillary bed during developing, peak, and stabilized cardiac hypertrophy in the SHR. Circ. Res. 51: 295-304, 1982.

Torchilin, V.P., A.V. Maksimenko, V.N. Smirnov, I.V. Berezin, A.M. Klibanov, and K. Martinek. The principles of enzyme stabilization. III. The effect of the length of intramolecular cross-linkages of thermostability of enzymes. Biochim. Biophys. Acta. 522: 277-283, 1978.

Turner, J.E., M.H. Oliver, D. Guerreiro, and G.J. Laurent. Collagen metabolism during right ventricular hypertrophy following induced lung injury. Am. J. Physiol. 251: H915-H919, 1986.

van Bilsen, M., G.J. van der Vusse, L.H. Snoeckx, T. Arts, W. A. Coumans, P.H. Willemsen, and R.S. Reneman. Effects of pyruvate on postischemic myocardial recovery at various workloads. Submitted.

van Bilsen, M., G.J. van der Vusse, L.H. Snoeckx, and R.S.Reneman.

The effect of a left ventricular-aortic pressure gradient on cardiac performance of isolated rat hearts. J. Mol. Cell. Cardiol. 16 Suppl. 2: 67, 1984.

van den Bogaard, A.E.J.M., and W.F. Wiedema. Antimicrobial prophylaxis in veterinary surgery. J. Am. Vet. Assoc. 186: 990-992, 1985.

van der Laarse, A., H.A. Davids, L. Hollaar, and W.Th. Hermens. Enhanced release of mitochondrial aspartate aminotransferase (mAST) from anoxic rat heart cell cultures during reoxygenation. Comparison to plasma mAST levels in patients after acute myocardial infarction and after cardiac surgery. Cardiovasc. Res. 15: 11-20, 1981.

van der Laarse, A., C.H.F. Bloys van Treslong, H.W. Vliegen, and $L$. Ricciardi. Relation between ventricular DNA content and number of myocytes and non-myocytes in hearts of normotensive and spontaneously hypertensive rats. Cardiovasc. Res. 21: 223-229, 1987. 
van der Laarse, A., P.R.M. van Dijckman, J.C. Altona, A.M.C. Zoet, and P.V. Oemrawsingh. Coronary flow rate dependent enzyme release rate from normoxic and anoxic rat hearts in vitro. Cardiovasc. Res. 18: 438$442,1984$.

van der Vusse, G.J., W.A. Coumans, F.H. van der Veen, A. Drake, W. Flameng, and R. Suy. ATP, creatine phosphate and glycogen content in human myocardial biopsies: markers for the efficacy of cardioprotection during aorta-coronary bypass surgery. Vasc. Surg. 18: 127-134, 1984.

van der Vusse, G.J., and R.S. Reneman. Glycogen and lipids (endogenous substrates) In: Cardiac Metabolism. Ed. A.J. Drake-Holland and M.I.M. Noble. J. Wiley and Son Ltd, London. pp. 215-237, 1983.

van der Vusse, G.J. and R.S. Reneman. Pharmacological intervention inacute myocardial ischemia and reperfusion. Trends Pharmacol. Sci. 6: 76$79,1985$.

van der Vusse, G.J., Th.H.M. Roemen, F.W. Prinzen, W.A. Coumans, and R.S. Reneman. Uptake and tissue content of fatty acids in dog myocardium under normoxic and ischemic conditions. Circ. Res. 50: 538-546, 1982.

Vogel, W.M., A.W. Cerel, and C. Apstein. Post-ischemic cardiac chamber stiffness and coronary vasomotion: the role of edema and effects of dextran. J. Mol. Cell. Cardiol. 18: 1207-1218, 1986.

Waldenström, A.P., Å.C. Hjalmarson, M. Jodal, and J. Waldenström. Significance of enzyme release from ischemic isolated rat heart. Acta. Med. Scand. 201: 525-532, 1977.

Warner, K.G., S.F. Shukei, R.A. Kloner, M. Josa, K.M. Dalecki-Chipperfield, M.D. Butler, S.N. Assoussa, S.S. Lee, E.M. Barsamian, and M. Seiler. Structural and metabolic correlates of cell injury in the hypertrophied myocardium during valve replacement. J. Thor. Cardiovasc. Surg. 93: 741-754, 1987.

Wei, J.Y., H.A. Spurgeon, and E.G. Lakatta. Excitation-contraction in rat myocardium: alterations with adult aging. Am. J. Physiol. 246: H784H791, 1984.

Wynants, J., and H. van Belle. Single-run high-performance liquid chromatography of nucleotides, nucleosides and major purine bases and its application to different tissue extracts. Anal. Biochem. 144: 258-266, 1985.

Willems, G.M. Assessment of myocardial injury. Analysis of simultaneously sampled plasma activities of several cardiac enzymes. PhD Thesis, University of Limburg, Maastricht; 1985.

Yamashita, T., A. Kobayashi, N. Yamazaki, K. Miura, and H. Shirasawa. Effects of 1-carnitine and verapamil on myocardial carnitine concentration and histopathology of Syrian hamster BIO 14.6. Cardiovasc. Res. 20: $614-620,1986$. 
Yamori, $Y_{*}, T$. Kanbe, T. Igawa. Electrolyte balance in cultured smooth muscle cells from the aorta of SHR. In: Rasher, W., D. Clough and D. Ganten (Eds), Hypertensive Mechanisms: the spontaneously hypertensive rat as a model to study human hypertension. Schattauer Verlag, Stutlgart, New York. pp 281-285, 1982.

Younes, A, J.M. Schneider, J. Bercovici, and B. Swrynghedauw. Redistribution of creatine kinase isoenzymes in chronically overloaded myocardium. Cardiovasc. Res. 19: 15-19, 1984. 


\section{SUTMMARY}

Serious complications can be encountered during open heart surgery of the hypertrophied human myocardium. Indeed, this type of heart is known to have a decreased tolerance for global ischemia as induced during surgical cardiac arrest. Cardiac performance during recovery after surgery can be seriously impaired while structural damage is present to a higher degree than in non-hypertrophied hearts. In combination with these events, among others, a pronounced depletion of intracellular energy stores is found. The underlying mechanisms causing these phenomena are incompletely understood.

The aim of the present thesis is to investigate whether a decreased tolerance for global ischemia is also occurring in the isolated rat heart, hypertrophied as a consequence of increased blood pressure, induced by abdominal aortic constriction or by genetic selection as in the spontaneously hypertensive rat (SHR). To obtain more insight in the nature of the decreased tolerance to ischemia and/or reperfusion the functional recovery of these hearts after a period of global ischemia, if any, has been investigated in relation to different variables, including the type of hypertrophy, the age of the experimental animal, the pre-ischemic and post-ischemic coronary perfusion pressure, the pre-ischemic and post-ischemic regional coronary flow distribution, the pre-ischemic, end-ischemic and post-ischemic tissue content of energy-rich phosphates, the post-ischemic loss of intracellular enzymes and degradation products of adenine nucleotides, and the post-ischemic occurrence of ventricular fibrillation.

In chapter II the materials and biochemical techniques, applied in the various studies, are described. A modified isolated heart perfusion 
system has been presented, in which special attention is paid to the physical characteristics of the artificial aortic outflow tract. The determination of the tissue contents of energy-rich phosphates and the degradation products of adenine nucleotides by high pressure liquid chromatography is described in detail. The finding that bovine serum albumin can stabilize and enhance enzyme activity in artificial perfusion solutions, as used in the isolated heart perfusion set-up, is also described in this chapter.

An automated system for data aquisition in the isolated, ejecting. heart preparation is presented in chapter III. It is shown that reliable information about the hemodynamic behavior of the isolated heart can be obtained in a fast way by using a a relatively inexpensive microcomputer in combination with a home-made preprocessor.

In chapter IV, the hemodynamic and biochemical behavior of the isolated, ejecting heart preparation under normoxic conditions is described. It is shown that hypertrophied rat hearts can maintain a stable hemodynamic function for more than 2 hours after isolation from the body. Besides, it was found that biochemical variables, like the tissue content of adenine nucleotides, glycogen, lactate and inorganic phosphate hardly change during this period, while the content of creatine phosphate and the energy charge of the cardiac tissue increase. Biochemical determinations reveal that in native heart tissue of relatively old (16 months) SHR the adenosine triphosphate (ATP; $p<0.05$ ) and creatine phosphate (CP) content is significantly lower than in hearts of age-matched, nonhypertensive Wistar-Kyoto (WKY) rats. In contrast, in hearts of relatively young ( 5 months) aorta-banded rats no differences in these variables are found between aorta-banded and sham-operated animals. Significantly lower activities of lactate dehydrogenase (LDH) and aspartate aminotransferase (AST) are found in native heart tissue of SHR than WKY rats at the age of 8 months. At higher age, however, these differences disappear. At the age of 16 months higher $\mathrm{LDH}$ activities are found in SHR than in WKY rats.

The first experiments, in which hypertrophied hearts are subjected to ischemia are described in chapter V. For this purpose, hearts of relatively old (16 months) SHR and age-matched WKY rats are used. Following a period of global ischemia the hypertrophied hearts show a significantly less pronounced recovery of cardiac output than the hearts of WKY rats, i. e. $10 \%$ versus $70 \%$. The pressure-volume curves, as constructed during the reperfusion period, reveal that changes in preload from 0.66 to $2.66 \mathrm{kPa}$ at afterloads varying between 10.6 and $18.6 \mathrm{kPa}$ do not result in pump function of the hypertrophied myocardium. Related to this finding is the observation that significantly higher postischemic activities of $L D H$ and AST are found in the coronary effluent of the hypertrophied than of the control hearts. Besides, after one hour reperfusion the tissue content of ATP and CP are less decreased in the WKY than in the SHR hearts. These results suggest a higher susceptibi- 
lity to global ischemia of the hypertrophied heart of relatively old SHR as compared to the heart of age-matched WKY rats.

Basically the same protocol is used in a study on hearts of 5 months old aorta-banded and sham-operated rats, 10 weeks after abdominall surgery. The results of these experiments are described in chapter VI. Only 4 out of 9 hypertrophied hearts show normal electrical and mechanical recovery following ischemia. In contrast to the control hearts, in the bypertrophied hearts a significantly depressed post-ischemic pump function is observed, although the pre-ischemic function is at least as high as in the control hearts. The diminished functional recovery of the hypertrophied hearts after global ischemia is associated with significantly lower coronary flow values. Significantly higher LDH activies are released from the recovering hypertrophied hearts than from the control hearts. Extensive investigation of the loss of degradation products of adenine nucleotides reveals a significantly higher loss of these products in control hearts than in hypertrophied hearts during the first 10 minutes of the reperfusion period. This is compensated by a more pronounced loss of metabolites in the hypertrophied hearts during the remaining reperfusion period. Comparison of the tissue adenine nucleotide content and the energy charge at the end of the reperfusion period show comparable values in the control and recovering hypertrophied hearts. Significantly lower values are found in the non-recovering hypertrophied hearts. From this study it is concluded that the decreased tolerance of the hypertrophied heart to ischemia is also present in the relatively young aorta-banded animal. This phenomenon can be associated with a delayed wash-out of degradation products of adenine nucleotides, in both the recovering and the non-recovering hypertrophied heart. If functional recovery is present in the hypertrophied heart, the loss of LDH is high, indicating a more pronounced irreversible damage of myocardial cells. In contrast to the findings in the old SHR hearts, the less pronounced post-ischemic restoration of myocardial pump function is not associated with a lower tissue adenine nucleotide content at the end of the reperfusion period, at least not in the recovering hypertrophied hearts. These results suggest that the delayed washout of myocardial metabolites is related to post-ischemic changes in the regional distribution of coronary flow.

The experiments, as described in chapter VII, are designed for extensive investigation of the coronary flow distribution with radioactive microspheres. Again in isolated hearts of relatively old (18 months) SHR, the mechanical activity is completely absent during reperfusion after global ischemia, when a coronary perfusion pressure of $8.0 \mathrm{kPa}$ is applied. At higher perfusion pressure $(13.3 \mathrm{kPa})$ hypertrophied hearts regain regular electrical and mechanical activity, but do not exert pump function of any importance. At a post-ischemic coronary perfusion pressure of $8.0 \mathrm{kPa}$, hypertrophied hearts show no-reflow in the left ventricular endocardium and substantially reduced myocardial flow in the epi- 
cardial layers. No-reflow is associated with significantly elevated postischemic tissue levels of lactate, inorganic phosphate, and degradation products of adenine nucleotides such as adenosine, inosine, hypoxanthine, and xanthine. At a relatively high reperfusion pressure (13.3 kPa), epicardial flow normalizes completely but the endocardial layers remain significantly underperfused ( $43 \%$ of the pre-ischemic levels). In these hearts, post-ischemic accumulation of metabolites is absent, while the tissue content of CP, ATP and glycogen is significantly higher than in hearts perfused at $8.0 \mathrm{kPa}$. These findings indicate that the diminished tolerance to ischemia of the hypertrophied heart of the relatively old SHR can be partially explained by inadequate reperfusion of the myocardial tissue when perfusion pressure is relatively low. Although elevation of the coronary perfusion pressure does not result in ejection function of any importance, it ameliorates mechanical performance and coronary perfusion without the occurrence of tissue edema of any significance, and prevents ventricular fibrillation.

Finally, susceptibility to ischemic damage is evaluated in hypertrophied hearts of relatively young, ( 8 months) SHR, in which the stage of myocardial hypertrophy is stable and fully compensated (chapter VIII). The findings in this study indicate that, as in the old SHR, the degree of post-ischemic functional recovery of the hypertrophied hearts is dependent on the height of the coronary perfusion pressure. In contrast to old $S H R$, at $8.0 \mathrm{kPa}$ normal electrical function is regained. Recovery of pump function is even present, although to a modest degree. At $13.3 \mathrm{kPa}$, the recovery in cardiac output is almost complete. In combination with these findings, post-ischemic accumulation or delayed wash-out of metabolites of cardiac metabolism was absent.

In conclusion, it can be stated that two majors factors are involved in the increased susceptibility to global ischemia of the hypertrophied rat heart. Firstly, hearts of relatively old animals, in which cardiac decompensation is present or developing, are very vulnerable to ischemic damage. Adequate post-ischemic recovery of cardiac pump function is never encountered in these hearts. Secondly, probably because of altered coronary vascular properties, inadequate reperfusion of the hypertrophied myocardial tissue can occur, even when pre-ischemic regional myocardial perfusion is normal.

It is tempting to state that the present experimental findings have important clinical significance. Post-operative malfunction of hypertrophied hearts subdued to global ischemia during cardiac surgery may be prevented by initial reperfusion at relatively high perfusion pressures. 
Tijdens open-hartchirurgie bij patiënten met een hypertroof hart kunnen ernstige cardiale complicaties optreden. Het hypertrofe hart beeft namelijk een verlaagde tolerantie voor ischemie, zoals deze zich voordoet tijdens het intra-operatief stilleggen van de doorbloeding van het hart, nodig voor het verrichten van intracardiale ingrepen. Het herstel van de pompfunctie van het hart tijdens de directe post-operatieve fase kan ernstig afgenomen zijn, terwijl in het hypertrofe hart meer uitgesproken structurele beschadigingen gevonden worden dan in niet-gehypertrofieerde harten. Tegelijkertijd treedt ernstige depletie van intracellulaire energievoorraden op. De mechanismen verantwoordelijk voor deze verschijnselen zijn niet geheel duidelijk.

In deze thesis wordt onderzocht of de verminderde ischemietolerantie ook aantoonbaar is in geisoleerde ratteharten, gehypertrofieerd ten gevolge van verhoogde bloeddruk, geinduceerd door vernauwing van de abdominale aorta, of genetische selektie, zoals in de spontaan hypertensieve rat. Het eventuele functionele herstel van deze hypertrofe harten na een periode van ischemie wordt gerelateerd aan verschillende variabelen zoals het type hypertrofie, de leeftijd van het proefdier, de pre- en post-ischemische perfusiedruk in de kransslagaders, de preen post-ischemische regionale verdeling van de myocardiale doorbloeding, de pre-, eind-en post-ischemische weefselinhoud aan energierijke fosfaten en hun afbraakprodukten, het post-ischemische verlies van enzymen en het post-ischemische optreden van ventrikel fibrilleren.

De gebruikte materialen en methoden worden gepresenteerd in hoofdstuk II. Een perfusie-opstelling voor geïsoleerde harten wordt beschreven waarbij vooral aandacht wordt besteed aan de fysische eigenschappen van de uitstroomopening van de aorta. Het gebruik van hoge- 
druk kolomchromatografie voor de bepaling van energierijke fosfaten en hun afbraakprodukten wordt uitvoerig beschreven. Ook wordt aandacht besteed aan de bevinding dat de toevoeging van runderserum albumine aan kunstmatige perfusievloeistoffen de eventueel hierin aanwezige enzymactiviteit kan stabiliseren.

Een geautomatiseerd systeem voor dataverwerking wordt gepresenteerd in hoofdstuk III. Aangetoond wordt dat betrouwbare informatie omtrent het hemodynamisch gedrag van het geïsoleerde hart verkregen kan worden met behulp van een relatief goedkope microcomputer in combinatie met een preprocessor.

Het hemodynamische en biochemische gedrag van het geisoleerde, ejecterende rattehart onder normoxische omstandigheden wordt beschreven in hoofdstuk IV. Aangetoond wordt dat het geisoleerde hypertrofe rattehart in stat is langer dan twee uur een stabiele hemodynamische functie te behouden. Ook wordt vastgesteld dat biochemische variabelen, zoals de weefselinhoud aan adenine nucleotiden, glycogeen, laktaat en anorganisch fosfaat nauwelijks wijzigen tijdens deze perfusieperiode, terwijl de inhoud aan creatinefosfaat (CP) en de energy charge zelfs toenemen. Biochemische bepalingen in natief hartweefsel van relatief oude (16 maanden) spontaan hypertensieve ratten (SHR) laten zien dat er een significant lager gehalte aan adenosinetrifosfaat (ATP) en (CP) aanwezig is in deze harten dan in harten van even oude, niet-hypertensieve WistarKyotoratten (WKY). In hypertrofe harten van relatief jonge (5 maanden) ratten daarentegen worden geen verschillen gevonden tussen ratten met een vernauwde aorta en even oude sham-geopereerde dieren. Significant lagere laktaatdehydrogenase $(\mathrm{LDH})$ en aspartaataminotransferase (AST) activiteiten worden aangetroffen in natief hartweefsel van 8 maanden oude SHR dan in de harten van even oude WKY. In 16 maanden oude dieren daarentegen zijn deze verschillen niet meer aanwezig. Hier worden zelfs hogere LDH activiteiten aangetroffen in harten van SHR dan in deze van WKY.

De eerste experimenten, waarin hypertrofe harten worden onderworpen aan een periode van ischemie, worden beschreven in hoofdstuk $V$. Hiervoor worden harten van relatief oude (16 maanden) SHR en WKY gebruikt. Na een periode van totale ischemie vertonen de hypertrofe harten een significant geringer herstel in hartminuutvolume dan harten van WKY $(10 \%$ versus $70 \%)$. De druk-volume curves, zoals geconstrueerd tijdens de reperfusiefase, laten zien dat verhoging van de preload van 0.66 tot $2.66 \mathrm{kPa}$ bij afterloads, variërend tussen $10.6 \mathrm{en} 18.6 \mathrm{kPa}$, geen verandering induceert in de pompfunctie van het hypertrofe myocard. Tevens wordt vastgesteld dat significant hogere post-ischemische LDHen AST-activiteiten werden aangetroffen in het kransadereffluent van hypertrofe dan van controleharten. Tevens wordt wastgesteld dat aanhet einde van de reperfusieperiode de weefselinhoud aan ATP en CP minder sterk is afgenomen in harten van WKY dan van SHR. Deze resultaten suggereren dat het relatief oude hypertrofe SHR hart meer gevoe- 
lig is voor ischemische beschadiging dan het niet-hypertrofe hart van even oude WKY.

Nagenoeg hetzelfde protocol wordt gebruikt in een studie van harten van 5 maanden oude aorta-gebandeerde en controleratten, uitgevoerd 10 weken na operatief ingrijpen (hoofdstuk VI). Na ischemie tonen slechts 4 van de 9 gehypertrofieerde harten normale elektrische activiteit en mechanisch herstel. In tegenstelling tot in de controleharten wordt in deze harten een sterk verlaagde post-ischemische pompfunctie vastgesteld, die gepaard gaat met een significant verlaagde myocardiale doorbloeding. De hypertrofe harten stellen significant hogere postischemische LDH-activiteiten vrij dan de controleharten. Tijdens de eerste 10 minuten van de reperfusiefase verliezen deze laatste meer afbrakprodukten van energierijke fosfaten dan de hypertrofe harten. Dit verschil wordt evenwel gecompenseerd door een meer uitgesproken verlies van deze afbraakprodukten door de hypertrofe harten tijdens de latere reperfusiefase. Vergelijking van de weefselinhouden aan energierijke fosfaten en de energy charge aan het einde van de reperfusieperiode tonen vergelijkbare waarden in de controleharten en de herstellende hypertrofe harten, terwijl significant lagere waarden gevonden worden in de niet-herstellende hypertrofe harten. Deze resultaten tonen ondermeer aan dat de verhoogde gevoeligheid voor ischemische beschadiging ook aanwezig is in het hypertrofe hart van de relatief jonge rat. Bovendien kan worden vastgesteld dat het slechtere functieherstel gepaard kan gaan met een vertraagde uitwas van afbrakprodukten van adenine nucleotiden, zowel in de herstellende als niet-herstellende hypertrofe harten. Indien functieherstel aanwezig is in het hypertrofe hart treedt er een groot verlies aan LDH op, wat duidt op een meer uitgesproken beschadiging van myocardiale cellen dan in controleharten. In tegenstelling tot de bevindingen in de oudere SHR kan bet slechtere herstel in de hypertrofe harten van aorta-gebandeerde ratten niet worden verklaard door een lagere weefselinhoud aan adeninenucleotiden. De resultaten van deze studie indiceren dat er een causaal verband bestaat tussen post-ischemische regionale verdeling van de hartspierdoorbloeding en de vertraagde uitwas van afbraakprodukten.

In hoofdstuk VII worden experimenten beschreven die tot doel hebben uitvoeriger de myocarddoorbloeding tijdens de pre-en post-ischemische fase te bestuderen met behulp van radioactieve microsferen. In geissoleerde harten van relatief oude (18 maanden) SHR wordt vastgesteld dat de mechanische activiteit volledig afwezig is tijdens reperfusie na een periode wan globale ischemie wanneer een perfusiedruk van 8.0 $\mathrm{kPa}$ wordt gebruikt. Bij een hogere perfusiedruk (13.3 $\mathrm{kPa}$ ) treedt er wel een normaal elektrisch en mechanisch herstel op, maar de harten vertonen geen pompfunctie van enige betekenis. Bij een perfusiedruk van 8.0 kPa vertonen hypertofe harten geen herstel van doorstroming ("noreflow") in het endocard en een sterk afgenomen doorstroming in het epicard. No-reflow in het endocard gaat gepaard met significant toegeno- 
men weefselconcentraties aan laktaat, anorganisch fosfaat, en van afbraakprodukten van adeninenucleotiden zoals adenosine, inosine, hypoxanthine, en xanthine. Bij een hoge perfusiedruk treedt er een normalisatie op wan de epicardiale doorstroming, maar deze van het endocard blijft significant verlaagd (43\% van de pre-ischemische waarde). In deze harten treedt geen accumulatie op van afbrakprodukten, terwijl de inhoud aan CP, ATP en glycogeen significant hoger is dan in harten die geperfundeerd worden bij $8.0 \mathrm{kPa}$. Deze bevindingen tonen aan dat, wanneer de perfusiedruk relatief laag is, de verminderde tolerantie voor ischemische beschadiging van het hypertrofe hart van de relatief oude SHR tot op zekere hoogte verklaard kan worden door de onvoldoende doorstroming van het myocardweefsel. Alhoewel verhoging van de perfusiedruk niet resulteert in pompfunctie van enige betekenis, verbetert de elektrische functie, de contractiekracht en de myocardiale doorbloeding zonder een significante toename in weefseloedeem.

Tenslotte wordt de gevoeligheid voor ischemische beschadiging geevalueerd in hypertrofe harten van relatief jonge SHR (hoofdstuk VIII). Evenals in de oude SHR laten de bevindingen in deze studie zien dat de graad van post-ischemisch herstel afhankelijk is van de hoogte van de perfusiedruk in de kransslagaders. Bij $8.0 \mathrm{kPa}$ wordt in tegenstelling tot bij de oudere harten, een normaal elektrisch herstel aangetroffen. Ook functioneel herstel is aanwezig, hoewel matig. Bij een perfusiedruk wan $13.3 \mathrm{kPa}$ is het herstel in hartminuutvolume nagenoeg volledig. Post-ischemische ophoping of vertraagde uitwas van afbraakprodukten wordt niet aangetroffen.

Samenvattend kan worden gesteld dat 2 factoren een belangrijke rol spelen bij de verhoogde gevoeligheid van het hypertrofe hart voor ischemische beschadiging. Ten eerste wordt een zeer uitgesproken gevoeligheid voor ischemische beschadiging aangetroffen bij hypertrofe harten van relatief oude dieren, waarin cardiale decompensatie aanwezig is of zich ontwikkelt. Onder de omstandigheden van deze studies werd een adequaat post-ischemisch pompfunctieherstel van deze harten nooit aangetroffen. Ten tweede kan onvolledige reperfusie van myocardweefsel optreden tengevolge van veranderde vasculaire eigenschappen, zelfs wanneer de pre-ischemische regionale hartspierdoorbloeding normaal is. Afwezigheid van of een gevoelig tekort aan perfusie tijdens de initiële reperfusiefase kan de ischemische beschadiging versterken.

Het lijkt aannemelijk dat de resultaten van deze thesis belangrijke clinische implicaties hebben. De bevindingen suggereren dat het slechte post-operatieve functioneren van het hypertrofe hart dat werd onderworpen aan intracardiale ingrepen, verbeterd kan worden door een initiële doorstroming van het kransslagadervaatbed bij een selektief verhoogde perfusiedruk. 


\section{CURRICULUM VITAE}

Luc Snoeckx

03-08-1947 : geboren te Turnhout, België

1964-1968 : onderwijzeropleiding (richting wetenschappen) te Turnhout

1969-1970 : onderwijzer aan het Xaveriuscollege in Antwerpen, België

1970-1976 : researchmedewerker laboratoria Janssen Pharmaceutica Beerse, België

1977-heden : researchmedewerker vakgroep Fysiologie, Rijksuniversiteit Limburg, Nederland

1977-1982 : biologiestudie an de Universitaire Instellingen Diepenbeek (L.U.C.) en Antwerpen (U.I.A.), België.

\section{BIBLIOGRAPHY}

Schaper W., Flameng W., Snoeckx L., and Jagenau A. Der einfluss körperlichen Trainings auf den Kollateralkreislauf des Herzens. Verhandl. Disch. Ges. Kreislaufforsch. 37: 112-121, 1971.

Lewi P.J., Schaper W.K.A., Van Riel D.G., Braet W.W., Snoeckx L.H., Flameng WJ., and Nuyens R.F. The use of a minicomputer in cardiovascular pharmacology. Arznmitt forsch. 23: 436-441, 1973.

Wellens D., Snoeckx L., De Reese R., Kruger R., Van de Water A., Wouters L., and Reneman R.S. Antihypertensive activity of erythro-1-1. [2(1,4-benzodioxan-2-y1)-2-OH-ET]-4-piperidyl-2-benzimidazolinone ( $R$ 28935). Arch. Int. Pharmacodyn. Ther. 215: 119-132, 1975. 
Wellens D., Snoeckr L.H., De Wilde A.M.J, and Reneman R.S. Influence of guanethidine on the nicotinic effects of acetylcholine in atropinized dogs. Arch. Int. Pharmacodyn. Ther. 215: 20-30, 1975.

Snoeckx L., Verheyen J.L., Van de Water A, Lewi P., and Reneman R.S.

The on-line computation of cardiac output with the thermodilution method, using a digital minicomputer. Cardiovasc. Res. 10: 556-564, 1976.

Snoeckx L.H, Bruyneel K, de Clerck F, Verheyen A, and Reneman R.S.

Electrically induced coronary artery thrombosis in closed-chest anesthetized dogs. Bas. Res. Cardiol. 73: 241-255, 1978.

Reneman R.S., Schmitz J.J., Snoeckx L.H., and Lambregts J.A. Differences in the echocardiographic dimensions of the heart between females and males. In: Echocardiology. Martinus Nyhoff, The Hague-Boston-London. pp. 53-60, 1979.

Snoeckx L.H. Functionele en biochemische aspecten van partiële en totale ischemie van bet geisoleerde rattehart. Het effect van lidoflazine. Licenciaatswerhandeling U.I.A., Antwerpen, 1981.

Verstappen F.T.J., Huppertz R.M., and Snoeckx L.H. Effect of training on maximal treadmill and bicycle ergometer exercise. Int. J. Sports Med. 3: 43-46, 1982.

Snoeckx L.H., Abeling H.F., Lambregts J.A., and Reneman R.S. Echocardiographic dimensions in athletes in relation to their training program. Med. \& Science in Sports \& Exercise 14: 428-434, 1982.

Snoeckx L.H. Het sporthart. In: Harttonen. Bohn, Scheltema \& Holkema. Utrecht-Antwerpen. 1983.

Snoeckx L.H., Abeling H.F., Lambregts J.A., and Reneman R.S. Cardiac dimensions in athletes in relation to variations in their training program. Eur. J. Appl. Physiol. 52: 20-28, 1983.

van der Vusse G.J., Schols J., Snoeckx L.H., Coumans W.A., and Reneman R.S. The effect of lidoflazine on ischemic and reperfused myocardial tissue. Clin. Res. Rev. 4: 37-39, 1984.

Snoeckx L.H., van der Vusse G.J., Coumans W.A., Willemsen P.H., van der Nagel T., and Reneman R.S. Myocardial function in normal and spontaneously hypertensive rats during reperfusion following a period of global ischemia. Cardiovasc. Res. 20: 67-75, 1.986.

Snoeckx L.H., Schrijen J.J., van Bilsen M., Lammers W.J., van der Nagel T., van der Vusse G.J., and Reneman R.S. A microcomputer system for hemodynamic measurements in isolated, working rat hearts. Comp. Biol. Med. 4: 301-309, 1986.

van Bilsen M., van der Vusse G.J., Snoeckx L., Arts T., Coumans W.A., Willemsen P.H. and Reneman R.S. Effects of pyruvate on post-ischemic myocardial recovery at various workloads. Submitted.

Snocckx, L.H., van der Vusse G.J., van der Veen F.H., Coumans W.A. and Reneman R.S. Recovery of hypertrophied rat hearts after global normothermic ischemia at different perfusion pressures. Submitted. 


\section{DANKWOORD}

Prof. Reneman, beste Rob. Reeds meer dan 10 jaar heb ik mogen genieten van uw inspirerende invloed. Dat voorrecht heeft mij de gelegenheid verschaft u te leren kennen als een persoon die voortdurend, tot in het detail, begaan is zowel met het wetenschappelijke als het sociale welzijn van zijn medewerkers. Uw steun tijdens moeilijke momenten en uw kritiek tijdens de gemakkelijke heeft mij steeds aangemoedigd om verder te studeren en dit onderzoek uit te voeren. Hopelijk blijft u nog lang in mijn buurt.

Dr. van der Vusse, beste Ger. Tijdens de voorbije jaren heb ik achter uw eerder noordelijke karakter een volledig ander persoon leren kennen. Mijn appreciatie voor de uitzonderlijke begeleiding van dit onderzoek, vooral op het terrein van de biochemie, is erg groot. Ook uw niet aflatende zorg voor het uiteindelijke - hier ingediende - resultaat strekt tot voorbeeld en heeft mijn gevoel voor gezonde zelfkritiek sterk aangescherpt.

Prof. Schaper, $U$ wil ik in de eerste plaats danken voor de belangstelling die $U$ in mij, toen wij nog in het hetzelfde laboratorium werkten, heeft gewekt voor het cardiovasculaire onderzoek. Dat dit proelschrift meer dan 10 jaar nadat onze wegen zijn gesplitst, tot stand is gekomen, is nog voor een groot deel aan uw stimulerende invloed te danken. Dat $U$ tenslotte referent van dit werk hebt willen zijn, heb ik als eervol ervaren. In vergelijkbare termen wil ik Prof. Struyker-Boudier dank zeggen voor het zorgvuldig refereren van dit werk.

Een grote bijdrage tot het optimaliseren van de geïsoleerde hartperfusieopstelling werd geleverd door Marc van Bilsen. Beste Marc, de verbeteringen die jij aan onze apparaten aanbracht, zijn van een onschatbare waarde geweest.

Zovele anderen hebben mij geholpen bij de biochemische bepalingen 
en het automatiseren wan de geilsoleerde hartperfusieopstelling. In de eerste plaats wil ik Will Coumans danken. Beste Will, jij hebt steeds met grote toewijding de fluorimetrische en hogedruk kolomchromatografische bepalingen uitgewoerd. Daarnaast was jij steeds een enthousiaste, ja zelfs uitbundige, medewerker, wiens optimisme aanstekelijk kon werken op het juiste ogenblik. Dat jij ook als paranimf wilde optreden heb ik eveneens geapprecieerd.

Tegelijkertijd wil ik ook de andere mensen danken die bijdragen leverden voor dit werk. De hulp van Peter Willemsen en Theo Roemen was onontbeerlijk. De mensen van de vakgroep Pathologie die mij hielpen bij het lichten electronenmicroscopisch werk wil ik van harte danken woor het ter beschikking stellen van de apparatuur. De bijdragen van de stagiaires Jenny van Oostrum, Arlene van Vliet en Rob Loefen op het terrein van de enzymbepalingen ben ik niet vergeten. Theo van der Nagel heeft uitzonderlijk veel grafisch werk verricht, waarvoor ik hem will danken. Wiel Schrijen heeft de bouw van de pre-processor en het schrijven van de software voor zijn rekening genomen.

Jan Glatz wil ik hartelijk danken voor zijn enthousiaste inzet als paranimf en voor zijn niet aflatende interesse voor de grafische vorderingen van dit werk. Zovele andere medewerkers vond ik stimulerende discussiepartners, zodat nieuwe gezichtspunten voor mij duidelijk werden. Daarvoor wil ik in dit dankwoord Erik van der Veen, Frits Prinzen, en Geert Jan Tangelder betrekken.

Alle medewerkers van de Algemene Instrumentele Dienst die behulpzaam zijn geweest bij de bouw van de perfusieopstelling en de toegewijde dierenverzorgers, die de soms erg oude proefdieren uitzonderlijk goed hebben verzorgd, hebben mijn welgemeende dank.

Lucienne de Boer, de snelheid waarmee in het secretariaat begrip voor een bepaald probleem kan worden opgebracht, wordt nog steeds niet overtroffen door de chipsnelheid van de personal computer. Voor alle inspanningen die je deed, samen met Jos Heemskerk, Karin van Brussel en Emmy van Roosmalen ben ik je dankbaar. In het bijzonder wil ik het secretariaat van de vakgroep Pathologie hartelijk danken voor het gebruik van de laserprinter.

Naast deze mensen zijn er zovele andere die op soms onverwachte ogenblikken hebben bijgedragen aan het tot standkomen van dit proefschrift. Ik heb de - eerder onwaarschijnlijke - Nederlandse gulheid leren kennen, evenals de grote sociale verantwoordelijkheidszin. Dit alles is mij ten goede gekomen. Ook buiten Nederland wil ik mijn vrienden en familieleden, die steeds met grote belangstelling mijn verrichtingen 'in den vreemde' zijn blijven volgen, bedanken voor hun steun en voor hun vertrouwen in de goede afloop van dit werk. Moge de toekomst zo blijven. 